\title{
PUBLICATIONS
} (1)

\section{Alll0b 040448}

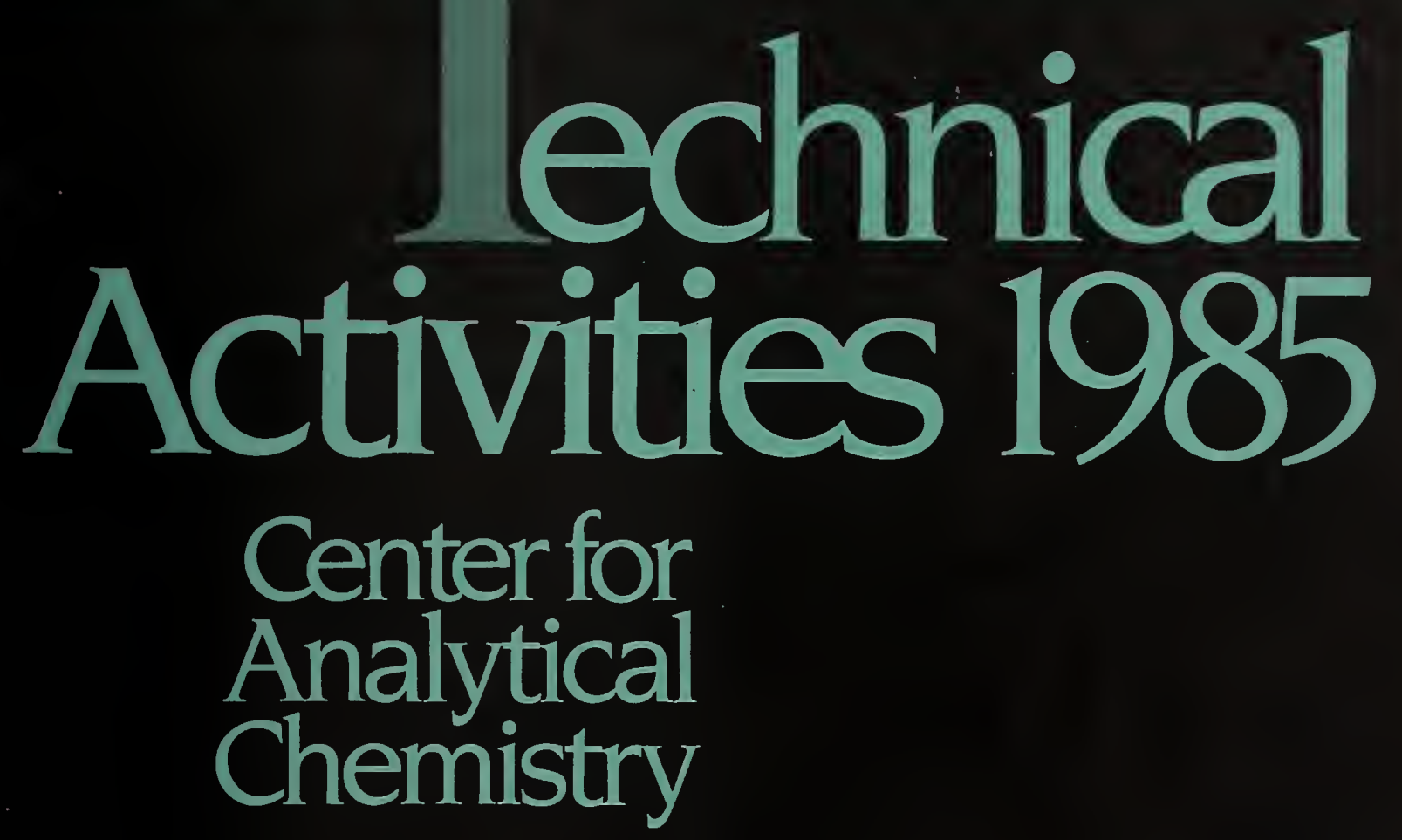

November 1985

U.S. DEPARTMENT OF COMMERCE National Bureau of Standards 


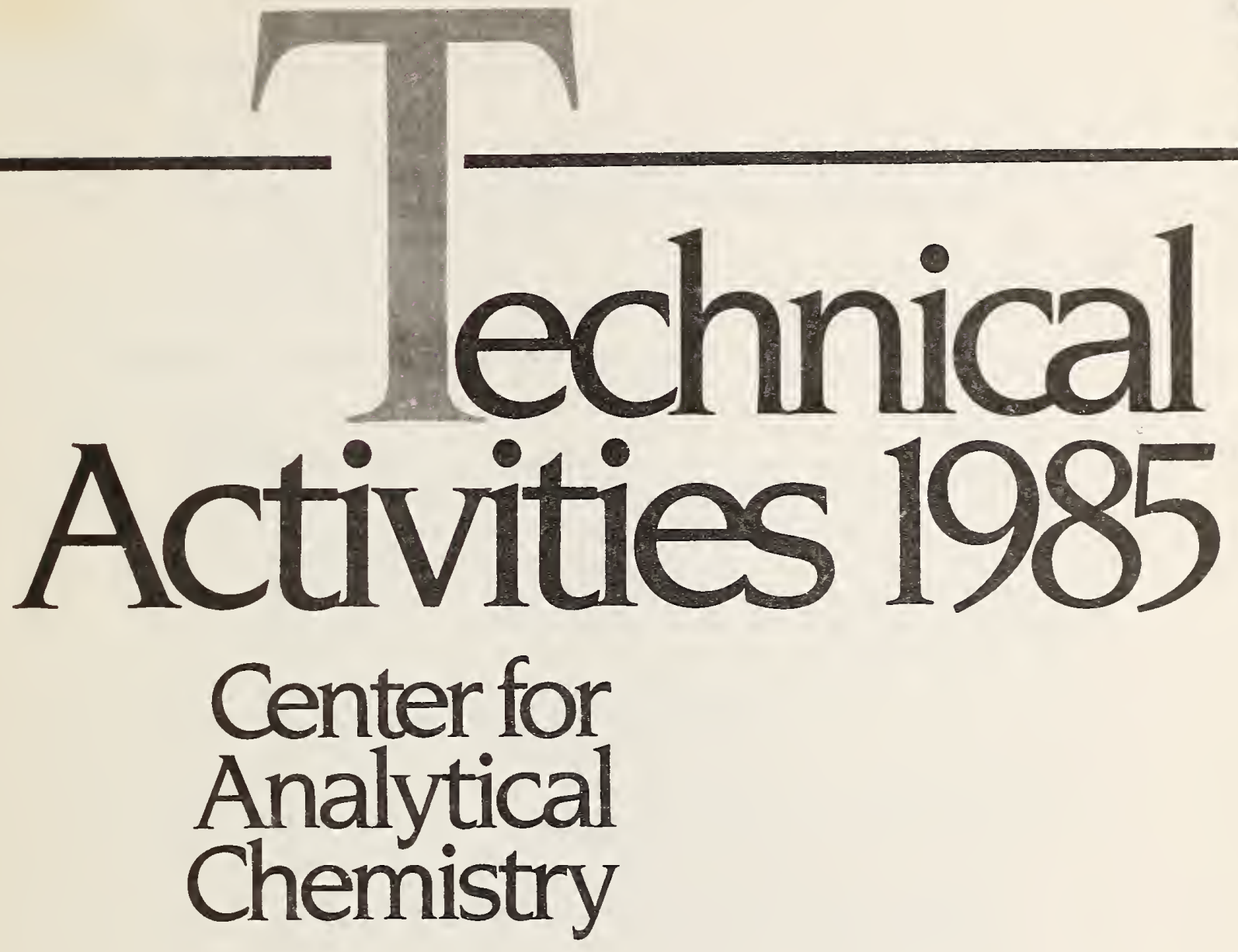

Richard A. Durst

Harry S. Hertz

John K. Taylor

\section{U.S. DEPARTMENT OF COMMERCE National Bureau of Standards National Measurement Laboratory Center for Analytical Chemistry Gaithersburg, MD 20899}

November 1985

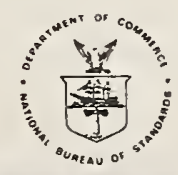



I. CENTER FOR ANALYTICAL CHEMISTRY

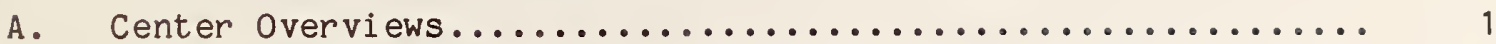

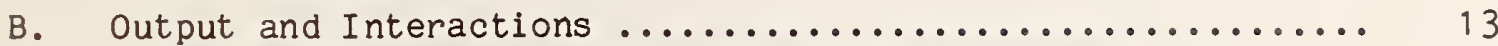

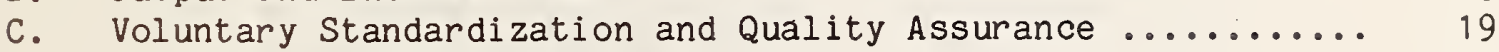

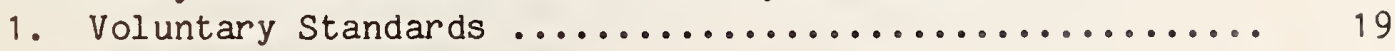

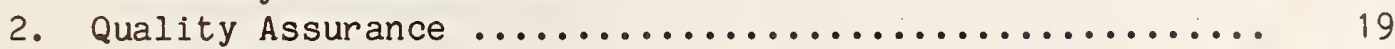

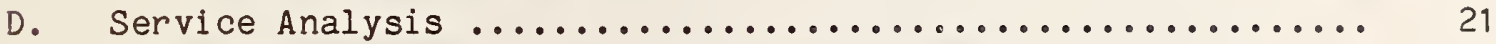

II. INORGANIC ANALYTICAL RESEARCH DIVISION

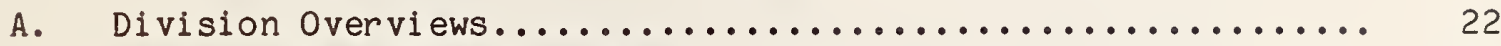

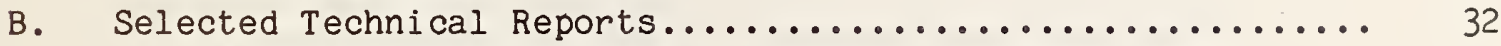

1. Three-Dimensional Atomic Sepectra in Flames Using

Stepwise Excitation Laser-Enhanced Ionization

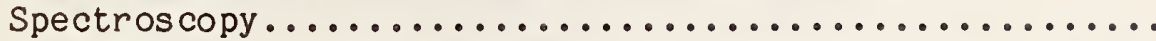

2. Evaluation of Several Pulsed Dye Lasers as Excitation

Sources for Flame Atomic Fluorescence Spectrometry.....

3. Determination of $\mathrm{Cr}$ (VI) in Natural Waters by LC/AAS

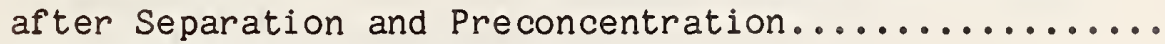

4. Development of an SRM to Calibrate

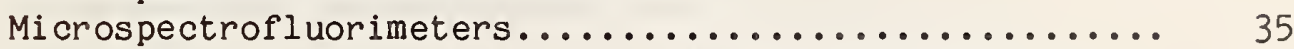

5. Spectrometric Analysis of Spark-Generated Aerosols..... 35

6. Resonant Laser-Induced Ionization of Atoms in an

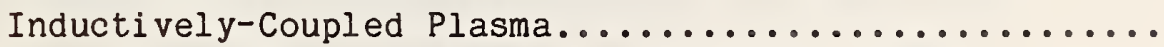

7. An $X-Y$ Scanning Photometer for Verifying the Transmittance Uniformity of Solid Filter SRMs.........

8. Statistical Ruggedness Testing of Acid Rain $\mathrm{pH}$

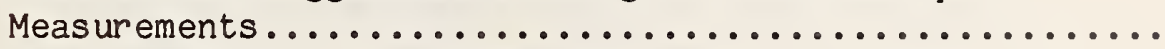

9. Improvements in the Determination of Sulfide by Ion

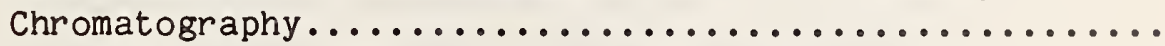

10. Direct Microwave Coupling Closed-Vessel Acid

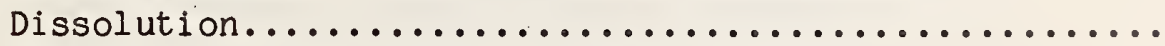

11. Leaching of Trace Metals from High Purity

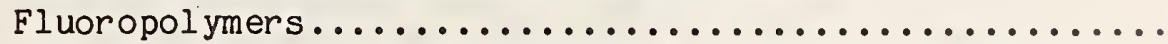

12. Development of an Electrometer for Use with Thermal

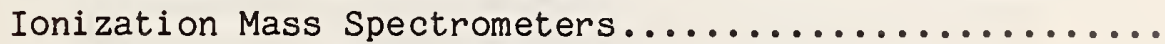

13. Determination of the Lead Isotopic Composition in Human Blood from the Italian Isotopic Lead Experiment..

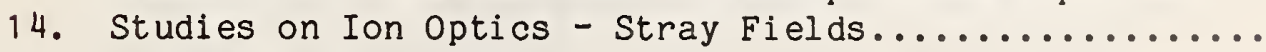

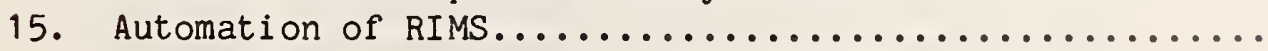

16. Methodology Development for Sub-ppm Boron

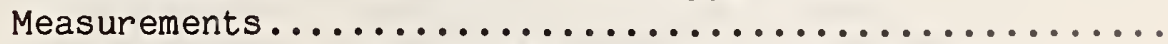

17. Time-Resolved, Magnetic-Dispersion for Large Isotope Ratio Measurements By Resonance Ionization Mass

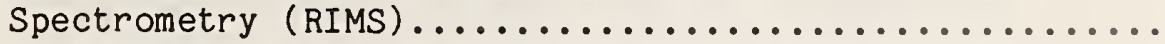

18. A New Method for the Accurate and Precise

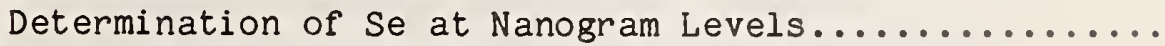

19. The Determination of Iodine in Foods and Other Biological Materials by Epithermal Neutron Activation

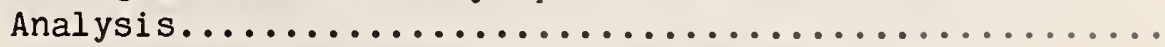


21. Light Element Determination by Neutron Activation

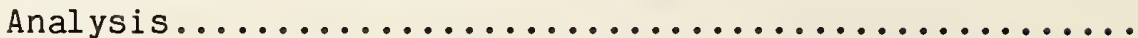

22. Neutron Depth Profiling: Industrial Interaction and

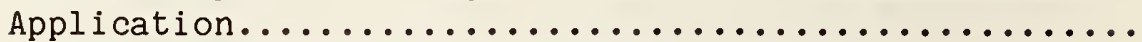

23. Re-Characterization of the NBSR at $20 \mathrm{MW} . \ldots \ldots \ldots \ldots \ldots$

24. Determination of Gold and Platinum in Urine at

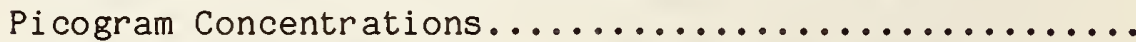

25. Optimized Measurement of Iodine Isotopic Ratio by

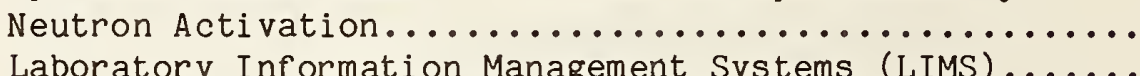

26. Laboratory Information Management Systems (LIMS)...... 57

27. Development of a Standard Reference Material for

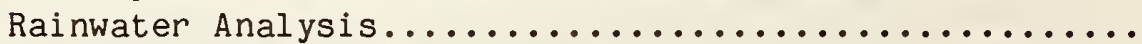

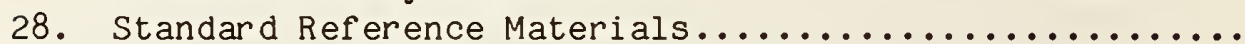

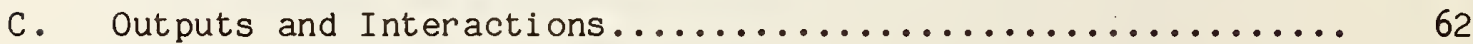

III. ORGANIC ANALYTICAL RESEARCH DIVISION

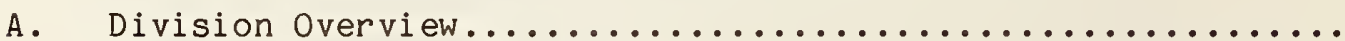

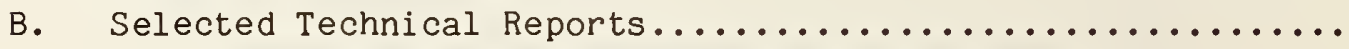

1. Investigations of Substrate Morphology in

Chromatographic Sorbents by Small-Angle Neutron

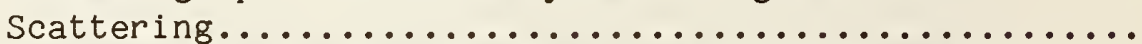

2. Investigation of Secondary Chemical Equilibria in

Liquid Chromatography: Verification of Optimization

Theory for Acid-Base Equilibria and Identification of

Factors which Influence Self-Selectivity............

3. Optimization of Selectivity Using Sequentially

Coupled Capillary Gas Chromatographic Columns.........

4. On-Line Two-Dimensional Chromatography Using

Supercritical Carbon Dioxide as a Mobile Phase.........

5. Developinent of a Supercritical Extraction Procedure for the Removal of Trace Organic Species from Solid

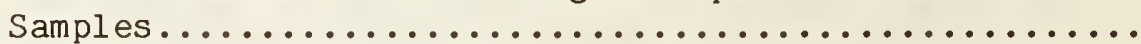

6. Development of a Method for the Stabilization of Ascorbic Acid in Solution and in Human Serum...........

7. Investigations of the Stability and Recovery of Toxic

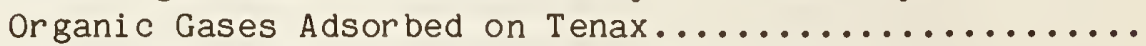

8. Design and Implementation of a Comprehensive Laboratory Information Management System to Acquire, Manipulate, and Archive Chromatographic Data Bases.....

9. Photodissociation of Ions Generated by Cesium Ion Bombardment for Determination of the Structures of

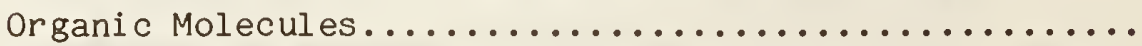

10. Comparison of Two Methods for the Calibration of Gas Chromatography/Mass Spectrometry Instrumentation Used for the Analysis of Volatile Organic Compounds.........

11. Comparison of the College of American Pathologists Proficiency Testing Program Results and NBS Definitive Method Results for Four Organic Analytes in Serum......

12. Stabilization of Polymer-Film Electrode Morphology by Thermal and Photochemical Crosslinking.............. 
13. Polyvinylf errocene-Modified Reference Electrode for

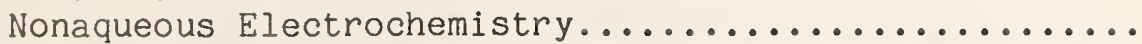

14. Investigation of the Electrochemical Behavior of

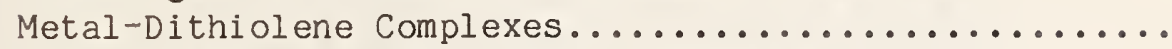

15. Investigation of the Electro-oxidative Products of

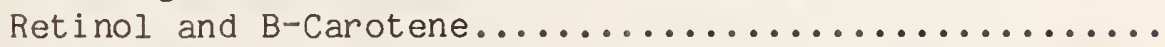

16. Development of Two-Dimensional DEPT $\mathrm{CH}$ J-Resolved

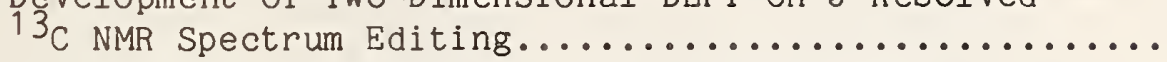

17. Investigation of Metal-Protein Interactions...........

18. Viral Proteins from Vaccine Studied by Two-Dimensional

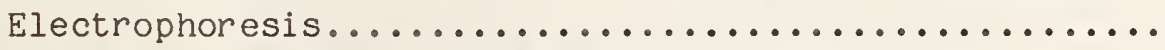

19. Proteins from Honey Differential by Ultra-Thin Isoelectric Focusing and Two-Dimensional

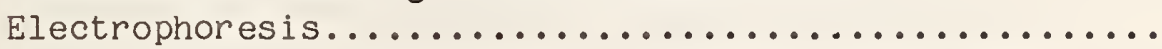

20. Results from Interlaboratory Analyses of Vitamins

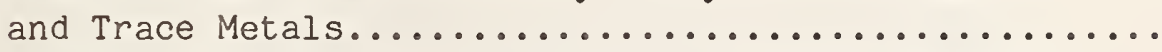

21. Preparation and Certification of Standard Reference Materials for Dioxins, Chlorinated Pesticides and

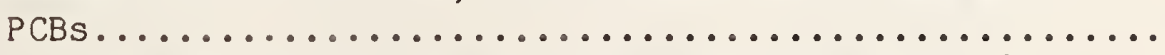

22. Certification of Standard Reference Material 1587 Nitrated Polycyclic Aromatic Hydrocarbons in

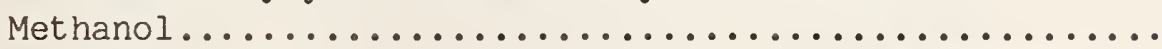

23. NBS Participation in the Certification of a Canadian

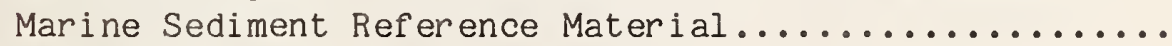

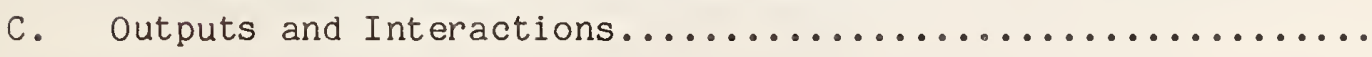

IV. GAS AND PARTICULATE SCIENCE DIVISION

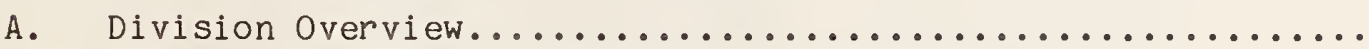
132

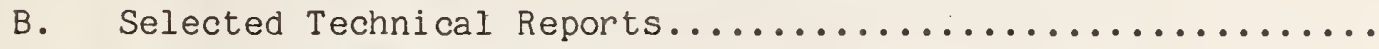

1. Development of Ultra-Trace (1 ppb) and SRM

Multi-Component Toxic Organic Gas Standards..........

2. Sampling and Analysis of Nitrous Oxide, Carbon Dioxide, and Methane to Characterize Nitrogen and Carbon Cycles During NITROP-85 Cruise in the Peru

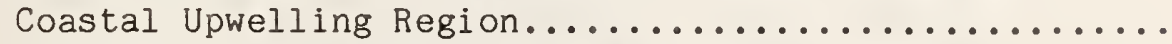

3. Application of Electrochemical Methods for the

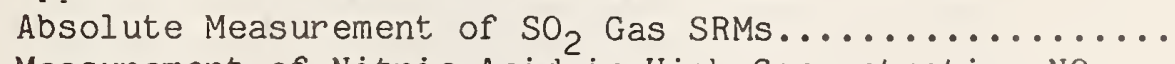

4. Measurement of Nitric Acid in High Concentration $\mathrm{NO}_{2}$ SRMs Using Diode Laser Spectroscopy Coupled with

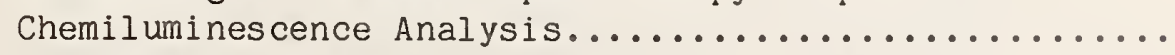

5. Development of New SRMS for $\mathrm{CO}_{2}$ in Air at Atmospheric Concentrations for World-Wide Monitoring of

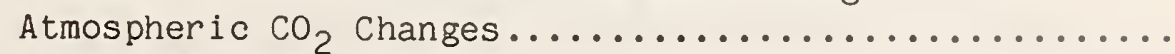

6. Indoor Air Measurements for Sulfur Dioxide, Nitrogen Oxides, and Ozone in the National Library of Medicine..

7. Development of NBS Traceable Standards for Measurements of U.S. Natural Gas Quality.............

8. Development of Tritiated Methane Standards for Atmospheric Moni toring. 
9. Characterization of Stable NBS Traceable Standards of $\mathrm{SO}_{2}$ in Air at $100 \mathrm{ppb}$ for Dry Acid Deposition Studies..

10. Intercomparison of Tunable Diode Laser, Chemiluminescent Detector, and Fourier Transform IR Measurements of $\mathrm{High}$ Concentration $\mathrm{NO}_{2} / \mathrm{A}$ ir SRMs.......

11. Identification and Characterization of Systematic Error Sources in Tunable Diode Laser Absorption

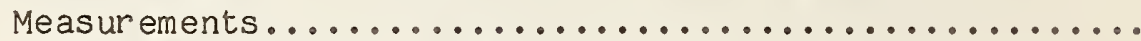

12. The Investigation of Simulated Test Data (STD) for Basic Research and Accuracy Evaluation in

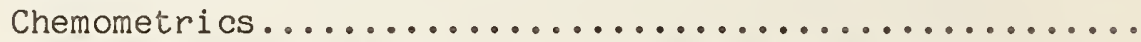

13. Improved Measurements of Environmental Radiocarbon via Chemical and Isotopic Separation Coupled to

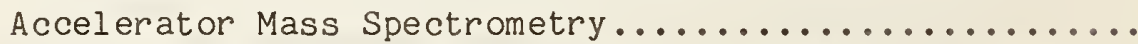

14. Carbon Isotope Measurements for Source Apportionment

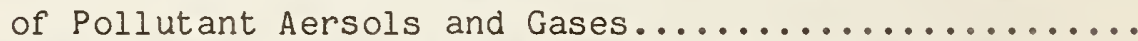

15. Quantitative Compositional Mapping with the Electron Microprobe Using Wavelength and Energy Dispersive

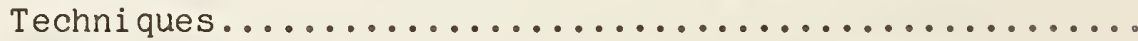

16. Development of New Techniques for Light Element and Trace Element Compositional Mapping ${ }^{2} . . . . . . . . . . .160$

17. Determination of the Half-Life of ${ }^{987}$ Re by Laser Microprobe Mass Spectrometry for Geochemical Dating....

18. Unique Molecular Characterization of Complex Minerals

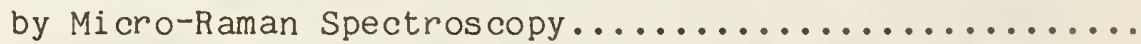

19. Development of Digital Imaging on the Analytical

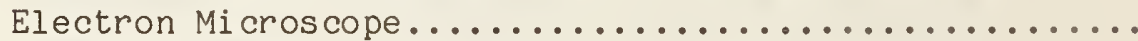

20. The Development of a Particle Collector for

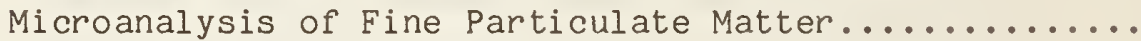

21. The Determination of the Visibility of Chrysotile Asbestos Fibers Imaged in the Scanning Electron

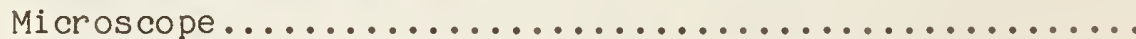

22. Magnification Calibration of the Scanning Transmission Electron Microscope by Hough-Transformed

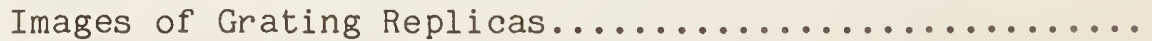

23. A Comparison of Two Transient Recorders for Use with The Laser Microprobe Mass Analyzer................

24. Automated Method for Analyzing Images Containing

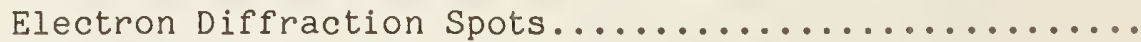

25. Determination of the Radiation Damage to Polycarbonate Film SRMs Used in X-Ray Spectrometry.....

26. Improvements in NBSGSC - A Fortran Program for Quantitative X-Ray Fluorescence Analysis.............. 


\section{Center for Analytical Chemistry}

Harry S. Hertz, Director

Richard A. Durst, Acting Deputy Director

\section{A. Center Overview}

The Center for Analytical Chemistry develops and maintains the scientific competences and the experimental facilities necessary to provide the Nation with the basis for uniform measurements through development of measurement methodology and reference materials and provision of measurement services in the field of analytical chemistry. Analytical measurements provide a foundation for scientific and technological research and development concerning materials and their practical application. Moreover, analytical measurements are increasingly used as the basis for industrial, regulatory, and health-related decisions. The Center serves as the National Reference Laboratory for assuring the reliability of analytical measurements.

The principal means by - which the Center has served as a National Reference Laboratory is through the development of measurement concepts and methods, provision of quality assurance services, and certification of Standard Reference Materials (SRMS). The ubiquity of and demand $f$ or analytical measurements in modern society is reflected in the diversity of SRMs produced in the center. These reference materials are widely used in such diverse areas as the metal and chemical industries and in clinical and environmental laboratories. Each standard is supported by research on homogeneity and stability and is certified as to chemical composition using the most reliable analytical methods available.

Analytical chemistry is increasingly being called upon to provide key data for highly complex sample types - hazardous chemical wastes, body fluids, plant and animal tissues, foods, and high-technology materials. Increasingly, analytical values as a function of location within a sample are needed. As the demands upon analytical chemistry become more sophisticated, the problem of standardization becomes more challenging both in terms of the number and the complexity of the needed measurement methods and reference materials. As it is not reasonable to contemplate the development of SRMs to deal with every measurement problem, the Center's program must be multifaceted, seeking a variety of avenues to influence the quality of analytical measurements made in the United States. In addition to research publications and the certification of reference materials, the Center exerts influence through close contacts with various communities by means of workshops, symposia, and participation in professional societies and voluntary standards committees. Through such contacts, priorities are established for the development of measurement methods and the production of reference materials, and mechanisms are set in place for their effective use.

NOTE: Certain commercial equipment, instruments, or materials are identified in this report to specify adequately the experimental procedure. Such identification does not imply recommendation or endorsement by the National Bureau of Standards, nor does it imply that the materials or equipment identified are necessarily the best available for the purpose. 
In an effort initiated in 1983, we are devoting considerable attention in the Center to better definition of our user communities and the various mechanisms for interacting with these communities. During the past year several new activities have been initiated, as well as maintaining our traditional contacts with user communities. We have initiated a process of visits to keys members of our industrial constituency, to obtain direct input to our planning process and to identify chemical measurement needs for the next few years and for the future. Companies visited included Monsanto, DuPont, Air Products, and Eli Lily. A meeting of the Analytical Group of the Directors of Industrial Research was held at NBS in February 1985. Ongoing interactions with this group are taking place and should prove beneficial. We have become members of the Analytical Laboratory Managers Association and are finding this a valuable mode for interacting with industrial, government and academic laboratory managers. Also, during the past year our direct research for industry has increased with Center for Analytical Chemistry scientists performing both proprietary and nonproprietary research, where our unique expertise could not be matched in the private sector.

A concerted effort is being made to bring the research accomplishments of the Center for Analytical Chemistry to the attention of the general public through press releases and direct written contributions to the general media. Several examples of these activities are contained on the next, few pages.

The general quality assurance concerns of chemical laboratories within the country have had a direct impact on our activities during the past year. We, of course, have always provided quality assurance services to our constituency and have considered this our major organizational commitment. During the last year these activities have been increased through the formation of a CAC Quality Assurance Task Force. This Task Force has two responsibilities, an "inward" one and an "outward" one. The "inward" responsibility involves a review of quality assurance practices within the Center and the issuance of guidelines documents to improve or standardize those practices. The "outward" responsibility deals with the relationship of NBS services to constituency claims and constituency needs. Some of the guideline documents issued during the past year are on the meaning of traceability of chemical measurements, the contents of NBS Reports of Analysis, and laboratory record keeping.

Directly related to our interactions with user communities is our major planning effort in chemical measurement. services. As part of this activity, we have been seeking advice from constituents on the measurement science, measurement technology, and technology transfer needs which the Center must prepare for today, to deliver relevant services in the 1990's. A major factor in our planning is the realization that in an era of increased reliance on voluntary standards it is vital, in our opinion, to assure the integrity of the measurement system through traceability to nationally accepted measurement standards. In this era, a scientifically accurate measurement base is the best support mechanism for both the industrial and regulatory sectors of the communities we serve. 
The program of the Center strives to achieve a balance between the provision of currently needed reference materials and research efforts on new types of reference materials and methods of measurement. The work of the Center is performed in three Divisions, each focusing upon specific analytes - Inorganics, organics, and gases and particles. Within each Division there are several groups representing separate analytical chemical disciplines, e.8., mass spectrometry and electrochemistry. Each Division is responsible for a program in basic and applied research and maintains contacts with appropriate scientific and user communities.

In the following, some of the major recent activities and technical directions of the Divisions and groups are summarized. Much of the work in progress is omitted but will be included in subsequent Annual Reports. 


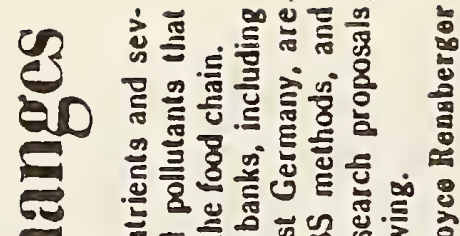

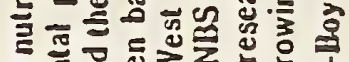 \\ 纯 \\ ง}

万人

을

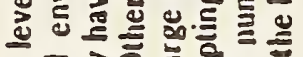

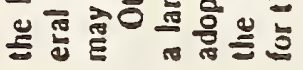

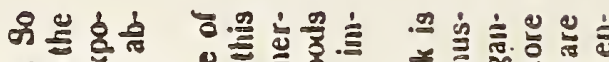

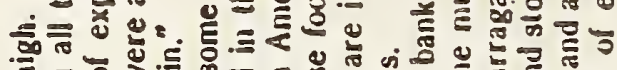

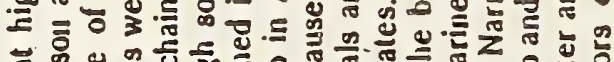

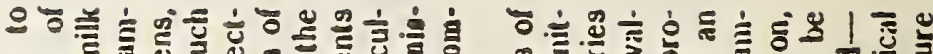
उ

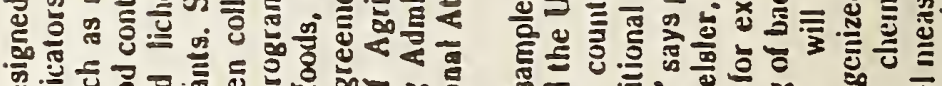

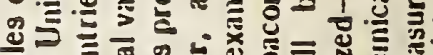

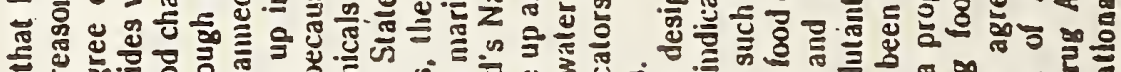

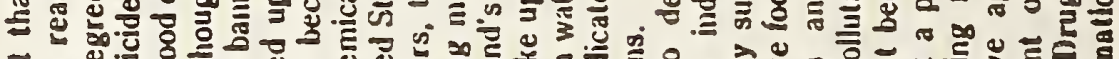
- D

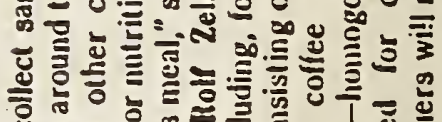

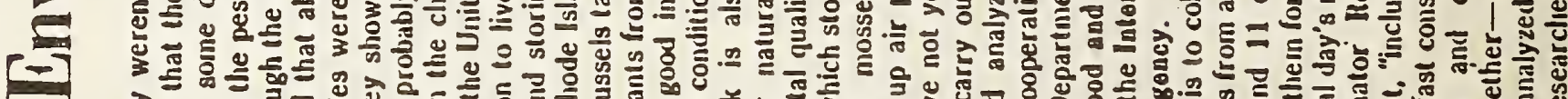

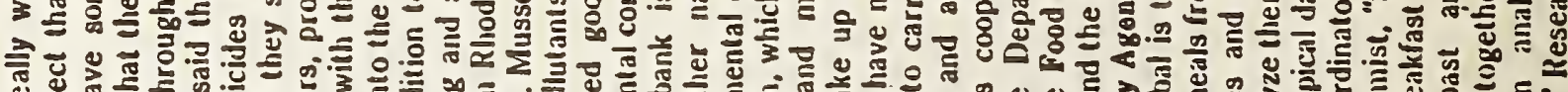

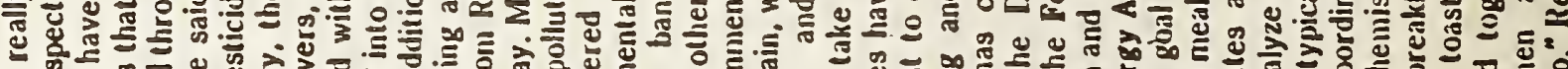

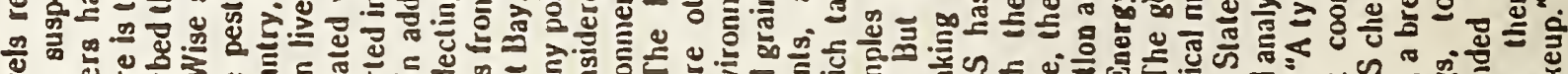

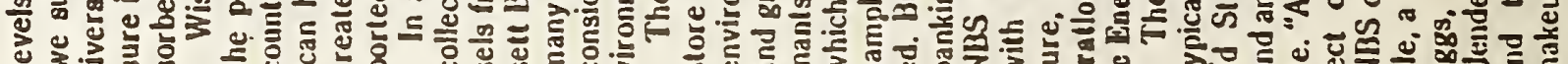

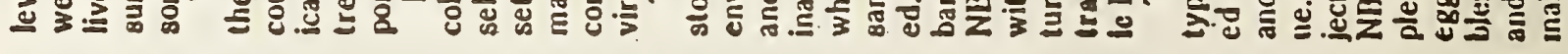

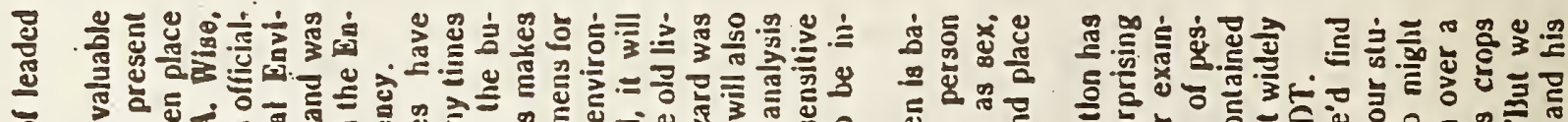
б

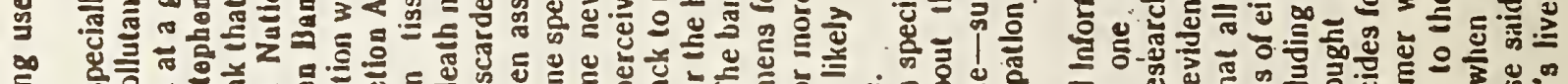

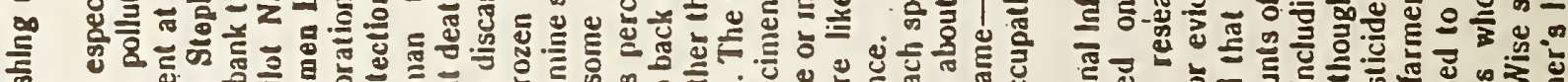

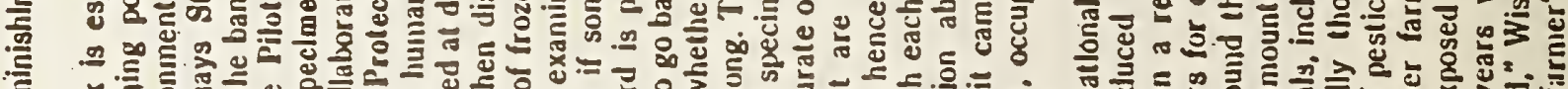

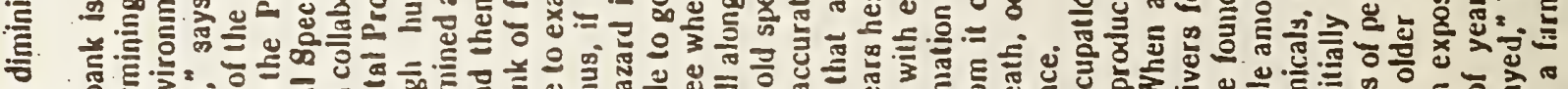
足.

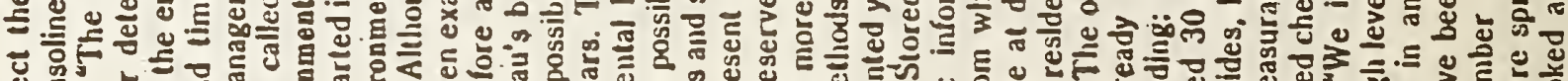

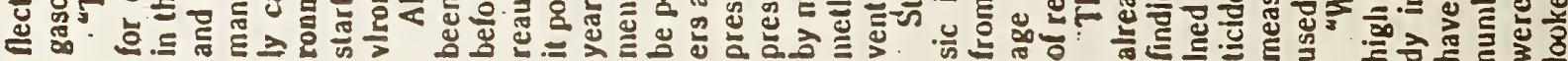

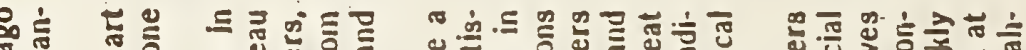

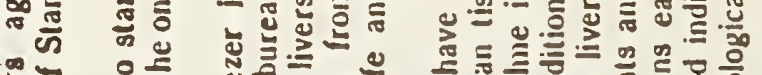

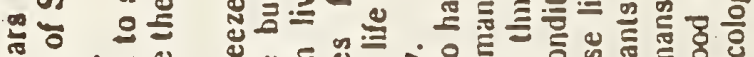

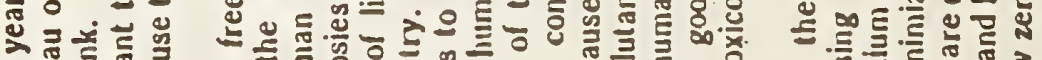

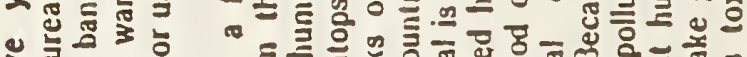

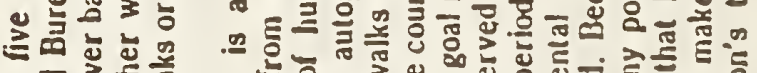

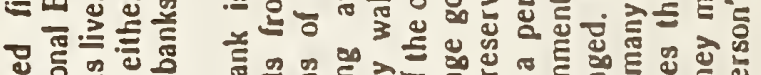

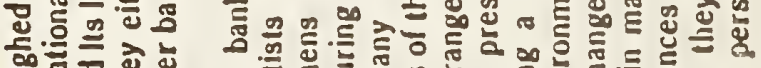

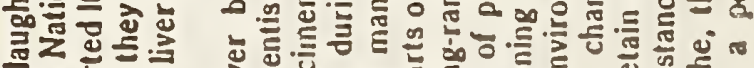
.

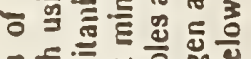
on

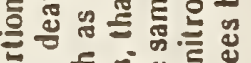

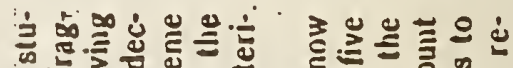

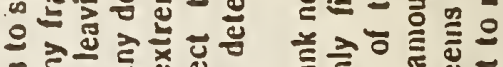

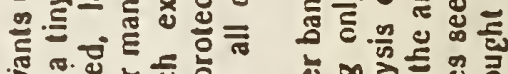

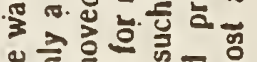

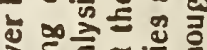

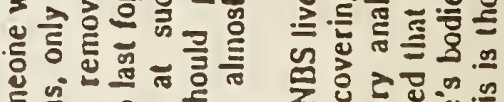

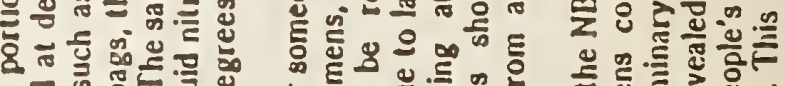

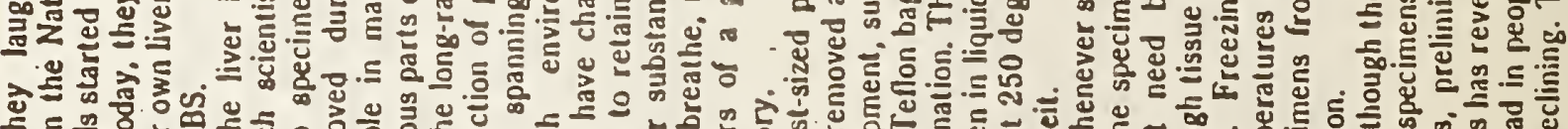

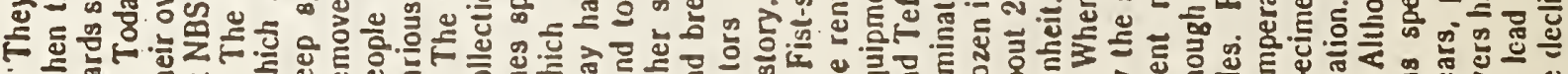

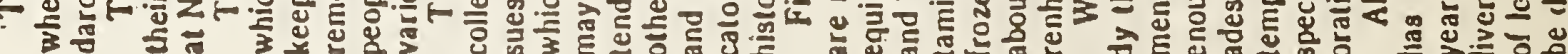




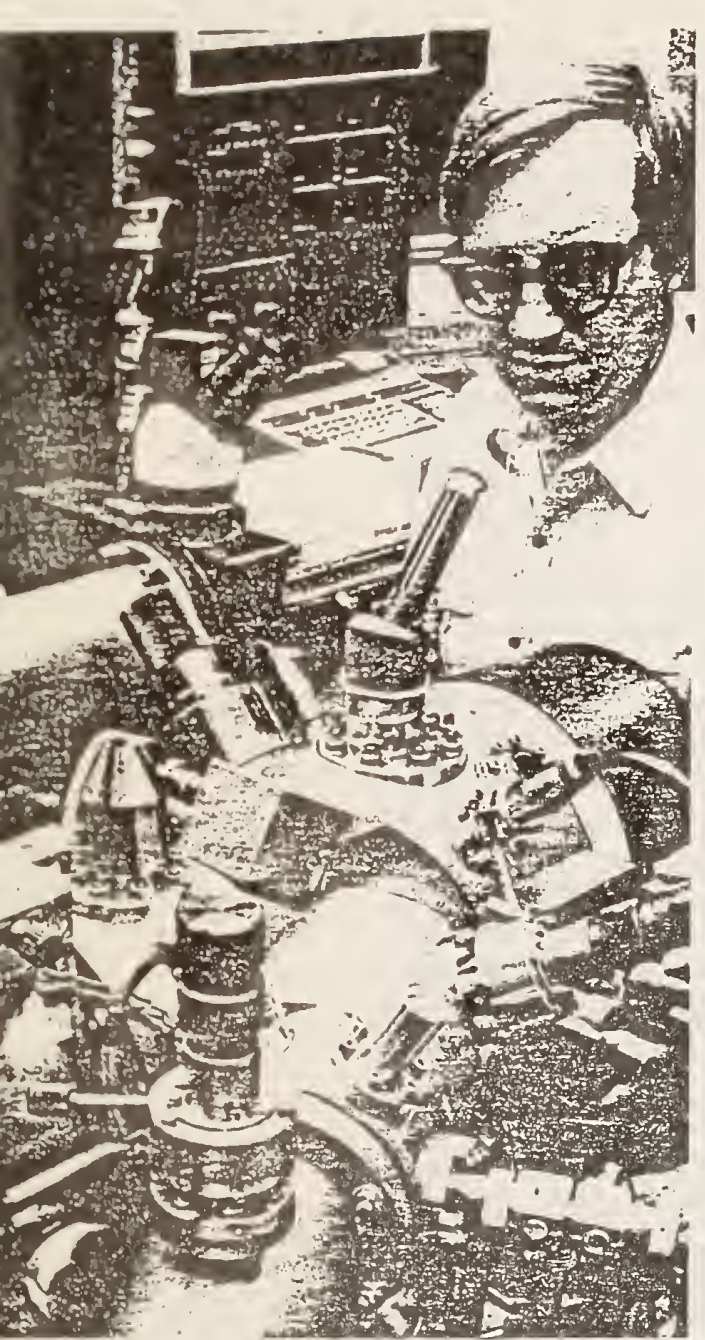

NBS metallurgist can map elements on and below a sample's surface with this instrument.

$\mathbf{T}_{\text {h }}$

he National Bureau of Standards may have a portentous-sounding name, but its activities are essential to the day-to-day operations of industry.

For instance, under the government agency's research associate program, founded in 1921, some 500 industry, university and government representatives annually work alongside NBS researchers in the government's laboratories. Under the program this fall, researchers from Mobil Research \& Development Co. investigated the effectiveness of various distillation methods in removing arsenic impurities from coal and shale oil. Other investigators from Exxon Chemical Co. used the NBS

\section{Measuring the Nation's Measurement Capability}

\section{BY DONALD VERASKA}

nuclear reactor in a neutron-scattering experiment designed to measure the compatibilities of polymer blends.

In addition to working relationships with industry laboratories, the government metrology agency also maintains close ties with a number of industry groups. As explained by John A. Blair, manager of standards development, at the polymer products department of $\mathrm{E}$. I. du Pont de Nemours \& Co., Wilmington, DE, "I'd say the bureau plays a key role in working with industry. I don't know how it would be replaced. Certainly, industry would have to be doing a lot more if there were no $\mathrm{Na}$ tional Bureau of Standards. Du Pont, Dow [Chemical Co., Midland, MI], Monsanto [Co., St. Louis, MO] and all the companies would have to be doing what the bureau is now and there'd be a lot of overlap."

In one of these industry relationships the American Chemical Society, along with the American Institute of Physics, publishes and distributes the quarterly Journal of Chemical \& Physical Reference Data. Something of a bible for the two disciplines, it contains tables of physical and chemical properties of materials as well as articles about the research on those data.

The information had been printed and distributed through the Government Printing Office, but that changed in 1972 when the journal was created to assure a more effective dissemination of the data.

NBS also has research contracts with the Chemical Manufacturers Association, in which CMA represents a consortium of chlorofluorocarbon manufacturers seeking data about the measurement of $\mathrm{CFC}$ in the atmosphere. CMA regularly conducts workshops with the bureau on this and other topics of mutual concern.
Specifically, the CFC manufacturers want NBS help in developing methods to determine atmospheric ozone changes that are actually occurring, as a way to prove or refute current conclusions based on theoretical or calculated ozone changes. Such a determination would help both parties in regulatory matters concerning the commercial uses of chlorofluorocarbons.

This national metrology agency also has a close relationship with the $\mathrm{Na}$ tional Research Council of the National Academy of Sciences, which, since 1958, has reviewed and evaluated the functions and operacions of the bureau through a series of appointed panels.

The panels, whose members represent research and administration in industry, universities and government, meet annually with counterparts in NBS program areas. They examine the importance and set priorities for NBS projects, quality of staff, equipment needs, finances and the relationship of the programs to its overall mission.

Founded in 1901, three years before the creation of the Department of Commerce, the agency was directed to develop and maintain the measurement capabilities required to advance science, industry and commerce and to carry out research to determine the properties of materials.

As far as the chemical industry is concerned, that charter has evolved to create a number of programs, among them the Standard Reference Materials (SRMs). Produced by the bureau since 1905, when the American Foundrymen's Association asked for help in producing standard samples of cast iron, there are more than 1,000 SRMs today. The bureau develops and sells them to users wanting to develop accurate testing methods and to calibrate instruments and measurement systems for quality 
control. The 174-page Standard Reference Materials Catalog is the Sears catalog of industry, listing such items as a 65-gram unit of potassium iodide for $\$ 200$.

Another program produces Standard Reference Data (SRD). Although the bureau has provided data on the properties of materials almost since its inception, the formal system did not take shape until 1963 when the Federal Council for Science \& Technology asked NBS to take responsibility for promoting and coordinating the evaluation of numerical data in the physical sciences. A formal legislative mandate for the program came in 1968.

Under the SRD program, the properties of hundreds of thousands of materials are determined, cataloged and distributed through the ACS/AIP journal. Some 1,000 corporate and industrial subscribers pay $\$ 200$ a year per copy. The data are also distributed on magnetic tape, using six databases which are leased for up to $\$ 7,500$. There is also an on-line computer network operated by the bureau, along with the Environmental Protection Agency, the National Institutes of Health and other federal agencies.

Physically, NBS facilities are at two principal locations. Within the Joint Institute for Laboratory Astrophysics, operated with the University of Colorado in Boulder, are 380 staffers carrying out studies in atomic and molecular physics and astrophysics.

At the main headquarters on a campus-like 576-acre setting in Gaithersburg, MD, some 2,300 full-time employees work in 27 buildings that include a high-flux nuclear research reactor, an electronic accelerator, a fire research laboratory, an experimental computer facility and several environmental test chambers.

The agency is considered free from political pressures, although its director is a presidential appointee. Dr. Ernest Ambler has filled the post since 1978 (he was acting director for three years before that) and his appointment was continued during the Reagan Administration. His agency's budget for fiscal 1985 comes to $\$ 207.4$ million, up from $\$ 196.7$ million in FY 1984 and from $\$ 186.5$ million for FY 1983.

The Gaithersburg facility is organized into the National Measurement Laboratory, the National Engineering Laboratory, the Institute for Computer Sciences \& Technology and the Center for Materials Science. Within them are three groups with a direct relationship with the chemical industry.

$\square$ The Center for Chemical Physics. It conducts research into such subjects as environmental monitoring, fossil fuel combustion and biotechnology. Its researchers develop advanced measurement techniques in surface science, chemical kinetics, thermodynamies and molecular foundations of complex physicochemical systems.

Among the practical applications of this center's work are proposals to monitor the effectiveness of the burning of hazardous waste, using sulfur hexafluoride tracer compounds, and a process to help limit acid rain through removal of sulfur dioxide from industrial gas streams by converting sulfur and nitrogen to more easily removed acids.

$\square$ The Center for Chemical Engineering. It provides industry with measurements and databases through research into chemical process technology, thermophysical properties of fluids and solids, and chemical engineering science. Results of the research include calibration and measurement services to the chemical, petrochemical, plastic and petroleum industries.

The center is about to publish data gathered in a three-year study of orifice meters to measure pipeline flow of gas and oil. With existing data, such meters now measure flow only to within 1 per- 
cent accuracy. Dr. Merrill Hessel, deputy director of the center, says that the new data will help improve that accuracy by a factor of 10 .

$\square$ The Toxic Chemicals Handling Laboratory. This facility stores, handles and analyzes organic compounds that are extremely toxic or possess undesirable biological activity. The laboratory allows scientists to characterize or analyze such materials in a safe manner.

Dr. Stephan Chesler, group leader of chromatography at the laboratory, notes that the facility recently prepared and certified a Standard Reference Material solution of 2,3,7,8-tetrachlorodibenzop-dioxin, known commonly as dioxin. This SRM will be available soon and will permit industry and health laboratories to standardize and calibrate their laboratory measurements in evaluating dioxin samples.

$\square$ The Center for Analytical Chemistry. According to its director, Dr. Harry S. Hertz, it probably impacts more directly on the chemical industry than any other division within the bureau. The center helps ensure the accuracy of the more than 30 billion chemical analyses performed annually in the US by government, industrial and public and private testing laboratories. It is a reference laboratory for chemical compositional measurements of inorganic, organic, gaseous and particulate materials.

Beginning this year, the center for the first time is making its facilities available for proprietary testing research by industry. Says Dr. Ambler in the bureau's annual report, "By increasing industry's access to our advanced measurement capabilities, we hope to help industry improve its products and processes and thus its international competitiveness."

It may be worth noting that the bureau is organized within the Department of Commerce, whose primary function is to promote US business. Until this spring, the bureau's policy was to disseminate openly all measurement and standards information coming from industry requests for testing; the new policy will, in certain instances, allow the results to be given only to the contracting party.
Use of the bureau's facilities for outside parties, including other government agencies, is on an at-cost basis. In fact, perhaps 40 percent of this center's budget comes through work performed for such other agencies as the Environmental Protection Agency and the military. Perhaps the one exception is the Food \& Drug Administration, which, says Dr. Hertz, has its own substantial in-house laboratory capability.

While the center normally does not duplicate testing that can be done by private laboratories, it may take on such a project when federal regulatory policy is a consideration. Last year, for instance, it tested surgical implant devices-hip joints, lenses for cataract patients and cardiac pacemakers were among them-for residues of ethylene oxide, a sterilant. The results from industrial and private testing showed wide discrepancies. The $\$ 40,000$ cost of the project was reimbursed by FDA.

\section{"l'd say the bureau plays a key role."}

An example of the more direct working relationship between the bureau and the chemical industry is seen in its association with the Chemical Manufacturers Association. During the past decade it has centered on the Fluorocarbon Research Program of CMA's Special Programs Division. A consortium of 19 worldwide chemical companies that manufacture chlorofluorocarbons has financed hundreds of programs designed to assess the impact of CFCs on the environment, particularly in the stratospheric ozone layer. The group includes Allied Corp., Du Pont, Essex Chemical Corp., Kaiser Aluminum \& Chemical Corp., Pennwalt Corp. and Union Carbide Corp.

Eight of those studies have been awarded to the National Bureau of Standards. Five have been completed and three-kinetic measurements of atmospheric constituents, temperature dependence of the infrared bond strength for CFC 11 and CFC 12 and high-resolution infrared spectroscopy of hydrogen chloride-are continuing at a cost of $\$ 140,000$. 
UNITED STATES DEPARTMENT OF

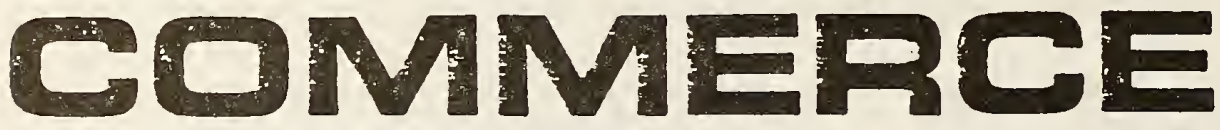

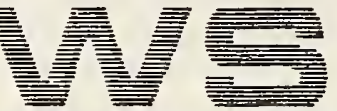

GAITHERSBURG, MD
20899

A National Bureau of Standards News Eeature

HOLD FOR RELEASE UNTIL:

March 29, 1985
NATIONAL BUREAU OF STANDARDS

John Henkel

301/921-3181

TN-5531

\section{MEASURING THE TWO "PERSONALITIES" OF OZONE: \\ IT'S A STANDARD PROBLEM AT FEDERAL LAB}

Ozone is the Jekyll and Hyde of the environment: It's both a boon and a bane to humanity.

Consider its "split personality." Ten miles or so into the earth's atmosphere, ozone is a lifesaver. It acts as a screen for keeping humans-and every other Iiving thing-from being scorched by the sun's ultraviolet rays. But on the earth's surface, ozone is a noxious gas-a byproduct of auto exhaust that federal and local governments go to much trouble to regulate.

At the heart of ozone's odd nature is its behavior as gas. Unlike most others, it is impossible to contain and difficult to measure. While scientists labor over just how much this gas is harming or helping the environment, they need another party to help determine if the sophisticated instruments used to measure ozone concentration on the ground or in the upper atmosphere are providing accurate numbers. The place they turn to is the Commerce Department's National Bureau of Standards (NBS), where making such acute measurements is a specialty. 
Scientists in the NBS Center for Analytical Chemistry routinely provide reierence materials for checking how well gas analysis equipment performs. But ensuring such accuracy for ozone is tricky. Regulatory agencies responsible for measuring ground-level ozone must periodically calibrate the instruments that gauge ozone concentration. Such calibrations are fairly easy when using the equipment that measures many of ozone's pollutant gas cousins such as sulfur dioxide or nitrogen dioxide. This is because bottled, pre-measured standards of these gases can be bought from NBS to ascertain equipment performance.

But ozone is different.

"If you have a steel cylinder and you put pure oxygen in it, you can come back in 100 years and the oxygen will still be there," says Dr. Arnold Bass, who manages the NBS ozone calibration laboratory. "But put ozone in there and by the time you finish putting it in and closing the valve, most of it will be gone." What happens, he explains, is that ozone reacts quickly with the container material and is destroyed almost instantly.

With containment out of the question, scientists look to other ways of measuring the elusive gas. Though there are several techniques for determining ozone concentration, the current method of choice is photometry, developed commercially in the 1970 s as an altemative to the messier, less reliable "wet chemical" methods used for years. (Environmental ozone is regulated by EPA, but controls are administered by local governments which can use EPA photometry standards to ensure accurate readings. EPA then turns to NBS, which has no regulatory authority, for technical assurance that the standards are accurate.)

NBS uses a device, appropriately dubbed an ozone reference photometer, to calibrate the EPA standards. First developed at the bureau in 1976 at the request of EPA, this standard began as a bulky, 10-foot-long device. With the help of Dr. Richard Pauer of EPA, it has since been reinvented and shrunk to about one-third its original size. Now it's portable and 50 times more sensitive than the earlier device, which can be attributed, Bass says, to "improved technology and streamlined design."

\section{Shedding Light on a Samole}

Photometers-whether they are used in the field for environmental measurements or in the laboratory as standards-work on the principle that ozone absorbs light in the ultraviolet (UV) portion of the spectrum proportionate to the concentration of the gas. By shining UV light through an air sample, scientists can calculate the ozone concentration in that sample by determining the difference in light intensity between the entrance and exit points of the air sample container. At NBS, researchers have worked out methods where a known quantity of ozone can be produced by the NBS reference photometer, then fed into another monitoring instrument, such as a photometer maintained by EPA, to check its accuracy. If the monitoring instrument comes up with the same readings as the NBS standard, it is working properly. Otherwise, the instrument will have to be recalibrated. 
EPA requires local agencies to use photometry for ozone measurement and depends on NBS to assure the accuracy of ozone instruments. NBS initially accomplished this by having agencies come to the bureau to calibrate their instruments against the NBS standard. But now NBS is in the process of building photometer standards that can be placed in EPA regional laboratories across the country so local governments can bring their photometers to those labs for calibration. The EPA labs then periodically will check their instruments against the NBS reference photometer. EPA's central laboratory near Raleigh, N.C., is equipped with a photometer standard supplied by NBS, as are EPA labs in California and New Jersey. Four more of the devices will be delivered by the end of this year.

Without a photometer standard, all the user in the field can do is check his instrument's results against those of a neighboring locality, and in that situation, both instruments may be wrong," says Larry J. Purdue, acting director of the quality assurance division of EPA. What [the NBS reference photometer ] will do is find photometers in the field that are not working properly. Users then will have to do maintenance on their defective equipment."

Ozone measurements also have been a concern of industrial firms which have consulted NBS. For example, one manufacturer of office machines has requested assistance in determining the levels of ozone that might be produced by photocopiers. And a large aircraft company has asked for measurement help from NBS in its study of the effects of breathing ozone from the stratosphere when aboard a plane.

The bad name ozone gets as a pollutant underscores its highly reactive nature-that is, the gas reacts chemically with just about everything it comes in contact with. If inhaled, ozone can act as a strong oxidant, reacting with lung tissue and irritating the respiratory tract. And it can cause wear on car tires by reacting with rubber. "Just how much an effect it has on tires we don't know," says Bass. "We do know that if you leave a box of rubber bands in an ozone environment in the laboratory, then come back in a month, they'll just fall apart."

There's a Good Side Too

Ozone is not all bad. In fact, if the layer of ozone that surrounds the earth 10 to 30 miles up-which screens the harmful UV rays of the sun-were to be seriously diminished, scientists predict that crops would dry up, the earth's oxygen cycle would be interrupted, and skin cancer would become an epidemic. That's why researchers worldwide have studied the ozone layer extensively to determine if it is being depleted, and if so, how to head off disaster.

Many suspected causes of ozone depletion have been studied in the last decade, the most celebrated probably being the chlorofluorocarbons formerly found in nearly all refrigeration equipment, hairsprays, and spray deodorants. These compounds have since been removed from many products, but the effects of when they were used as propellants in spray cans remain. 
"The problem with chlorofluorocarbons is that they are stable and inert, so when they are released they just drift up into the atmosphere and there's nothing to remove them on the way up. They just keep going," says Bass. When they get high enough the action of the sun can release chlorine atoms and start a chain reaction that reacts very quickly with ozone, destroying many ozone molecules. It could take as long as 100 years to decompose the Zuorocarbons that are already in the atmosphere." There are other suspected ozone destroyers, such as methane gas produced by rice paddies and grazing animals, and even airplane exhaust.

Resetting the Table

Before any conclusions can be made about the state of the earth's ozone layer, scientists must find out just how much ozone is in the atmosphere compared to how much was once there. This is done by sophisticated instruments that measure the ozone layer from the earth and from the sky through balloons, high-altitude planes, rockets, satellites, and in the future, from the space shuttle. Many of these instruments work on the same principle of UV absorption as photometers. However, in order to reliably monitor the ozone composition of the high atmosphere as contrasted with that determined at ground Ievel-two measurements that ideally should agree-scientists need an accurate system of measuring the transmission of UV radiation through the atmosphere.

NBS has contributed to these measurements by developing-in cooperation with the NASA Upper Atmosphere Research Office-a table of 1,200 measurement points that indicates how much UV radiation will be absorbed at various temperatures and at different wavelengths of ultraviolet light. This table of values, or cross sections, refines a French study done in 1953 under which ground-based and airborne instrument results varied as much as 8 percent. The NBS research has cut these differences to no more than 2 percent.

"What we've done is greatly reduce the discrepancy between the two methods of observing atmospheric ozone so the differences that remain may reflect differences in other aspects of the monitoring," Bass says. "Now someone who is making these measurements, and needs to interpret what the distribution of ozone is in the atmosphere, can use these cross sections for that interpretation. The measurement system is much more accurate now."

The bureau's work in this area has been recognized internationally as evidenced in September 1984 at the Quadrennial Ozone Symoosium in Halkidiki, Greece. There, the International Ozone Cormission recomended that the NBS ozone cross-section table be accepted as the international standard for determining ozone concentration from satellite instruments.

Ozone's strange nature will no doubt continue to prompt debate over whether the ozone layer is depleting, as well as concern over the gas as a pollutant. The environment's jekyll and Hyde isn't about to go away anytime soon. But, as NBS' Bass says: 'Whether the ozone is on the ground or in the upper atmosphere, someone needs to be responsible for the accuracy of ozone measurements. And that's what our job is." 


\section{Taking Measures Against Poisons}

P. d. Hingate's Auz. 5 cdltortal-page ir. liete on loxie suostances contains con. vincing szimment lop carefully consudenng the amount of toxic matenat present be lore jumping to conclusions aboul the dan. per to the environmenc However. ine sciual mezurement acearacy lor many pollutanes is a sourte of major concern and dlserepancy.

Vumerous lederal studles over ithe las decade have mown mderantine resuls whes several lasoratones were called on to mensure use sume zumple. Sometmes it

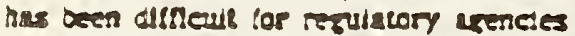
to say tur how mues of an environmental harard is present ind. inerefore. jux how herardous it is. Par of the prodern is chat for many pollutanes ihere nas oeen no resl. sole reference mutenal: chat is no pro meacursd anmples hac latos ean andyze to ensure tast gqupment and mewoods ure cosanke. But ials is cansthe.

Tate the menurement of rsoesen is a IIt Bnvioamentes Prolecion Agescy audy exemputie. The $3 P A$ lone year wasted is exunin Moneromery County. Md. ronds surrecod wis crussed rone to determine the imount of isoertos ibersviten oceus iaturaliy in come vocs - in

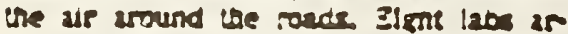
ived at vexty differcal toures: one ratd 1.800 llbers were in a cublc meter sumple. anouner urnved as 13 mullion libers lor use ame ample. This umang drourty prompted the 3PA to have the vauonal Gucesu of Standards devetop terenesce materia ior 3 soestos. That materna-par : lesiary difhesl and ume-consumune is produce-beenme avalable last year and

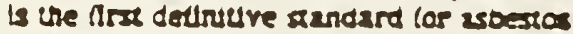
mesurements.

There are ouber "horror mones." anc" Ine trom mesurement of loxic PCos in oil to determining the concentrition of lesd la blood ample io the very idenuftcauton of the different coure ctemicus present in contuminated vater and sost. In exen of inese xudles. thonate resuls were to ported trom' vartery of sources in une lase ese. not aniy the emount of a pollu. int we in question. but eren the idenuly of the pollutancs.

These proolems are oetng addresed by ine buresu. Howerer. meaurement and its sceuracy are not issues one can reterate stratly to ine domain of ine lab. The social and economic impileations of bad neas. urement maxe imis an issue of reterance :0 eyeryone. Bad mersurements lead lo dicn. euty in detecting pollution irends. iningerlne soclety from eyniualing regtonal differ enees or making proctress in pollutani controi. Bad dala cause jelays in voluncary and resulatory sciton ounts to the incon: etusive nature of ine intormation. Moss se nousty. bed dala ean lesd to erroneous conelustons. All of inese social coss have the potental for detarting realun-lleces to searen.

The sconomte cans of bad meerure ment to Industry ire also meat. Studies are llkely to be overoesigned. resulung in costly repeal analyes. The price of inter. grethe insceurate dalz and sorting pood dacs from and Is greal becuse poor daln In a larte study diminish che value of he rood dals also presene.

Appropriate envronmental scions ear not be uren bared on inconcturive sing But unce the prtice is iligh roote ure xcrining to gay utsenuon. Authortles sem to arree chat ervironmental mezsurements ure sredually improving. NBS sundard referesce maserials ear late some of use creatl alone nith more reilable squoment and better zuatty ontrol in the laces. But It is a stow process to ensure has lacs.pro duce dau lhat are more tact than lletion. Untll we resch las mesorement nirvans. the quesuon not oniy is solne to oe "How much is 00 muen?" is Mr. Wingice pointed sue bue "How much Is revily there?".

Havar S. Harz Dinze:or

Center for Analyesal Cemisry National Bureau of Siandares Gathersour. Md.

\section{Blood lead scandards available from NBS}

A reliable standard for determining the accuracy of aralyses or lead levels in blood is now available from NBS. The new Standard Reierence Material is in the form of four viais of porcine blood, containing lead at concentracions ranging from 5.7 to $73.2 \mu g$ per deciliter. The standards can be used by elinical chemistry laboratories both to calibrate their anaivical instruments and to verify the accuracy of differ. ent analvecal procedures. The material is available from the Office of Standard Reference Materials. B311 Chemistry Bldg., National Bureau of Standards. Gaithersourz, Md. 20899, and costs $\$ 104$. 
B. Outputs and Interactions

(Center for Analytical Chemistry)

1. Publications

Taylor, J. K., Quality Assurance of a Measurement Program, ACS Symposium Series $267(1984)$.

Velapoldi, R. A., Hertz, H.S., and Taylor, J. K., Technical Activities 1984 , Center for Analytical Chemistry, NBSIR 84-2979 (1984).

Velapoldi, R. A. and Hertz, H. S., The Bases for Quality Assurance of Chemical Measurements and Standards for Speciation, Dahlem Konferenzen, Proceedings of Workshop on the Importance of Chemical Speciation In Environmental Processes, Berlin, Federal Republic of Germany, 1984 (in press).

Hertz, H. S., Search for Hay in a Needlestack, Book Review, Nature, 315, 163 (1985).

Hertz, H. S., Wolf, W. R., Chapter 7 -- Open Discussion On Needs and Uses for Biological Reference Materials, Biological Reference Materials: Availability, Uses and Need for Validation of Nutrient Measurement, Wolf, W. R., ed., John Wiley \& Sons, Inc. (1985).

Hertz, H. S., Taking Measures Against Poisons, Letters to the Editor, Wall Street Journal, September 11, 1985.

Hertz, H. S., Accuracy in Clinical Chemistry: The Roles of Definitive Methods and Roger K. Gilbert, Archives of Pathology and Laboratory Medicine 1985, in press.

Taylor, J. K., Principles of Quality Assurance of Chemical Measurements, NBSIR 85-3105 (February 1985).

Taylor, J. K., State Measurement Laboratories: Part 1, Certification of Capability; Part 2, Authorization for Type Evaluation. (with H. V. Oppermann), NBS Handbook 143 (1985).

Taylor, J. K., Handbook for SRM Users, NBS SP 260-100 (1985).

Taylor, J. K., The Quest for Quality Assurance, accepted for publication in American Laboratory (1985).

Taylor, J. K., The VD Conspiracy (with E. Goldberg), Marine Pollution Bull. 16, No. 1 (1985).

Taylor, J. K. and Kratochivil, B G., Sampling of Bulk Substances for Chemical Analysis, ISAS Newsletter (submitted 06-20-85).

Taylor, J. K. and Stanley, T. W., eds., Quality Assurance for Environmental Measurements, STP 867, ASTM, Philadelphia, PA 19103 (1985). 
Taylor, J. K., What is Quality Assurance?, Quality Assurance for Environmental Measurements, ASTM STP 867, J. K. Taylor and T. W. Stanley, eds., American Society for Testing and Materials, Philadelphia, 1985, pp. 5-11.

Velapoldi, R.A. and Burke, R. W., Recommended Reference Materials for Realization of Physicochemical Properties: Wavelength and Transmittance, IUPAC Commission on Physicochemical Measurements and Standards, in press.

\section{Talks}

Hertz, H. S., "Ten Years of Quantitative Analytical Chemistry - A Decade to Trace", Federation of Analytical Chemistry and Spectroscopy Societies, Philadelphia, PA, September 1984.

Velapoldi, R. A., "What is the NBS Research Associat,e Program?", College of American Pathologists, Industrial Liaison Committee, New Orleans, LA, October 28, 1984.

Hertz, H. S., "Quality Assurance, Reference Materials and Environmental Specimen Banking: Three Important Components of Environmental Monitoring Programs", The 1984 International Chemical Congress of Pacific Basin Societies, Honolulu, Hawaii, December 1984.

Taylor, J. K., "Guidelines for Data Acquisition and Data Quality Evaluation in Environmental Chemistry," Coastal Empire Section, ACS, Savannah, GA, November 12, 1984. Invited

Taylor, J. K., "Quality Assurance of Chemical Measurements," Savannah River Section, ACS, Aiken, SC, November 13, 1984. Invited

Taylor, J. K., "Standards for Chemical Analysis," South Carolina Section, ACS, Florence, SC, November 14, 1984. Invited

Taylor, J. K., "Quality Assurance of Chemical Measurements," CarolinaPiedmont Section, ACS, Charlotte, NC, November 15, 1984. Invited

Taylor, J. K., "The Professional Practice of Chemistry," Northeast Tennessee Section, ACS, Kingsport, TN, November 16, 1984. Invited

Taylor, J. K., "Principles of Quality Assurance," NBS-NOAA Workshop on QA, National Bureau of Standards.

Velapoldi, R. A., "Spectrophotometry/Spectrofluorimetry", 4th Annual ADABSE Workshop, November 1984.

Taylor, J. K., "The Use of Control Charts in Chemical Analysis," PACHEM Meeting, Honolulu, Hawaii, Dec. 21, 1984.

Taylor, J. K., "General Aspects of Quality Assurance," Brazosport Local Section ACS, Lake Jackson, TX, January 15, 1985. Invited

Taylor, J. K., "General Aspects of Quality Assurance,", Sabine-Neches Local Section ACS, Beaumont, TX, January 16, 1985. Invited 
Taylor, J. K., "Principles of Environmental Analysis," Southwest Louisiana Local Section ACS, Lake Charles, LA, January 17, 1985. Invited

Taylor, J. K., "Professional Practice of Chemistry," Louisiana Local Section, New Orleans, LA, January 18, 1985. Invited

Taylor, J. K., "Eaneral Aspects of Quality Assurance," University of Cincinnati, Institute of Environmental Health, Cincinnati, Ohio, January 30, 1985. Invited

Taylor, J. K., "Quality Assurance of Chemical Measurements," ACS Short Course, New Orleans, LA Feb. 22-24, 1985

Taylor, J. K., "Statistics for Chemists," Pittsburgh Conference, New Orleans, LA, March 1, 1985. Invited

Taylor, J. K., "Quality Assurance of Chemical Measurements," ACS Short Course, Nashville, TN March 7-8, 1985.

Taylor, J. K., "Quality Assurance of Chemical Measurements," NBS/FDA, Rockville, MD March 18-19, 1985.

Taylor, J. K., "Principles of Quality Assurance," Johnson Controls, Milwaukee, WI, April 17, 1985. Invited

Taylor, J. K., "Quality Assurance of Chemical Measurements," ACS Short Course Miami, FL - April 27 - 28, 1985.

Hertz, H. S., "Quality Assurance, Reference Materials and The Role of a Reference Laboratory in Pollutant Measurements", Analytical Techniques in Water Pollution Control, Water Pollution Control Federation Conference, Cincinnati, Ohio, May 1985.

Taylor, J. K., "Quality Assurance of Chemical Measurements," NBS - May 1 , 1985.

Taylor, J. K., "Quality Assurance of Chemical Measurements," NBS - May 8-9, 1985.

Taylor, J. K., "Control Charts for Chemical Analysis" - NBS Div. 551 Seminar, May 14, 1985. Invited

Taylor, J. K., "The Quest for Quality Data," Chemical Institute of Canada, Queen's University, Kingston, Ontario, Canada, June 5, 1985. Invited

Taylor, J. K., "Quality Assurance of Chemical Measurements," Kingston, Canada Short course, June 4-7, 1985.

Taylor, J. K., "Quality Assurance of Chemical Measurements," ACS Short Course, Toronto, Canada, June 25-26, 1985.

Taylor, J. K., "Quality Assurance of Chemical Measurements," Army Chemical Center, Edgewood, MD, July 2-3, 1985. 
Taylor, J. K., "Quality Assurance of Chemical Measurements," ACS Short Course, Denver, C0, July 17-18, 1985.

Taylor, J. K., "Quality Assurance of Chemical Measurements," ACS Short Course, Edmonton, Canada, July 23-24, 1985.

Taylor, J. K., "Principles of Calibration," ASTM Conference, Boulder, CO August 12, 1985. Invited

Taylor, J. K., "Quality Assurance of Chemical Measurements," Los Alamos National Laboratory, Los Alamos, NM, August 29-30, 1985.

Taylor, J. K., "Quality Assurance of Chemical Measurements," ACS Short Course, Chicago, IL, Sept. 7-8, 1985.

Taylor, J. K., "The Impact of Instrumentation of Analytical Chemistry," ACS Meeting, Chicago, IL, September 9, 1985. Invited

Taylor, J. K., "Statistics for Chemists," ASTM Committee E-2 Meeting, Hershey, PA, September 11, 1985. Invited

Taylor, J. K., "Quality Assurance of Chemical Measurements," EPA Office of Toxic Substances, Washington, DC, September 17-18, 1985.

Taylor, J. K., "Quality Assurance of Chemical Measurements," Army Chemical Center, Edgewood, MD, September 23-24, 1985.

Taylor, J. K., "Quality Assurance of Chemical Measurements," ACS Short Course, Philadelphia, PA, September 27-28, 1985.

\section{Committee Assignments}

Harry S. Hertz

Secretary, American Society for Mass Spectrometry (Term completed July 1985)

Chairman, Education Committee, American Society for Mass Spectrometry Member, ASTM, Committee D19 on Water

President-Elect, National Committee for Clinical Laboratory Standards

Technical Advisor, OIML, SP26, Subcommittee SR5 on Reference Materials

for Calibration of Instruments Meant for Checking Substances During Medico-Biological and Research Analyses

Member, Analytical Laboratory Managers' Association

Member, Department of Energy Health and Environmental Research Advisory Committee

Member, Editorial Advisory Board, Analytical Chemistry

Rance A. Velapoldi

Member, Interagency Toxic Substances Data Committee

Working Advisor, ASTM, Committee E7 on Nondestructive Testing, Subcommittee E7.03 on Liquid Penetrant and MPI Methods, Task Group E7.03.03 on E-270 Glossary Revision 
Member, ASTM, Committee E13 on Molecular Spectroscopy,

Subcommittee E13.06 on Molecular Luminescence

Task Group E13.06.01 on Presentation of Corrected Fluorescence Spectra

Task Group E13.06.02 on Recommended Practices on Molecular Fluorescence Spectroscopy

John K. Taylor

Member, ISO/TC48, Glassware and Related Apparatus

ISO/TC48/SC01, Volumetric Glassware

ISO/TC146, Air Quality

ISO/TC01, Stationary Source Emission

ISO/TC02, Work Place Atmospheres

ISO/TC03, Ambient Atmospheres

ISO/TCO4, General Aspects

Chairman, ASTM D19.01, International Standards

ASTM D22, Sampling and Analysis of Atmospheres

Member, ASTM D19, Water

ASTM D19.02, General Specifications and Technical Resources

ASTM D19.05, Inorganic Constituents in Water

ASTM D19.07, Sediments

ASTM D22.01, Quality Control

ASTM D22.02, Source Measurements

ASTM D22.03, Ambient Measurements

ASTM D22.04, Analysis of Work Space Atmospheres

ASTM D22.09, ISO TAG for ISO/TC146

ASTM E34, Occupational Safety and Health

ASTM E36, Criteria For the Evaluation of Testing and/or Inspection Agencies

ASTM E36.10, Generic Criteria

ASTM E36.30, Nomenclature and Definitions

ASTM E41, Laboratory Apparatus

ASTM E41.01, Glass and Plastic Apparatus

ASTM E41.06, Weighing Devices

ASTM E41.07, Microchemical Apparatus

Collaborative Testing Subcommittee - Standard Methods

Advisory Committee - CHEMTECH (ACS)

ACS Committee on Environmental Chemistry - Subcommittee on Environmental Analytical Chemistry

NBS Museum Committee

NBS Representative - Interagency Advisory Committee on Water Data

4. Other

a. Conferences

H. S. Hertz, Analytical Group of the Directors of Industrial Research, National Bureau of Standards, Gaithersburg, MD, February 8, 1985.

5. Center Colloquium Series

October 17,1984

Professor Milton L. Lee, Department of Chemistry, Brigham Young University, Provo, UT, "Stationary and Mobile Phases in Capillary Chromatography". 
December 13,1984

January 9, 1985

February 13, 1985

March 4, 1985

March 13, 1985

April 1, 1985

August 1, 1985

September 11,1985
Professor Konrad Mauersberger, University of Minnesota, Minneapolis, MN, "Ozone: Laboratory Studies and Stratospheric Measurements".

Professor Roland F. Hirsch, Seton Hall University, South Orange, $\mathrm{NJ}$, "Application of DARC Topological Analysis to Research in Analytical Chemistry".

Dr. Jack M. Holl, U. S. Department of Energy, Germantown, MD, "The Great Nuclear Debate: The Management and Control of Nuclear Energy Since World War II".

Dr. Christopher Burgess, Glaxo Operations, Durham, Great Britain, "Documentation, Analytical Control, and Robotics in Analytical Chemistry".

Dr. Seymon Suckewere, Princeton University, Princeton, NJ, "Soft X-Ray Laser Gain Measurements in a Recombining Plasma Column".

Dr. Ivo Allegrini, Instituto Sull'inquinamento Atmosferico, Rome, Italy, "Recent Developments in Instrumentation and Methods for Air Pollution Measurements".

Dr. U. Haas, University of Hohenheim, West Germany, "The Capabilities of Photoacoustic Spectroscopy in Depth-Profiling and Thickness Measur ement".

Dr. Edward M. Chait, E. I. DuPont de Nemours and Co., Inc., Wilmington, DE, "An Industrial Perspective of Biotechnology". 


\section{Voluntary Standardization and Quality Assurance}

\section{Voluntary Standardization}

The center continues to play an important role in standardization activities. Thirty-six members of the staff hold 149 memberships on standards committees, including positions of leaderships on 10 of these, as follows:
ASTM C-26
ASTM D-19
ASTM D-22
ASTM E-02
ASTM E-03
ASTM E-07
ISO/TC146
ISO /TC 147
IUPAC
NCCLS

\author{
Nuclear Fuel Cycle \\ water \\ Sampling and Analysis of Atmospheres \\ Emission Spectroscopy \\ Chemical Analysis of Metals \\ Nondestructive Testing \\ Air Quality \\ Water Quality \\ Commission on Atomic Weights \\ National Committee for Clinical Laboratory Standards
}

Leadership was provided in organizing a "Conference on Sampling and Calibration for Atmospheric Measurements", sponsored by ASTM Committee D22. Center personnel presented 5 papers at the conference which will be published in the proceedings.

\section{Quality Assurance}

The Center's program to provide quality assurance education and assistance to other government agencies and to the public has been very active during the past year. A key feature of this is the Quality Assurance Seminar series initiated in 1983. These seminars are of two types: those held at NBS consist of 10 hours of lectures and 4 hours of small-group discussions (mini-workshops) in selected measurement areas; those presented away from NBS consist entirely of 16 hours of lectures given during a two-day period. Essentially the same material is presented in the lectures of both seminars, except that the content is enlarged in the case of the latter type. Three seminars of the first type were presented at NBS to a total of 150 persons. Seminars were presented at the Food \& Drug Administration, EPA office of Toxic Substances; Army Chemical Center, Lawrence Livermore Laboratory, and Los Alamos National Laboratory. A seminar co-sponsored by NES and the National Research Council of Canada was presented at the meeting of the Chemical Institute of Canada held at Kingston, Ontario in June 1985. E1ght seminars were presented under ACS sponsorship and two in cooperation with the 1985 Pittsburgh Conference and Exposition. Since its inception in 1981, 58 seminars have been presented to a total audience of 2500 persons.

An experimental Chemical Measurement Assurance Program (CHEMAP) is in the planning stage. This will consist of the systematic use of SRMs together with control charts to assure statistical control of a measurement system. The center will provide guidance in the selection of appropriate SRMs and in the evaluation of the measurement data. The program has been presented to several grilups and several laboratories have expressed interest in participating during the coming year. Based on the experience gained, it is expected that the CHEMAP Program will be made available to a wider audience in the following year. 
The center has organized a quality assurance task group that is developing selected aspects of its QA program. During the year, the group has developed a document on Traceability which discusses the concept and describes how SRMs may be used for this purpose. A second document establishes the format for analytical reports and gives guidance for their preparation. A document setting forth policy and guidance for laboratory record keeping has been prepared as well as a form for use in defining the work to be done in service analysis or for SRM certification measurements. A document providing guidance for the more uniform statistical treatment of measurement data is now in preparation.

John K. Taylor 


\section{Service Analysis}

The performance of service analyses continues to be an important function of the Center for Analytical Chemistry (CAC). Within the scope of this activity, the technical staff gives advice, performs accurate chemical analyses, and provides state-of-the-art calibrations on a wide range of research and standard materials. This service is available, on request, to

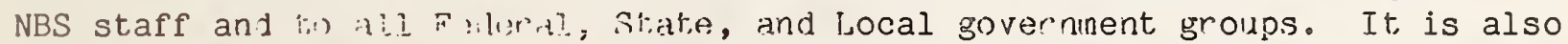
available for use by the private sector in those special instances for which CAC possesses a unique neasurenenl: capability. Within the latter category, the two most frequent types of requests are for the verification of spectrophotometric transmittance SRiMs and for the recalibration of SRM gas mixtures.

In the performance of the service analysis function, every member of the CAC staff is dedicated to providing timely, cost effective, and informative analyses. The turnaround time for the most straight-forward analyses ranges typically from several days to about two weeks. All work is performed on a cost reimbursable basis. Within NBS, funds are obligated on an interdivision work order and designated cost centers are cross-charged. All outside work is performed via a purchase order.

During the first 11 months of FY85, CAC staff provided analyses or recalibrations for some 130 requests at a cost of $\$ 290,200$. These requests and their associated funding were divided among the three categories of customers as follows: NBS - 29 jobs $(\$ 77,200)$; other government agencies - 28 jobs $(\$ 131,600)$; and private industry - 73 jobs $(\$ 81,400)$.

Other government agencies continue to be the largest user (on a funding basis) of our analytical services. It is also noteworthy that there was a significant increase in the number of NBS requests during FY85; this increase was in sharp contrast to the slow but steady decline that has been observed for in-house requests over the past five or six years.

R. W. Burke and M. V. Smith 
II. Inorganic Analytical Research Division

James R. DeVoe, Chief

Barry I. Diamondstone, Deputy Chief

A. Division Overview

The Inorganic Analytical Research Division conducts research that is directed toward improving the accuracy of compositional measurements of inorganic constituents in a variety of materials. This research takes the form of basic studies on new principles of chemical analysis as well as improvements to existing methods. In addition, the Division uses accurate methods to certify Standard Reference Materials, to provide analytical services for other government agencies and to provide analytical support for solving problems related to national needs. The Division is organized into four Groups which are oriented to specific technical disciplines. The Groups are: Analytical Mass Spectrometry, Atomic and Molecular spectrometry, Electroanalytical Research, and Nuclear Methods.

We believe that, in order to increase our expertise in certification capability, developmental research pursuant to the preparation and certification of SRMs should be significantly increased. The developmental effort can take many forms. For example, there is a need to investigate exhaustively the reason for analytical biases. More time should be taken to study the process by which a new reference material is made, and to design carefully homogeneity testing particularly when element specific problems are suspected. We have established the concept of a technical champion who is responsible for the scientific considerations associated with the fabrication and certification of an SRM. This person works with the coordinator for the Division and the Office of Standard Reference Materials. We also need to investigate methodology for certain elements or group of elements sometimes associated with a particular material or group of materials. For example, the analysis of gases in metals is an area where considerable effort must be placed in order to provide a high level of accuracy. Quite often, special dissolution techniques must be developed in order to be assured that the sample is totally decomposed to the solvated ion. These and others need immediate attention.

There have been significant advances in the developmental research area this past year, and sone of these can be read in the various reports to follow. Several have not been included but are of equal importance. For example, progress has been made toward automating some of the radioactive sample handling for activation analysis. Isotope dilution mass spectrometric methods (IDMS) have been developed for selenium which is the sulfur analog that won an IR-100 award last year. A fast neutron activation analysis method has been developed for minor and trace amounts of silicon which is difficult to analyze by other methods. Good progress has been made on the reinstitution of voltammetry for the certification of SRMs. We are very pleased that a third IR-100 award has been received (within the last two years) by a member of our Division. Ronald W. Shideler has won this latest one for his design of a parametric amplifier which has extremely low noise and high input sensitivity. The design concept is currently being evaluated by instrument manufacturers. 
In addition, developmental projects have supported other agencies as evidenced by the fact that we have developed a method for the direct collection and injection of aerosols into an inductively coupled plasma. We were the initiators of an ASTM task group on Nuclear Methods of Chemical Analysis. We have established a multi-agency program involving the Food and Drug Administration, Department of Agriculture, and International Atomic Energy Agency to develop methodology for the trace element analysis of foods. We have analyzed for the EPA, several series of secondary water reference materials containing trace elements.

The analysis of SRMs continues to occupy a major part of our effort. We have begun to implement a laboratory data management system by incorporating many of our reports of analysis for the certification of SRMs over the past years. This database is expected to provide much improved information on previous methods used for certification, agreement between methods, etc. This past year, we have carefully studied our role in this program and believe that we can contribute in all areas of standards development.

We have had a good year in research. There are a number of studies in addition to those described in the reports to follow. For example, in collaboration with the Organic Analytical Research Division, it has been found possible to identify the presence of phospho-proteins in 2-dimensional electrophoresis layers by autoradiography. Neutron depth profiling continues to reveal new surface properties of materials with the completed study of helium-3 transport in nickel. This study may lead to understanding of how gases migrate through metals and change structural characteristics. Initial results on the IDMS measurements of carbon dioxide show accuracies to better than one part per thousand. Our initial research in aqueous electrolyte conductance has provided impetus to begin experimental studies preparatory to the certification of an SRM.

During this past year, the Division has continued to have excellent collaboration with many guest workers and research associates. This provides us with added stimulation from exposure to new ideas.

Our future plans involve consolidating our research ideas into areas in which significant funding can generate an effort that can be most effective. This means that group element separations and preconcentration techniques utilizing robotics and automation will be investigated in most of the Groups within the Division. Chemical dissolution techniques which have been long neglected should now be reexamined in the light of new technology which is available for measuring the efficacy of the methods. Other plans include development of a cold neutron source for neutron depth profiling and prompt gamma activation analysis, resonance ionization mass spectrometry for studying sputter atomization and time-of-flight processes, ion optics in mass spectrometry, material transport and new atom reservoir design in atomic spectroscopy and generation of new basic considerations for standardization of $\mathrm{pH}$.

1. Analytical Mass Spectrometry Group: Overview

The Analytical Mass Spectrometry Group develops and maintains the capabilities required to perform compositional measurements using the analytical sciences of chemical separation and mass spectrometry. For many years, the Group has been involved in chemical separations, plus the highly precise and accurate isotope ratio measurements required to determine the atomic 
weights of the elements and to make very accurate measurements of trace element concentrations. While maintaining the basic thrust in the traditional areas, the horizons of the Group have broadened markedly in the past few years. Predicated on the competence building program in ionization mechanisms and related basic research, substantial changes have been initiated to develop new capabilities for chemical separations and ion spectroscopy. By combining the foundation evolved from many years of measurement research and applications with the recently initiated fundamental changes described below, we anticipate that a new generation of measurement capabilities for analytical mass spectrometry and compositional analysis will be achieved.

Rapid progress in the ionization mechanisms competence building program has accelerated the maturation of resonance ionization mass spectrometry (RIMS) as a major new analytical tool for elemental and isotopic analysis. Accordingly, this competence will be brought into the mainstream of analytical research and development within the Center during the next year. During the past year, efforts in this area have focused on the auto-ionizing states of magnesium in collaboration with researchers in the Center for Radiation Research, design and construction of an instrument for ion bombardment and laser ablation studies of solids, preparation for multicomponent isotope dilution analysis, studies of osmium and rhenium resonance ionization and spectroscopy, and the study of time-resolved magnetic dispersion mass spectrometry to improve isotopic selectivity measurements.

Building upon the IR-100 award-winning sulfur work of last year, the thermal formation of arsenic-containing molecular ions has been extended to include selenium as the $\mathrm{AsSe}^{+}$ion, which has been used successfully with newly developed chemical separations to determine trace selenium in SRMs using isotope dilution mass spectrometry. Utilizing negative ion mass spectrometry and the $\mathrm{BO}_{2}^{-}$ion, a method has been developed in collaboration with Dr. Heinz Zeininger to determine boron concentrations at the sub-ppm level.

We are most pleased to announce that Ronald $W$. Shideler has been awarded one of the highly competitive IR-100 awards for his development of the NBS parametric amplifier electrometer (see Technical Report 12). This amplifier provides significant improvement in signal-to-noise ratio over others that we have used. It is currently being installed on mass spectrometers in our laboratory and we have (ICP-MS) requests from others as well.

An inductively coupled plasma mass spectrometer has been acquired, installed and its performance characteristics demonstrated at solution detection limits of $0.1 \mathrm{ppb}$ and isotope ratio precisions of $0.25 \%$, RSD for selected elements. Although there are still a few start-up problems to resolve, this technology appears to offer potential as a cost-effective means to provide the analytical reliability inherent in isotope dilution mass spectrometry.

A wide variety of analytical services has been provided to other government agencies and private sector businesses. Examples of these outputs are participation in the international lead isotope tracer experiment in Turin, Italy, elemental and isotopic analyses of boron and chlorine in nuclear reprocessing plant construction materials, and in collaboration with Dupont an assay of trace element contamination in fluorocarbon polymers used in the semiconductor industry. In addition to these services, the Group has 
carried a much larger component of SRM analyses this past year, providing high accuracy trace element analysis using isotope dilution mass spectrometry.

Research plans for next year include the investigation of robotics applications in the chemical separations laboratory, development of microwave dissolution and automated separations, diagnostic and analytical studies of ion bombardment and laser ablation of solids, modeling studies of continuous and pulsed ion transport and manipulation in electric and magnetic fields, thermal formation of negative ions, and metal speciation and isotope dilution studies using the ICP-MS. Sufficient progress has been made on the chemical assay and isotopic analysis of nickel that we anticipate completion of the atomic weight and absolute isotope abundance measurements during next year. Also next year a study, funded by the Electric Power Research Institute, of the feasibility of using rare earth element stable isotopes as surrogate tracers to follow the path of coal fired power plant sulfur emissions will be initiated.

Larry J. Moore, Group Leader; I. Lynus Barnes, Ellyn S. Beary, William A. Bowman, III, Karen A. Brletic, Courtney A. Clements, Emile C. Deal, Jack D. Fassett, John W. Gramlich, Scott A. Hotes, Lois B. Jassie, W. Robert Kelly, Howard M. Kingston, George M. Lambert, Larry A. Machlan, John R. Moody, Thomas J. Murphy, Paul J. Paulsen, Lura J. Powell, Ronald W. Shideler, Heinz Zeininger, and Richard J. Walker.

\section{Atomic and Molecular Spectrometry Group: Overview}

The principal objectives of the Atomic and Molecular Spectrometry Group are to conduct research in the fundamental processes associated with analytical atomic spectroscopy, to conduct developmental research on methodology using existing analytical spectroscopies, to evaluate all types of errors, and to apply the results of these efforts to the certification of standard Reference Materials and to the publication of technical results.

In July a few changes were made in the organizational structure of the Group. The Laser Analytical Chemistry Group was combined with this Group. In order to more effectively carry out our major program in certification of Standard Reference Materials, T. Rains returned to the laboratory and will continue to provide assistance to the Group via his many contacts in the field of atomic absorption spectroscopy. The Group is temporarily headed by the Division Chief.

The characterization of Standard Reference Materials and the analysis of highly complex samples from other government agencies as well as other Divisions at NBS via the service analysis program comprise major areas of effort within the Group. A few of the accomplishments using the techniques of the Group include the characterization of major, minor and trace elements in 55 SRMs which include matrices listed in Technical Report 28. The recently released nine Aqueous Spectrometric Standard Solutions are being widely accepted by instrument manufacturers, supply houses, service and research laboratories. At present, this series of SRMs provides standard solutions for 36 elements. 
One of our Group members ( $R$. L. Watters, Jr.) co-chaired a conference on chemometrics held at NBS. This conference was unique in bringing statisticians together with chemists in a forum in which the impact of research in statistics and probability on research in chemistry could be discussed. The proceedings of the conference will be published in a special issue of the NBS Journal of Research.

Research on material transport via the spark discharge revealed a previously unrecognized phenomenon. It appears that the atomic composition of the vapor from which optical emission signals are produced is not representative of the bulk composition. The vapor is enriched in the more volatile component and is depleted in the less volatile one. More studies need to be performed in order to determine if this is a prevalent phenomenon among a number of materials. If this is the case, the accuracy of spark-inductively coupled emission plasma systems may have to be reevaluated.

The NBS-developed laser enhanced ionization (LEI) technique has evolved into a more routine chemical analysis system, and was used for the analysis of several Standard Reference Materials. In addition, a computer controlled two-wavelength calibrated instrument was developed to further enhance the accuracy of the method by utilizing the resultant three dimensionality of the data.

The Group now contains the necessary expertise to automate most types of instruments by interfacing to microcomputers. Several projects are already underway including an automated chemical separator for the alkali metals.

Collaborative research is proceeding well in the Group. This past year we have instituted research projects with the following: Dr. C. Spiegelman, Center for Applied Mathematics, with Dr. R. Watters, Jr., on the statistical interpretation of calibration curve data; Dr. L. Moore, Analytical Mass Spectrometry Group with Dr. J. Travis on the mechanism of laser ionization in the source of a mass spectrometer; Dr. K. Mielenz, Radiometric Physics Division with Dr. R. Mavrodineanu on the development of spectrophotometric standards; Prof. A. Syty, Indiana University of Pennsylvania, and R. Christensen, Liquid Chromatography Group, with $T$. Rains on the combination of liquid chromatography with atomic absorption spectroscopy; Dr. L. Moore, Analytical Mass Spectrometry Group (IARD), with F. Ruegg on the development of an interface for a transient digitizer with a microcomputer for high speed readout; Dr. N. Valette-Silver, Carnegie Institute of Washington, with Dr. R. Watters, Jr., on the trace element analysis of deep oceanic springs; and Dr. B. Davis, EPA, with $\mathrm{T}$. Rains on the use of atomic absorption spectroscopy for the analysis of residues from chemical waste disposal. In addition, we have had a number of Chinese guest workers who have spent from one to two years with us.

The type of work performed for other government agencies has varied from method development to the analysis of a variety of materials that are to be used as secondary standards. The level of effort which goes into these materials is frequently equivalent to that used for the certification of Standard Reference Materials. When this is the case, every effort is made to arrange for the material to be treated as an SRM. We are now characterizing micrometer-sized spheres of glass (inorganic-ion doped) with the goal of producing an SRM to calibrate microspectrofluorimeters. Such an SRM, with suitable stability and spectral characteristics, will be extremely useful in the standardization of fluorescence-tagging procedures used in medical research. 
The gases in metals program is progressing well, but is limited in available diagnostic studies that can measure systematic error in the measurement process. Alternate methodology such as manometric measurement of fixed volumes, qualitative identification of gaseous mixtures, and totally different methods such as neutron activation analysis will be studied.

Development of transmittance filters for spectrophotometers has progressed well. The stray light problem which existed for some spectrometers in the past has been corrected by design changes incorporated by the manufacturers. Future developments which are described below will be coordinated with the manufacturers, concurrently with the filters development, so that technical problems with the standard can be minimized.

Spark optical emission spectroscopy which is the mainstay for homogeneity testing of all SRMs continues to provide excellent results. The statistical analysis program which is used on all of the spectroscopic data will be rewritten this next year to improve its overall capability and to consolidate the processing thereby reducing the cost of analysis.

James R. DeVoe, Acting Group Leader; Robert W. Burke, Therese A. Butler, Barry I. Diamondstone, Michael S. Epstein, Robert C. Gauer, Radu Mavrodineanu, De M. Mo, John A. Norris, Theodore C. Rains, Fillmer C. Ruegg, Teresa A. Rush, R. L. Sams, Melody V. Smith, John C. Travis, Gregory C. Turk, J. Nathalie Valette-Silver, Thomas W. Vetter, Robert L. Watters, Jr., Jesse Wen, and Yang $\mathrm{Z}$. Zhang

\section{Electroanalytical Research Group: Overview}

The Electroanalytical Research Group conducts basic research and utilizes electrochemical principles to develop new techniques, to improve existing techniques, and to apply them to chemical analyses. The techniques in practice include amperometry, conductimetry, coulometry, ion chromatography, polarography, potentiometry, and voltammetry. Research activities are directed toward attaining a more thorough understanding of the complex electrochemical systems encountered in the development and implementation of electroanalytical methods.

A major project in this past year has been the development, production, and analysis of a Standard Reference Material for acid rain analyses, (SRM 2694, Simulated Rainwater). The primary goal of this material is to provide a control standard for $\mathrm{pH}$ measurements in rainwater, which will compensate for residual liquid junction potential, thereby minimizing a major source of bias in this critically important measurement. This material represents the first issuance of a matrix-specific pH standard by the National Bureau of Standards. This material is also the first SRM certified for aqueous electrolytic conductance, albeit not a high-accuracy standard. In addition, the SRM is certified for trace anions, and for trace alkali, alkaline earth and ammonium ions, representing another first in the SRM program. Problems with the stability of the ammonium ion have recently been discovered, and research has been initiated to determine the cause and to identify and implement an appropriate correction. Research must also be conducted to develop a new generation of storage container, one which has the inertness and freedom from contamination of fluorocarbons or polyethylene, but without the transpiration 
problems of these materials. This work is essential to this project and to other projects in the division requiring long-term storage of dilute aqueous solutions.

A joint project was conducted with Robert C. Paule, statistical consultant to the National Measurement Laboratory and ASTM. This project was a statistical ruggedness test of a procedure for $\mathrm{pH}$ measurements in rainwater, in which several selected parameters were varied in order to determine and quantify their individual and interactive effects on the measurement. The parameters were stirring, temperature, immersion depth, addition of neutral salts, dilution, and equilibration time. Of these, the factors which have the greatest effects, (and hence must be carefully controlled), are stirring and addition of neutral salts. Based on these results, a recommended procedure for $\mathrm{pH}$ measurements in rainwater is included as part of the "Certificate of Analysis" of SRM 2694 and has been submitted to ASTM for acceptance as a standard method. A complete report of the ruggedness test is being published.

Voltammetry is becoming a viable analytical tool within the Group with the successful demonstration of anodic stripping voltammetry (ASV) directed toward the determination of copper, cadmium and lead in SRM 1643a, Trace Elements in Water, and of differential pulse polarography toward the determination of copper and zinc in SRM 1577a, Bovine Liver. A most notable advance in the precision and accuracy of ASV was achieved through the use of indium (III) as an internal standard. This is the first use of an internal standard in ASV, and aids the determination by taking into account and correcting for variations in mass transport to the electrode during the plating step.

Research in conductance has continued this year. Dr. Walter J. Hamer has contributed to this effort by providing a thorough review of this discipline and by recalculating the historical and widely accepted values of the specific conductance of select concentrations of potassium chloride on the basis of the currently adopted fundamental constants, base units, and atomic weights. Instrumentation for temperature control and measurement, critical to high accuracy conductance measurements, is now operational. Commercially manufactured two-electrode conductance cells have been purchased and tested. Still to be acquired is a Jones Bridge. Next year, in collaboration with the Office of National Measures of Hungary, it is intended to develop the working basis for a high accuracy SRM for aqueous electrolytic conductance. Longer term research involves the development of a four-terminal cell (with an adjustable cell constant), and, in conjunction with the Electricity Division and the Electrosystems Division, the development of a new generation of conductance measurement instrumentation. The ultimate goal of this research is to link the conductance measurement to basic metrology.

Research in ion chromatography was active on several fronts, most notably in improving the precision and accuracy of the advanced instrumentation purchased the previous year. This effort, aided by the Dionex Corporation, led to the development by Dionex of a substantial improvement in their anion separator columns and to a better understanding of the various factors affecting peak shapes, retention times, and linearity of response. The capability for cation determinations was demonstrated via SRM 2694, Simulated Rainwater. Research in ion chromatography with amperometric detection was highlighted by improvements in the determination of ultra-trace (sub-ppb) concentrations of sulfide (see below), and by improvements in the 
determination of trace iodide in difficult matrices, such as table salt and cadmium sulfide. A project to develop a rapid method for the accurate determination of fluoride in vegetation is in progress. A new data acquisition device has been acquired for the advanced ion chromatograph and is being implemented.

Based on high accuracy potentiometric measurements, the thermodynamic properties of $\mathrm{DCl}$ in $\mathrm{D}_{2} \mathrm{O}$ and of phthalic acid in $\mathrm{D}_{2} \mathrm{O}$, including the first and second dissociation constants, have been evaluated, and submitted for publication.

The Electroanalytical Research Group continues to expand its resources and scope of research through active use of the guest worker program, and industrial, international, and academic collaborations. Two scientists from the National office of Measures of Hungary have visited for one month each to exchange information on $\mathrm{pH}$ and conductance measurements and research. The Group maintains its involvement with ASTM and NCCLS through participation in meetings and task groups, and is active in Task Group D (Monitoring) of the National Acid Precipitation Assessment Program.

Research in $\mathrm{pH}$ will continue as a long-term commitment to provide reliable and thermodynamically significant measurements and standards in this most widely used analytical parameter. The development of a series of matrix-specific $\mathrm{pH}$ standards is a high priority. Investigations of aqueous conductance will continue; advancements in ion chromatography will be explored. Voltammetry will be used extensively as a valuable analytical research technique within the Group. Flow-injection analysis with electrochemical detection will be implemented for determinations of trace metals in complex matrices.

William F. Koch, Group Leader; George Marinenko, Yung Chi Wu, Kenneth W. Pratt, Jr., Melissa Knoerdel, Lisa A. Holland, and Han Kai

4. Nuclear Methods Group: Overview

The development and application of nuclear analytical techniques for greater accuracy, higher sensitivity and better selectivity are the goals of the Nuclear Methods Group. A high level of competence has been developed in reactor-based activation analysis, which includes instrumental and radiochemical neutron activation analysis (INAA and RNAA). In addition, the Group has a unique capability in neutron beam analysis with both prompt gamma activation analysis (PGAA) and neutron depth profiling (NDP). The NDP technique utilizes prompt charged particle emission to determine elemental distributions within the first few micrometers of a surface while the PGAA technique utilizes prompt gamma-ray emission to measure the total amount of an element in a sample, regardless of its distribution. These four techniques provide an arsenal of tools to address a wide variety of analytical problems in science and technology.

The activities during the past year have been dominated by the upgrade of the NBS Research Reactor (NBSR) to an operating power of $20 \mathrm{MW}$ from 1 ts previous $10 \mathrm{MW}$ level. The power increase and the associated repositioning of the irradiation tubes resulted in the NBSR being shut down during the first half of the year and required a total recharacterization of our irradiation facilities. The reactor characterization has been completed and the Group's 
irradiation capability has been significantly improved. The result has been a doubling of the neutron flux available for both our beam and in-core measurements, and for the nearly-installed cold neutron source.

With the NBSR unavailable for use for the first half of the year, we had the opportunity to gain experience with other reactors. The ability to irradiate large samples in a well-thermalized neutron flux made the MIT reactor the facility of choice for bioanalytical measurements, especially for the activation of whole electrophoresis gels. The nearby light-water reactors at the University of Maryland (College Park) and the University of Virginia (Charlottesville) were used for a variety of irradiations. The relatively high fast-to-thermal neutron flux ratio at these latter two facilities made epithermal and fast neutron activation analysis convenient, especially for iodine and silicon.

Radiochemical neutron activation analysis continues to make significant contributions to the Group's measurement capability. The determination of tin in the milk powder, wheat flour and rice flour SRMs at the few ng/g level and the determination of gold and platinum in the human urine SRM at the few $\mathrm{pg} / \mathrm{mL}$ level are examples of this work. The determination of platinum, in particular, at environmental baseline levels means that this important element can be added to the list of those which can be monitored in real samples.

Largely at the instigation of the Group's members, a new ASTM task group on Nuclear Methods of Chemical Analysis (E10.05.12) has been formed to insure that the ASTM standards in this area reflect the current state of the art and to enhance communication within this community. After three meetings, the task group has over forty members and six active subgroups: Quality Assurance, Biology Medicine and Health, Geochemistry and Archeometry, Reactors, Neutron Generators, and Forensic Applications.

The Group's collaborative research with industry and other government agencies continues to increase. Thirteen fluoropolymer materials were analyzed for over twenty elements for Dupont, and a series of high purity quartz samples were analyzed for Fort Monmouth. Our research in neutron depth profiling continues to enjoy a strong interaction with U.S. industry on the measurement of elemental distributions in high-technology materials. In addition to our ongoing bio-analytical collaborations with NOAA, NIH, USDA and FDA, a new IAEA program in nutritional monitoring of the human diet has been initiated jointly with FDA and USDA.

The National Environmental Specimen Bank, which in prior years has been devoted solely to a pilot program of collecting, analyzing and banking human liver samples under EPA sponsorship, has expanded this year to include several new sample types. Preliminary banking has begun on honey bee samples from EPA and on the USDA/FDA human diet samples. In collaboration with the NOAA National Status and Trends program, samples of marine sediment and fish liver and muscle are being banked. A goal for the coming year is the development of one or more of these materials as standard reference materials.

The past year has seen a major upgrade in our detection and data analysis capability. A second front-end detector system (ND 6700) has been installed for low level counting with two new germanium detectors. A 
duplicate ND 6620 counting system with an automated sample changer has been obtained for the analysis of the diet samples in the nutritional program. The VAX computer is now fully operational for data acquisition with its own sample changer. The addition of this improved data acquisition and computational capability for modeling the measurement process will continue to enhance our accuracy and throughput for activation analysis.

During the coming year, the Group will continue to consolidate the development of its data acquisition and computation capability and to apply nuclear methods to elements which are not done well presently. These new elements will include nickel, silicon and iodine by fast or epithermal NAA, nitrogen and phosphorus by thermal NAA with beta counting, and lithium and boron by a relatively new technique, neutron activation mass spectrometry. In addition to the ongoing application programs, work will continue in reducing and quantifying the various sources of systematic error in analysis by nuclear methods.

Ronald F. Fleming, Group Leader; M. James Blackman, Donald A. Becker, B. Stephen Carpenter, R. Gregory Downing, Kathleen A. Fitzpatrick, Robert R. Greenberg, G. Venkatesh Iyengar, John K. Langland, Richard M. Lindstrom, George J. Lutz, John T. Maki, Bruce R. Norman, Susan F. Stone, and Rolf L. Zeisler 
B. Selected Technical Reports

(Inorganic Analytical Research Division)

1. Three-Dimensional Atomic Spectra in Flames Using Stepwise Excitation Laser-Enhanced Ionization Spectroscopy

G. C. Turk, F. C. Ruegg, J. C. Travis, and J. R. DeVoe

The collisional ionization of the excited state atoms produced by laserexcitation in a flame forms the basis of the spectroscopic method called laser-enhanced ionization (LEI). Among the variety of modes of laser excitation which have been used, the technique called stepwise excitation offers significant advantages in both sensitivity and selectivity. Stepwise excitation is a double resonance method which utilizes two independently tunable synchronized pulsed dye lasers. In the most common situation, the first laser excites the analyte atoms from the ground state to some intermediate excited state, and the second laser further excites these atoms from the intermediate level to a higher level. Since collisional ionization rates from excited states increase exponentially as the ionization energy is approached, sensitivity is enhanced.

Previously, stepwise excitation LEI spectra have been recorded by scanning one of the lasers while the other laser was kept fixed on the resonance wavelength. We have now developed a computer controlled LEI spectrometer which is capable of measuring and storing LEI signals while scanning both laser wavelengths. The result is a three-dimensional LEI spectrum -- first step wavelength vs. second step wavelength vs LEI signal amplitude. When plotted as a 3-D projection or as a contour, features are revealed which have not previously been observed.

The wavelength drives of both lasers are stepper motor-controlled by a 16 bit microcomputer which also collects and stores the LEI signal output from a gated integrator. In addition, the computer calculates the wavelength of the lasers by analyzing the fringe pattern of a Fizeau interferometer which is projected on a photodiode array interfaced with the computer. This assures accurate wavelength axes of the spectrum.

The most interesting feature which has been revealed is a diagonal ridge which corresponds to the points where the sum of the energies of the two wavelengths equal that of the upper energy level. This ridge represents a two-photon transition, which is resonantly enhanced by the intermediate level. Unlike the typical two-photon transition, the two photons in this situation are of different wavelengths. This diagonal ridge feature is very difficult to observe without measuring the 3-D spectrum, and can be quite confusing when encountered in complex samples containing many elements. The new system will be utilized to verify the spectral purity of analysis lines for samples being analyzed by LEI spectrometry. 
2. Evaluation of Several Pulsed Dye Lasers as Excitation Sources for Flame Atomic Fluorescence Spectrometry

M. S. Epstein, J. C. Travis, and G. C. Turk

The sensitivity, precision, and accuracy of spectrochemical methods of analysis are the figures-of-merit which determine their usefulness for quant1 tative analytical measurements. In Laser-Excited Atomic Fluorescence Spectrometry (LEAFS), these figures-of-merit are primarily determined by the characteristics of the laser source used for excitation. For pulsed lasers, such characteristics are the peak power ( $\mathrm{kW}$ ), the temporal pulse width (ns), the spectral bandwidth $(\mathrm{nm})$, and the repetition rate $(\mathrm{Hz})$. Since the pertinent characteristics of tunable dye lasers vary significantly, we have investigated the performance of $\mathrm{Nd}: Y A G-l a s e r-p u m p e d$ and $\mathrm{Cu}$-vapor-laser pumped dye lasers as excitation sources for LEAFS. The study included evaluation of detection limits, calibration linearity, noise sources, and accuracy in real sample analysis. Results were compared to previous investigations of these parameters using a flashlamp-pumped dye laser.

Non-resonance transitions of iron $(296.690 / 373.487 \mathrm{~nm})$ and nickel $(300.249 /-342 \mathrm{~nm})$ were used in the study. Fluorescence was measured in an argon-separated air-acetylene flame using a $0.1 \mathrm{~m}$ monochromator and boxcar integrator detection system. Detection limits for the Nd:YAG laser were approximately 2 orders of magnitude poorer than those obtained with the $\mathrm{Cu}-$ vapor laser; the latter were essentially equivalent to those from the flashlamp-pumped dye laser. This was a result of scattered light/background fluorescence noise sources which limited detection using the Nd:YAG laser source. The high peak power of the Nd:YAG laser caused saturation of the fluorescence transitions which magnified the effect of these noise sources. Beam expansion to reduce the laser intensity below the saturation region did not improve detection limits significantly and magnified the effect of source flicker on the analyte flicker noise.

Detection limits using the Cu-vapor laser were defined by a combination of radio-frequency noise and photomultiplier shot noise. The high repetition rate $(5 \mathrm{KHz})$ of this laser reduced the effect of source flicker noise to the extent that the relative standard deviation for concentrations significantly higher than the detection limit was less than $1 \%$.

The determination of nickel in SRM 1645 (River Sediment) using LEAFS required background correction to compensate for background fluorescence induced by wing excitation of iron transitions lying near to the nickel resonance line. Analytical results agreed closely with the certified value.

This study illustrates the major concepts to be considered in choosing a laser system for LEAFS. The Cu-vapor laser appears to be the ideal excitation source for LEAFS, particularly if radio-frequency noise can be reduced. The high repetition rate makes it ideal for continuous atomization sources, such as the flame, where high precision can be obtained, as well as for transient atomization sources, such as electrothermal atomizers and gas generation systems. The application of the Cu-vapor-laser-pumped dye laser to these dynamic atomizers will be investigated in the future. 
3. Determination of $\mathrm{Cr}$ (VI) in Natural Waters by LC/AAS after Separation and Preconcentration

A. Syty, R. G. Christensen, and T. C. Rains

Chromium is an element of considerable environmental significance and exists in solution predominantly in +3 and +6 oxidation states. Hexavalent chromium is considered to be toxic because of its oxidizing potential, whereas, trivalent chromium is an essential micronutrient required for maintenance of normal glucose tolerance. Hexavalent chromium finds its way into natural waters chiefly from industrial effluents, such as electroplating and tanning industries, from dyeing operations, as leachings from sanitary land fills, and from water cooling towers. With current maximum concentration of $\mathrm{Cr}(\mathrm{VI})$ of $50 \mathrm{ng} / \mathrm{mL}$ permitted in potable water, the goal of this work was to develop a rapid and accurate method for the determination of $\mathrm{Cr}(\mathrm{VI})$ in natural waters.

In order to improve the sensitivity of chromium analysis, several preconcentration approaches have been used in the past. These include coprecipitation, solvent extraction, ion exchange, and thin-layer, gas, and adsorption chromatography. All of these methods of preconcentration introduce additional labor-intensive and time-consuming sample manipulation steps into the analysis, and are subject to all the attendant sources of variability. The method developed here utilizes a rapid on-line chromatographic preconcentration technique coupled with a flame atomic absorption spectrometer (AAS) as the detector. The sample of natural water is treated with tetrabutyl-ammonium phosphate, an ion-pairing agent, and then pumped through a $\mathrm{C}_{18}$ bonded silica column. The $\mathrm{Cr}(\mathrm{VI})$ is selectively preconcentrated on the column while $\mathrm{Cr}$ (III) passes through unretained. By switching to a $50 / 50$ methanol/water solvent, the $\mathrm{Cr}$ (VI) is rapidly eluted from the column which produces a sharp peak with the AAS instrument.

With a short 4-cm column the preconcentration or trace enrichment factor is about 10, while the $25-\mathrm{cm}$ long column gave an enrichment factor of 300 . A detection limit of $0.8 \mathrm{ng} / \mathrm{mL}$ was obtained using a 25-cm column and a flame AAS as the detector.

Samples of NBS pond water were collected in early spring and in late spring when the organic content of the water was very high. $\mathrm{Cr}$ (VI) could not be detected in either sample $[\mathrm{Cr}$ (VI) $\leq 1 \mathrm{ng} / \mathrm{mL}]$. As a check of the recovery of the method, each sample was spiked with varying amounts of $\mathrm{Cr}$ (VI) and $\mathrm{Cr}$ (III). When these samples were analyzed on the same day of spiking, complete recovery of the $\mathrm{Cr}$ (VI) was obtained. After one day of standing, the recovery of $\mathrm{Cr}$ (VI) was 80 to 85 percent with a corresponding increase in the $\mathrm{Cr}$ (III) concentration. In all cases, the rate of $\mathrm{Cr}$ (VI) reduction was higher in the water collected in late spring than in water collected earlier.

Future directions for this project include application of the method for the determination of $\mathrm{Cr}$ (VI) in a variety of fresh and saline waters. In addition, the general technique will be tested as a means of preconcentration of other ions in aqueous systems. A further modification of the method would be the use of electrothermal atomization AAS to improve its detection limits. 
M. Epstein, R. Velapoldi, and D. Blackburn

A joint program involving the National Bureau of Standards and the Food and Drug Administration is concerned with the development of standards for the calibration of microspectrofluorimeters used for the quantitative measurement of immunofluorescence of species tagged with fluorescein isothiocyanate (FITC). Research at NBS is being performed using a Leitz MPV3 microspectrofluorimeter modified by the addition of a $0.25 \mathrm{~m}$ scanning emission monochromator and a $\mathrm{N}_{2}$-laser-pumped dye laser excitation source. Several approaches are being investigated:

\section{(a) Inorganic Ion Doped Glass Microspheres}

Small spheres of glass ( $<20 \mu$ m diameter) doped with $\mathrm{Mn}, \mathrm{U}, \mathrm{Tb}$, or $\mathrm{Nd}$ ions have been prepared by flowing crushed glass particles through a bigh temperature furnace. These spheres are homogeneous and exhibit the theoretical (diameter) ${ }^{3}$ proportionality to fluorescence intensity when excited via epi-illumination in a microspectrofluorimeter. Ideally, in order for these standards to be useful to the clinical laboratory, they should mimic the excitation and emission spectra of FITC. Of the several glass compositions investigated, only uranyl glass exhibits a fluorescence intensity (with excitation in the 450-490 nm wavelength range) and an emission spectrum identical to FITC. The excitation maximum, however, is at $423 \mathrm{~nm}$ rather than at the $490 \mathrm{~nm}$ maximum observed for FITC, possibly limiting the use of these glass spheres as absolute intensity standards for FITC measurements without prior calibration against a stable FITC standard on the user's microscope. Excitation bandpass and source spectra may vary significantly between different microscopes, resulting in varying intensity ratios between the glass and FITC. Nevertheless, the glass microspheres should be quite useful as general purpose standards, both as a source of corrected spectra and as a measure of instrument stability.

\section{(b) FITC Doped Latex Microspheres}

Since a relatively stable FITC standard is required for initial calibration of the uranyl glass microspheres on the user's microscope, we are currently studying commercially produced latex microspheres with a surface coating of FITC. These spheres exhibit rapid fading of fluorescence intensity under continuous irradiation, but are relatively stable under nanosecond-pulse laser irradiation. We are attempting to develop a methodology to stabilize these standards for short periods of time to make them useful for calibration of the uranyl glass microspheres. The latter may then be used for long term calibration purposes.

\section{Spectrometric Analysis of Spark-Generated Aerosols}

R. L. Watters, Jr., T. C. Rains, M. S. Epstein, and G. C. Turk

Analytical techniques such as inductively coupled plasma (ICP) and atomic absorption spectrometry (AAS) are usually applied to the analysis of liquid samples or solid samples that have been dissolved. Over the past several years there has been increased interest in developing direct solld sample introduction systems for use with these techniques. We have been 
studying the use of a spark discharge as a sampling device for ICP spectrometry. Although this technique has shown promise, it does not presently exhibit the accuracy needed for the analysis of Standard Reference Materials (SRMs). In order to study further the sampling processes of the spark discharge, we have examined the physical characteristics and chemical composition of aerosols produced by sparking certain SRMs.

The preliminary results for brass SRMs, reported in the 1984 Annual Report, indicated systematic errors in the $\mathrm{Zn} / \mathrm{Cu}$ ratios for aerosols produced by the spark and collected on coarse and fine filter media. This year we have verified these results and have shown that although there are differences between the SRM $\mathrm{Zn} / \mathrm{Cu}$ ratios and the aerosol $\mathrm{Zn} / \mathrm{Cu}$ ratios, the aerosol ratios fall on a linear calibration curve for the series of 6 SRMs. Furthermore, the aerosol $\mathrm{Zn} / \mathrm{Cu}$ ratio for a given material is a function of spark repetition rate and peak discharge current.

We have extended these measurements to include the determination of $\mathrm{Mn}$, $\mathrm{Cu}, \mathrm{Cr}, \mathrm{Ni}$, and $\mathrm{Mo}$ ratios to $\mathrm{Fe}$ in a number of ferrous SRMs and have found similar systematic errors in aerosol composition. In general, more refractory elements, such as Mo, are depleted in the aerosol, and others, such as $\mathrm{Mn}$ and $\mathrm{Cu}$, are concentrated in the aerosol, when compared to their respective concentrations in the bulk sample. The successful applications of spark-ICP spectrometry for the analysis of metals, which have been previously reported, have therefore depended on the calibration process of the spark-ICP spectrometer system to normalize this sampling bias.

As a further extension of this work, we have examined the feasibility of making real-time measurements of metal aerosols in air using both ICP and AAS techniques. Low concentrations of $\mathrm{Fe}$ in aerosols were generated by sparking the same set of brass SRMs that contain certified trace amounts of Fe. The aerosol was carried in the argon stream from the spark chamber to the sample input of the ICP torch or the AAS flame. Although the fractional amount of $\mathrm{Fe}$ in the aerosol is likely to be different than the certified concentration of the sampled material, satisfactory calibration curves for Fe were obtained using ICP and AAS detection. The expected systematic error due to bias in the Fe aerosol concentration compared to the SRM value is $20 \%$. The detection limit for $\mathrm{Fe}$ in a stream of argon was found to be $0.002 \mu \mathrm{g} / \mathrm{L}$.

The effects of ICP input power, observation height in the plasma, and air/argon gas mixtures were used to optimize the response for Fe in a stream of air. The sample aerosol was produced by solution nebulization in this case. One of the most critical parameters of the system is the physical geometry of the plasma torch. With a specially designed low-flow torch, the best sensitivity for $\mathrm{Fe}$ in air was obtained using an $\mathrm{rf}$ power of only $1.5 \mathrm{~kW}$. Ambient air was sampled by a regenerative blower and forced into the plasma. The same approach was used to introduce the aerosol into the AAS flame. Calibration curves were obtained as before using spark sampling of the series of brass SRMs and placing the outlet from the spark chamber near the blower inlet. Linear calibration curves and a detection limit of better than 0.01 $\mu \mathrm{g} / \mathrm{L}$ were obtained for $\mathrm{Fe}$ in air using either the ICP or AAS.

Aerosol characterization work will continue for solid samples other than ferrous materials. Calibration of the ICP or AAS systems for the analysis of aerosols in air will be studied using a conventional solution nebulization 
system and a desolvation apparatus to produce dry aerosol. The output characteristics of this aerosol generation system will be measured by total collection of the analyte on filters. The collected aerosol will be dissolved and analyzed by conventional ICP or AAS. This system will eliminate changes in the calibration curve caused by the presence of argon in the sample stream.

6. Resonant Laser-Induced Ionization of Atoms in an Inductively-Coupled Plasma

G. C. Turk and R. L. Watters, Jr.

The use of tunable dye laser radiation to selectively ionize atoms in an inductively coupled argon plasma (ICP) has been investigated. Our objective in this research was to determine if the method of laser-enhanced ionization (LEI) spectrometry, which normally utilizes a flame as an atomization source, could be applied to the ICP. If successful, the adaptation of LEI to the ICP would have the benefit of an environment which has been demonstrated to be less susceptible to many of the chemical interferences encountered in flamebased spectroscopic methods. In addition, this application may prove to be an effective mechanistic probe for elucidating excitation and collisional processes in the ICP.

Laser induced enhanced ionization was measured as an increase in current between biased electrodes on either side of the laser irradiated volume of the ICP. Interaction between the radio-frequency plasma and the detection circuitry required that an extended ICP torch be used with the electrodes placed $19 \mathrm{~cm}$ above the load coil. This is well above the observation zone used in ICP emission spectroscopy and the atom population is much lower. As a consequence, the sensitivity of the measurement was found to be unsuitable for analytical application, but was found to be sufficient for some diagnostic studies. A study of the effect of laser power on the magnitude of laserinduced ionization was undertaken as a means of determining the mechanism of the ionization. In addition, a series of previously unobserved two-photon transitions of copper were recorded.

Several possibilities for improvement of the sensitivity of the measurement are being considered. The radio-frequency loading circuitry of the ICP can be modified to prevent arcing between the plasma and the ionization detection electrodes. This would enable detection in regions of the plasma with higher atom densities. Another possibility is the use of a nitrogen ICP, which has characteristics which are more favorable for LEI than the Ar ICP.

7. An $X-Y$ Scanning Photometer for Verifying the Transmittance Uniformity of Solid Filter SRMs

R. Mavrodineanu, R. W. Burke, M. V. Smith, F. C. Ruegg, and W. A. Bowman

Long-term stability and transmittance uniformity are the critical parameters that ultimately determine the quality and general usefulness of solid transmittance standards. Experience has shown that the stab1lity of both the colored glass and thin-film type standards is largely dependent on the conditions of preparation, i.e., grinding, polishing, coating, etc., and 
can be adequately monitored on a batch-to-batch basis. Such is not the case for transmittance uniformity, however, and each filter must be individually verified to guarantee this parameter.

Previously, the transmittance uniformity of NBS SRM 930 Glass and SRM 2031 Metal-on-Quartz Filters was monitored on the CAC high-accuracy spectrophotometer. This check involved manual movement of the filters and was both time consuming and an inappropriate use of this instrumentation. This situation was remedied during the past year by the design and construction of a dedicated instrument for checking the transmittance uniformity of candidate solid filter standards. The major features of this instrument include: (a) the use of a tritium-activated phosphor as a stable radiation source, (b) an automated $x-y$ scanning system consisting of two stepping motors interfaced to a microcomputer, and (c) a conventional photomultiplier preceded by a quartz diffuser. The system is operated in an AC mode and has a short-term stability of 1 part in 10,000. This instrumentation is now being used routinely to check the transmittance uniformity of every filter being considered for issuance as an SRM. This check is presently being made at nine locations over the $6 \mathrm{~mm} \times 20 \mathrm{~mm}$ area of the filter. The size of the monitoring beam is $1 \mathrm{~mm}$ $x 4 \mathrm{~mm}$. The accuracy with which the transmittance uniformity can be established varies with the transmittance level of the filter under test. For filters having transmittances of 0.5 and above, this verification can be made with an uncertainty of one or two parts in 10,000; for filters having transmittances near 0.01 the uncertainty is about one part in 1000 .

In the future, the measuring capability of the new instrument will be used to guarantee the transmittance uniformity of current SRMs and also to develop an expanded range of new SRMs.

\section{Statistical Ruggedness Testing of Acid Rain pH Measurements}

G. Marinenko, M. Knoerdel, and W. F. Koch

The purpose of a statistical ruggedness test is to establish the factors which strongly influence the measurement results, and to determine how closely one needs to control these factors. The measurement of $\mathrm{pH}$ in several dilute strong acid solutions, including simulated acid rain reference materials, was subjected to the ruggedness test. The Plackett-Burman (PB) experimental design was used with seven factors and eight different factor combinations per experiment. The design specifies that each factor is used at one of two chosen high and low levels. In this symmetrical, experimental design of eight measurements, each factor appears an equal number of times (4) at its high and low level. The main effect of any factor, then is calculated simply as the average of the measurements made at the high level minus the average of the measurements made at the low level for that factor. Making some assumptions and conducting 16 measurements (in our case) one can separate the effects from the two factor interactions. The factors investigated were temperature, stirring, dilution, electrode immersion depth, addition of $\mathrm{NaNO}_{3}$, addition of $\mathrm{KCl}$, and equilibration time.

Stirring has adverse effects on the measurement of $\mathrm{pH}$ of dilute acid solutions. It not only amplifies the signal noise but also biases the mean measured value. Moderate temperature control $\left( \pm 0.5{ }^{\circ} \mathrm{C}\right)$ is sufficient for maintaining measurements accurate to $0.01 \mathrm{pH}$. Addition of neutral salts $\left(\mathrm{NaNO}_{3}\right.$ or $\left.\mathrm{KCl}\right)$ cannot be tolerated in accurate $\mathrm{pH}$ measurements, as these 
salts predictably change the mean activity coefficients of solutions, and hence $\mathrm{pH}$. The ruggedness test has revealed not only the above main effects, but also two effects involving two-factor interactions, not determinable by experimental design which entails changes of one parameter at a time.

Two sets of two-factor interactions were isolated and examined. The two-factor interactions result either from the partial compensation of the main factors such as stirring and salt addition or from a nonlinear relationship in the additivity of the effects as is the case with two salt additions.

\section{Improvements in the Determination of Sulfide by Ion Chromatography}

H. Kai and W. F. Koch

Previous research in the Division has enhanced the determination of cyanide through the use of ion chromatography with electrochemical detection (IC/EC). The detection limits for cyanide were lowered to below $10^{-9} \mathrm{~g} / \mathrm{g}$ $(\mathrm{ppb})$. From thermodynamic considerations, sulfide should be even more sensitive than cyanide, and yet earlier attempts to measure sulfide at levels below $20 \mathrm{ppb}$ had failed. A research effort was launched to determine the reasons for this anomaly and to optimize the conditions for the determination of sulfide at the $\mathrm{ppb}$ level. Several factors were investigated which were suspected of having an adverse affect on the determination of sulfide by IC/EC: the instability of sulfide due to oxidation; the complexation of sulfide with impurities; the adsorption of sulfide on the anion exchange column; the condition of the surface of the silver working electrode; the applied potential of the silver electrode; the composition of the eluent; and temperature.

A stock solution of sulfide was prepared and assayed by iodometric titration. Standard solutions were made by serial dilution of this stock with the chromatographic eluant (an admixture of ethylene diamine, sodium borate, and sodium carbonate with a $\mathrm{pH}$ of about 11). A stability test of a $20 \mathrm{ppb}$ sulfide solution was conducted by monitoring the peak height response using IC/EC over a four-hour period. It was concluded that air-oxidation of sulfide was not a limiting factor. The effect of temperature was studied over the range of $11^{\circ} \mathrm{C}$ to $35{ }^{\circ} \mathrm{C}$. Below $25{ }^{\circ} \mathrm{C}$, the temperature coefficient was $2.9 \% / \mathrm{K}$; above $25{ }^{\circ} \mathrm{C}$ the effect of temperature became non-linear.

The electrochemical detection system consisted of a three-electrode potentiostat in the amperometric mode. The condition and applied potential of the silver working electrode was critical to high sensitivities toward sulfide. The electrode had to be polished daily and then reconditioned with several injections of sulfide before stable readings were obtained. Although excellent chromatographic resolution of cyanide and sulfide can be achieved, care must be exercised in the choice of applied potential to the working electrode to avoid fouling of the electrode with silver-cyano complexes. The optimum applied potential was determined to be +0.06 volts versus a silversilver chloride reference electrode. The anion exchange column appeared to adsorb sulfide and had to be conditioned with repeated injections of sulflde to saturate the adsorption sites before reproducible results could be obtained. 
The major problem affecting the quantitation of sulfide at levels below $20 \mathrm{ppb}$ was found to be loss of sulfide due to impurities. Metal impurities which had become concentrated on the anion exchange column after several years of use complexed the sulfide and retarded its elution. The metals, as determined by spark source mass spectrometry, are conjectured to come from various sources: tin from the distilled water lines, iron, chromium, and nickel from the IC pump, and copper, lead, and zinc from the reagents used in preparing the eluent. Organic impurities, especially from discolored ethylene diamine, also caused a reduction in the sulfide signal at the detector. To remedy this, it was necessary to develop a column cleaning procedure which in itself would be non-contaminating. The recommended procedure involves the use of high-purity sulfuric acid $(0.5 \mathrm{~mol} / \mathrm{L})$ which is passed through a guard column prior to the column to-be-cleaned in order to trap the impurities in the sulfuric acid. Only freshly opened bottles of ethylene diamine which do not show signs of oxidation can be used to prepare the eluant. Finally, it was necessary to install a guard column in the ion chromatograph before the sample injection loop (rather than in the conventional place after the loop) to remove impurities from the eluant immediately prior to the introduction of sulfide.

This effort has resulted in a method for determination of sulfide which exhibits excellent linearity over the range of 0.1 to $1000 \mathrm{ppb}$. The relative standard deviation is 1 percent for $20 \mathrm{ppb}$ and above, 4 percent for $1 \mathrm{ppb}$, and 10 percent for $0.1 \mathrm{ppb}$. Research in IC/EC is continuing with the development of an improved procedure for the determination of trace levels of iodide in complex matrices.

\section{Direct Microwave Coupling Closed-Vessel Acid Dissolution}

H. M. Kingston and L. Jassie

Sample preparation is an essential step in achieving both accuracy and precision in the analysis of materials. It is also one of the most time consuming portions of many analyses and has become the limiting step for such multi-element techniques as ICP, DCP, XRF, and atomic absorption and emission. Acid digestion of biological and botanical samples can take from 4 to 48 hours using classical digestion techniques. Feasibility studies have previously shown the potential for accelerating the process of sample preparation by using microwave ovens as a direct coupling heat source in acid digestion of samples. However, no systematic research linking microwave interaction with acid dissolution has been done. All previous work has been experimentally based.

During the past year, research has been conducted into the basic parameters governing microwave-acid coupling. The development of real time monitors of temperature and pressure in the microwave environment permits the investigation of closed vessel digestion using microwave energy as the heat source. This technique uses Teflon (PFA) vessels (torqued closed) for the evaluation of temperature and pressure acid digestion of biological and botanical samples. This procedure has been used to successfully digest samples in less than 10 minutes. Additionally, the digestion appears to be more complete due to the high temperatures and pressures achieved. Typical sample temperatures of $200{ }^{\circ} \mathrm{C}$ and pressures of $945 \mathrm{kP}$ are achieved in 90 seconds. 
Microwave dissolution has been tested on all the major classes of samples (biological, botanical, geological, metallic, and glassy) and has advantages for each of these sample types. Because the digestion is done in closed vessels the technique can be applied to sample preparations where volatile components are a prime consideration. Not only is it a much more rapid digestion technique, but it also produces a more complete digestion that results in a reduction of instrumental inteferences.

The fundamental relationships between the mineral acids, the $2450 \mathrm{MHz}$ microwave and the vessel limitations are being investigated to provide a theoretical basis for calculating final temperature and pressure conditions directly from microwave power (including: time, volume, acid composition, and sample type). These relationships will allow the use of the technique by most laboratories performing acid digestions, without specialized equipment for applications development.

This work has opened up many new and inviting applications. For example, because microwave digestion is a well defined system, it is suitable for integration into an automated application. Acid digestions have previously been too judgmental and variable for automation to be practical. This technique has direct control over the exact power and time of the digestion and has become structured to the point it may be possible to automate. Additionally, new vessels currently being engineered will allow the use of higher temperatures and pressures in the future, allowing the use of other reagents and making this form of digestion even more efficient.

Currently over 200 industries, universities or research laboratories have requested help with their specific development applications. We have been able to provide many of them with enough information to allow them to proceed efficiently and safely with closed vessel microwave acid digestion of their particular samples. The research into these basic microwave relationships has led to a cooperative research program with the CEM Corporation. The collaboration not only has addressed basic understanding but also safety aspects. A safety valve which works in the microwave environment has been invented which autcmatically limits the pressure in the Teflon digestion vessel and makes it impossible to over pressurize this closed system.

\section{Leaching of Trace Metals from High Purity Fluoropolymers}

J. R. Moody, E. S. Beary, and P. J. Paulsen

The availability of suitable, clean labware of fluoropolymers is one of the major determining factors in the size of the analytical blank. Efforts to improve analytical reagent purity and lower apparatus blanks must focus on identifying or developing the appropriate fluoropolymer of the highest purity. Commercially, the contamination from fluoropolymers is important to the semiconductor industry since the wafer fabrication process is extremely sensitive to contamination. Aside from an earlier NBS publication on polymer purity which included 3 fluoropolymers, no reliable estimate of trace metals in all fluoropolymers is available.

Thus, because of unique experience and facilities, as well as interest, NBS agreed to perform basic analytical research on fluoropolymer purlty for the E.I. DuPont Co. Large amounts of twelve fluororesins were obtalned from commercial sources. Portions of these samples were analyzed for gross trace 
element composition at NBS by neutron activation analysis. The same resins were carefully blow-molded by the DuPont Co. into 1.5 liter bottles convenient for use in the laboratory. All of the samples and replicates were exhaustively cleaned in the trace element laboratories at NBS.

The clean containers were then charged at the same time and in the same place using a single lot of ultrapure nitric acid ( $70 \% \mathrm{HNO}_{3}$ by wt.) distilled by the mass spectrometry group. All samples were stored in class 10 air in a clean laboratory and subsampled $(350 \mathrm{~g})$ at 3.7 and 37 days. These samples were split and processed as necessary for isotope dilution analysis by spark source mass spectrometry (20 elements) and for atomic absorption (AAS and AES) analysis ( 6 elements).

The crucial elements in the design of the experiment were the availability of appropriate high purity reagents for the leaching experiment as well as non-contaminating laboratory facilities for sample manipulation and pre-coneentration for analysis. The size of the analytical blank was known to be critical in establishing an upper limit of impurities that could be leached from the fluoropolymers.

The actual results confirmed this expectation since only one element (Ca) was found in the 37 day leachates at concentrations greater than the analytical blank. Thus, for most polymers, the elemental impurities found were statistically indistinguishable from the blanks which except for Fe were less than $1 \mathrm{ppb}$. Results for split samples processed by IDSSMS and AAS agreed within a factor of two which is extraordinary agreement for $\mathrm{Ca}, \mathrm{Mg}, \mathrm{Na}, \mathrm{K}$, $\mathrm{Pb}$, and $\mathrm{Zn}$ at levels of $0.1-1.0 \mathrm{ppb}$. A new sampling is planned in the fall of 1985 ( 370 days) and further experiments with ultrapure $\mathrm{H}_{2} \mathrm{O}, \mathrm{HCl}$, and $\mathrm{NH}_{4} \mathrm{OH}$ are planned for FY86.

12. Development of an Electrometer for Use with Thermal Ionization Mass Spectrometers

R. W. Shideler, G. M. Lambert, and W. A. Bowman III

The development of an electrometer for use with thermal ionization mass spectrometers has been completed. There has been a long standing need for an electrometer which has features specifically designed for this area of low current measurement. Several fine instruments, marketed both presently and in the past, have been used. Most notably the Cary 401 (no longer manufactured) is widely used in the data systems of the mass spectrometers for which this instrument has been designed. This instrument differs chiefly by its generally improved performance and the ability to select, in six well characterized steps, the best response time and, thereby, the optimum noise performance for a given task.

The newly designed electrometer is a precision instrument capable of measuring extremely low levels of current while having exceptional noise performance with improved speed of response as well as outstanding linearity. The unit is designed to be used in the computer controlled data collection system of thermal-ionization mass spectrometers, and is tailored to that application. A commercially available parametric electrometer operationalamplifier module is used as the input current-to-voltage device in a circuit carefully designed for optimal frequency response. This circuit is followed 
by a unique averaging filter having a near-ideal step response characterist1c. The filter is constructed with six switch-selectable response times giving the operator control over the tradeoff between response time and noise level. The accurate characterization of noise bandwidth also permits a highly refined statistical analysis of data obtained using this instrument.

The instrument is constructed entirely of off-the-shelf electronic components and is quite inexpensive to construct. Compared to other general purpose electrometers currently available, it has significantly better linearity than those units tested. The principle aspect of improvement however, lies in the low levels of nolse obtained for a given speed of response and the ability to select that response over a range of values in order to match the measurement both to instrumental and experimental considerations. Using a $1 \times 10^{1}$ ohm input feedback resistor with a one second response time (step response >99\%) the measured noise is about 37 microvolts RMS, which corresponds to $3.7 \times 10^{-16}$ amperes.

The instrument may be used on all similar types of mass spectrometers and other measurement systems where slowly changing small current signals must be measured with high precision. Examples are ionization chambers, alpha detectors, low light photomultiplier detectors, and leakage measurement systems. Future applications may include other low level measurement systems where the ability to control the trade-off between response time and noise can be of advantage.

The instrument may represent a turning point in the measurement of low level signals by virtue of its enhanced capabilities of control over the fundamental parameters of base line noise and speed of response and also by making the analyst more aware of the consequences of this relationship. The better characterization of these parameters can have considerable impact on the subsequent statistical treatment of data obtained for the analysis of very low level signals. These factors and the superior measurement performance of low noise and excellent linearity will contribute to substantially improved accuracy of analysis.

This instrument was submitted to the IR-100 awards competition and was selected as one of the 100 most important developments of 1985.

\section{Determination of the Lead Isotopic Composition in Human Blood from the Italian Isotopic Lead Experiment}

W. R. Kelly and K. A. Brletic

The Italian Isotopic Lead Experiment (ILE) was a large scale field study designed to determine the fraction of $\mathrm{Pb}$ in human blood derived from leaded gasoline. To accomplish this general objective, $\mathrm{Pb}$ of a different 1sotopic composition was substituted for that normally used in the fuel. The usual $206 \mathrm{~Pb} / 207 \mathrm{pb}$ ratio is about 1.18. Lead from Broken Hill, Australia, which has a ${ }^{206} \mathrm{~Pb} / 207 \mathrm{~Pb}$ ratio of 1.04 , was substituted almost completely for that normally used in the Northern Italian Piedmont region for the period 1977-1979 and then was allowed to return to normal. During the main phase of the experiment the airborne $\mathrm{Pb}$ in the city of Turin contained about $90 \%$ Australian $\mathrm{Pb}$ and that in the rural areas about $60 \%$. 
The specific objectives of the ILE project were the following:

1. to determine the contribution of gasoline lead to total lead in urban and rural areas.

2. to determine the contribution of gasoline lead to blood lead levels in various population groups.

3. to follow more generally the pathway of gasoline lead through the environment.

The NBS role in this experiment was to provide quality assurance and to serve as a reference laboratory. One hundred whole blood samples of $0.5-2 \mathrm{~mL}$ were delivered to us for isotopic analyses. The established $\mathrm{Pb}$ separation procedure was minaturized by about a factor of 5 in an effort to reduce the chemical blank and the separation time. The blood samples were wet ashed and the residue was subjected to anion exchange separation for $\mathrm{Pb}$. The $\mathrm{Pb}$ fraction was purified by electrodeposition onto high purity $\mathrm{Pt}$ wires and the $\mathrm{Pb}$ isotopic ratios were determined by thermal ionization mass spectrometry using Faraday cup detection.

The results from this study were presented at the ILE Steering Committee meeting hosted by NBS on November 26 thru 28, 1984. A number of common samples had been analyzed by CEC laboratories in Brussels and Ispra, and by NBS. The agreement among the three laboratories was within $0.5 \%$ which is considered excellent for environmental data.

The experimental data are being interpreted using a model that assumes there is thorough isotopic mixing among three reserviors: blood, soft tissues, and skeleton. The model determined that the percentages of local petrol affecting the blood reservior were $26 \%, 17 \%$, and $14 \%$, for Turin, near, and far countryside, respectively. The data are still being interpreted and additional samples have been received by NBS.

\section{Studies on Ion Optics - Stray Fields}

I. L. Barnes, P. Morales (Univ. of Mexico), and K. R. Eberhardt (Statistical Engineering Division)

The stray fields generated by sector magnets have relatively small effects on ion beams that enter and leave the magnet normal to the pole faces. The major effect is to cause a small shift in the position of the focal point of the magnetic system, i.e., a deviation from "Barbers Rule". With newer ion optical systems, however, knowledge of the stray magnetic field is of great importance since the field is a component of the focusing properties of the system in both the $X$ and $Z$ directions.

To gain some information about the magnitude of this force on the ions in a typical mass spectrometer with non-normal entry, a careful study was made of the field around sector magnets operated at various values of magnet field. Using a precision $X, Y, Z$ positioner and several calibrated gaussmeters, we have mapped the magnetic fields at 4,6, 8, and $9 \mathrm{kG}$ of several 60 and 90 degree radius magnets from a point of constant field inside the gap to 
a distance $35-40 \mathrm{~cm}$ away from the pole face. This process was also repeated with one magnet using varlous gap widths ranging from 1.27 to $3.18 \mathrm{~cm}(0.5$ to 1.25 inches).

A non-linear least squares fit of the data to various models was performed and in all cases, the data show an excellent fit to an equation of the type:

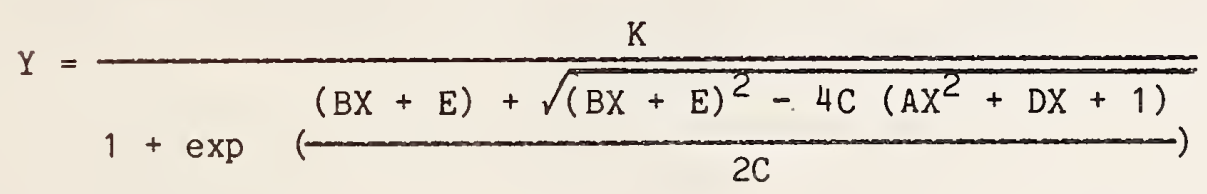

where:

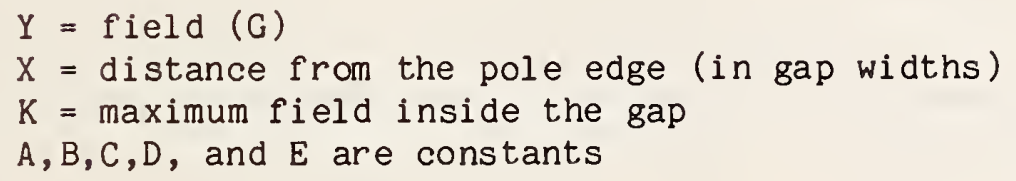

The values for the constants for any magnet of gap width, $W$, may be obtained by:

$$
\begin{aligned}
& A=-0.0398460-0.1305136 \mathrm{~W} \\
& B=-0.784763-0.098426 \mathrm{~W} \\
& C=-0.0653538-0.0102984 \mathrm{~W} \\
& D=-1.99784+0.0149582 \mathrm{~W} \\
& E=-0.512966+0.0251027 \mathrm{~W}
\end{aligned}
$$

The above equation may be integrated by numerical methods to determine both the total value of the stray field and the effective pole edge. These values have been incorporated into the programs TRANSPORT and TRIO to give much more realistic mass spectrometer designs.

In addition, this information is being used in a computer program now under development which will permit the examination of the perturbation of real ion beams at any point in the flight path. Preliminary results indicate that smaller, more efficient mass spectrometers may be designed using new lon optic systems and an experimental instrument using these designs is now under construction.

15. Automation of RIMS

F. C. Ruegg

In order to time-average the data produced by the Tektronix transient. digitizer at a rate of $10 \mathrm{~Hz}$ or greater, it was necessary to interface the digitizer to a more powerful computer than the HP 9845. A $8086 / 808716$ b1t I.E.E.E. 696(S100) based microcomputer with 33 megabyte hard disk was interfaced to the digitizer. A data acquisition program was written in Fortran-77 with 8086 assembly language I/O drivers to average digitizer data at rates up 
to $42 \mathrm{~Hz}$ (1024 points). The HP 9845 is connected as the 8086 's console, and is the master computer. The 9845 controls data acquisition by sending commands to the 8086, such as, when and for how long to take data.

The computer hardware is based on the I.E.E.E. 696(S100) bus, and consists of the following components:

1) Lomas Data Products $8 \mathrm{MHz}$ Lighting One $8086 / 8087 \mathrm{cpu}$ board

2) Lomas Data Products floppy disk controller board

3) Lomas Data Products Hazitall I/O board

4) Macrotech Max-384k - 384k byte memory board

5) Scion MA-520 512 X 480 graphics display board

6) National Instruments I.E.E.E. 488 interface

7) Video-100 graphics display

8) Dual Qume-242, 8 inch double sided disk drives

9) Quantum Q540, 40 Megabyte 5-1/4 inch hard disk

10) Qume QVT-102 terminal

The computer software runs under the CP/M-86 disk operating system and was written in Digital Research's Fortran-77 and RASM-86. The program performs the following functions:

1) Initialization of the I.E.E.E. 488 interface bus

2) Clear all I.E.E.E. 488 devices

3) Turn remote enable on

4) Get disk drive and root data filename from operator

5) Get ' $N$ ' number of laser pulses to average from operator. If ' $N$ ' $=0$ then stop

6) Command Tektronix digitizer to digitize ' $N$ ' laser pulses and transmit each data set to the computer

7) The data is summed for each laser pulse in array in memory for ' $N$ ' pulses

8) The data is then scaled and displayed on CRT graphics display

9) The data is written to the named (root.ext) disk file

10) The filename extension is incremented

11) Loop through item 5-11

The 8086 microcomputer and the HP 9845 computer are connected together using RS-232 interfaces with the HP 9845 acting as the console to the 8086 microcomputer. An HP Basic program has been written utilizing an HP supplied binary program which allows the 9845 to emulate a terminal. This program allows the HP 9845 to control the microcomputer's data acquisition program and to exchange data with it.

\section{Methodology Development for Sub-ppm Boron Measurements}

J. W. Gramlich, L. A. Machlan, H. Zeininger, and K. A. Brletic

The Mass Spectrometry Group several years ago developed a procedure for the accurate measurement of boron at high concentrations. This technique was used to certify the absolute isotopic abundance of boron in SRMs 951 and 952 (boric acid) and the boron concentration, by isotope dilution mass spectrometry, in several Standard Reference Materials. Although this technique is definitive for high concentrations, it is not applicable to ppm or lower levels of boron. 
During the past year, the group was fortunate to have as a guest worker from Germany, Dr. Heinz Zeininger. Dr. Zeininger developed unique chemical and mass spectrometric procedures for trace level boron analyses as part of his Ph.D. research at the University of Regensburg. A major effort was undertaken to take full advantage of this opportunity to develop the capability for trace level boron measurements at NBS.

Mass spectrometric procedures have been developed to allow the precise measurement of nanogram quantities of boron. The mass spectrometric technique involves the mixing of lanthanium nitrate with the sample, in the form of boric acid. It is postulated that the lanthanium and boric acid react to form lanthanium hexaborate, which is known to provide an extremely low work function filament surface $(-2.7 \mathrm{eV})$, conducive to negative ion formation; the species observed in the mass spectrometer spectrum is the $\mathrm{BO}_{2}^{-}$ion.

Research on the chemical separation and purification of trace amounts of boron have resulted in the construction of specialized quartz apparatus for the refluxing and distillation of the samples. The chemical and mass spectrometric procedures have been tested on samples of milk powder and steel (considerably different matrices) and have shown the general technique to be successful. Major problems still exist in the control of the analytical blank. Current research is focusing on identification of sources of the blank, sample recoveries, and complete sample decomposition.

The boron contents of numerous nuclear reprocessing plant construction materials were determined during the year using the large sample positive ion mass spectrometric technique. Many of these samples have been archived and will be re-analyzed using the newly developed negative ion technique as a verification of accuracy.

17. Time-Resolved, Magnetic-Dispersion for Large Isotope Ratio Measurements By Resonance Ionization Mass Spectrometry (RIMS)

J. D. Fassett, H. Zeininger, and L. J. Moore

The measurement of large elemental isotopic ratios by conventional mass spectrometry is limited primarily by molecular isobaric interferences and ion scattering. Both of these problems can be addressed by resonant, multiphoton ionization using pulsed lasers. Resonance ionization mass spectrometry (RIMS) uses tunable lasers to selectively and efficiently ionize gas phase atomic species. Thus, RIMS can be used to characterize and reduce molecular isobaric interferences, which typically result from non-selectivity in the ionization process combined with impurities in the sample or residual gases in the mass spectrometer. Time-resolved, magnetic dispersion of the pulsed ion beams, which are formed by the laser, combines time-of-flight (velocity) and magnetic (momentum) mass filterings. Ions scattered from a large peak into adjacent mass channels of a magnetic sector mass spectrometer can be distinguished from unscattered ions by their respective times-of-flight. Thus, the abundance sensitivity of the mass spectrometer increases along with the ability to make large iostope ratio measurements. We have experimentally verified the feasibility of time-resolved, magnetic dispersion in the past year, and are preparing to apply the technique to the measurement of the lowlevel, long-lived radioisotope ${ }^{129} \mathrm{I}$. 
We have demonstrated time-resolved, magnetic dispersion by doing RIMS of both $\mathrm{Re}$ and $\mathrm{Ta}$. Since $\mathrm{Ta}$ has a naturally large isotopic abundance ratio $\left({ }^{180} \mathrm{Ta} /{ }^{181} \mathrm{Ta}=10^{-4}\right)$, it provides a good demonstration of the effective improvement of abundance sensitivity. The normal position of the laser in the RIMS instrument was changed to minimize the width of the laser-generated ion pulse and to maximize the time-of-flight resolution. By focusing the laser between the first and second plates of the ion source, a timeresolution of $25 \mathrm{nsec}$ was achieved. The ion signal was detected using a 17stage electron multiplier whose output was preamplified using a high-speed, inverting pulse amplifier with $100 \mathrm{MHz}$ frequency response. The output of the preamplifier was directed into a $200 \mathrm{MHz}$ digitizer, which was operated at the maximum time resolution of $5 \mathrm{nsec}$ per channel. Extensive signal averaging of the time-of-flight spectra was done as the magnetic field was stepped. Both the elastically and inelastically scattered ions are readily apparent in the plane defined by the magnetic field and time. Furthermore, for Ta a nonselectively ionized interference at $\mathrm{m} / \mathrm{e} 180$ position was simply identified by focusing the laser away from the Ta resonance wavelength.

We have further explored the resonance ionization mass spectrometry of iodine in the past year, in order to define an optimal measurement strategy for the determination of ${ }^{129}$ I in real, environmental samples. A threephoton, single-color resonance ionization process is required for iodine because of its large ionization potential. Achievement of efficient ionization with this three-photon scheme necessitates the tight focusing of the laser beam, which has both positive and negative ramifications. A negative result is that specificity is reduced, both iodine and hydrocarbon interferences are non-selectively ionized. A positive result is that the focused ion beam produces iodine by the dissociation of AgI, the prominent species that is thermally vaporized. We discovered that the resonance wavelength at 298.2 $\mathrm{nm}$ possesses a number of important advantages over the previously studied resonant wavelengths for RIMS of I. Apparently, because of the lower energy of the photons at this wavelength, the selectivity of resonance ionization increases tremendously, with no major decrease in the overall sensitivity of the ionization process.

A high-speed system has been developed by Fillmer Ruegg, Atomic and Molecular Spectroscopy Group, to acquire and signal-average the magnetically dispersed, time-of-flight spectra in real time. The system will allow the efficient determination of the very low ion count rates that must be detected in the measurement of large isotopic rates. In the coming year, we plan to combine the time-resolved, magnetic dispersion technique with real-time signal-averaging or pulse-counting in order to make RIMS measurements of ${ }^{129} \mathrm{I} / 127$ I ratios of less than $10^{-6}$.

18. A New Method for the Accurate and Precise Determination of Se at Nanogram Levels

P. J. Paulsen and E. S. Beary

In recent years, there has been increased interest in the precise and accurate determination of $\mathrm{Se}$ at low concentrations. Industrial interest stems from the fact that se contamination alters chemical and physical properties of metals. In agriculture and medicine, both standards and techniques are desired to determine selenium in biological materials at the 
nanogram level. The role of $\mathrm{Se}$ in nutrition is not well understood, however the devastating effects of both se deficiency and Se toxicity are well documented.

During the method development for the determination of sulfur as $\mathrm{AsS}^{+}$, it was noted that an $\mathrm{ASSe}^{+}$ion beam could also be produced directly from a reaction on a silica-gel $\mathrm{H}_{3} \mathrm{PO}_{4}$-Re filament (between $\mathrm{SeO}_{3}^{-2}$ and $\mathrm{As}^{+3}$ ). When the filament is heated to $900^{\circ} \mathrm{C}$, a ${ }^{75} \mathrm{As}^{80} \mathrm{Se}^{+}$ion beam of $3 \times 10^{-12}$ amps is obtained from a loading of $60-100 \mathrm{ng}$ of $\left.\mathrm{Se}_{\mathrm{AsSeO}}{ }^{-2}\right]$. The Se iostopic abundances were measured between mass $157\left({ }^{75} \mathrm{As}{ }^{82} \mathrm{Se}\right)$ and mass $149\left({ }^{75} \mathrm{As}{ }^{74} \mathrm{Se}\right)$.

The ${ }^{82} \mathrm{Se} /{ }^{80} \mathrm{Se}$ isotopic ratio measured from $\mathrm{AsSe}^{+}$ions, can be determined with $\pm 0.1 \%$ precision for both natural Se and the enriched ${ }^{82} \mathrm{Se}$ isotopic spike. Mixes of ${ }^{82}$ Se spike solution and accurately known amounts of natural Se were analyzed to determine the ${ }^{82}$ Se spike concentration. Replicate measurements yielded values agreeing to $\pm 0.1 \%$ rsd. These analyses proved that this procedure has the potential of accurately determining the concentration of se at the nanogram levels.

An analytical scheme was developed for the determination of selenium in copper (SRM 1251). The separation involved the initial separation of Se and other volatile elements by use of a quartz combustion tube at $1000^{\circ} \mathrm{C}$. Selenium was isolated by selective reduction to the metal. This analysis yielded a Se concentration of $10.45 \pm 0.05 \mu \mathrm{g} / \mathrm{g}$. This is in excellent agreement with the NBS certified value of $10.5 \mu \mathrm{g} / \mathrm{g}$ based on values obtained by IDSSMS and Atomic Absorption Spectroscopy. These data proved to be encouraging and improved understanding of Se chemistry makes future determinations of se in organic matrices promising.

19. The Determination of Iodine in Foods and Other Biological Materials by Epithermal Neutron Activation Analysis

George Lutz

Epithermal neutron activation analysis (ENAA) has been used for the rapid reliable nondestructive determination of iodine in foods and other biological materials. Samples are encapsulated in boron nitride containers with wall thickness of several millimeters. The boron serves to substantially absorb thermal neutrons, but to allow epithermal neutrons to activate the sample. Iodine exhibits neutron capture resonances in the epithermal region, enhancing the productivity of the neutron capture reaction of iodine relative to that of interferring elements, such as sodium, potassium, manganese, chlorine, and bromine. There are three primary applications of this technique in the CAC.

(1) Iodine is used as a stable tracer in the NAA of ${ }^{129}$ I. The first step of the analytical procedure is the lyophilization of the sample and subsequent pulverizing and homogenization. An aliquot of the sample is taken and analyzed by ENAA. Stable iodine in the sample can be determined at other plints in the analysis serving as a measure of the radiochemical yield of

(2) The second application is the determination and certification of iodine in Standard Reference Materials. Although instrumental photon activation analysis (IPAA) has been used successfully in the group for lodine 
determinations, ENAA gives results with comparable reliability and somewhat better sensitivity at a small fraction of the personnel and measurement time relative to IPAA.

(3) ENAA is being used for the rapid routine determination of iodine in foods for measuring total dietary content. This work is being done in collaboration with Dr. W. Stroube of FDA.

Irradiations have been conducted at the reactors at the University of Virginia and Maryland, in addition to that at NBS. The reactor power level is not very relevant to sensitivity. The nature of the neutron moderation and proximity of the sample to the reactor core are more significant. Sensitivities are of the order of $0.1 \mathrm{ppm}$ and analysis time is 30-60 minutes.

\section{Multielement Analysis of Biological Macromolecules}

S. F. Stone, R. Zeisler, and D. Hancock

The importance of the role of trace elements associated with biological macromolecules has become increasingly apparent in the last twenty years. For example, studies of metalloproteins has revealed the structural and functional importance of certain trace metals associated with proteins. The biological specificity of metalloenzymes depends on the presence of both the protein and the metal ion. Removal of the metal ion results in a loss of biological activity. Trace metals have also been found to be structurally important in stabilizing secondary, tertiary, or quarternary protein structures. Detection of trace elements associated with proteins may be accomplished with a newly-developed combination of biological separation techniques with analytical nuclear methods.

Polyacrylamide gel electrophoresis (PAGE) separation of proteins by molecular weight is one technique that we have used. Several proteins were separated by electrophoresis on a 10-20\% gradient polyacrylamide gel. The whole gel was then irradiated with neutrons, and following a short time, an autoradiograph was developed to detect any beta-emitting isotopes of fairly high energy that had been produced. The location of a phosphoprotein phosvitin, was visualized in this way. Phosphorous the isotope detected in the autoradiograph, indicates the location of the phosvitin on the gel. The autoradiography technique has a much more sensitive threshold of detection for this protein than does the non-specific protein stain, Coomassie Blue. As protein band corresponding to phosvitin is barely visible on a duplicate gel that was stained with Coomassie Blue.

In addition to autoradiography, gamma-counting has also been used for other metalloproteins using neutron activation analysis. Protein electrophoresis is often carried out in the presence of the denaturing detergent, sodium dodecyl sulfate (SDS). An electrophoretic separation of the zinc metalloprotein carbonic anhydrase was done using SDS, and a trace element analysis of gel sections was performed. A marked increase in zinc, was found in the protein band (gel section 5), compared to the background, as expected. However, many other trace elements, which have no known association with the enzyme, increased as well. In addition, the zinc concentration found in the protein band was more than should have been present from the 
amount of protein applied. Studies are currently in progress to learn more about trace element associations with proteins under both denatured and nondenatured conditions.

\section{Light Element Determination by Neutron Activation Analysis}

\section{R. Fleming}

Determination of the light elements, hydrogen through neon, by neutron induced activation is seldom exploited because of the small cross sections, short half-lives, and often decay without gamma emission. It is true that prompt gamma activation analysis (PGAA) has demonstrated the capability of measuring hydrogen and boron at the $\mathrm{ppm}$ level and can determine carbon and nitrogen at major constituent levels. Photon activation analysis (PAA) can also determine carbon at high levels using the ${ }^{12} \mathrm{C}(\gamma, n, \alpha){ }^{7} \mathrm{Be}$ reaction. The near-surface regime can be profiled for $3_{\mathrm{He},}{ }_{\mathrm{Li}},{ }_{\mathrm{B}} \mathrm{B}$, and $1 \mathrm{I}_{\mathrm{N}}$ using neutron depth profiling, but the ability to quantify elemental concentrations in this part of the periodic table remains less than satisfactory. Two new approaches are being taken to improve this situation.

The advent of modern liquid scintillation counters makes possible the simple, reliable and accurate measurement of nuclides that decay by pure beta decay over a large dynamic range. As is typical with beta counting, a preseparation of the beta emitting element is necessary. The most attractive element to quantify by neutron activation with beta counting is nitrogen, using the ${ }^{14} \mathrm{~N}(\mathrm{n}, \mathrm{p}){ }^{14} \mathrm{C}$ reaction and carbon-14 assay. In this way nitrogen can be determined at below the nanogram level. Possible interferences from ${ }^{13} \mathrm{C}(n, \gamma){ }^{14} \mathrm{C}$ or ${ }^{17} \mathrm{O}(n, \alpha){ }^{14} \mathrm{C}$ reactions or from natural carbon-14 levels can be shown to be small in most cases of interest. Extension of the beta counting approach to the determination of sulfur and of phosphorous appears promising, as well.

A collaboration with Professor W. Brian Clarke of McMaster University has provided us with the opportunity to determine both lithium and boron using neutron activation followed by $3 \mathrm{He} /{ }^{4} \mathrm{He}$ mass spectrometry. The samples are irradiated in evacuated lead capsules along with lithium and boron standards. The reactions ${ }_{\mathrm{Li}}(n, \alpha){ }^{3} \mathrm{H}$ and ${ }^{10} \mathrm{~B}(n, \alpha){ }_{\mathrm{Li}}$ both produce helium-4 from the alpha particle production and the tritium produced from the lithium reaction decays with a 12.3 year half-life to helium-3. Because both these reactions have very large cross sections, there are few potential interferences when a well-thermalized neutron flux is used. Measurements at the $\mathrm{ng} / \mathrm{g}$ level for lithium and $\mu \mathrm{g} / \mathrm{g}$ level for boron are possible with good accuracy. The method is now limited to materials such as botanicals or biologicals that are permeable to helium. With heating of the sample to release the helium prior to mass spectrometry, accurate determination of lithium and boron in metals could be achieved.

Work will be continued to improve our ability to quantify elements in this important part of the periodic table. A capability to assay nuclides with short half-lives and improvement of the prompt gamma sensitivity are obvious steps in this direction. 


\section{Neutron Depth Profiling: Industrial Interaction and Application}

\section{R. G. Downing, J. T. Maki, and R. F. Fleming}

The industrial interactions have steadily increased at the neutron depth profiling (NDP) facility during the last year. The capability of NDP to quantitatively and nondestructively analyze one-of-a-kind samples so that they are available for studies using other techniques or further processing is quite unique. These capabilities also allow intertechnique calibration on the same specimen. Consequently, a research associate and five guestworkers have formalized agreements between their companies and the Center for Analytical Chemistry for the use of the NDP facility. This brings the total number of outside industrial and academic users of NDP to over 15.

Electronic and high technology materials have dominated the types of investigations being performed, resulting in numerous technical papers and formal presentations. The increase in the NBS Reactor power level from 10 to $20 \mathrm{MW}$ has doubled the neutron beam intensity at the NDP facility making the investigation of nitrogen-rich materials practical. Profiles of silicon nitride, an optical wave guide material, and titanium nitride, a metallic film surface coating, are examples of recently completed studies. In addition, the profiling of lithium migration in corroding aluminum-lithium alloys (a new ultra-light material), measuring implant profiles of boron in mercury cadmium tellurides (an IR sensor material), and analyzing boron profiles in lanthanum boride (a thermionic electrode material) are a few of many new areas of research pursued this year. All of these studies have been initiated by the firms to understand current process related problems associated with the fabrication of products.

Two major facility improvements are currently being implemented. First, a spectral transfer system is being developed to allow direct transmission of NDP spectra and evaluated data from the facility computer to the computers of industrial and academic users. This will greatly enhance and expedite the usage of the information in solving process and research related problems. With the system, the now tedious and involved process of data reduction will be transferred to faster computers making deconvolution of the acquired NDP profiles readily available. Secondly, a turbomolecular vacuum pump is being installed at the reaction chamber to improve system stability. The pump will minimize system down time by reducing routine maintenance.

In the coming year, several new materials studies and facility upgrades are being planned. Using separated isotopes (i.e., oxygen-17 and beryllium-7), sensitivity can be enhanced thereby allowing specific process related problems to be addressed. Also planned is the incorporation of a goniometer into the sample chamber for more careful alignment of sample and detector. This piece of equipment will give greater positional control for enhanced depth resolution at interfacial boundaries and for the profiles of the near surface of specimens. 


\section{A. Becker}

Recently, the National Bureau of Standards nuclear reactor (NBSR) was upgraded to $20 \mathrm{MW}$ (thermal). With the higher neutron flux densities and modification to one of the pneumatic tube irradiation facilities, an extensive recharacterization was undertaken. This recharacterization extended the previous work on the NBSR, and several new techniques were developed which simplified data accumulation and resulted in better information about these facilities.

The measurements were designed to fulfill two primary purposes. First, knowledge of the neutron flux density and its variability over the irradiation volume are important for accurate and precise neutron activation analysis. All samples and standards must receive the same (or well known) neutron fluence. Further, information about the thermal/fast neutron ratios is very important for the selection of an optimum irradiation facility in a reactor or between different reactors. In one case, reactor characterization revealed that a small reactor (University of Maryland, at $150 \mathrm{~kW}$ power) provided greater sensitivity for a fast neutron activation analysis than was available at the NBSR.

The second purpose of these measurements was to establish maximum allowable irradiation conditions for the NBSR at the new power level. A thorough understanding of the relative neutron flux density before and after upgrading, along with extensive evaluation of the temperature and pressure limitations of the NBSR at $20 \mathrm{MW}$, significantly improved our ability to obtain approvals for the sample types and quantities needed for the NBS activation analysis program.

The parameters measured included the following: thermal neutron flux density; flux variations within an irradiation volume and between irradiations; relative fast neutron flux density; maximum temperatures generated by different sample matrices in the various irradiation facilities; and pressures generated in sealed containers by radiolytic decomposition. For the pressure measurements, a system was developed which utilized a hypodermic syringe and a mercury manometer to provide simple, yet accurate, measurements of small amounts of gaseous radiolytic decomposition products. This system substantially improved the pressure measurement data, and for the first time was able to show linear gas production with neutron fluence for a specific irradiation facility.

This effort has resulted in the NBSR having perhaps the most highly characterized irradiation facilities available, and provides the information needed for the high accuracy analyses required by the Nuclear Methods Group. At present, it appears that the NBSR upgrade to $20 \mathrm{MW}$ will provide a usable neutron fluence $50 \%$ greater than that available at $10 \mathrm{MW}$. 
R. R. Greenberg and R. Zeisler

There is continuing concern about the possible impact of platinum on the biosphere due to the increasing industrial and medical uses of this metal. Approximately $18700 \mathrm{~kg}$ (600,000 troy ounces) of platinum are used annually by the automotive industry, while therapeutic utilization of platinum compounds for their anti-cancer properties is increasing. Due to this expanding use of platinum, it is important to be able to measure it at the naturally occurring levels.

Accurate determination of $\mathrm{Au}$ and $\mathrm{Pt}$ at concentrations below $1 \mathrm{ng} / \mathrm{g}$ is extremely difficult and requires rigid control of the blank. Radiochemical neutron activation analysis (RNAA) provides an ideal method to determine these elements in that it can be performed in an almost blank-free manner. After irradiation, but before chemical manipulation of the samples, unirradiated carriers of the elements of interest can be added to minimize losses which typically occur when processing extremely dilute solutions of the noble metals. Several years ago a procedure was developed to determine both gold and platinum in solid biological samples via RNAA. This procedure has been modified to allow the determination of these metals in both the elevated and the natural level fractions of the Trace Elements in Urine Standard Reference Material (SRM 2670). Urine is a difficult matrix for NAA for two reasons. First, the high salt level in urine produces a large amount of background radiation which must be removed prior to gamma-ray spectroscopy, and second, a liquid is considerably more difficult to irradiate than is a solid, and often requires a pretreatment step, such as lyophilization, which can increase the blank.

The concentrations of $\mathrm{Au}$ and $\mathrm{Pt}$ observed in the elevated fraction of the Trace Elements in Urine SRM were $244.4 \pm 8.2$ and $125.1 \pm 8.0 \mathrm{ng} / \mathrm{mL}$, while the concentrations observed in the normal fraction of this SRM were $8.0 \pm 1.4$ and $8.0 \pm 2.7 \mathrm{ng} / \mathrm{mL}$. These concentrations are given for the specified dilution of the contents of each bottle of freeze-dried urine to $20.0 \mathrm{~mL}$. The uncertainties for these measurement were calculated by combining the standard deviation of the mean for each set of values mutliplied by the appropriate t-value for the $95 \%$ confidence level, and then adding the estimated systematic error. For the Au measurements in both the elevated and normal level urine samples, the estimated systematic error was $2 \%$ which was due mainly to potential counting geometry errors between the unknown samples and the standards since the samples were counted directly on top of the detector. The estimated systematic error for the Pt in the elevated urine was 4\%: $2 \%$ from counting geometry and an additional $2 \%$ from possible bias in peak integration of the $158 \mathrm{keV}$ peak of Au-199 which lies directly upon the backscatter peak of $\mathrm{Au}-198$. The estimated systematic error for the Pt in the normal urine was $12 \%$ (2\% from counting geometry and $10 \%$ from the determination of the Au interference; this $10 \%$ error also includes the bias from peak integration.

The observed sample standard deviation for $\mathrm{Au}$ in the elevated fraction of the urine ( $1.1 \%$, relative) was slightly greater than expected from counting statistics. This excess variance is probably due to counting geometry errors (discussed above). The observed sample standard deviation for Au in 
the normal fraction of the urine was significantly greater than the counting statistics. This may be due to variable losses of Au onto the walls of glass bottles (prior to lyophilization).

With an apppropriate separation procedure, RNAA can be used to determine the concentrations of $\mathrm{Au}$ and $\mathrm{Pt}$ in biological samples at the picogram per gram level. Both solid and liquid samples can be analyzed, however a lyophilization step prior to irradiation may be advantageous.

\section{Optimized Measurement of Iodine Isotopic Ratio by Neutron Activation}

R. M. Lindstrom and G. J. Lutz

A procedure has been developed to perform reliable measurements of lodine-129 concentrations and ${ }^{129} \mathrm{I} / 127$ I ratios in a few grams of sample, down to the present-day background level, of approximatel y $10^{8}$ atoms/gram (5 aCi/g. with acceptable precision and low blank. ${ }^{129} \mathrm{I} /{ }^{127} \mathrm{I}$ ratios as low as $6 \times 10^{-10}$ have been measured in natural materials. Neutron activation is used to measure both iodine isotopes simultaneously from the ratio of ${ }^{130}$ I to ${ }^{126}$ I activities, produced by thermal and fast neutrons respectively. By tailoring the irradiation conditions, such systematic errors as chemical yield and counting efficiency are made to cancel in the measurement of the ratio.

In a space of thermal neutron flux versus fast (fission spectrum) neutron flux, the analytically optimum region is defined by four boundaries: to produce a large enough 130 I signal to be detectable, the thermal neutron flux must exceed $5 \times 10^{12} \mathrm{n} / \mathrm{cm}^{2} \mathrm{~s}$; however, to avoid interference from the triple capture reaction on ${ }^{127} \mathrm{I}$ it cannot exceed $8 \times 10^{14} \mathrm{n} / \mathrm{cm}^{2} \mathrm{~s}$. For the ${ }^{126} \mathrm{I}$ signal to be detectable, the fast flux must exceed $1.4 \times 10^{11} \mathrm{n} / \mathrm{cm}^{2} \mathrm{~s}$, but in order that both radionuclides to be measurable in the same spectrum the fast/thermal flux ratio must not exceed unity.

A powerful heavy-water reactor like the NBSR offers a variety of neutron environments which span the ideal range. An irradiation facility tailored and dedicated specifically for this task will provide high quality iodine isotopic ratio measurements. When this is done, the ultimate sensitivity will have been reached as far as the irradiation parameters are concerned.

\section{Laboratory Information Management Systems (LIMS)}

B. I. Diamondstone and M. S. Epstein

A database has been established in the Division during the past year that contains important information regarding the analysis of Standard Reference Materials (SRMs). The database is menu-driven and can be used without any knowledge of the database management system operation. The information contained in this database is derived from the Reports of Analysis that have been generated for approximately the last $f i v e$ years and includes the following information: 


-Element of interest
-Matrix
-SRM number
-Analyst
-Technique
-Date of Report

-Element of interest

-Matrix

-SRM number

-Technique

Date of Report
-Value

-Uncertainty

-Units

-Control

- SRM \#

- Certified value

- Determined value

These data fields have been selected as the minimum amount of information needed for each analysis. As more experience is gained with using the system, additional fields can be added. If an elemental concentration is recommended by the analyst it is entered in the field labeled value. If not, the mean of all values listed in the report is used in this field. Similarly, the uncertainty entered is one recommended by the analyst or is one sigma of the mean. If a control sample has been analyzed, the certificate value is listed along with the recommended uncertainty when this information is available. If this value is an information-only value, then no uncertainties are listed. The value ( $s$ ) obtained for the control sample and the uncertainty are also listed.

The concept of LIMS is not new and, in fact, systems like the one described have been used in industry for many years. For the most part, the industrial systems are designed to handle large numbers of samples and are intended to carefully document the history of samples, from the time they arrive in the laboratory to the completion of all analyses. Although the heart of these systems is simply a data base management system, the systems are often directly connected to various instruments and use baseline information on calibration samples and controls to determine whether the analyst can proceed with the analysis. The results of analyses are fed directly into the system, a statistical evaluation is done, and a final report of analysis is produced.

The system which has been developed in the Division is intended to provide more of an information source rather than to control a total operational procedure. The information compiled will have many uses in the process of estimating and planning work on future Standard Reference Materials. For example, as plans are developed for a new SRM, the data base can be searched to provide information on which techniques have been used for analyses on specific matrices, which techniques have the capability to analyze specific elements, and what are typical levels of detection for each element. In addition, the database can provide information on analysts who have had experience with certain matrices or elements. Another potential use of this system would be in the critical area of resolution of discrepant data. Data collected for previous analyses can provide information on possible bias trends for particular analytical techniques. Values obtained on control samples can be evaluated for particular elements, over a series of different matrices, and compared to the certified values. This type of information would be useful to a statistician in resolving differences between techniques if one technique has shown a tendency to be either higher or lower on the control samples. 
As more uses for this information become apparent, the database can easily be expanded and updated to provide additional information that can be extracted from Reports of Analysis. In fact, it would be possible to electronically provide interested individuals with copies of the Reports of Analysis for their own use. The availability of databases such as the one described here emphasize the need for providing complete and accurate information in the Reports of Analysis. In the future, this system could be used to assign sample identification numbers and establish sample custody when many analyses are to be done. In addition, it could conceivably be used to schedule analytical work in the Division and to assign recommended control samples and procedures for specific analyses.

27. Development of a Standard Reference Material for Rainwater Analysis

W. F. Koch, G. Marinenko, and Y. C. Wu

Wet deposition is monitored by various laboratories and agencies as part of national and international networks to record accurately the composition of rainfall. These efforts are intended to determine the extent of the problem of "acid rain", and to establish spatial and temporal trends. Discrepancies in data often occur due to differences in instruments and techniques. These discrepancies limit the conclusions which may be drawn from the data. To establish a common basis for chemical measurements in rainwater, a multiyear research effort in the Inorganic Analytical Research Division, Center for Analytical Chemistry has been established. This effort has resulted in the issuance of a Standard Reference Material (SRM) 2694, Simulated Rainwater.

The decision to prepare simulated rainwater, rather than collecting natural rainfall was based on the need to minimize contamination and unwanted components which would compromise the overall stability of the solutions. Thus, simulated rainwater prepared by the dissolution of salts and acids in water was the best recourse. Low density polyethylene (LDPE) bottles (60-mL capacity) were chosen for this project based on earlier research. The bottles were cleaned by a rigorous and tedious procedure to minimize contamination. At all times, the bottles were kept clear of areas with acid fumes. Two levels of simulated rainwater containing the cations and anions commonly found in acid rain were formulated in such a way so as to span a useful analytical range of concentrations of all components. It should be noted that the measurement of $\mathrm{pH}$ was the primary driving force behind the development of this SRM. Hence, the stability of the solutions with respect to $\mathrm{pH}$ was an over-riding constraint. It has been found that unbuffered solutions above about $\mathrm{pH} 4.5$ are extremely susceptible to fluctuations in $\mathrm{pH}$ and acidity due to absorption and desorption of atmospheric carbon dioxide. These processes occur even through the walls of the polyethylene bottles. For this reason, although it would have been desirable to issue a solution of $\mathrm{pH} 5.0$, SRM 2694-I was targeted at $\mathrm{pH} 4.3$ to be on the safe side.

Approximately 170 liters of 2694-I and approximately 150 liters of $2694-$ II were prepared in February 1985. The solution was thoroughly homogenized by intermittent vigorous stirring over a 24-hour period. Note that although care was taken to add exact amounts of each component and to dilute with the correct amount of water, there was no convenient way to accurately assess the final volume. Hence, one cannot use the weights and volumes as an analytical measure of the concentrations of the various components. Before the bottling 
commenced, a sample of each level was analyzed by ion chromatography and potentiometry to verify that the target values had been met. The bottles were filled manually, capped immediately, and placed sequentially in numbered cartons. Concurrent with the bottling operation, a homogeneity test was run. One out of every 120 bottles was pulled from the line and tested for specific conductance. After establishing the homogeneity of the solutions, the statistical design for the sampling and analysis of the other components was configured. It involved the determination of each component in triplicate in each of three bottles (selected from the beginning, middle and end of the bottling operation) by each technique. Because of experimental exigencies of some techniques, this analysis design was not strictly adhered to in every case, but was followed whenever possible.

The techniques used in the analysis of SRM 2694 were ion chromatography (IC), conductivity, potentiometry, coulometry, isotope dilution mass spectrometry (IDMS), spectrophotometry, laser enhanced ionization flame spectrometry (LEIS), flame emission spectrometry (FES), inductively coupled plasma (ICP), and flame atomic absorption spectrometry (FAAS). Details of the analytical procedures for each technique will be published in a forthcoming special publication. Values for fluoride, nitrate, sulfate, sodium, potassium, calcium, magnesium, $\mathrm{pH}$, acidity, and specific conductance have been certified in SRM 2694. Values for chloride and ammonium are listed for information purposes only. Chloride was not certified because it was felt that the potentiometric method had insufficient precision and accuracy at these levels to corroborate the ion chromatographic data. Ammonium ion was not certified because of very real concerns about the stability of this ion in these solutions.

The problem with the stability of ammonium ion was first noticed upon re-analysis of RM 8409 eight months after its preparation. The concentration of ammonium in RM $8409-\mathrm{I}$ had decreased from $0.085 \mathrm{mg} / \mathrm{L}$ to $0.025 \mathrm{mg} / \mathrm{L}$. On rechecking other samples of simulated rainwater which were part of a longterm stability study of $\mathrm{pH}$ and conductivity, similar decreases in ammonium ion were observed. The decrease was quite significant when the initial concentration of ammonium was extremely low [below $200 \mathrm{mg} / \mathrm{L}$ ] and the $\mathrm{pH}$ was above 4.0. The cause of this decrease is not known at this time, but it is suspected to be bacteriological. The loss of ammonium does not appear to have affected significantly any other components.

Investigations are underway to remedy this problem with the instability of ammonium. Also this year it is planned to explore new types of bottles which are inert and free from contamination, and at the same time which do not have problems with transpiration. Related research will involve the stabilization of phosphate in acidic media and investigations into the needs for standards and methods in dry deposition. The primary foci will be on the assessment of analytical errors and on the stability of solutions containing inorganic species at the sub-ppb level.

28. Standard Reference Materials

B. I. Diamondstone

The analysis and certification of Standard Reference Materials (SRMs) has again been a major part of the total scientific effort of this Division. As in the past, there are three sources of support for work on SRMs: the 
Office of Standard Reference Materials (OSRM) provides STRS (Scientific and Technical Research Services) and WCF (Working Capital Funds), and the Technical Division also provides STRS funds. The OSRM portion of the STRS funding is intended for the preliminary research necessary to develop the methodologies required for the actual production of SRMs. Input in these areas is provided by the entire scientific staff with a considerable portion representing cooperative efforts between groups within the Division.

This year a new concept has been implemented in the Division, the designation of selected senior staff personnel as "technical champions". The purpose of a technical champion is to interact closely with the OSRM technical coordinator and to provide scientific oversight for the entire process of producing an SRM. It is hoped that by being involved with the SRM from concept to certification, the technical champion will provide continuity throughout the certification process by giving the analysts a better understanding of the sample history and by providing the technical coordinators with a direct and continuous link to the analytical process. This year, about six technical champions were designated for a variety of potential SRMs such as simulated rainwaters, oyster tissue, and river sediment.

Listed below are ten different areas of research that were funded by OSRM during the past year.

\section{STRS Projects Supported by OSRM during FY85}

Task

Transmittance SRMS

Vol tammetry

Gases in Metals

ICP-Mass Spec

\section{Description}

Research leading to the development of methods and the evaluation of materials for the production of transmittance SRMs for the near IR. All components are in hand and evaluation is in progress.

Research leading to the development and implementation of anodic stripping voltammetry for trace and ultratrace levels of electroactive metals in SRMs. A method has been implemented for the determination of cadmium and copper in SRM 1643 b using indium as an internal standard.

Research leading to the evaluation of two independent procedures for the analysis of carbon in SRMs. Emphasis on the manometric procedure with some interaction between NBS and Univ. of Ghent for PAA analysis. Work is completed on the determination of total carbon in a series of biological SRMs using a fusion technique. Manometric measurements are in progress.

Research leading to the application of Inductively Coupled Plasma Mass Sepctrometry to the analysis of SRMs. The new ICP-MS instrumentation is operational and preliminary experiments to evaluate accuracy are in progress. 
Aqueous Electrolytic Conductance Stds

LEI Measurements

Diode Laser

F in Biologicals

State-of-the-Art SRMs

Trace Boron
Continued research leading to an understanding of the fundamentals of conductivity and the feasibility of producing aqueous conductivity SRMs. Literature review and recalculation of existing values is complete. Instrumentation for preliminary measurements is operational.

Research leading to the adaptation of Laser Enhanced Ionization instrumentation to trace element analysis in SRMs. Proposed work is completed and various parameters of the system have been optimized for the analysis of SRMs.

Research leading to the identification and quantitation of gas species in NBS gas SRMs. Work in progress on intercomparing high concentrations of $\mathrm{NO}_{3}$ /air compressed gas mixtures by tunable diode laser absorption spectrometry and chemiluminescense detection.

Research leading to the development of an ion chromatographic procedure for the analysis of fluoride in biologicals. Work is in progress.

Research leading to the development of measurements and procedures for a series of new state-of-the-art reference materials. The first material will be human liver. Work is in progress to evaluate the collected human liver samples as a potential SRM.

Research leading to the development of the necessary chemical separations and ionization technology required for isotope dilution mass spectrometric determination of boron. Instrumental procedures have been developed for the measurement of boron as a negative ion as work continues on developing the necessary sample preparation procedures.

The actual certification for chemical composition on a marketable standard is carried out as a WCF project. Once again, analyses were carried out on approximately 70 different SRMs covering a wide variety of matrices including metals, fossil fuels, foods, glasses and environmental materials. In many cases, each certification involves several or all of the Groups in the Division and can require 20-30 individual analyses on each SRM. Examples of the SRMs worked on during the past year are listed below: 


\begin{tabular}{ll} 
Standard Reference Materials Analyzed During FY85 \\
SRM Number & \\
\hline $1645 a$ & River Sediment \\
$97 a$ & Flint Clay \\
$98 a$ & Plastic Clay \\
1616,1617 & Kerosene \\
1621 c, 1622c & Residual Fuel Oil \\
$88 \mathrm{~b}$ & Dolomitic Limestone \\
2031 & Metal on Quartz Filters \\
$930 d$ & Glass Filters for Spectrometry \\
$2123-2128$ & Spectrometric Solutions \\
2677 & Be/As on Filter Media \\
$2415-2418$ & High Purity Lead \\
$1761-1767$ & Low alloy Steels \\
$1295-1296$ & Ferritic Stainless Steel \\
$1255-1256$ & Aluminum Alloys \\
C1248 & Cast Monel \\
C2423-C2425 & Alloy Cast Irons \\
C2423a-C2425a & \\
$7 \mathrm{~g}$ & Cast Iron \\
$1871-1873$ & Microchemical Standards \\
2030 & Neutral Glass Filter \\
$1567 a, 1568 a$ & Rice and Wheat Flours \\
2694 & Simulated Rain \\
1549 & Powdered Milk \\
2695,2696 & Fluoride in Vegetation \\
$1632 b$ & Coal \\
2423 & Ductile Iron \\
$120 \mathrm{c}$ & Phosphate Rock \\
$2689-2691$ & Fly Ash \\
$1638 b$ & Reference Fuel \\
332 & Copper Concentrate \\
$1261-1265$ & Boron in Low Alloy Steels \\
&
\end{tabular}

Additional elements were determined this year in some SRMs which were originally certified during FY84. These materials include coal, fuel oil and milk powder. In addition, test samples were collected and analyzed for the replacement River sediment SRM, carbon was determined by gas fusion in nine biological SRMs in which this element had not previously been determined, and work was started on the replacements for the rice flour and wheat flour SRMs.

A number of new materials for which certification analyses were started this year include kerosene, simulated rainwater, fluoride in vegetation, and $\mathrm{Be} / \mathrm{As}$ on Filter Media. 
C. Outputs and Interactions

(Inorganic Analytical Research Division)

1. Publications

Barnes, I. L., Gills, T. E., and Reed, W. P., Copper Standard Reference Materials (Benchmark Series), Sampling and Analysis of Copper Cathodes, W. M. Tuddenham and R. J. Hibbeln, eds., ASTM Special Technical Publication No. 831, (1984).

Becker, D. A., Quality Assurance Techniques for Activation Analysis, Proceedings Fifth International Conference on Nuclear Methods in Environmental and Energy Research, U.S. DOE Publ. CONF-840408, U.S. Dept. of Energy, Washington, DC (1984).

Blackman, M. J., Provenience Studies of Middle Eastern Obsidian from Sites in Highland Iran, Archaeological Chemistry III, Joseph Lambert, ed., American Chemical Society, Washington, D.C. (1984).

Burke, R. W., Mavrodineanu, R., and Smith, M. V., Standard Reference Materials for Verifying the Accuracy of Spectrophotometers, American Clinical Products Review and American Laboratory, 12-20 (1984).

Clark, C. W., Fassett, J. D., Lucatorto, T. B., and Moore, L. J., Enhancement of the Isotopic Abundance Sensitivity of Mass Spectrometry by DopplerFree Resonance Ionization, Resonance Ionization Spectroscopy 1984, G. H. Hurst, M. G. Payne, eds., The Institute of Physics, Bristol, 107-117 $(1984)$.

DeBievre, P. J., Gallet, M., Hendrickx, F., Lycke, W., Wolters, W. H., Eberhardt, K. R., Fassett, J. D., Gramlich, J. W., Machlan, L. A., Maimka, E., and Wertenbach, H., The IDA-80 Measurement Evaluation Programme on Mass Spectrometric Isotope Dilution Analysis of Uranium and Plutomium; Volume II: Preparation, Characterization and Transport of the Test Samples, KfK 3761 /EUR 7991e (1984).

DeBievre, P. J., Gallet, M., Holden, N. E., and Barnes, I. L., Isotopic Abundances and Atomic Weights of the Elements, J. Phys. Chem. Ref. Data $13,809-891$ (1984).

Diamondstone, B. I., Wise, S. A., and Sander, L. C., Carbon Analysis for the Study of Bonded Phases in Liquid Chromatography, J. Chrom., (321), 319-324 (1984).

Downing, R. G., Fleming, R. F., Maki, J. T., Simons, D. S., and Stallard, B. R., Near-Surface and Interfacial Profiling by Neutron Depth Profiling (NDP) and Secondary Mass Spectrometry (SIMS), Proc. of Materials Research Society, Thin Films and Interfaces II, Vol. 25, J. E. Baglin, D. R. Campbell, and W. K. Chu, eds., North Holland, 655-666 (1984).

Fassett, J. D., Powell, L. J., and Moore, L. J., Determination of Iron in Serum and Water by Resonance Ionization Isotope Dilution Mass Spectrometry, Anal. Chem., 56, 2228-2233 (1984). 
Fassett, J. D., Travis, J. C., and Moore, L. J., Thermal Atomization Sources and Resonance Ionization Mass Spectrometry (RIMS), Applications of Laser Chemistry and Diagnostics, A. B. Harvey, ed., Proc. SPIE 482, 36-43(1984).

Greenberg, R. R., Radiochemical Procedures Used for Improved Low-Level Determinations of Critical Elements in Biological Materials, Use and Development of Low and Medium Flux Research Reactors, Supplement to A tomkernenergie-Kerntechnik 44 , 659 (1984).

Greenberg, R. R. and Carpenter, B. S., High Accuracy/High Precision Determination of U-235 in Nondestructive Assay Standards by Gamma-Ray Spectrometry, Proc. Fifth Intl. Conf. on Nuclear Methods in Environmental and Energy Research, 644 (1984).

Greenberg, R. R., Multielement Analysis of NBS Coals by Instrumental Neutron Activation Analysis, Methods and Procedures Used at the National Bureau of Standards to Certify Sulfur in Coal SRM's for Sulfur Content, Calorific Value, Ash Content, T. E. Gills, ed., NBS Spec. Publ.260-94, $32(1984)$.

Greenberg, R. R., Fleming, R. F., and Zeisler, R., High Sensitivity Neutron Activation Analysis of Biological/Environmental Standard Reference Materials, Environ. Intern., 10, 129-136 (1984).

Kelly, W. R. and Paulsen P. J., Precise and Accurate Determination of High Concentrations of Sulfur by Isotope Dilution Thermal Ionization Mass Spectrometry, Talanta, 31, 1063-1068 (1984).

Kelly, W. R. and Paulsen P. J., Determination of Sulfur in NBS Coals by Isotope Dilution Thermal Ionization Mass Spectroscopy, Methods and Procedures Used at the National Bureau of Standards to Certify Sulfur in Coal SRMs for Sulfur Content, Calorific Value, Ash Content, T. E. Gills, ed., NBS Spec. Publ. 260-94 (1984).

Kingston, H. M. and Greenberg, R. R., An Elemental Ratioing Technique for Assessing Concentration Data from a Complex Water System, Environ. Intern. 10, 153 (1984).

Kingston, H. M., Paulsen, P. J., and Lambert, G. M., The Determination of Selenium and Tellurium in Stainless Steel, White Cast Iron, and Nickel Base Alloy Standard Reference Materials by Isotope Dilution Spark Source Mass Spectrometry, Appl. Spectrosc., 38, 385 (1984).

Koch, W. F., Marinenko, G., and Wu, Y. C., The Development of Reference Materials for Acid Rain Research, Environ. Intern., 10, 117-121 (1984).

Koch, W. F. and Stolz, J. W., Determination of Sulfur in NBS Coals by Ion Chromotography, Methods and Procedures Used at the National Bureau of Standards, to Certify Sulfur in Coal SRMs for Sulfur content, Calorific Value, Ash Content, T. E. Gills, ed., NBS Spec. Publ. 260-94 $1-6(1984)$. 
Lutz, G. J., Rook, H. L., and Lindstrom, R. M., Determination of I-129 at Natural Levels by Thermal Neutron Activation Analysis, Journal of Trace and Microprobe Techniques, 2 (1), 33-51 (1984).

Michel, R., Iyengar, G. V., and Zeisler, R., Current Aspects of Multielement Analysis in the Life Sciences, Proc. Symp. Instrumental Multielement Analysis, Jülich, FRG, April 2-5, (1984).

Moody, J. R., New Developments in Laboratory Design in the USA, Chapter 6 in Design, Construction and Refurbishment of Laboratories, $R$. Lees, and A. F. Smith, eds., Ellis Horwood Ltd, Chichester, UK (1984).

Moore, L. J., Fassett, J. D., and Travis, J. C., Systematics of Multielement Determination with Resonance Ionization Mass Spectrometry and Thermal Atomization, Anal. Chem., 56, 2770-2775 (1984).

Moore, L. J., Kingston, H. M., Murphy, T. J., and Paulsen, P. J., The Use of Isotope Dilution Mass Spectrometry for the Certification of Standard Reference Materials, Environ. Intern., 10, 169-73 (1984).

Powell, L. J., Murphy, T. J., and Gramlich, J. W., A New Determination of the Atomic Weight of Silver and an Improved Value for the Faraday, NBS Spec. Publ. 617, 357-8 (1984).

Powell, L. J. and Murphy, T. J., How Do You Know That's the Atomic Weight? Chem. Tech., 14, 726-730 (1984).

Pratt, K. W., Chronoamperometric Determination of Diffusion Layer Thicknesses at Hydrodynamic Electrodes, Anal. Chem., 트, 1967-1970 (1984).

Rains, T. C., Watters, R. L. Jr., and Epstein, M. S., Application of Atomic Absorption and Plasma Emission Spectroscopy for Environmental Analysis, Environ. Intern., 10, 163-168 (1984).

Riley, J. E. Jr., Mitchell, J. W., Downing, R. G., Fleming, R. F., Lindstrom, R. M., and Vincent, D. H., Materials Analysis Using Thermal Neutron Reactions: Applications, Materials Science Forum 2, 123-132 (1984).

Stone, S. F. and Zeisler, R., Evaluation of Biological Samples for Specimen Banking and Biomonitoring by Nuclear Methods, Proc. 5 th Conference on Nuclear Methods in Environment and Energy Technology, J. R. Vogt, ed., NTIS U.S. Dept. of Commerce, Springfield, VA, CONF-840408 (1984).

Wilson, S. R., Paulson, W. M., Gregory, R. B., Krause, R. J., Gressett, J. D., McDaniel, F. D., and Downing, R. G., Properties of Ion Implanted Polysilicon Layers Subjected to Rapid Thermal Annealing, Journal of the Electrochemical Society; Solid State Science and Technology, 132 (4), 922-929 (1984).

Wise, S. A. and Zeisler, R., The Pilot Environmental Specimen Bank Program, Environ. Sci. Technol ., 18, 302A-307A (1984).

Wu, Y. C., Koch, W. F., and Marinenko, G., A Report on The National Bureau of Standards pH Standards, J. Res. NBS 89, 395-400 (1984). 
Blackman, M. J., The Provenience of Obsidian Artifacts from Late Chalcolithic Levels at Aphrodisias, Turkey, Prehistoric Aphrodisias, M. Joukowsky, ed., Archaeologia Transatlantica, IV Louvain-la-Neuve; Institut Superieur D'Archelogie et Histoire de L'Art, Brown University (1985).

Blackman, M. J., Chemical Characterizations of Sealing Clays from Fourth Millenium B.C. Sites in Iran, in The Transactions of the American Nuclear Society, 49, 168-169 (1985).

Clark, C. W., Fassett, J. D., Lucatorto, T. B., and Moore, L. J., Observation of Autoinizing States of Beryllium by Resonance Ionization Mass Spectrometry, J. Opt. Soc. Am. B, 2, 891-896 (1985).

DeBievre, P. J. and Barnes, I. L., Table of the Isotope Composition of the Elements as Determined by Mass Spectrometry, Int. J. Mass Spect., Ion Process, 65, 211-230 (1985).

Gramlich, J. W. and Machlan, L. A., Isotopic Variations in Commercial High-Purity Gallium, Anal Chem., 57, 1788-1790 (1985).

Jornet, A., Blackman, M. J., and Olin, J. S., XIIIth to XVIIIth Century Ceramics from the Paterna-Manises Area (Spain), Ceramics and Civilization, D. Kingery, ed., American Ceramic Society (1985).

Kelly, W. R., On the Precise and Accurate Determination on the $241 \mathrm{Pu}$ Half-life by Mass Spectrometry, Int. J. Mass Spect., Ion Process, 64 , 85-90 (1985).

Lindstrom, R. M and Anderson, D. L., Analytical Neutron-Capture Gamma-Ray Spectroscopy: Statues and Prospects, Capture Gamma-Ray Spectroscopy and Related Topics-1984, S. Raman, ed., (AIP Conf. Proc. No. 125), Am. Inst. Physics, New York, 810-819 (1985).

Marinenko, G. and Koch, W. F., A Critical Review of Measurement Practices for the Determination of $\mathrm{pH}$ and Acidity of Atmospheric Precipitation, Environ. Intern., 10, 315-319 (1985).

Marinenko, G. and Koch, W. F., Evaluation of Methods for the Determination of Acidity in Acid Rain Samples, National Bureau of Standards, NBSIR $85-3114(1985)$.

Messman, J. D., O'Haver, T. C., and Epstein, M. S., Evaluation of a DirectCurrent Argon Plasma as a Primary Pseudocontinuum Radiation Source for Wavelength-Modulated Atomic Absorption Spectrometry, Anal. Chem., 57 , 416-420 (1985).

Moody, J. R., Sampling, Storage and Handling of Materials for Trace Elements Analysis, Sample Preparation Technology, Zymark Corp, Hopkinton, MA (1985).

Myers, J. E. and Blackman, M. J., Conical Plates from Medieval Qsar es-Seghir; The Proceedings of the Third International Congress on Medieval Ceramics (1985). 
Stroube, W. B. and Lutz, G. J., Epithermal Neutron Activation Analysis of Powdered Infant Formula for Iodine, Trans. Amer. Nucl. Soc., 49, 164-165 (1985).

Tanaka, T., Marinenko, G., and Koch W. F., Further Developments in the High Precision Coulometric Titration of Uranium, Talanta, 32, 525-530 (1985).

Turk, G. C. and Watters, R. L. Jr., Resonant Laser-Induced Ionization of Atoms in an Inductively Coupled Plasma, Anal. Chem., 57, 1979-1983, (1985).

Weidner, V. R., Mavrodineanu, R., Mielenz, K. D., Velapoldi, R. A., Eckerle, K. L., and Adams B., Spectral Characteristics of Holmium Oxide in Perchloric Acid Solution, J. of Res. NBS 90, No.(2), 115-125 (1985).

Barnes, I. L., Brill, R. H., Deal, E. C., and Piercy, G. V., Lead Isotope Studies of Some of the Finds from the Serce Liman Shipwreck, Proc. 1984 Symposium on Archaeometry, J. S. OIin and M. J. Blackman, eds., Smithsonian Institution, Washington, DC, in press.

Barnes, I. L., Deal, E., Chase, W. T., Holmes, L., Myers, P., and Sayre, E. V., The Nine Tripods and the Six Formulas: Lead and Lead Isotope Ratios in Ancient Chinese Bronzes, Proc. 1984 Symposium on Archaeometry, J. S. Olin and M. J. Blackman, eds., Smithsonian Institution, Washington, DC, in press.

Barnes, I. L., Brill, R. H., and Deal, E. C., Lead Isotope Studies of Early Chinese Glasses, Proc. Symposium on Ancient Glass and Glass Making, Beijing, August 27-31, 1984, Special Publication, American Ceramic Society, in press.

Becker, D. A., The Role of Reactor Characterization in NBS Quality Assurance, Journal of Radioanalytical and Nuclear Chemistry, in press.

Brill, R. H. and Barnes, I. L., Examination of Some Glasses from Timna, Proc. Symposium on Examination of objects from the Timna Excavation, B. Rothenberg, ed., The University Press, Athens, in press.

Downing, R. G., Maki, J. T., and Fleming R. F., Application of Neutron Depth Profiling to Microelectronic Materials Processing, Special Proceedings of the Industrial Chemical Division Session for the 187th National Meeting of the American Chemical Society, L. A. Casper, ed., in press.

Fassett, J. D. and Kingston, H. M., Determination of Nanogram Quantities of Vanadium in Biological Material by Isotope Dilution Thermal Ionization Mass Spectrometry with Ion Counting Detection, Anal. Chem., in press.

Fassett, J. D., Moore, L. J., Travis J. C., and DeVoe, J. R., Laser Resonance Ionization Mass Spectrometry, Science, in press.

Imbalzano, J. F. and Moody, J. R., Preliminary Studies of the Effects of Semiconductor Reagents on Polymers Containing Fluorine and of Trace Metallic Leachated from Molded Fluorocarbon Resin, J. Environ. Science 1985, in press. 
Vandervost, W., Shepherd, F. R., and Downing, R. G., High Resolution SIMS and Neutron Depth Profiling of B through Oxide-Silicon Interfaces, J. of the Amercian Vacuum Society, Sci. Technol., A3 (3), 1318-1321 (1985):

Koch, W. F., ed., Direct Potentiometric Measurements in Blood, Proceedings of the Workshop on Direct Potentiometric Measurements in Blood, Galthersburg, MD, May 18-20, 1983, National Committee for Clinical Laboratory Standards, Villanova, PA, in press.

Lindstrom, R. L., Activation Analysis of Semiconductor Materials, in ACS Books, in press.

Michael, R., Iyengar, G. V., and Zeisler, R., Current Aspects of Multielement Analysis in the Life Sciences, Proc. Symp. Instrumental Multielement Analysis, Jülich, FRG, April 2-5, 1985, in press.

Moore, L. J., Fassett, J. D., Travis, J. C., Lucatorto, T. B., and Clark, C. W., Resonance Ionization Mass Spectrometry of Carbon, J. Opt. Soc. Am. B, in press.

Pratt, K. W. and Koch, W. F., Determination of Trace-Level $\mathrm{Cr}(\mathrm{VI})$ in the Presence of $\mathrm{Cr}$ (III) and $\mathrm{Fe}$ (III) by Flow-Injection Amperometry without Prior Separation, Anal. Chem., in press.

Sams, R. L. and Fried, A., Potential Sources of Systematic Errors in Tunable Diode Laser Absorption Measurements, Appl. Spect., in press.

Stroube, W. B. and Lutz, G. J., Determination of Iodine in Liquid Infant Formula by Epithermal Neutron Activation Analysis, in press.

Velapoldi, R. A. and Burke, R. W., Recommended Reference Materials for Realization of Physicochemical Properties: Wavelength and Transmittance, IUPAC Commission on Physicochemical Measurements and Standards, in press.

Burke, R. W., Smith, M. V., Powell, L. J., and Mavrodineanu, R., Performance Characteristics of NBS Glass and Metal-on-Quartz Transmittance Standards, submitted for publication.

Diamondstone, B. I. and Gauer, R. C., Total Carbon Determinations in Biological Materials, submitted for publication.

Fried, A. and Sams, R. L., Tunable Diode Laser Absorption Spectrometry for Ultra-Trace Measurement and Calibration of Atmosphere Constituents, submitted for publication.

Koch, W. F., Marinenko, G., and Paule, R. C., Development of an SRM for Rainwater, J. Res. NBS, submitted for publication.

Koch, W. F., Marinenko, G., and Paule, R. C., An Interlaboratory Test of pH Measurements in Rainwater, J. Res. NBS, submitted for publication.

Leifer, R., Juzdan, Z. R., Kelly, W. R., and Fassett, J. D., Detection of Cosmos-1402 in the stratosphere, submitted for publication. 
Paule, R. C., Marinenko, G., Knordel, M., and Koch, W. F., Ruggedness Testing I: Theory and Statistical Experiment Design, J. Res. NBS, submitted for publication.

Paule, R. C., Marinenko, G., Knordel, M., and Koch W. F., Ruggedness Testing II: Practical Application to pH Measurements in Rainwater, J. Res. NBS, submitted for publication

Marinenko, G., Paule, R. C., and Koch, W. F., Ruggedness Testing III: Multifactor Interactions in Rainwater, J. Res. NBS, submitted for publication.

Rains, T. C., Reference Materials: Development and Characterization, Pure App. Chem., submitted for publication.

Syty, A., Christensen, R. G., and Rains, T. C., Trace Determination of $\mathrm{Cr}$ (VI) by LC/AAS with On-line Preconcentration, Atomic Spectroscopy, submitted for publication.

Wu, Y. C., Koch, W. F., and Marinenko, G., Thermodynamic Properties of DCl in $\mathrm{D}_{2} \mathrm{O}$ Solution, $(0.002$ to $1 \mathrm{~m})$ from 5 to $50{ }^{\circ} \mathrm{C}, \mathrm{J}$. Soln. Chem, submitted for publication.

Wu, Y. C. and Koch, W. F., The First and Second Dissociation Constants of Deuterio-o-phthalic Acid in $\mathrm{D}_{2} \mathrm{O}$ from EMF Measurements from 5 to $50{ }^{\circ} \mathrm{C}$, J. Soln. Chem., submitted for publication.

2. Talks

Pratt, K. W. and Koch W. F., "Electrochemical Flow-Injection Analysis Using Vibrating Electrodes: Application to the Determination of $\mathrm{Cr}$ (VI)," 27th ORNL/DOE Conference on Analytical Chemistry in Energy Technology, Knoxville, TN, October 2, 1984.

Marinenko, G. and Koch, W. F., "Evaluation of Acidity and pH Measurements for Acid Rain Studies," 166th Meeting of the Electrochemical Society, New Orleans, LA, October 9, 1984.

Fleming, R. F., "Analysis of Materials Using Neutron Beam Techniques," Institute for Materials Research Seminar, McMaster University, Hamilton, Ontario, Canada, October 15, 1984.

Elkins, J. W. and Sams, R. L., "Current Laboratory Spectroscopy Techniques by FT-IR," NASA Langley Research Center Spectroscopic Parameters Workshop, Hampton, VA, October 17, 1984.

Downing, R. G., "Nondestructive Depth Profiles of Light Elements by Neutron Depth Profiling," Kodak Laboratories, Rochester, NY, October 25, 1984. Invited

Moody, J. R., "Chemical Methods for Improved Precision and Sensitivity in Trace Metal Analysis," Baltimore-Washington Section of the Society for Applied Spectroscopy, Gaithersburg, MD, October 25, 1984. Invited 
Epstein, M. S., "DC Plasma Emission/Laser-Excited Atomic Fluorescence Spectrometry," 4th NBS-ADBASE Analytical Chemistry Workshop, National Bureau of Standards, Gai thersburg, MD, November 6, 1984.

Rains, T. C., "State of the Art of Atomic Absorption Spectrometry," 4th NBS-ADBASE Analytical Chemistry Workshop, National Bureau of Standards, Gaithersburg, MD, November 6, 1984.

Turk, G. C., "Laser-Enhanced Ionization Spectrometry," 4th NBS-ADABSE Analytical Chemistry Workshop, National Bureau of Standards, Gaithersburg, MD, November 6, 1984.

Watters, R. L., Jr., "Atomic Emission Spectrometry," 4th NBS-ADABASE Analytical Chemistry Workshop. National Bureau of Standards, Gaithersburg, MD, November 6, 1984.

Barnes, I. L., "The Atomic Weights of the Elements," 4th NBS-ADBASE Analytical Chemistry Workshop, National Bureau of Standards, Gait thersburg, MD, November 7, 1984. Invited

Gramlich, J. W., "Inorganic Mass Spectrometry Applications," 4th NBS-ADABSE Analytical Chemistry Workshop, National Bureau of Standards, Gaithersburg, MD, November 8, 1984. Invited

Downing, R. G., "Neutron Beams," Conference on the Use of Small Accelerators in Research and Industry, Denton, TX, November, 11-15, 1984. Invited

Zeisler, R., "Sampling and Analysis of Human Livers," American Nuclear Society and European Nuclear Society 1984 International Conference, Washington, DC, November 13, 1984. Invited

Fassett, J. D., "Resonance Ionization Mass Spectrometry for Elemental Analysis, Eastern Analytical Symposium, New York, NY, November, 1984. Invited

Moody, J. R., "Contamination Control for Laboratory and Manufacturing," Comsat Laboratories, Clarksburg, MD, December 6, 1984. Invited

Kingston, H. M., "Microwave Digestion," CEM Corporation, Indian Head Trail, NC, December 12, 1984. Invited

Moody, J. R., "Clean Chemistry for Trace Analysis," Eastman Kodak Research Laboratories, Rochester, NY, December 17, 1984. Invited

Koch, W. F., "Reference Materials and Methods for the Measurements of $\mathrm{pH}$ in Acidic Precipitation," 1984 International Chemical Congress of Pacific Basin Societies, Honolulu, HI, December 21, 1984. Invited

Barnes, I. L., "The Shipwreck of Serce Liman - Lead Isotope Studies," Center for Chemical Physics, Surface Science Division Seminar, National Bureau of Standards, Gaithersburg, MD, January 8, 1985. Invited

Moody, J. R., "The Application of Clean Room Concepts in Analytical Chemistry," International Symposium on Artificial Radioactivity, University of Pune, Pune, India, January 9, 1985. Invited 
Moody, J. R., "Clean Room Technology: Present and Future for Analytical Chemistry," Departmental Seminar, Bhabha Atomic Research Centre, Bombay, India, January 14, 1985. Invited

Moody, J. R., "The Use and Design of Clean Room and Pure Reagent Facilities at NBS," Departmental Seminar, National Meteorological Institute, Tsukuba, Japan, January 22, 1985. Invited

Moody, J. R., "The Use of NBS Clean Rooms in Standard Reference Material Certification," Departmental Seminar, National Institute for Environmental Studies, Tsukuba, Japan, January 22, 1985. Invited

Downing, G. R., "Neutron Depth Profiling (NDP) for the Nondestructive Analysis of Light Elements," Aluminum Company of America, Alcoa, PA, January 24, 1985. Invited

Kingston, H. M., "Legislative Alternatives in the 99th Congress," Society for Risk Analysis, McLean, VA, February 8, 1985. Invited

Downing, G. R., "Neutron Depth Profiling: The Technique and Applications," University of Missouri-Rolla, Rolla, MO, February 11, 1985. Invited

Rains, T. C., "The Art of Sample Preparation for Atomic Spectroscopy," George Washington University, Washington, DC, February 15, 1985. Invited

Rains, T. C., "Atomic Absorption and Plasma Emission Spectroscopy," ACS Short Course, 36th Pittsburgh Conference on Analytical Chemistry and Applied Spectroscopy, New Orleans, LA, February 22-24, 1985.

Fried, A., Sams, R., and Dorko, B., "Simultaneous Quantitative Tunable Diode Laser and Chemiluminescent Detector Measurements of High Concentration $\mathrm{NO}_{2}$ in Air Gas Mixtures," 36th Pittsburgh Conference on Analytical Chemistry and Applied Spectroscopy, New Orleans, LA, February 25-March $1,1985$.

Mo, D. M., Ueda, J., Watters, R. L., Jr., and Rains, T. C., "Determination of Molybdenum, Titanium, and Vanadium in Refractory Materials by ICPES," 36th Pittsburgh Conference, on Analytical Chemistry and Applied Spectroscopy, New Orleans, LA, February 25, 1985.

Powell, L. J., Burke, R. W., Smith, M. V., and Mavrodineanu, R., "Performance Characterstics of NBS Glass and Metal-on-Quartz Transmittance Standards," 36th Pittsburgh Conference on Analytical Chemistry and Applied Spectroscopy, New Orleans, LA, February 26, 1985.

Turk, G. C., "Applications of Laser-Enhanced Ionization Spectrometry at NBS," Shell Development Company, Houston, TX, February 26, 1985. Invited

Fassett, J. D., "Application of Resonance Ionization Mass Spectrometry to Elemental Analysis," University of Maryland, College Park, MD, March 29, 1985. Invited 
Barnes, I. L., "Modern Ion Optics," Inorganic Analytical Research Division Seminar, National Bureau of Standards, Gaithersburg, MD, April 9, 1985. Invited

Rains, T. C., "Zinc and Selenium Methods Used at NBS," NBS/NCI Micronutrient Analysis QA Workshop, National Bureau of Standards Gaithersburg, MD, April 11, 1985.

Moody, J. R., "Clean Laboratories and Their Use for Trace Metal Analysis," Society for Applied Spectroscopy Tour Lecture, Toronto, Canada, April 15, 1985. Invited

Moody, J. R., "Chemical Methods for Enhancement of Trace Metal Analysis," Society for Applied Spectroscopy Tour Lecture, National Science Foundation, Ottowa, Canada, April 16, 1985. Invited

Moody, J. R., "Chemical Methods for Enhancements of Trace Metal Analysis," Society for Applied Spectroscopy Tour Lecture, McGill University, Montreal, Canada, April 17, 1985. Invited

Moody, J. R., "Ultra-Pure Reagents and Clean Rooms, Their Use in Analytical Chemistry," Society for Applied Spectroscopy Tour Lecture, Dalhousie University, Halifax, Canada, April 18, 1985. Invited

Watters, R. L., Jr., "Quality Assurance and Data Reporting," 6th Midwest Analytical Symposium, Society for Applied Spectroscopy, St. Louis, MO, April 18, 1985. Invited

Rains, T. C., "Reference Materials: Development and Characterization," 2nd International Symposium on Analytical Chemistry in the Exploration, Mining and Processing of Materials, CSIR Conference Centre, Pretoria, South Africa, April 19, 1985. Invited

Rains, T. C., "The Characterization of Standard Reference Materials by AAS and ICP," University of Cape Town, Cape Town, South Africa, April 24, 1985. Invited

Rains, T. C., "The Art of Sample Preparation," University of Port Elizabeth, Port Elizabeth, South Africa, April 26, 1985. Invited

Watters, R. L., Jr., "Quality Assurance and Data Reporting," Professional Development Program, Baltimore-Washington Section, Society for Applied Spectroscopy, USDA, Beltsville, MD, April 29, 1985. Invited

Imbalzano, J. F. and Moody, J. R., "Preliminary Studies of the Effects of Semiconductior Reagents on Polymers Containing Fluorine and of Trace Metallic Leachate from Molded Fluorocarbon Resin," 31st Annual Meeting of the Institute for Environmental Science, Las Vegas, NV, May 1 , 1985.

Blackman, M. J. and Wright, R. P., "Technological and Stylistic Changes in Ceramics from the 4th Millenium B.C. in Highland Iran," 87th Annual Meeting of the American Ceramic Society, Cincinnati, OH, May 6, 1985. 
Jornet, A., Blackman, M. J., and Olin, J. S., "Investigations on PostMedieval Glazed Ware from the Sevilla and Talavera Puente Areas (Spain)," 87th Annual Meeting of the American Ceramic Society, Cincinnati, $\mathrm{OH}$, May $6,1985$.

Rains, T. C., "Flame Atomic Absorption Spectrometry," Assay and Weights Administration, Gamalia, Egypt, May 6-9, 13, 1985. Invited

Wolf, W. R., and Zeisler, R., "Biomonitoring of Dietary Intakes," 9th U.S:-German Seminar of State and Planning on Environmental Specimen Banking, Schloss Reisenburg, FRG, May 13, 1985. Invited

Rains, T. C., "Trace Elemental Analysis by AAS," Egyptian Organization for Standardization and Quality Control, Cairo, Egypt, May 14, 1985. Invited

Zeisler, R. and Stoeppler, M., "Intercomparison of Analytical Techniques Used for the Characterization of Human Livers," 9th U.S-German Seminar of State and Planning on Environmental Specimen Banking, Schloss Reisenburg, FRG, May 14, 1985. Invited

Stone, S. F. and Zeisler, R., "Sequential Analysis of 44 Trace Elements in Marine Bivalves," $9 \mathrm{th}$.U.S.-German Seminar of State and Planning on Environmental Specimen Banking, Schloss Reisenburg, FRG, May 15, 1985. Invited

Imbalazano, J. F., and Moody J. R., "The Effect of Selected Aqueous Semiconductor Reagents on Commercial Piping of Perfluoroalkoxy Fluorocarbon Resin and of Ethylene-Chlorotrifluoro Ethylene Fluoropolymer Resin, Millipore Corporation Technical Symposium, San Mateo, CA, May 20, 1985.

Rains, T. C., "Application of Electrothermal Atomization Atomic Absorption Spectrometry," Professional Development Program for Scientists, Baltimore-Washington Section of Society for Applied Spectroscopy, Department of Agriculture, Beltsville, MD, May 20, 1985. Invited

Vetter, T. W. and Diamondstone, B. I., "Affect of Accelerator on Sulfur Determination in Low Sulfur Ductile Iron," 19th Middle Atlantic Regional Meeting, American Chemical Society, Monmouth College, West Long Branch, NJ, May $21,1985$.

Imbalazano, J. F. and Moody, J. R., "The Effect of Selected Aqueous Semiconductor Reagents on Commercial Piping of Perfluoroalkoxy Fluorocarbon Resin and of Polyvinyldene Difluoride Fluoropolymer," Semicon West San Matco, CA, May 22, 1985.

Zeisler, R., "Applications of Instrumental Neutron Activation Analysis in Biological Research," Mini-Symposium on Neutron Activation Analysis and Trace Element Research in Biology and Medicine, Studsvik Energiteknik, Nykoping, Sweden, May 23, 1985. Invited 
Fassett, J. D., "Observation of New States of Beryllium by Resonance Ionization Mass Spectrometry," 33rd Annual Conference of the American Society for Mass Spectrometry and Allied Topics, San Diego, CA, May 27, 1985.

Paulsen, P. J. and Beary, E. S., "Selenium Isotopic Ratio Measurements from ASSE + Ions Generated with $\mathrm{SEO}_{3}, \mathrm{As}^{+3}$ Loaded Silica Gel," 33rd Annual Conference of the American Society for Mass Spectrometry and Allied Topics, San Diego, CA, May 29, 1985.

Fassett, J. D., Kelly, W. R., Leifer, R., and Judzan, J. R., "Detection of the Atomspheric Burnup of the Cosmos 1402 Satellite by Thermal Ionization Mass Spectrometry," 33rd Annual Conference of the American Scciety for Mass Spectrometry and Allied Topics, San Diego, CA, May 28, 1985.

Downing, R. G., "Near-Surface Analysis of Light Elements by Neutron Depth Profiling," Aluminum-Lithium Workshop, Hidden Valley, PA, June 5, 1985. Invited

Greenberg, R. R. and Carpenter, B. S., "High Accuracy Determination of U-235 Abundances in Nondestructive Assay Standards by Gamma Spectrometry," International Symposium on Nuclear Analytical Chemistry, Halifax, Canada, June 5, 1985. Invited

Becker, D. A, "The Role of Reactor Characterization in NAA Quality Assurance," the International Symposium on Nuclear Analytical Chemistry, Dalhousie University, Halifax, Canada, June 6, 1985.

Zeisler, R., "Advances in Instrumental Neutron Activation Analysis of Biological Materials," International Symposium on Nuclear Analytical Chemistry, Dalhousie University, Halifax, Canada, June 6, 1985. Invited

Wu, Y. C. and Koch, W. F., "The First and Second Dissociations Constants of Deuterio-o-ph' atic Acid in $\mathrm{D}_{2} \mathrm{O}$ from EMF Measurements from 5 to $50{ }^{\circ} \mathrm{C}, "$ Conference on Electrolyte Solutions, National Bureau of Standards, Gaithersburg, MD, June 11, 1985.

Zeisler, R., "The Determination of Trace Elements in Biological Macromolecules by Neutron Activation Analysis," American Nuclear Society 1985 Annual Meeting, Boston, MA, June 11, 1985. Invited

Fleming, R. F., "An Assessment of the Induced Radioactivity in Foods Using Isotopic Gamma-Ray Sources," American Nuclear Society 1985 Annual Meeting, Boston, MA, June 13, 1985. Invited

Moody, J. R., "The Selection of Materials for Ultra-Pure Water Systems," Millipore Corporation Symposium on High Purity Water, Bedford, MA, June 20, 1985. Invited

Klouda, G. A., Currie, L. A., Tompkins, G. B., Wise, S. A., and Diamondstone, B. I., "Reference Materials and Blank Evaluation.Techniques for ${ }^{14} \mathrm{C}$ Measurements on Small Aerosol Samples," 12th International Radio Carbon Conference, Trandhiem, Norway, June 24, 1985. 
Barnes, I. L., "The Analysis of Carbon Dioxide," The Summer Seminar of the Center for Analytical Chemistry, National Bureau of Standards, Gaithersburg, MD, July 25, 1985. Invited

Downing, R. G., "Light Element Profiling in Electronic Materials," Aerospace Corporation, Los Angeles, CA, July 25, 1985. Invited

White, V. E., Welch, M. L., Pereles, D. J., and Sams, R. L., "Laser Photodissociation of Ions from Soft 'Ionization Techniques," 10th International Mass Spectrometry Conference, Swansea, U.K., September $9-12,1985$.

Koch, W. F., "The Development of a Standard Reference Material for Wet Deposition," Review Meeting of the National Acid Precipitation Assessment Program, Boulder, CO, September 10, 1985.

Turk, G. C., Ruegg, F. C., Travis, J. C., and DeVoe, J. R., "ThreeDimensional Atomic Spectra in Flames Using Using Stepwise Excitation Laser-Enhanced Ionization Spectroscopy," CSI XXIV, GarmischPartenkirchen, FRG, September 20, 1985.

Butler T. A., Rush, T. A., and Rains, T. C., "Determination of Trace Elements in Coal by Atomic Absorption and Inductively Coupled Plasma Spectrometry," 12th Annual Meeting of the Federation of Analytical Chemistry and Spectrometry Societies, Philadelphia, PA, September 30, 1985.

Rains, T. C., "The Art of Sample Preparation," 12th Annual Meeting of the Federation of Analytical Chemistry and Spectroscopy Societies, Philadelphia, PA, September 30, 1985.

Zhang, Y. Z., Watters, R. L., Jr., and Rains, T. C., "Determination of Phosphorus in Refractory Materials by Inductively Coupled Plasma Atomic Emission Spectrometry," 12th Annual Meeting of the Federation of Analytical Chemistry and Spectroscopy Societies, Philadelphia, PA, September $30,1985$.

\section{Committee Assignments}

I. Lynus Barnes

Member, Department of Health, Education, and Welfare, Chemistry Task Force of the National Shellfish Sanitation Program Washington Editorial Review Board

International Union of Pure and Applied Chemistry, Commission of Atomic Weights and Isotopic Abundances

Chairman, IUPAC, Commission on Atomic Weights and Isotopic Abundances, Working Group on Statistics Applied to Atomic Weights 
Donald A. Becker

Member, ASTM E-10, Nuclear Technology and Applications

ASTM E-10.05, Nuclear Radiation Metrology

ASTM D-19, Water

ASTM D-19.01, Statistical Methods

ASTM D-19.02, General Specification and Technical Resources

ASTM D-19.03, Sampling of Water and Water-Formed Deposits, and Surveillance of Water

ASTM D-19.04, Methods of Radiochemical Analysis

ASTM D-19.05, Inorganic Constituents in Water

ASTM D-19.07, Sediment.s

ASTM D-19.33, Water Associated with Synthetic Fuel Production

Member, ANS, Activation Analysis Committee, Isotopes and Radiation Division

Member, ANS, Trace Element Analysis Committee, Technical Group on Biology and Medicine

Chairman, ASTM E-10.05.12, Task Group on Nuclear Methods of Chemical Analysis

Ellyn S. Beary

Member, Inorganic Analytical Research Division Safety Committee

Robert W. Burke

Member, ASTM E-03, Chemical Analysis of Metals

ASTM D-34, Standards for Waste Characterization

Theresa A. Butler

Secretary, Baltimore-Washington Section of the Society for Applied Spectroscopy

Member, Inorganic Analytical Research Division Safety Committee

Barry I. Diamondstone

Member, ASTM D-34, Waste Disposal

ASTM D-34.02.01, Section on Batch Extractions

ASTM E-03, Chemical Analysis of Metals

ASTM E-03.01, Gases in Metals

ASTM E-03.93, Long Range Planning

Chairman, Task Force on Oxygen in Metals

Robert G. Downing

Member, ASTM E-10, Nuclear Methods for Chemical Analysis

Member, Inorganic Analytical Research Division Seminar Committee

Chairman, Inorganic Analytical Research Division Safety Committee

Michael S. Epstein

Member, ASTM D-19, Wat.er

Editorial Advisory Board, Progress in Analytical Atomic Spectroscopy

Treasurer, National Society for Applied Spectroscopy

Chairman, Baltimore-Washington Section of the Soclety for Applied Spectroscopy

Executive Secretary, Review Committee, Society for Applied Spectroscopy 
Ronald F. Fleming

Member, ASTM E-10.05, Nuclear Radiation Metrology

ASTM E-10:07, Radiation Effects on Materials

Organization Committee, Sixth Symposium on $\mathrm{X}-$ and Gamma-Ray

Sources and Applications

John W. Gramlich

Member, Institute of Nuclear Materials Management Committee N15.9.3, Non-Destructive Assay (Physical Methods)

Robert R. Greenberg

Member, ASTM E-10.05, Nuclear Radiation Metrology

Member, NBS Chemistry Storeroom Committee

Member, ANS, Trace Analysis Committee, Technical Group for Biology and Medicine

Howard M. Kingston

Member, ASTM C-26.05, Methods of Test ASTM C-26.07, Waste Materials

Task Group Leader, C-26.05, Leachate Analysis Methods

Technical Consultant, Congressional Science and Technology Committee

William F. Koch

Member, ASTM D-19, Water

ASTM D-19:02, General Specifications and Technical Resources

ASTM D-19:05, Inorganic Constituents in Water

ASTM D-22; Air

Personnel Officer, NBS Child Care Association, Board of Directors

John K. Langl and

Chairman, NBS Electronics Storeroom Committee

Richard M. Lindstrom

Alternate Member, NBSR Safety Evaluation Committee

Lawrence A. Machlan

Member, ASTM C-26, Nuclear Fuel Cycles

ASTM C-26.05, Test Methods

ASTM C-26.01, Editorial and Terminology

George Marinenko

Member, ASTM D-19, Water

Chairman, D-19.05.04.03, Voltammetry

D-19.09.06, Redox Potentials in Saline Water

D-19.09.07, pH in Saline Water and Brines

D-19.09:01, Chlorine Residuals in Saline Water

Councilor, National Capital Section of the Electrochemical Society

First Vice-Chairman, National Captial Section of the Electrochemical Society 
John R. Moody

Member, ASTM D-19, Water

ASTM D-19:05, Inorganic Constituents in Water

Chemical Society of Washington, Audit Committee

Contamination Control Standards and Practices for Federal Standard 209c, Institute for Environmental Sciences

Delegate, Society for Applied Spectroscopy

Representative, FACSS Governing Board

Chairman, Society for Applied Spectroscopy, Video Short Course Committee

Thomas J. Murphy

Member, American Chemical Society Committee on Analytical Reagents American Chemical Society Committee on Meetings and Expositions

Member, International Union of Pure and Applied Chemistry (IUPAC), Commission on Atomic Weights and Isotopic Abundances

Member, American Chemical Society, Admissions Committee

Chairman, Chemical Society of Washington, Audit Committee

Councilor, Chemical Society of Washington

John A. Norris

Member, ASTM E-02, Emission Spectroscopy

ASTM E-02.02, Statistics

ASTM E-02:04, Sampling and Standards

ASTM E-02.05, Copper, Cobalt, Nickel, and High Temperature

ASTM E-02:06, Lead, Tin, Zinc

ASTM E-02.07, Aluminum

ASTM E-02.08, Refractory Metals

ASTM E-02:09, Ferrous

ASTM E-02:13, Terminology

Member, Joint Committee on Atomic and Atomic and Molecular Physical Data

Chairman, ASTM E-02.01, Fundamental Practices

Representative, Society for Applied Spectroscopy

Lura J. Powell

Member, Chemical Society of Washington

Board of Directors, NBS Child Care Association

Chairman, American Society for Mass Spectrometry, Committee on Isotope Ratio Measurements

Treasurer, Chemical Society of Washington

President, Standards Committee for Women

Kenneth W. Pratt

Secretary, National Capital Section of the Electrochemical Society

Member, NBS Inorganic Analytical Research Division Safety Committee

Member, Inorganic Analytical Research Division Seminar Committee

Theodore C. Rains

Member, Proposal Evaluation Committee for National Science Foundation

Editorial Board of Annual Reports on Analytical Atomic Spectroscopy (The Chemical Society of London) and the Canadian Journal of Spectroscopy

Subcommittee No. 6 on Methods of Air Sampling and Analysis

ASTM E-02.10, Non-Metallic Materials

ASTM E-02:13, Nomenclature 
ASTM D-01, Paint and Related Coatings

ASTM D-19, Water

Past-Chairman, FACSS Governing Board

Professor-in-Charge, ACS Short Course on Atomic Absorption and Plasma Emission Spectroscopy

Task Force Leader, Scientific Instrumentation Information Network and Curricula (SIING) for project on "Atomic Absorption Spectroscopy"

Column Editor, Journal of Applied Spectroscopy

Ronald W. Shidel er

Member, NBS Electronics Storeroom Committee

John C. Travis,

Chairman, Analytical Laser Ionization Spectrometry

Thomas W. Vetter

Member, ASTM E-02, Emission Spectroscopy

ASTM E-02.02, Statistics

ASTM E-02.04, Sampling and Standards

ASTM E-02.06, Lead, Tin, Zinc

ASTM E-02.07, Alumi num

ASTM E-02.09, Ferrous

ASTM E-03, Chemical Analysis of Metals

ASTM E-03.01, Ferrous

ASTM E-03.91, Editorial

ASTM E-03.92, Standards

Chairman, ASTM E-03.01, Task Group on Low Concentration of Sulfur in Cast Iron, Combustion Method

Yung-Chi Wu

Member, ASTM D-19, Water

Rolf L. Zeisler

Member, NBSR Safety Evaluation Committee

Chairman, ANS, for Trace Element Analysis Committee, Technical Group for Biology and Medicine

4. Other

a. Seminars

October 15, 1984

Dr. David W. Crawford, New Brunswick Laboratory, "The Utilization of Mass Spectrometry in a Nuclear Material Laboratory ."

October 15, 1984 - Mr. John S. Beaty, Allied Analytical Systems, "Uses of a Finely Divided Metal Aerosol."

November 29, 1984 - Dr. R. Ganapathy, J. T. Baker Chemical Company, "Major Meterotie Impacts on the Earth." 
January 9, 1985

January 29, 1985

February 11, 1985

March 15, 1985

March 20, 1985

April 11, 1985

May 3, 1985

May 9, 1985

May 17,1985

June 3, 1985

June 14, 1985
Professor O. K. Manual, University of Missouri, "Chemical and Isotopic Heterogeneities in the Sun and its Planetary System: Remnants of Local Element Synthesis."

Professor Richard D. Sacks, University of Michigan, "Direct Determination of Metallic Elements in Solid Powder Samples Using Magnetically Tailored Plasmas from Electrically Vaporized Thin Metal Films."

Professor Nicholas Winograd, Pennsylvania State University, "Surface and Solids Characterization by Multiphoton Resonance Ionization of Sputtered Atoms."

Dr. Jacques P. Guertin, Electric Power Research Institute, "Recent Solar-Lunar Eclipses."

Dr. Henry N. Blount, III, National Science Foundation, "Electrochemical and Spectroelectrochemical Studies of Heterogeneous Electron Transfer in Micelles and Bilayers."

Professor Rabin Roy, Drury College, "pH Measurements of Biochemical Buffers in Aqueous and Mixed Solvents at Nominal and Subzero Temperatures."

Professor James A. Holcombe, University of Texas, "Recent Advances in Graphite Furnace Atomic Absorption."

Dr. Daniel W. Beekman, Atom Sciences, Inc., "Laser Ablation as an Atomization Source for Resonance Ioniztion Spectroscopy."

Professor Dr. Klaus G. Heumann, Institute for Inorganic Chemistry, "Accurate Anion Trace Analyses Using an Economical Thermal Ionization Mass Spectrometer."

Professor J. Hoste, Institute for Nuclear Studies, "Determination of Light Elements in Metals and Semiconductors by Charged Particle Activation Analysis."

Dr. Kaj Heydorn, Risø National Laboratory, "Improvements in the Characterization of Reference Materials." 


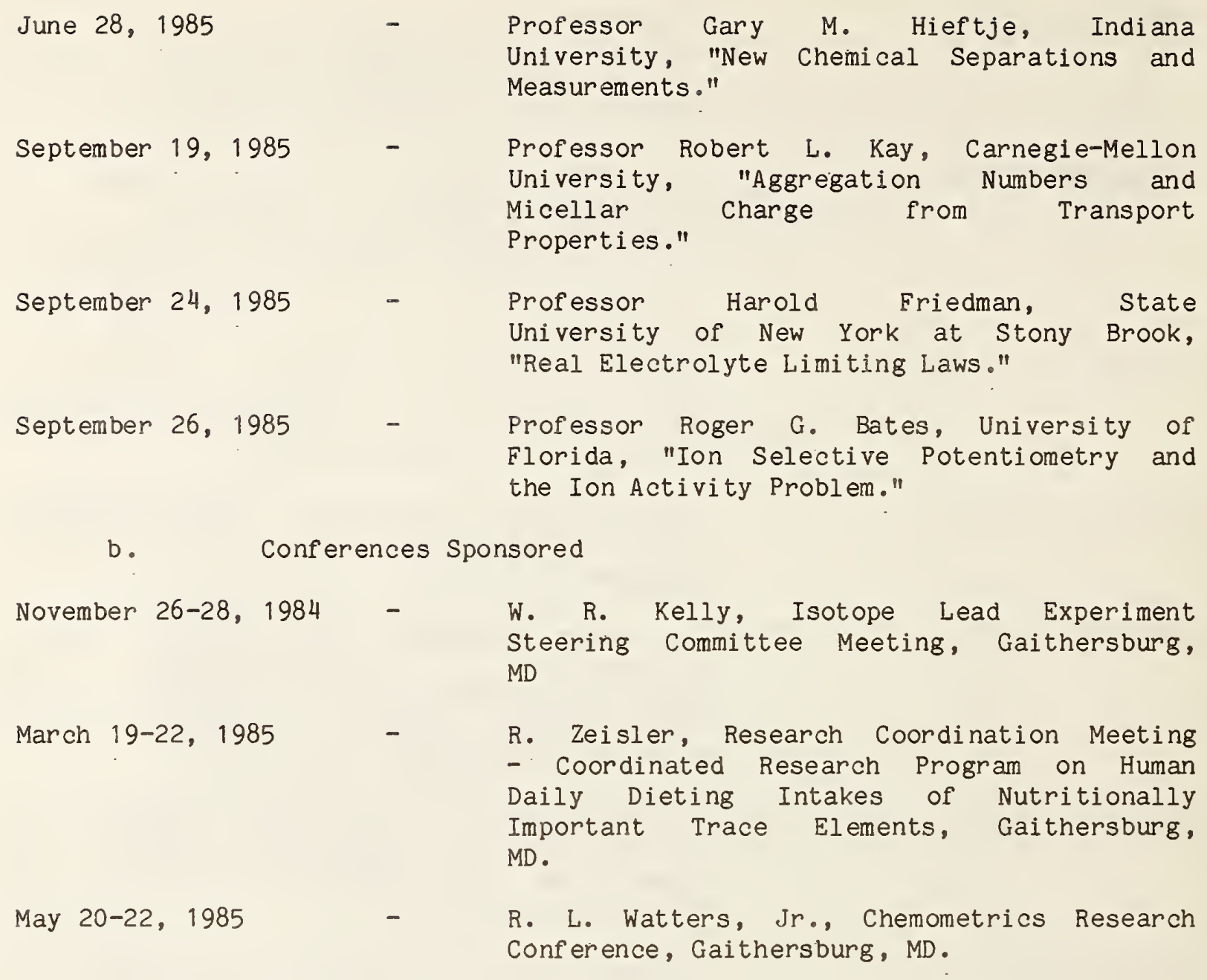


III. Organic Analytical Research Division

Willie E. May, Chief

Dennis J: Reeder, Deputy Chief

A. Division Overview

The Organic Analytical Research Division conducts research to develop and improve techniques for the preparation, purification, and analysis of organic compounds and employs these techniques in the solution of problems related to national needs. The Division's research is carried out in five groups that are organized along the following functional lines: Bioanalytical Techniques, Electrochemistry, Gas Chromatography, Liquid Chromatography, and Mass Spectrometry. Current activities in each of the groups will be discussed in the Group Overviews and Technical Reports that follow. Results from the Division's research activities are utilized by industry, other government agencies, public and private institutions and associations, and other research programs at the National Bureau of Standards. Research efforts in the Division during the past year have resulted in the publication of over 35 articles in archival journals and other technical media. An additional 21 articles are currently in press. Division scientists also presented more than 85 talks at technical meetings and conferences during the past year.

In FY85, approximately 50 percent of our efforts were directed toward basic research in organic analytical chemistry. The remainder of our efforts were in support of other Federal Agency programs and to a limited degree in short-term projects performed on a service analysis basis. The Division continues to be actively involved in three Competence Building Programs that have been selected for funding by the NBS Director: Organic Electrochemistry; Analysis of Ionization Mechanisms and Ion Structures in Organic Mass Spectrometry; and the Use of Proteins in Analytical Chemistry. Research in liquid chromatographic retention mechanisms has continued and a new effort in selectivity optimization in multidimensional gas chromatography has been initiated. Accomplishments in these areas will be discussed in the Group Overviews and Technical Reports that follow.

As in the past, the major portion of our other agency support has come from the Environmental Protection Agency (EPA), with substantial support also coming from the Department of Energy (DOE), Department of Defense (DOD), and the Food and Drug Administration (FDA). In addition, this year marked the commencement of a major multi-year program with the National Cancer Institute (NCI). Specific research efforts in support of other Federal Agency programs included: continued development of reference materials and the provision of analyses to establish NBS traceability on audit, quality control and proficiency testing samples for EPA; continuing in our role as Reference Laboratory for a network of DoE laboratories involved in the analysis of polar organic compounds in complex samples; development of SRMs for drugs of abuse in urine and an isotope-dilution gas chromatography/mass spectrometry method for the measurement of chemical warfare agent BZ in urine for the DoD; continued evaluation of methods for the determination of ethylene oxide on surgical tools for the FDA; and serving as a Reference Laboratory for NCI grantees involved in the determination of micronutrients in serum as part of chemoprevention clincial trials. We also collaborated with the Air Pollution Research Advisory Committee of the Coordinating Research Counc1l Inc. (CRC- 
APRAC) in conducting an international interlaboratory study on the measurement of polycyclic aromatic hydrocarbons and related compounds in ambient air and diesel particulate extracts. The CRC is a non-profit memberbased corporation organized to conduct research of mutual interest to the petroleum and automotive equipment industries and government. The objective of CRC-APRAC is to provide data on the environmental consequences of automotive emissions. Additional details concerning these activities are given in the Group Overviews and Technical Reports that follow.

During the past year, we have been involved in collaborative research programs with the Inorganic Analytical Research and Gas and Particulate Science Divisions, as well as several other NBS groups. Our studies concerning the separation of metal-binding proteins in acrylamide gels have continued to be supported and assisted by neutron activation analyses performed by scientists in the Inorganic Analytical Research Division. We are involved in two collaborative programs with scientists in the Gas and Particulate Science Division. Laser ionization mass spectrometric and Raman spectroscopic measurements were performed to assist in determining the structures of poly (4-vinylpyridine) (PVP) and PVP-metal complexes, chromatographic supports for biomolecule affinity chromatography. A series of SRM cylinders and several additional cylinders with known coricentrations of selected volatile toxic aromatic compounds were prepared and provided to us for measurement by GS/MS as part of a program to establish direct NBS traceability on EPA's measurements of toxic organics in air.

Collaborative research efforts are also ongoing with other Centers within NBS. We have collaborated with scientists in the Center for Chemical Physics in the development of a comprehensive sampling and analysis scheme for the determination of organic-chlorine species produced during the combustion of refuse derived fuels. We continued our collaboration with the Center for Fire Research in the development of an analytical method for arson accellerant detection. Additional details concerning this program are provided in the Gas Chromatography Group Overview. Scientists in our Liquid Chromatography Group have collaborated with scientists in the Center for Materials Science in the development of a small angle neutron scattering procedure for physical characterization of liquid chromatographic supports and bonded phases.

We have continued our active support of the NBS Standard Reference Materials program. SRM related activities represented approximately 12 percent of our budget. Six SRMs were certified during the past year and analytical measurements are in progress for certification of ten additional materials. We also provided polycyclic aromatic hydrocarbons measurements on four marine sediments to the Marine Analytical Standards Program of the National Research Council of Canada. These sediments are being certified by interlaboratory concensus utilizing data from a selected group of laboratories "qualified" in the determination of PAH in complex mixtures.

Our research programs in gas chromatography and bioanalytical chemistry have been strengthened by the additions of Dr's. Howard Mayfield and Jesse Edwards. Howard Mayfield came to us from the University of Alabama and is completing the first of a two-year appointment as a Postdoctoral Research Associate. Jesse Edwards joined us in early summer from the University of North Carolina and brings to us expertise in biochemistry and a wealth of experience in two-dimensional electrophoresis. Dr. Polly Ellerbe has joined 
us as the Roger $K$. Gilbert/College of American Pathologist Research Associate. She replaces $\mathrm{Dr}$. Kwokei $\mathrm{Ng}$ who has accepted an industrial position. Richard Durst has temporarily assumed the duties as Deputy Director of the Center and William MacCrehan has assumed Dr. Durst's responsibilities as Electrochemistry Group Leader. Dr's. Timothy Wozniak and Joe Foley have completed their postdoctoral appointments and accepted industrial and academic positions, respectively. They will be replaced by Dr's. Michael Ambrose (Bioanalytical Techniques/NMR) and Damian Shea (Electrochemistry/LC-EC).

In FY86 we will continue to direct a major portion of our efforts towards basic research in each of the five groups in the Division. Development of bioanalytical sensors is a very challenging and exciting new area of research that will be undertaken in the coming year. This research effort will be supported through the Competence Building program. We expect to make a key new hire in this area early in the coming year. Details concerning other specific basic research activities are provided in the respective Group Overviews that follow. Our support of EPA, DoE, and DoD programs will continue at FY85 levels. However, our efforts in the NCI Chemoprevention Program will be increased significantly in FY86 and we are planning a joint program with the Center for Radiation Research and other Federal Agencies to investigate the possible use of chemical markers as post-irradiation dosimeters for food products.

\section{Bioanalytical Group: Overview}

The Bioanalytical Techniques Group continues to focus its research efforts in three major areas: (1) separation methods applicable to biotechnology, (2) organic synthesis of compounds labeled with stable isotopes for high accuracy work in clinical/nutritional chemistry, and (3) maintenance of expertise and performance of research in high-field nuclear magnetic resonance spectroscopy. Our work has continued to be directed towards gaining a better understanding of the chemical processes involved in separations of biomolecules by isoelectric focusing, electrophoresis, and liquid chromatographic techniques, in improving our NMR spectroscopy capabilities, and in continuing our work in development high-accuracy methods for important analytes in clinical chemistry.

Our current goals include developing marker proteins for use in electrophoretic systems, studying sensitive techniques for specific staining of selected biomolecules, expanding our research on immobilized enzymes, completing development of an isotope dilution-mass spectrometric definitive method for serum creatinine and triglycerides, and implementing new capabilities in NMR techniques through research utilizing an improved data system for the $400 \mathrm{MHz}$ Spectrometer.

Our studies on marker proteins have led to the tentative selection of a molecular weight mixture which may be commercially produced as an SRM. Negotiations are currently underway to assess the capabilities of a company to produce this material in sufficient quantity. Development of stable, widerange isoelectric point markers is expected to be a more difficult problem and will be addressed in the coming year.

Research has continued in development of more sensitive and selective detection methods for electrophoretically separated proteins in polyacrylamide matrices. A collaborative study with the Inorganic Analytical Research 
Division is underway to study the experimental conditions necessary for successful detection of specific metal-binding proteins and phosphoproteins by neutron activation techniques. Prosphorproteins have been detected using neutron activation followed by autoradiography. This technique has been applied to one-dimensional molecular weight separations and preliminary work on two-dimensional electrophoretic gels is currently in progress. These studies should be of interest to research laboratories that are measuring levels of phosphoproteins in brain metabolism and in hormonal regulation.

Due to its high sensitivity, silver stain continues to gain popularity as a general protein stain despite its mysterious and troublesome nature. The mechanism of this stain is being probed in several ways in an effort to establish staining conditions on a more scientific basis than the current empirical approach. Neutron activation analysis has been used to compare the silver distribution in polyacrylamide gels that have been stained using both ammoniacal and non-ammoniacal silver stain procedures. These studies clearly indicate that silver is concentrated in the proteins bands in the ammoniacal stains but not necessarily in the non-ammoniacal gels. Negative images appear to arise from silver exclusion.

Preliminary studies have been carried out to determine the feasibility of studying some aspects of silver stain mechanisms on the molecular level using ${ }^{109} \mathrm{Ag}$ NMR. Despite literature reports of low sensitivity and extraordinarily long $\mathrm{T}_{1}$ values $(1000 \mathrm{~s})$ f or ${ }^{109} \mathrm{Ag}$, our measurements indicate that ammoniacal silver solutions have sufficiently small $T_{1}$ (8s) and high enough sensitivity to make continued studies feasible. Research is planned to determine the specific Ag binding sites on amino acids and polypeptides and the effect of $\mathrm{pH}$ and temperature on this binding.

Research on immobilized enzymes had been focused on following the stability of urease that was coupled by several different covalent binding techniques to sepharose supports. Some of the columns made with the bound enzymes on the supports are still fully active after four months storage.

We have started research in HPLC separation of proteins and peptides. Initial studies have been focused on the determination of monomer/dimer ratios in SRM 927a, Bovine Albumin Solution. We have also evaluated materials for three candidate SRMs: 1) creatinine, 2) cholesterol, and 3) bilirubin.

A series of new metal polymers were prepared and used for the study of the mechanism of separation of serum proteins by metal-chelate affinity mechanisms. Immobilized metal-ion affinity columns were prepared by chelating transition metal ions such as $\mathrm{Cu}$ (II), $\mathrm{Ni}$ (II), $\mathrm{Zn}$ (II), $\mathrm{Co}$ (II), and $\mathrm{Mn}$ (II) to iminodiacetate derivatives of styrene-divinylbenzene beads. This work is reported in Technical Report 17.

In collaboration with the Inorganic Analysis Division, the structure of poly(4-vinylpyridine) (PVP) and PVP-metal complexes has been examined by laser ionization mass spectrometry and by Raman spectroscopy. Two communications were prepared from this work. One has been accepted in Polymer Communications and the other has been submitted to the NBS Journal of Research. 
In our continuing efforts in "definitive" methodology, we have investigated the use of a silyl derivative of uric acid as a replacement for the previously used tetraethyl derivative. This less time-consuming procedure will provide another method for assessing the accuracy and precision of the IDMS work on serum uric acid.

This year a quality assurance program was established in our division to support clinical laboratories involved in the analysis of selected vitamins in human serum and plasma as part of the National Cancer Institutes Chemoprevention Program. In addition to the tasks involved in assuring measurement compatibility among laboratories performing vitamins in serum measurements, we began a research effort to improve some of the methodology. Work in our group has focused on the synthesis of isotoptically labeled vitamins $A$ and $C$. Guest worker J. Miller developed procedures for determining vitamin $C$ in natural samples by isotope dilution gas chromatography/mass spectrometry. That work is currently being refined to optimize the yield obtained in the extraction procedure.

A major effort in the NMR program has involved the development of an experimental method for two-dimensional, DEPT $\mathrm{CH}$ J-resolved ${ }^{13} \mathrm{C}$ NMR spectrum editing. This method facilitates the generation of separated, twodimensional $\mathrm{CH}, \mathrm{CH}_{2}$, and $\mathrm{CH}_{3}$ J-resolved ${ }^{13} \mathrm{C}$ NMR sub-spectra for complex molecules. The work has entalled substantial software development, as a result of which new Pascal programs have been written for construction of linear combinations of two-dimensional, rat data matrices and Fourier-transformed data matrices, and also for simulation of the NMR spectra of oligomers containing two of four components by co-addition of the theoretical spectra of the monomeric components. Other research efforts directed toward chemical synthesis of bilirubin glucuronide (needed for isotope dilution studies) have yielded and unexpected carbohydrate intermediate. The structure and conformation of this new intermediate (a glucuronate 1,2-cyclic carbonate) have been determined by a combination of proton and $13_{\mathrm{C}} \mathrm{NMR}$, including DEPT $13_{\mathrm{C}}$ multiplicity editing and two-dimensional, $\mathrm{CH}$ chemical shift correlation with proton decoupling in both dimensions.

NMR methods have also been used in analytical surveys of candidate materials for renewal of the cholesterol and creatinine SRMs, for analysis of walnut shell oils of interest to the National Park Service, and for monitoring incorporation of ${ }^{18} 0$ isotope into quinuclidone. This compound is needed for use in the development of an iostope dilution gas chromatography/mass spectrometry method for the determination of chemical warfare agent BZ and metabolic products in serum.

Our staff has grown this year with two new staff members joining the group. Margaret Kline brings experience from industry in separations of biomolecules, and Dr. Jesse Edwards brings experience in biochemistry and twodimensional electrophoresis which will help meet stated goals in several areas of research. Several guest workers have come to our group to add the ir enthusiasm and expertise; Paul Vetter from Rutgers University, Ken Keiler on his way to Stanford University, and Rita Choudry a protein biochemist from Texas A\&M University.

In FY86 we will increase efforts in the electrophoresis area, as well as in the separation techniques for selected proteins by HPLC and by metal-1on affinity chromatography. Future plans for NMR research include two- 
dimensional and polarization transfer studies of peptides and proteins, synthesis and $15_{\mathrm{N}}$ NMR studies of ${ }^{15} \mathrm{~N}$ labeled aminoglycosides (by a new postdoctoral research fellow), and installation of a new data system for the 400 $\mathrm{Hz}$ spectrometer, including an array processor and process controller module.

Dennis J. Reeder, Group Leader; Lyle A. Alexander, Rita R. Choudry, Alex Cohen, Bruce Coxon, Jesse Edwards, Alexander J. Fatiadi, Joyce F. Graf, Diane K. Hancock, Cindy L. Hsu, Ken Keiler, Margaret C. Kline, Millard Maienthal, Kristy L. Richie, Robert Schaffer, and Paul Vetter

\section{Electrochemistry Group: Overview}

A continuing need exists for the development of new approaches for trace organic and organometal analyses. Until recently, electrochemical techniques have not been widely used for such analyses because of their lack of resolution. The combination of chromatography with electrochemical detection and the advent of electrocatalysis at polymer-modified electrodes have provided new impetus for novel approaches for the analysis of organic compounds.

Our research efforts have continued to be focused on the study of organic and organometallic redox reactions using state-of-the-art electrochemical techniques: cyclic voltammetry, chronoamperometry, chronocoulometry, and rotating ring-disk electrochemistry; hybrid techniques, such as spectroelectrochemistry and liquid chromatography with electrochemical detection; the preparation and evaluation of chemically modified electrodes; and mathematical modeling of electrochemical processes in support of the Group research activities.

In the organic electrochemistry competence building program we have continued to make good progress toward our research objectives and have applied these results to NBS programmatic needs. In recent years, we have demonstrated the power and versatility of liquid chromatography with electrochemical detection (LCEC) for biochemical analyses. Most successful to date has been the development of novel electrochemical detectors for chromatographic analysis. Multiple electrode designs and various excitation waveforms have resulted in significant advances in selectivity and sensitivity. In addition, we have pioneered the use of reductive electrochemistry which has greatly extended the applicability of this method of detection. For example, a new method was developed for the determination of nitrated polycyclic aromatic hydrocarbons using gradient elution chromatography in combination with computer-controlled, potential-optimized, differential-pulse detection.

The most promising area of research in terms of both understanding fundamental processes at electrode surfaces and providing a novel class of chemical sensors is that of the chemical modification of metal, semiconductor, and carbon electrodes. Problems associated with polymer-film stability and loss of activity of the electrocatalytic redox centers are being overcome and highly selective and sensitive analytical devices are anticipated to be feasible soon.

Spectroelectrochemistry, in combination with cyclic voltammetry and double potential step chronocoulometry, has been effectively employed to study the electrochemical behavior of electron-withdrawing, dithiolene 
complexes of transition metals in acetonitrile. Correlations have been made between the formal potentials of the complexes and the structural character of the ligands.

In the area of LCEC, our plans call for continued research to enhance the sensitivity of this technique by the development of microarray electrodes to increase the signal-to-noise ratio and the use of chemically modified electrode detectors to provide increased analyte specificity. Unfortunately, demands from a major National Cancer Institute program have hampered the development of microarray detectors, but this obstacle was offset by an interesting study of the electrochemical behavior of two fat-soluble vitamins, retinol and $B$-carotene. At a glassy carbon electrode in aqueous media, the oxidation of both these compounds are mutli-step processes following the initial formation of unstable cation radicals. The oxidation of these compounds is being investigated chromatographically following the coulometric generation of the products. Knowledge of the electrochemical behavior will be employed to help optimize conditions for the electrochemical detection of these compounds in serum samples.

Until now, one of the major deterrents to the successful application of chemically modified electroanalytical sensors has been the instability of the polymer films used to attach electroactive or catalytic agents to the electrode surface. To increase stability without deleteriously affecting the immobilized catalyst, we have developed both thermal and photochemical crosslinking to provide enhanced bonding of the polymer film to the electrode. Crosslinking provides greater resistance to polymer dissolution and degradation in hostile matrices and solvents. Electrochemical characterization of these crosslinked films reveals facile charge transport across the membrane and permits the incorporation of large proportion amounts of metal-porphyrin catalyst.

The first important application of stabilized polymer-film electrodes has been the development of reference electrodes for non-aqueous electrochemistry. The absence of a convenient, broadly applicable reference redox system has long hindered research and the intercomparison of electromotive force (emf) data in nonaqueous solvents. Using the ferrocene/ferrocenium ion redox couple (recommended by the Electrochemistry Commission of the International Union of Pure and Applied Chemistry), we have developed a crosslinked, polyvinylferrocene-film electrode which exhibits excellent reference electrode potential in a variety of nonaqueous solvents. The stability of this electrode far exceeds any polymer reference electrode previously reported.

Substantial progress has been made in the development of a precise, mathematical model for the charge-transport through polymer-modified electrode. The accurate description of this phenomena will permit the prediction of the optimum parameters for electrode modification. In this past year's effort, the effect of the resistance/capacitance of the modifiedelectrode/solution interface has been added to the effect of charge migration in the electric field. For many possible values of resistance and capacitance, the current response to an applied potential step is dominated initially by the resistance/capacitance effect but later becomes dominated by the charge-migration effect. Experimental measurements of the current response of a polymer-modified electrode follow the model-predicted response quite well. 
The development of these chemically-modified electrodes will not be limited to inorganic metal-complex catalysts but, as a result of Biosensor Competence funding in FY86, will be extended to enzymatic and immunological reactions via immobilized enzymes and antibodies confined to the electrode surface. The use of sensitive marker compounds encapsulated in synthetic biomembranes (liposomes and vesicles) which rupture when contacted by specific analytes, e.g., antigens or other types of biocomponents, also are feasible using electrode modification procedures. It is expected that biotechnological approaches will become more widely used based on their high reaction specificity and which, when combined with the sensitivity of electrochemical methods, will lead to unique classes of analytical sensors.

Our permanent staff has remained stable and we have enjoyed the addition of several "temporary" scientists. On August 12th, however, R. A. Durst assumed the duties of Deputy Center Director and W. A. MacCrehan became Group Leader. Another graduate co-op student (R. M. Kannuck) and a guest scientist from Israel (Dr. E. Schonberger) have joined the group. In October, a NRC/NBS Postdoctoral Associate from the University of Maryland (D. Shea) will begin a research project concerned with trace metal complexation by natural ligands in seawater. To expand our research efforts into the area of bioanalytical sensors, both electrochemical and optical, we are currently recruiting a biochemist knowledgeable in the areas of enzymology, immunology, and biomembranes.

While most of the major pieces of equipment acquired in previous years are now operational and automation is proceeding on schedule, we are still in need of a versatile, rapid-scanning uv-visible spectrophotometer and, as part of our Biosensor program (and shared with the Bioanalytical Techniques Group), a phase-resolved, scanning subnanosecond spectrofluorometer. Additional LC and data acquisition equipment will also be needed to support the new postdoctoral research program.

Richard A. Durst; Group Leader; Elmo A. Blubaugh, Rosanne M. Kannuck, William A. MacCrehan, Gwendolyn S. Marbury, Emil Schonberger, and William T. Yap

\section{Gas Chromatography Group: Overview}

The Gas Chromatography Group conducts research in the areas of high resolution gas chromatography and computer automation to allow development of new techniques and maintain state-of-the-art competence, which are used to certify complex Standard Reference Materials (SRMs), meet other agency milestones, and disseminate technical information.

The group constantly produces large data bases of chromatographic analyses which must be statistically and mathematically manipulated and then presented in a clear and concise manner. To do these operations by hand, as we have done in the past, is inefficient, and sometimes statistical information is lost and both systematic and random errors can remain undetected in the process. For these reasons we have acquired computer hardware which is being used to build a state-of-the-art laboratory information system (LIMS). This equipment consists of two IBM 9000 data handling systems which serve to integrate the output signals of nine gas chromatographs, as well as act as one of the inputs to the LIMS system. Also purchased was a super microcomputer which operates on a UNIX system and acts as the LIMS controller. Additionally, we have obtained an IBM AT personal computer which, in 
addition to its main function as a component of the Divisions managerial AT network, will be utilized as a high resolution color terminal of the LIMS system. This system also will allow us to conduct applied research in the area of chromatographic LIMS applications and development. For detailed information on this subject see the Technical Report 8.

We would like to expand our range of analyzable compounds to include thermally labile compounds such as vitamins, non-chlorinated pesticides and high molecular weight compounds such as 7- to 10-ring polycyclic aromatic hydrocarbons (PAH). We have therefore embarked on a program to develop competence in the field of capillary column supercritical fluid chromatography (CSFC). This program has concentrated in two areas of development, first the modification of existing gas chromatographic instrumentation to run the CSFC experiment and second the development of a detector which will be compatible with the wide range of mobile phases we would like to use. A Varian 3700 GC has been successfully modified but is only capable of relatively unsophisticated measurements. We are optimistic that we will obtain support to procure a state-of-the-art instrument early in FY86. The detector development has produced a microwave cavity which is capable of sustaining a highly energetic helium plasma. The effluent of the CSFC will be introduced into this plasma to excite the eluted solutes; the resulting optical radiation will be monitored using a grating monochrometer. Initial results from this detector, using only gas chromatographic effluents, have been successful.

The research activities in the area of multidimensional gas chromatography are covered in Technical Report 3, and will not be discussed here. During the last year we participated in a cooperative program with the Center for Chemical Physics which involved the qualitative and quantitative determination of organo-chlorine species produced by the combustion of refuse derived fuels (RDF). Researchers within the GC group developed a comprehensive sampling and analytical procedure and have isolated and identified chlorophenols, chlorobenzenes, and polychlorinated biphenyls (PCBs) in fugitive emissions from the burning of RDF.

We have continued to refine our arson accellerant detection method, as described in last year's annual report, and are engaged in planning a joint study with the Bureau of Alcohol, Tobbacco, and Firearms in which we will field test the method under controlled conditions. This method is based upon the observation that hydrocarbon accelerants, used to start intentional fires, produce an inordinate amount of PAH. We can perform a PAH analysis on soot found deposited at a fire scene and the presence of a relatively high level of PAH in that soot should be indicative of the presence of a hydrocarbon liquid at the scene prior to the fire. During the past year, we have modified the method to add a dimethyl formamide partition procedure to remove almost all nonpolar interferences.

In FY85 the GC group has participated in the certification of four Standard Reference Materials (SRMs) (see Technical Report 23), and has performed several service analyses including an analysis of the PCB content of transformer fluids taken from the White House. The group also has been very active in other agency programs. We have continued our work for the U.S. Environmental Protection Agency (EPA) Cincinnati laboratories, providing NBS traceability to their Performance Evaluation Samples. We also have entered into an agreement with EPA to prepare, package and provide benchmark values for three separate PCBs-on-sediment materials for use in their performance 
evaluation program. We are involved in a program for the EPA at Research Triangle Park, NC, to evaluate the stability of low molecular weight compounds stored in Tenax-filled columns. If these solvent molecules prove to stable in this storage configuration, then these Tenax columns can be used to trap gaseous components from a CRM cylinder (produced in The Gas and Particulate Science Division) and used as secondary standards for GC/MS calibration of EPA instrumentation. Pesticide and PCBs analyses of human liver tissue samples are continuing for the EPA/NBS Pilot Specimen Bank. Methods are being developed for the analysis of polycyclic aromatic hydrocarbons, pesticides and PCBS in marine sediments and tissues for a NOAA project.

The Gas Chromatography Group personnel has been increased by the addition of a part-time high school student, Mr. Steven Olson. Mr. Olson will be working mainly on our hierarchically configured computer system.

During the coming year, we will continue to work in the areas of multidimensional gas chromatography, capillary column supercritical fluid chromatography, and laboratory information management systems. In particular, we will apply our multidimensional model to a real world separation problem, the dual column chromatographic behavior of nitrogen heterocycles extracted from a shale oil matrix (SRM 1580). If this application is successful we will be able to better determine the composition of this SRM, which should lead to the certification of additional compounds. We plan to investigate the effect of the mobile phase in CSFC on elution behavior of various model compounds to elucidate the mechanism of separation. Once our LIMS system is fully operational we will begin the development of an integrated software package, which will be downloaded to other systems within our division. Other areas of interest include picogram-per-gram analyses (chlorinated dioxins and furans), supercritical fluid extraction of matrixed solutes, and the development of an automated on-column injection system.

Stephen N. Chesler, Group Leader; Delmo P. Enagonio, Franklin R. Guenther, Howard T. Mayfield, Michelle M. Miller, Steven Olson, Reenie M. Parris, and Richard F. Rebbert.

\section{Liquid Chromatography Group: Overview}

The activities of the Liquid Chromatography Group are directed towards (1) gaining a better understanding of the mechanisms of retention and selectivity in LC, and (2) applying this information to the development of methods for the isolation, separation, identification, and quantification of individual compounds in simple and complex mixtures.

Research in the understanding of retention mechanisms has focused on the influence of both the stationary phase and the mobile phase on the retention process. Previous work in our laboratory has indicated that polymeric $\mathrm{C}_{18}$ phases have significantly different retention and selectivity characteristics when compared to the more conventional monomeric $C_{18}$ phases. These selectivity differences are particularly evident when planar and nonplanar or linear and nonlinear solutes are compared on the two phases. A series of planar/nonplanar and linear/nonlinear solute pairs were compared on a monomeric phase and three polymeric phases with varying surface coverage. The selectivity factors (i.e., relative retention) for the solute pairs were small for the monomeric phase and increased significantly on the polymeric phases, with further increases as the surface coverage of the polymeric 
phases increased. The observed influence of solute shape and planarity on retention and selectivity has been explained in terms of a schematic representation of the bonded phase referred to as the "slot model". This work was recently reported in Journal of High Resolution Chromatography and Chromatography Communications $(8: 248,1985)$.

Further investigations of the influence of the stationary phase on selectivity have been directed towards the physical characterization of these bonded phases to determine which properties are responsible for the unusual properties of polymeric $C_{18}$ phases as compared to the more conventional monomeric $\mathrm{C}_{18}$ phases. Traditional methods of characterization, such as elemental analysis for the determination of percent carbon and gas adsorption methods for the determination of surface areas, have been employed on a variety of bonded phases. Surface areas for the bonded phases were observed to decrease as carbon loading increased regardless of the phase type or alkyl chain length. The application of small angle neutron scattering (SANS) for the characterization of silica substrates and bonded phase substrates is under investigation. SANS has considerable potential for the characterization of chromatographic substrates since this technique can probe structural details in the range of 1-100 nm. Of particular interest was the use of SANS to determine if any of the silica pores were closed or inaccessible using a procedure known as contrast variation. The results of these SANS studies, which were conducted in conjunction with C. J. Glinka of the Center for Materials Science, were published in the September 1985 issue of Analytical Chemistry and are summarized in Technical Report 1. Based on our initial experiments with bonded phases, SANS offers considerable potential for the investigation of alkyl bonded phase morphology, e.g., information on pore blockage and perhaps phase thickness may be obtainable. SANS experiments are currently in progress in this area.

The role of the mobile phase in LC selectivity has been studied by Dr. Joe P. Foley, an NBS/NRC Postdoctoral Fellow who recently completed his two-year stay at NBS, and accepted a faculty position at Louisiana State University. Dr. Foley investigated the optimization of selectivity in isocratic reversed-phase LC via control of secondary chemical equilibrium (SCE). New equations were developed to predict the optimum conditions $(e \cdot 8 \cdot, \mathrm{pH})$. The new equations were verified with several test systems and the factors which influence the self-selectivity, a fundamental parameter in SCE-LC theory, were identified. The details of these studies are described in Technical Report 2.

In the area of supercritical fluid chromatography (SFC), we have developed a novel multidimensional chromatographic procedure using supercritical carbon dioxide as the mobile phase on conventional LC columns. In the past we have used extensively an off-line multidimensional LC procedure for the determination of polycyclic aromatic hydrocarbons (PAH) in complex mixtures (i.e., normal-phase LC on an amino phase followed by reversed-phase LC on an octadecylsilane phase). However, because of the use of incompatible solvents in the normal-phase and reversed-phase LC steps, it was difficult to implement an on-line procedure. This problem was overcome by using supercritical carbon dioxide as the mobile phase which provides similar retention and selectivity characteristics on both the amino phase and the $\mathrm{C}_{18}$ phase as $1 \mathrm{n}$ the conventional LC procedure. This application of SFC is described in Technical Report 4, and will be published in an upcoming issue of the Journal of High Resolution Chromatography and Chromatography Communications. 
In the past year, the LC group has been heavily involved in LC methods development and analyses in support of the National Cancer Institute (NCI) Chemoprevention program. LC methods have been developed for the measurement of selected fat-soluble vitamins (retinol, alpha-tocopherol, and betacarotene) and ascorbic acid in calibration solutions and in human serum. A method for stabilizing the ascorbic acid in solution and in serum using dithiothreitol has been studied. In addition, LC has been used extensively for the determination of the purity of the commercial vitamin standards. Semi-preparative-scale LC was also used to isolate and purify vitamin A (all trans-retinol) in order to determine accurate UV extinction coefficients for use in quantification. More details concerning the NCI program are included in Technical Report 20.

Two environmentally significant SRMs were certified during the past year using LC as one of the analytical techniques, SRM 1650 "Diesel Particulate Matter" and SRM 1587 "Nitrated Polycyclic Aromatic Hydrocarbons in Methanol". For the diesel particulate sample, 12 polycyclic aromatic hydrocarbons (PAH) and four nitro-PAH were quantified using a multidimensional LC procedure with fluorescence detection. The nitro-PAH, which do not exhibit fluorescence, were converted, on-line, to fluorescent amines prior to detection. SRM 1587 is a mixture of seven mono-nitrated polycyclic aromatic hydrocarbons in methanol. Reversed-phase LC was one of the techniques used to determine the seven nitro-PAH compounds in this SRM (see Technical Report 22). A third SRM, "Cholesterol in Coconut Oil", is currently in preparation. This material will consist of a coconut oil matrix to which cholesterol and selected vitamins have been added (e.g., retinol acetate, tocopherol acetate and vitamin $\mathrm{D}_{2}$ ). This material will be certified for the content of the added cholesterol and vitamins and for the natural content of alpha-tocopherol. LC procedures will be used to measure the vitamins in this matrix.

Two guest scientists have worked in the LC group during the past year. Dr. Azza Aziz Moustafa, from the Cairo University in Egypt and sponsored by an AMIDEAST Peace Fellowship, has been involved in the measurement of vitamins in the coconut oil SRM. Mr. Hui-Cong Liu from the People's Republic of China participated in several of the LC projects involving the measurement of environmental pollutants.

In the coming year, research in the area of LC retention mechanisms will continue to focus on the characterization of chromatographic phases, with particular emphasis on polymeric alkyl phases, using both physical and chromatographic methods for this characterization. For the physical characterization of the bonded phase, the use of SANS will be a major area of research. We will be funded next year by the office of Standard Reference Materials to investigate the feasibility of developing an SRM for the chromatographic characterization of LC columns (i.e., bonded phases). This SRM would consist of one or more test mixture solutions to characterize various column properties such as carbon loading, selectivity, phase type, residual silanols, efficiency, etc. Work will also continue on the influence of PAH structural features on retention and selectivity. 
In the area of SFC research, the LC group, in conjunction with the GC group will continue to develop competence in the understanding and the analytical use of this technique. Using a Hewlett Package HPLC unit that has been upgraded to include SFC capabilities, we intend to investigate the feasibility of utilizing this technique for solvent-free purification of some of the vitamins in the NCI project to overcone the photosensitivity problems encountered in conventional procedures. Our basic research efforts in understanding SFC mechanisms will be expanded with the addition to the LC Group of a graduate co-op student (A. M. Natoli, Georgetown University) who will compare the retention mechanisms in reversed-phase LC and SFC through the combination of thermodynamic and chromatographic measurements on appropriately selected systems. The dependence of retention on mobile phase density in SFC and the similarity between variations in SFC mobile phase density and LC mobile phase composition will be examined.

Development of methods and analyses in support of SRM work (e.g., PAH in acetonitrile (renewal), $\mathrm{PAH}$ in coal tar, vitamins in solution, drugs of abuse in urine, and dinitro-PAH in solution) and other agency programs (NCI, EPA, DoE, and DoD) will continue.

Stephen A. Wise, Group Leader; Bruce A. Benner, Jeanice Brown-Thomas, Richard G Christensen, Joe P. Foley, Walter F. Kline, H. C. Liu, Sam A. Margolis, Azza A. Moustafa, and Lane C. Sander

\section{Mass Spectrometry Group: Overview}

The mass spectrometry group has conducted research in a number of areas involving both basic and applied research. Efforts are continuing in the development of mass spectrometric methods for the accurate quantitation of Individual organic compounds in complex matrices and in the laser induced photodissociation of ions as part of the mass spectrometry competence building program, "Analysis of Ionization Mechanisms and Ion Structures".

Quantitative measurements made in the mass spectrometry group in the last year have been used in the certification of several SRMs including: SRM 1586 (Priority Pollutants in Methanol), SRM 1614 (Dioxin in Isooctane), SRM 1650 (Diesel Particulate Matter), and SRM 909 (Human Serum). The preparation and certification of SRM 1614 is described in Technical Report 21. Measurements of polycyclic aromatic hydrocarbons (PAH) were also made on a series of Canadian marine sediments. These results are being used in combination with results from several other laboratories for the certification of the concentrations of PAH in the materials by the Marine Analytical Chemistry Standards Program of the National Research Council of Canada. The NBS participation in this program is described in Technical Report 24.

Two methods for the calibration of GC/MS instrumentation used for the analysis of volatile organic compounds have been compared using GC/MS systems at NBS and EPA/RTP. A cryogenic trapping apparatus developed at NBS was evaluated on the system at EPA/RTP which is routinely calibrated using static dilution bottles. While the trap produced the same values at both locations, using calibration curves for analytes in gravimetrically prepared cylinders a systematic bias was found between the standard gas cylinders and the static dilution bottles. Further measurements are planned to resolve the discrepancy. This work is described in Technical Report 10. 
The use of isotope dilution definitive methods for the quantitative determination of constituents in human serum has continued in collaboration with the Bioanalytical Techniques Group. The glucose level in serum SRM 909 has been observed to decline with time and therefore the concentration has been remeasured and a new certified value assigned. After delays caused by a great diversity of opinion in the clinical community about exactly what constituted "triglycerides", work is again in progress on the development of an ID/MS method for triglycerides. The necessary measurements include triglycerides, a sum of di- and mono-glycerides, and free glycerol. The results of definitive method measurements and clinical chemistry laboratory measurements of four organic analytes in sera used by the College of American Pathologists in their proficiency testing program have been compared. The results are summarized in Technical Report 11, and will appear in Archives of Pathology and Laboratory Medicine.

Investigations into the laser induced photodissociation of ions, which are part of a competence building program in mass spectrometry, have continued and been extended. The photodissociation of both positive and negative ions generated by cesium ion bombardment has been observed. The technique appears to have considerable potential for the determination of the structures of large molecules, particularly those of biological origin. The results are presented in Technical Report 9.

In the year ahead we plan to continue work on the projects with which the group is presently involved. Specific efforts will include: the development of methods for the analysis of polar compounds in air particulates and diesel particulates; the extension to more volatile constituents of the cryogenic trapping method; the development of a method for triglycerides and a new method for uric acid, followed by use of these methods to certify values for these analytes in serum; and, as part of the mass spectrometry competence building program, modifications to permit use of the data system for acquisition of data from photodissociation experiments, extension of the mass range for which photodissociation is observable, and increasing the extent of photodissociation achieved. A project for the Department of the Army, begun in March 1985, and intended to provide an analytical method for the detection of 3-quinuclidinyl benzilate (BZ) and its metabolities in urine for the purpose of monitoring workers during the decommissioning of chemical weapons, will be completed.

We have been fortunate to have with us $\mathrm{Dr}$. Kwokei $\mathrm{Ng}$ as the Roger $\mathrm{K}$. Gilbert/College of American Pathologists Fellow. Dr. Ng has left to join private industry. We are also pleased to have had with us in the group, Professor James M. Miller of Drew University, Nydia Rodriguez, a student at the University of Puerto Rico, Dr. Timothy Wozniak, an NRC Postdoctoral Research Associate now with private industry, Mrs. H. X. Gu who contributed greatly to several of our projects, and Mr. Y Gao of the People's Republic of China. Dr. Polly Ellerbe has joined us as the new College of American Pathologists Fellow.

Edward White V, Group Leader; Gary D. Byrd, Polly Ellerbe, Laurence R. Hilpert, Stanley Meiselman, Larry R. Phillips, Lorna T. Sniegoski, and Michael J. Welch 
B. Selected Technical Reports

(Organic Analytical Research Division)

1. Investigations of Substrate Morphology in Chromatographic Sorbents by Small-Angle Neutron Scattering

L. C. Sander, S. A. Wise, and C. J. Glinka

The careful measurement of physical and chemical properties of chromatographic sorbents in liquid chromatography is fundamental to the study of solute retention. A better understanding of retention mechanisms may permit the optimization of separations and the preparation of new types of sorbent materials. As part of our continuing research into the properties of chromatographic sorbents, the Liquid Chromatography Group has utilized smallangle neutron scattering (SANS) to assess structural characteristics of silica microparticles. Small-angle neutron scattering can be used to probe details within the size range of 1-100 nm. Since most chromatographic substrates have pore diameters within the range of 6-30 nm, SANS is well suited to the study of these materials. Three properties can be assessed using SANS: pore size, surface area, and pore accessibility.

Small-angle neutron scattering measurements on narrow and wide pore silica substrates were carried out on the SANS spectrometer at the NBS research reactor. Surface area measurements were also performed using a nitrogen adsorption technique similar to the classical BET measurement. The results of the measurements on three representative substrates are presented here: Zorbax 60 silica, Partisil silica, and Vydac TP silica (see Table 1).

Table 1. Comparison of SANS and BET Results

\begin{tabular}{ccrcc}
\hline & Area $\begin{array}{c}\text { (SANS) } \\
\mathrm{m}^{2} / \mathrm{g}\end{array}$ & $\begin{array}{c}\text { Area }_{\left(\mathrm{N}_{2}\right)} / \mathrm{g} \\
\mathrm{m}^{2}\end{array}$ & $\begin{array}{c}\text { Cord Length } \\
\mathrm{nm}\end{array}$ & $\begin{array}{c}\text { Pore } \\
\text { Diameter, nm }\end{array}$ \\
\hline Zorbax 60 & $375 \pm 50$ & $430 \pm 5$ & 4.6 & 6 \\
Partisil & $450 \pm 60$ & $430 \pm 5$ & 3.7 & 8.5 \\
Vydac TP & $60 \pm 10$ & $80 \pm 10$ & 30 & 33 \\
\hline
\end{tabular}

Good agreement exists between area values obtained by SANS and by nitrogen adsorption. The mean cord length listed in Table 1 is a measure of the average dimensions of the silica skeleton and does not directly correspond to pore diameter. Even so, we have found a high degree of correlation between these mean cord length values and pore dimensions provided by the manufacturer.

Pore accessibility in silica substrates was determined by using a SANS technique referred to as density matching. The pores of the sample are filled using a liquid that has the same index of refraction (for neutron scattering) as bulk silica. The reduction in scattering intensity that results is directly proportional to the fraction of filled pores. For the three silicas listed in Table 1, essentially no scattering was observed in the presence of a matching solvent $\left(\mathrm{H}_{2} \mathrm{O} / \mathrm{D}_{2} \mathrm{O}\right.$ mixture). Thus, essentially all of the pore volume $(>99 \%)$ was found to be accessible to the $\mathrm{H}_{2} \mathrm{O} / \mathrm{D}_{2} \mathrm{O}$ mixture. 
The density matching technique was further applied to the study of three alkyl bonded phase substrates. Monomeric alkyl phases $\left(C_{4}, C_{8}, C_{18}\right)$ were prepared on Zorbax 60 silica by reaction with dimethylalklychlorosilane. Scattering patterns were collected for the bonded substrates in the presence of a mixture of methanol and deuterated methanol, prepared to match the silica portion of the sorbent. Scattering was reduced but not eliminated in each case. Since no scattering was observed for the unbonded Zorbax control sample, scattering for the bonded phase sorbents must be attributed to the bonded phase itself. It is hoped that detailed analysis of the scattering patterns will lead to a direct evaluation of the thickness of the bonded monomeric layer.

2. Investigation of Secondary Chemical Equilibria in Liquid Chromatography: Verification of Optimization Theory for Acid-Base Equilibria and Identification of Factors which Influence Self-Selectivity

J. P. Foley and W. E. May

The purpose of this study was twofold: to verify our theory for the optimization of secondary chemical equilibria in liquid chromatography (SCELC); and to identify which factors influence "self-selectivity", a fundamental parameter in the SCE-LC optimization theory.

The SCE-LC theory which we have derived is summarized in the equations below: $\mathrm{AX}$ and $\mathrm{A}$ represent the associated and dissociated forms of a given analyte; $X$ represents the equilibrant in the mobile phase; $K$ is an equilibrium constant; $\mathrm{k}^{\prime} \mathrm{AX}$ and $\mathrm{k}_{\mathrm{A}}{ }_{\mathrm{A}}$ are limiting capacity factors; and $\mathrm{F}_{\mathrm{AX}}$ and $\mathrm{F}_{\mathrm{A}}$ are stoichiometric fractions. For the separation of a pair of compounds, the optimum concentration of equilibrant in the mobile phase may be calculated from either the linear or quadratic optimization equations. The linear equation is a simple approximation, accurate whenever the self-selectivity -- the ratio of limiting capacity factors, $\mathrm{k}^{\prime} \mathrm{AX}^{/ \mathrm{k}^{\prime}} \mathrm{A}^{--}$is similar for a pair of compounds. The quadratic equation is more general and is applicable under all conditions. The parameters, $A, B$, and $C$ in the quadratic equation are functions of the limiting capacity factors and equilibrium constants of the analytes.

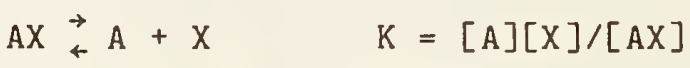

$$
\begin{aligned}
& k^{\prime}=F_{A X} k^{\prime}{ }_{A X}+F_{A^{\prime}{ }_{A}^{\prime}} \\
& \mathrm{pX}_{\mathrm{OPT}}=\mathrm{pK}_{\mathrm{AVG}}+1 / 2 \mathrm{LOG}\left(\mathrm{k}_{\mathrm{AX}} / \mathrm{k}_{\mathrm{A}}{ }_{\mathrm{A}}\right) \\
& A[X]^{2}{ }_{O P T}+B[X]_{O P T}+C=0
\end{aligned}
$$

secondary equilibrium

retention model

linear optimization equation

quadratic optimization equation

The retention model upon which the optimization equations are based was verified experimentally using various combinations of solutes, mobile and stationary phases. The behavior of amino acids, dinitrophenols, and substituted benzoic acids were evaluated using acetate or formate buffered organic solutions with conventional reversed-phase columns. The behavior of methylated phenols was evaluated using bicarbonate-carbonate buffered organic solutions with poly(styrene-divinylbenzene) columns. 
More important than the verification of the retention model was the direct verification of the optimization equations using several pairs of compounds. Shown in Table 1 are results for two pairs of compounds, 3-chloro and 4-chlorobenzoic acid and 2,6-dinitro and 2,4-dinitrophenol. As seen from Table 1, the agreement between theory and experiment is excellent.

Because the self-selectivity $\left(k^{\prime} A X^{/ K^{\prime}}{ }_{A}\right)$ determines the mobile phase composition for maximum resolution of two solutes, the effects of several experimental parameters on $\mathrm{K}^{\prime} \mathrm{AX}^{\prime} \mathrm{K}^{\prime} \mathrm{A}$ were investigated. These parameters are listed below in order of decreasing significance:

1. nature of stationary phase

2. identity of the acid-base buffer

3. alkyl chain length of the stationary phase

4. identity and amount of organic solvent in the mobile phase

5. temperature.

Only the nature of the stationary phase and the identity of the acidbase buffer had significant affect on the self-selectivity. Variations of as much as two orders of magnitude were observed by varying reversed-phase packings. Changes of up to a factor of 3 were observed due to differences in acid-base buffer systems. Variations of the remaining parameters resulted in self-selectivity changes of less than 10 percent.

Table 1. Direct Verification of the SCE-LC Optimization Equations

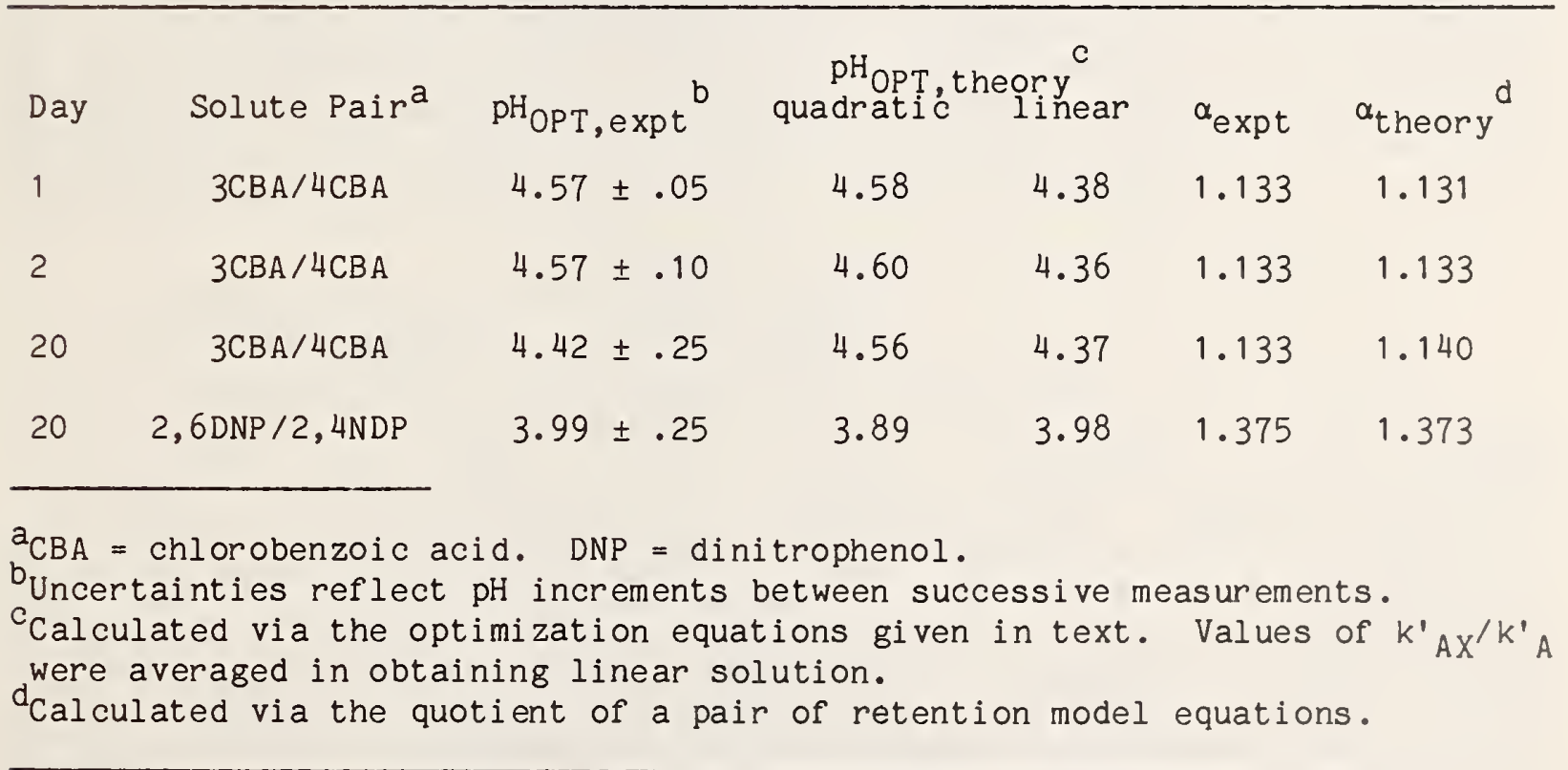

3. Optimization of Selectivity Using Sequentially Coupled Capillary Gas Chromatographic Columns

H. T. Mayfield and S. N. Chesler

In this project we have sought to develop the means for predicting conditions for optimized selectivity for systems of sequentially coupled CC capillary columns. The systems considered consisted of two or more columns 
coupled sequentially and mounted in separate ovens so that the individual column temperatures can be independently controlled. Such systems offer the potential for separating mixtures which cannot be separated on single columns coated with single component phases. These systems also offer greater flexibility for selectivity optimization than do systems made up of single columns coated with mixed phases. The retention behavior in a sequentially coupled column is a combination of the retention behaviors for the individual columns of the system. This can be described by a parameter of the system called the effective capacity factor, $k_{e f f}$. The effective capacity factor is defined in equation 1, and its calculation is analogous to that of the capacity factor of an analyte on a single column where $t_{m s}$ is the retention time of solute and $t_{m}$ is the gas holdup time.

$$
k_{\text {eff }}=\left(t_{m s}-t_{m}\right) / t_{m}
$$

The effective capacity factor can be related to the capacity factors of the individual columns of the systems through

$$
k_{\text {eff }}=\Sigma\left(P_{i} k_{i}\right)
$$

where $P_{i}$ is the fractional carrier gas holdup time for the $i$-th column in the system, and $k_{i}$ is the capacity factor of an analyte on column $i$. The capacity factor of a compound on a single column is a function of temperature which can easily be determined experimentally. The carrier gas holdup time for each column, and hence $P_{i}$, is dependent upon column length and cross section, operating pressures and temperatures, and is difficult to determine experimentally. Several methods of calculating $t_{m i}$, or $P_{i}$, have been investigated with promising results. These make it possible to calculate keff for a compound given its $k_{i}$ values and the set of operating parameters for the system. The selectivity for a sequentially coupled column system is analogous to that of the individual columns, such that between any pair of compounds, designated by subscripts, $i$ and $j$, the selectivity $s_{i j}$ is given by

$$
s_{i j}=\operatorname{MAX}\left(k_{i}, k_{j}\right) / \operatorname{MIN}\left(k_{i}, k_{j}\right)
$$

For a sequentially coupled column system, keff values are used instead of $k$ values. For a given mixture of compounds, the lowest possible value of $s_{i j}$ describes the separation between the two compounds in the mixture which separate least. The term $s_{\min }$ will be used to denote the lowest value of selectivity between compounds of a mixture. Low values of $s_{\text {min }}$ near 1.0 , indicate conditions where at least two of the components of the mixture are poorly separated. High values of $\mathrm{s}_{\mathrm{min}}$ indicate conditions where all compounds of the mixture are well separated. In order to optimize selectivity for a mixture of compounds, their capacity factors are measured on the individual columns, at several temperatures. The capacity factors are then expressed as functions of temperature for each compound. A computer program is then used to calculate $k_{\text {eff }}$ values for the compounds for all temperature combinations possible within certain limits. The limits are set to bracket reasonable values of temperatures, based on the working ranges of the individual columns. The largest value of $\mathrm{s}_{\mathrm{min}}$ encountered in the designated temperature ranges is reported, along with the temperatures of the two columns from which it results. Also, a response surface of $s_{\text {min }}$ versus temperature of columns 1 and 2 can be displayed on a graphics terminal or plotted. From these results, optimal operating temperatures for the columns of the combined system can be chosen. 
4. On-Line Two-Dimensional Chromatography Using Supercritical Carbon

Dioxide as a Mobile Phase

R. G. Christensen

Two properties of supercritical carbon dioxide which differ from the properties of ordinary liquid chromatographic (LC) mobile phases have been used to effect a two-dimensional chromatographic separation. The first unusual property is that supercritical $\mathrm{CO}_{2}$ provides separations on aminebonded columns similar to the normal-phase LC separations obtained on these columns with hexane, and separations on octadecyl-bonded columns similar to reversed-phase separations obtained with aqueous/organic solvents. The second property which differs from that of other solvents is that its solvating power can be varied in different parts of the stream by changing the pressure or temperature to alter the density.

To achieve a two-dimensional supercritical fluid chromatographic separation using the columns mentioned above, we connected the two columns in series, with provision for switching either column in or out of the stream, and with a restriction between them. A sample of aromatic hydrocarbons extracted from coal tar was injected onto the amine column and was separated according to increasing number of aromatic carbon atoms. When a desired fraction was about to elute, the octadecyl-bonded column was switched into the mobile phase stream. The pressure drop across the restrictor lowered the pressure, and hence the density, to a point where the eluting fraction was retalned on the octadecyl-bonded column. The amine-bonded column was then switched out of the stream, and the components of the trapped fraction were eluted by lowering the temperature, thus increasing the density. Baseline resolution of many of the compounds containing 16-to-18 aromatic carbon atoms was attained from single injections of this complex mixture. Analysis time is 10-to-20 minutes, compared with several hours required for the off-line separations with conventional solvents. If routine analyses of this type were required, it would be easy to automate the operation using valves controlled by the existing microprocessor in the instrument.

\section{Development of a Supercritical Extraction Procedure for the Removal of} Trace Organic Species from Solid Samples

S. N. Chesler, R. G. Christensen, and M. M. Miller

Prior to this study, analysts at NBS could only rely upon solvent extraction as the sole method for removing organic analytes from solid matrices in which they were bound. It is well known that supercritical fluids have high solubilization powers. For that reason, a supercritical fluid extraction should be as effective as continuous solvent extraction in removing matrix-bound compounds. We, therefore, modified an existing packed column supercritical fluid chromatograph so that it could be used to extract polychlorinated biphenyls(PCBs) from a sediment sample. A stainless steel extraction column $25 \mathrm{~cm}$ in length and $0.63 \mathrm{~cm}(1 / 4 \mathrm{inch}) 0 . d$. was packed with approximately 6 grams of sediment. The inlet of the extraction column was then connected to the $\mathrm{CO}_{2}$ outlet of the chromatograph, and the outlet of the column was attached to a $66 \mathrm{~cm}$ section of $60 \mu \mathrm{m} 1 . d$. fused s111ca cap1llary by use of a low dead volume reducing union. The end of the caplllary was connected to a solute trap constructed from a $5 \mathrm{~cm}$ section of $0.63 \mathrm{~cm}(1 / 4$ inch) o.d. stainless steel tubing filled with C-18 liquid chromatographic 
packing material held in place by frits. The capillary acted as a pneumatic resistor and provided essentially all the pressure drop for the flow system, such that the $\mathrm{CO}_{2}$ is maintained in the fluid phase in the extraction column and in the gas phase in the trapping column. The extraction column and most of the fused silica capillary were maintained at $40^{\circ} \mathrm{C}$ inside the chromatographic oven while the trapping column was located outside of the oven and was maintained at room temperature. A flow of $1 \mathrm{~mL}$ of supercritical $\mathrm{CO}_{2}$ per minute was pumped through this extraction apparatus for approximately 4 hours at an inlet pressure of $33.8 \mathrm{MP}$. After this extraction period, the trapping column was disconnected from the extraction apparatus and connected to an HPLC pump which was used to elute the solutes from the trap with methylene chloride. The trap was eluted with $40 \mathrm{~mL}$ of solvent, which was then evaporatively concentrated prior to analysis.

To compare relative extraction efficiencies, samples of the PCB containing sediment was subjected to a 12 hour Soxhlet extraction as well as the supercritical fluid extraction. Two internal standards, PCB \#10 and 非198, were added to the extracts after extraction to measure the absolute amount of solute PCB removed. The amounts extracted for each of the two methods are presented in the Table below:

Concentration ( $\mathrm{ppm}$ ) of Arochlor 1254 in Sediment

\begin{tabular}{ccc}
\hline Extraction & Soxhlet & SFC \\
\hline 1 & $6.61 \pm 0.21$ & $6.84 \pm 0.18$ \\
2 & $6.71 \pm 0.16$ & $6.61 \pm 0.19$ \\
\hline
\end{tabular}

As can be seen from the table, the results from the 4 hour SFC extraction were comparable to the 24 hour Soxhlet extraction. During the SCF extraction a second trapping column was connected in tandem with the primary column to test for solute breakthrough. Analysis of this second column showed there was no breakthrough from the first C-18 column.

\section{Development of a Method for the Stabilization of Ascorbic Acid in Solution and in Human Serum}

\section{S. A. Margolis}

The development of a method for the stabilization of ascorbic acid was a threefold process: stabilization during HPLC analysis, stabilization of solutions of the analyte alone, and stabilization of ascorbic acid in a serum matrix. The ascorbic acid was stabilized during chromatography by using argon sparged solvents. Under these conditions the coefficients of variation for the HPLC analyses of solutions of concentrations $4.04 \mu \mathrm{g} / \mathrm{mL}$ and 29.01 $\mu \mathrm{g} / \mathrm{mL}$ were $5.2 \%$ and $0.5 \%$, respectively $(n=10)$. We followed the stability of these solutions for 67 days. This study indicated that ascorbic acid in a solution of acetonitrile: water $(3: 1 \mathrm{v} / \mathrm{v})$, in the presence of the antioxidant dithiothreitol ( $1 \mathrm{mg} / \mathrm{mL}$ ) was stable for 67 days when it was stored at $-20{ }^{\circ} \mathrm{C}$ under argon in a sealed amber glass ampoule. Examination of these solutions after eight months of storage indicated that approximately $30 \%$ of 
the ascorblc acld had degraded. Additional studies will be performed to assess more accurately the ascorbic acid stability between the second and elghth months.

In serum, ascorbic acid degrades unless a stabilizer is added. Classically, metaphosphoric acid is added to serum to achieve this objective. However, this stabilizing agent precipitates serum proteins and renders impossible the aliquoting of serum samples for laboratory testing. This problem was circumvented by the addition of dithithreitol at a concentration of $1 \mathrm{mg} / \mathrm{mL}$. Lower concentrations of dithiothreitol were tested and found to incompletely protect the ascorbic acid. These results were confirmed by one of the laboratories participating in the NCI/NBS study and by the results of the first round robin study on serum, spiked with either 51 or $99 \mu g$ of ascorbic acid per $\mathrm{mL}$ of serum. These samples appear to be stable for at least 10 days. Longer-term stability studies on ascorbic acid in serum are in progress.

In the most recent study on serum obtained from a donor ingesting large doses of ascorbic acid, $13.6 \mu \mathrm{g}$ of ascorbic acid/mL was measured in the serum. These serum samples will also be studied for long-term stability of the ascorbic acid.

\section{Investigations of the Stability and Recovery of Toxic Organic Gases Adsorbed on Tenax}

F. R. Guenther and S. N. Chesler

Adsorption tubes, which contain Tenax as the trapping medium, are used by the U.S. Environmental Protection Agency (EPA) to collect remote ambient air samples for analysis of volatile organic carbon (VOC) content. The EPA laboratory analysis method calls for the thermal desorption of the Tenax traps directly into the inlet of a gas chromatograph-mass spectrometer (GC/MS). However, the stability of compounds stored on Tenax has not been fully established nor has the feasibility of using tubes dosed from SRM gas cylinders as secondary standards been determined. The objectives of this project are fivefold: 1) to measure the magnitude and reproducibility of Tenax blanks over a period of time; 2) to determine the best method of charging the traps, specifically using Certified Reference Material (CRM) gas cylinders which contain precisely known amounts of organic gases; 3) to ascertain the stability of volatile organic species on the charged traps over time; 4) to determine the efficacy of repetitive use of the traps; and 5) to evaluate two commercially available Tenax adsorbants, Tenax GC and Tenax TA.

A thermal desorber was constructed and installed on a Varian 3700 gas chromatograph (GC). The desorber was capable of heating $10 \mathrm{~cm} \times 0.9 \mathrm{~cm}$ Tenax-filled columns to $250^{\circ} \mathrm{C}$ within 30 seconds. The Tenax traps are connected to the injection port of the GC using a specially constructed fitting. The desorber unit is secured around the trap and a tube supplying a hellum carrier gas is then connected to the other end of the trap. A flow controller is used to maintain a minimum flow of $10 \mathrm{~mL}$ of helium gas/min through the trap and a pressure regulator is used to maintain any desired minimum system pressure. Prior to desorption, the head of the GC caplllary column is immersed in a liquid nitrogen bath to thermally trap and focus any desorbed solutes. The desorber is then ballistically heated to $250^{\circ} \mathrm{C}$ and desorption 
is allowed to proceed. When desorption is complete, the GC oven is heated to its operating temperature, which acts to evaporate the liquid nitrogen bath and allows the trapped solutes to move and separate along columns.

The apparatus used to remotely load the Tenax traps consists of a calibrated sample loop in a thermostated water bath and attached to an eight port gas sampling valve. The valve can alternately place the loop in series with a CRM gas cylinder or a Tenax trap. The sample loop is loaded with the gaseous solutes by continuously flushing. Since the gas in the CRM cylinder can be extremely high pressure ( $1800 \mathrm{psig})$, a stainless steel needle valve is used to drop the delivery pressure to a usable value. The valve is then switched and the gas in the sample loop is transferred to the Tenax trap by a $10 \mathrm{~mL} / \mathrm{min}$ flow of helium delivered from a flow controller attached to the valve. After the transfer is complete, the Tenax trap is removed and capped.

The eight solute molecules investigated in this study were benzene, toluene, carbon tetrachloride, chlorobenzene, bromobenzene, vinyl chloride, tetrachloroethylene, and chloroform. The measurement precision of the chromatographic system was found to be $1-2 \%$. This was determined by directly coupling the sample loop to the injection port, thereby passing the Tenax columns. The data obtained from the initial stability studies of VOC on Tenax demonstrated large irreproducibility $(10-100 \%)$; this problem has been traced to irregularities of the Tenax bed within the trap itself. The Tenax traps are thermally precleaning by heating the traps to $280{ }^{\circ} \mathrm{C}$ for 4 hours under a flow of an inert gas. This process seems to physically change the adsorption bed by 'clumping' the Tenax. The alteration of the Tenax bed is such that channels form allowing the gas being trapped to bypass most of the Tenax and escape. Studies will be undertaken to determine a better way to pack the Tenax within the columns to avoid the deterioration of the bed upon thermal stress.

At the time of this report, not all the data have been collected and analyzed. However, certain conclusions can be drawn from the available data. 1) There is no advantage in using either of the two commercially available Tenax adsorbants. After the recommended cleanup procedure, the blanks were the same and neither one performed superior to the other. 2) Tenax cartridges can be reproducibly charged using CRM cylinders $( \pm 5 \%)$. The rate is obtained by charging the cartridges and immediately desorbing them.

8. Design and Implementation of a Comprehensive Laboratory Information Management System to Acquire, Manipulate, and Archive Chromatographic Data Bases

F. R. Guenther, S. J. Olsen, and S. N. Chesler

The time of the simple gas chromatograph/recorder combination is way in the past. The modern chromatography laboratory is now equipped with microprocessor controlled chromatographs feeding into multi-processing microcomputers running chromatography sof tware that acquires up to four channels of raw data, analyzes and reports the results, and stores the raw signal on a high density storage medium. The modern laboratory may have many of these combinations within a group which may want to share data or use common programs to organize and analyze the data. Within the past two years, we have 
attempted to link all our laboratory computers together such that any chromatogram or chromatographic report produced in our lab can be processed and analyzed on a central computer.

At present, the system consists of two IBM 9000 laboratory computers and one Varian 401 integrator processing data from 10 gas chromatographic channels. Raw data and result files can be stored on floppy disk and hard disk media for future transfer to our host computer, a Cromemco 3000 system running Unix System $V$. The host is configured with 1 Mbyte of memory, 50 mbytes hard disk storage, 13 serial ports, 2 parallel ports, a fast floating point processor, and one 1.2 Mbyte floppy disk drive. At present, the computer can accommodate 5 users simultaneously. Software is available to receive and report raw data from the dedicated integrators and to prepare and analyze these data.

A comprehensive software package was written in the Pascal programming language and includes a graphics program to display, manipulate, and analyze the raw chromatographic data, and to prepare presentation quality graphics. Also, there are programs to search and extract data from result files for insertion into a spreadsheet program for further analysis. Commercially procured programs are also available for word processing, communications to remote computers (such as the NBS supercomputer) for access to statistical packages, and programming languages (Pascal, C, Basic) for special purpose programs.

During the next year, the network should be in place and fully functional. Plans include an inventory program for the Toxic Chemical Handling Facility with a remote terminal within the lab, increased memory so the additional load can be handled by the computer, a tape backup system to insure the safety of our data, and perhaps integration of the LC laboratory within the network.

9. Photodissociation of Ions Generated by Cesium Ion Bombardment for Determination of the Structures of Organic Molecules

M. J. Welch and E. White V

Techniques such as field desorption, fast atom bombardment, and cesium ion bombardment (CIB), are very useful for ionizing large and thermally labile molecules not amenable to electron impact ionization, but are soft ionization processes which generally produce little fragmentation. Photodissociation is a promising approach for obtaining increased fragmentation, and hence increased structural information, from ions generated by such techniques. Photodissociation has been extensively used in studies of the thermodynamics and kinetics of gaseous ions and molecules but, until recently, only relatively low molecular weight species ionized by electron impact have been studied.

We have investigated the use of photodissociation for obtaining structural information from ions, both positive and negative, generated by CIB. An argon ion laser is used to irradiate the first field-free region of a double-focusing mass spectrometer. Ions formed by dissociation of ions in this region are detected by the use of linked scans. To measure those dissociations which are photon induced, we utilize a mechanical chopper in the laser beam and phase-sensitive detection of the product ions with a lock-in 
amplifier. Maximum photodissociation occurs when the laser beam enters through the source so that it is colinear with the ion beam. For cesium ion bombardment, however, the sample target in its usual position blocks the laser beam. Modification of the source to allow for separate control of the two half-extraction plates permitted moving the target out of the laser beam without serious loss of sensitivity.

A variety of compounds were tested for photodissociation activity under irradiation by visible light. For both positive and negative ions, detectable activity was found to correlate with chromaphores in the ions. Thus for compounds such as methyl red, bisbenzimide, rhodamine B, and riboflavin, the photodissociation of positive ions gave signals sufficiently strong to permit the acquisition of a complete spectrum of daughter ions generated by photodissociation. For each of these compounds, the daughter ion spectrum generated by photodissociation was distinctly different from the non-irradiated daughter ion spectrum. A number of peptides and nucleosides were tested and no photodissociation activity was found, as might be expected considering the lack of chromaphores which absorb in the visible range in these types of compounds. For negative ions, photodissociation competes with electron detachment. The parent ion decreases in intensity with either. of these processes, but only with photodissociation are increased daugther ion levels found. For most negative ions tested, the decrease in parent ion was much greater than the production of daughter ions (relative to what is observed for positive ions), thus indicating that both photodissociation and electron detachment are occurring.

Our results demonstrate that ions generated by soft ionization techniques, such as cesium ion bombardment, can be photodissociated and that information useful for the determination of the structure of the molecule is obtained. We have also observed that, as expected, the photons must be within the energy range absorbed by the ions. For this technique to become a generally useful tool for structure determinations, significantly shorter wavelengths of light, capable of photodissociating a wider range of compounds are necessary. In addition, the photon-ion interaction and the detection of ions generated by photodissociation must be improved.

10. Comparison of Two Methods for the Calibration of Gas Chromatography/Mass Spectrometry Instrumentation Used for the Analysis of Volatile Organic Compounds

G. D. Byrd and E. White V

A gas chromatography/mass spectrometry (GC/MS) method based on cryogenic trapping was developed that permits a direct comparison of the concentration of trace components from two gas sources. In this method, the concentrations of selected analytes in an unknown gaseous sample are determined based on a calibration curve that is established using a reference gas. When used in conjunction with an SRM gas cylinder, traceability of measurements on the gaseous sample to the SRM is achieved. This method of using a calibration curve to determine analytes at unknown concentrations was successfully demonstrated on several samples at NBS and also at an EPA laboratory at Research Triangle Park, NC (EPA/RTP). Using the cryogenic trap on the GC/MS instrument at EPA/RTP afforded an opportunity to compare the amount delivered by our system (trap and cylinders of known concentration) with the amount measured using EPA/RTP's static dilution-bottle calibration of their instrument. 
The cryogenic trap consists of a coil of stainless steel tubing with provision for connection to a gas cylinder at one end and a needle at the other end for insertion into a GC injection port. The device also contains $i$ ts own heated injection port to allow for the addition of liquid samples to permit measurements by isotope dilution. When trapping gas samples, the coils of the trap are immersed in a cryogenic bath and the volume of gas passed through is measured with a wet test meter. The needle on the trap is then inserted into the $G C$ and the trap coils are resistively heated while flushing the trap with helium.

Experiments showed that the system provides a linear response between the amount trapped and the amount measured. A multicomponent aromatic mixture (benzene, chlorobenzene, and bromobenzene) was selected for the evaluation of the system. Well-characterized gases were selected as calibrants and used to establish a calibration curve by trapping different measured volumes from the cylinders. Volumes from cylinders of test gases containing between 10 and $200 \mathrm{ppb}$ of the analytes were then trapped and analyzed by GC/MS using selected ion monitoring. Good agreement was obtained between the measured and the prepared concentration values for all analytes. When the same analyses were repeated at EPA/RTP, no significant differences were found in the results. This agreement demonstrates the efficacy of the use of the cryogenic trap for precisely transferring gaseous mixtures to GC/MS systems. Measurements made on an SRM cylinder using isotope dilution GC/MS, in which the isotope diluent was added as a liquid, confirmed the accuracy of the measurements.

The data system on the EPA/RTP instrument was calibrated for certain compounds, including the ones used in the evaluation, using a rigorous calibration curve generated by analyzing gaseous mixtures from static dilution bottles. This permitted a direct comparison of the values measured by our calibration curve method and the values routinely generated by the EPA/RTP system. The results showed a bias in all cases with 11-to-35 percent more of the sample being delivered than detected by the EPA/RTP instrument, with agreement best for benzene and progressively worse for the less volatile chlorobenzene and bromobenzene. The source of this systematic bias is not known at this time and further measurements will be required to resolve this discrepancy. Research is also planned for evaluating the cryogenic trap on more volatile compounds using isotope dilution measurements.

11. Comparison of the College of American Pathologists Proficiency Testing Program Results and NBS Definitive Method Results for Four Organic Analytes in Serum

A. Cohen, R. Schaffer, L. T. Sniegoski, M. J. Welch, and E. White V

The College of American Pathologists (CAP) operates a large, voluntary proficiency testing program for clinical laboratories. They have long recognized the need for an accuracy base for evaluating participant results and have interacted with NBS for many years regarding such an accuracy base. Early collaboration involved several electrolytes, and for one in particular, calcium, definitive method results demonstrated the lack of accuracy in many of the commonly used procedures. In 1978, the CAP sponsored a Research Associate (later named the Roger K. Gilbert Fellowship) at NBS for work in 
the Organic Analytical Research Division on the development of definitive methods for organic constituents of serum. This position continues to this day, and the third fellow, Dr. Polly Ellerbe, has recently begun her duties.

Isotope dilution/mass spectrometric definitive methods have now been developed for five organic analytes in serum and all have been used to accurately determine analyte concentrations in selected CAP sera. Recently, a group under the direction of Dr. Alfred Hartmann of the McKennan Hospital, Sioux Falls, SD, has evaluated results from over 7000 clinical laboratories for glucose, cholesterol, urea, and uric acid in 1979, 1980, 1981, and 1983 CAP Survey Sera and compared them with NBS definitive values.

Overall agreement between the CAP mean values and NBS results was quite good. For glucose, the data (were subdivided) into 75 methods of five general types. Most of the methods exhibited a small positive bias versus the NBS results, with the largest relative bias at low glucose concentrations. The glucose oxidase methods which electrochemically measure oxygen consumption rates gave the best overall agreement. For cholesterol, the data were subdivided into 26 methods of two general types, Liebermann-Burchard and enzymatic. Both gave results in good agreement with the NBS values, but the former generally had a positive bias while the latter had a negative bias. For uric acid, the data were subdivided into 58 methods of four general types. The two less commonly used types of methods exhibited considerable bias, one high and one low. Both of the commonly used types gave good results overall, but some of the individual methods had large biases. For urea, the data were subdivided into 44 methods of seven types. Two of the less commonly used types showed significant bias versus the NBS results, while the others generally had a small positive bias.

This comparison demonstrates that the most commonly used clinical methods generally give reasonably accurate mean results. However, for all the analytes in this study, methods which have significant biases are currently being used in clinical laboratories. The results of this comparison study will appear in Archives of Pathology and Laboratory Medicine and should result in greater utilization of accurate methods by clinical laboratories.

\section{Stabilization of Polymer-Film Electrode Morphology by Thermal and} Photochemical Crosslinking

\section{E. A. Blubaugh}

Our interest in chemically modified electrodes (CME) is focused on the development of these modified surfaces for analytical sensors. However, one of the major deterrents to the successful application of modified electroanalytical sensors is the instability of the polymer films used to attach the catalytic agents to the electrode surface. To increase the stability without deleteriously affecting the immobilized electrocatalyst, we have investigated both thermal and photochemical crosslinking to provide enhanced bonding of the polymer film to the electrode and greater resistance to polymer degradation and dissolution in host1le matrices and solvents.

Thermal crosslinking was promoted by a free-radical initiator (benzene radical) which undergoes reaction with both the copolymer [poly-(vinylpyridine-styrene) 9:1] (PVP-costy) and the crosslinking agent (triallyltrimellitate). These reactions may involve deprotonation of the copolymer and 
triallyltrimellitate to form free radicals which then couple to generate crosslinked polymer macromolecules. We found that crosslinking agents with larger molecular radii gave more stable polymer-film electrodes (vs. the smaller molecular radii for the monomeric agents). Additional work involved using polymeric crosslinking agents (e.g., poly-trans-isoprene) produced equally stable polymer-film electrodes but requiring only about one-fifth the amount of crosslinking agent. The poly-trans-isoprene crosslinking agent at 2 wt \% was the best crosslinking agent of the 11 monomeric and polymeric agent tested.

The photochemical crosslinking procedure involves photo-excitation of a 3-ketocoumarin dye sensitizer. The coumarin dye sensitizer is used in conJunction with a cosensitizer, such as ethyl-p-dimethylaminobenzoate, which acts to initiate the crosslinking reaction. The photochemically crosslinked films gave analogous stability to the thermally crosslinked films with respect to the particular crosslinking agent.

Photoacoustic-ETIR spectroscopy has shown that the crosslinking agent is retained in the film and that all available crosslinking sites (carbon-carbon double bonds) have been utilized.

The electrochemical response of these electrodes has been encouraging. A large amount of metalloporphyrin (e.g., rhodium(III)tetraphenlyporphyrin chloride) has been successfully immobilized as evidenced by the large values of current passed $\left(-10 \mathrm{~mA} / \mathrm{cm}^{2}\right)$ in potential step experiments. The films retain their electroactivity for periods of up to 5 hours.

Work in progress involves combining these polymer films with different electroactive catalysts, choosing the optimum amount of crosslinking and film thickness for maximum stability and electrochemical response.

\section{Polyvinylferrocene-Modified Reference Electrode for Nonaqueous Electrochemistry}

R. M. Kannuck

The ability to measure meaningful electromotive force (emf) data of species in aprotic solvents has been hampered by the common practice of measuring these values versus aqueous reference electrodes or soluble redox couples. In the former case, an unknown and/or irreproducible liquid junction potential occurs at the aqueous/nonaqueous interface. Furthermore, the test solution is susceptible to contamination by foreign ions (such as $\mathrm{K}^{+}$or $\mathrm{Cl}^{-}$when employing a saturated calomel electrode) or water. Reference redox couples in solution are inconvenient to use and may interact with test species.

In an attempt to establish a basis for intercomparison of these types of measurements, the Electrochemistry Commission of the International Union of Pure and Applied Chemistry has recommended utllizing the ferrocene/ ferrocinium ion redox couple as one possible reference system. Extending the original work of Peerce and Bard [J. Electroanal. Chem. 108 (1980) 121-125], we used our thermal crosslinking procedure to increase the stability of polyvinylferrocene (PVE) in a variety of solvents. 
The polymer film is first electrodeposited in its oxidized form onto Pt disk electrodes. An aliquot of the crosslinking agent, triallyltrimellitate (TATM) is pipetted onto the polymer-film electrode surface and the solvent is allowed to evaporate. The resulting electrodes are heated for 2.5 hours at $95{ }^{\circ} \mathrm{C}$. Crosslinking is promoted by benzoyl peroxide (a radical initiator) undergoing a thermal reaction with the polymer and the crosslinking agent to form free radicals. These radicals can then couple to generate crosslinked PVF macromolecules. This increase in the average molecular weight of the polymer gives rise to a less soluble and, consequently, more stable film.

The stability of this type of electrode exceeds any nonaqueous reference electrode previously reported. The addition of a $40 \%$ (by weight) aliquot of TATM onto the electrode resulted in stability for up to 24 hours if the reference electrode was stored continuously in the test solvent. These electrodes, if removed from the solvent at the end of each day, could be used for 4 days with a maximum variation in the reference potential of $\pm 2.5 \mathrm{mV}$.

In methanol solutions, we found that the addition of $40 \%$ TATM improved the stability of PVF/Pt electrodes for 24 hours with a maximum deviation of $\pm 3.2 \mathrm{mV}$. If removed from the methanol overnight, the electrodes could be used for 2 days. Without the addition of the crosslinking agent, PVF/Pt electrodes drifted $-50 \mathrm{mV}$ in 4 hours.

Thermal crosslinking has proven to be effective in situations where the polyvinlyferrocinium (perchlorate) is extremely soluble. In aqueous solutions, for example, a 40\% addition of TATM stabilized PVF films for 7 hours. This same amount of TATM also improved the behavior of PVF/Pt reference electrodes in dimethylformamide (DMF). Where potentials of the uncrosslinked polymer films drifted more than $500 \mathrm{mV}$ in 15 minutes, this procedure reduced the drift to within $18 \mathrm{mV}$ over 30 minutes. In this case, doubling the amount of TATM resulted in a reference electrode that was stable to within $2 \mathrm{mV}$ for approximately 3 hours. It is clear that, while further improvements are still needed, the thermal crosslinking process significantly improves the stability of PVF reference electrodes in a number of widely used solvents.

14. Investigation of the Electrochemical Behavior of Metal-Dithiolene Complexes

G. Marbury

Dithiolene ligands derived from oxocarbon anions have been used successfully to synthesize complexes with nickel, palladium, platinum, copper and gold. These new, highly electron-withdrawing ligands include dithiosquarate (dtsq), dithiocroconate (dtcr) and dicyanomethylenedithiocroconate (dcmdtcr). These complexes exhibit a 2:1 (ligand:metal) stoichiometry.

This work focused primarily on the electrochemical characterization of the $\mathrm{Cu}(\mathrm{II}) / \mathrm{CU}$ (I) redox couple as it is influenced by varying the dithiolene ligand. The electron transfer process was studied in aprotic solvents using cyclic voltammetry (CV), double potential step chronocoulometry and spectroelectrochemistry. 
Cyclic voltammetric studies of the complexes in dimethylformamide (dmf) showed reversible behavior with formal potentials ( $E^{\circ}$ ) of $-0.384 \mathrm{~V}$ (dtsq), $-0.328 \mathrm{~V}$ (dtcr), and $-0.059 \mathrm{~V}$ (dcmdtcr) Vs. SCE, respectively. Spectroelectrochemical Nernst plots gave $E^{\circ}$ values of $-0.380 \mathrm{~V},-0.328 \mathrm{~V}$, and $-0.063 \mathrm{~V}$, respectively, again showing the expected trend toward less negative reduction potential with increased electron-withdrawing ability of the ligand. In addition, anodic/cathodic peak potential separation and current ratios indicated that these systems were electrochemically well behaved.

Unlike other metal dithiolenes, the electron transfer reactions of these complexes in acetonitrile are significantly less well behaved than in dimethylformamide. The $E^{\circ}$ values were estimated to be $-0.407 \mathrm{~V},-0.333 \mathrm{~V}$, and $-0.179 \mathrm{~V}$, respectively. Cathodic/anodic peak potential separations suggest significant departure from Nernstian behavior. The $E^{\circ}$ values were not related to electron-withdrawing properties of the ligands in a systematic way.

The diffusion coefficients calculated from chronocoulometric data follow the expected trend of decreasing with increasing size of the complex in both solvents.

Spectroelectrochemical studies of the complexes in DMF gave a range of electron transfer ( $n$ ) values instead of the expected single-integer value. The spectroelectrochemical studies are based on two premises: (1) Nernstian charge transfer in the complex, and (2) adherence to Beer's Law. Since CV studies had already suggested Nernstian behavior, the electronic spectral behavior was investigated as a possible cause of this non-ideal behavior. Non-adherence to Beer's Law was confirmed in an experiment in which the product of path-length times concentration was held constant. At high concentrations and short path lengths, the absorbance values were not constant; behavior consistent with dimerization. Because of this spectral difficulty, a non-spectrophotometric method was sought to confirm the $n$ values. The technique chosen was thin-layer staircase coulometry. This technique is presently being used to determine $\mathrm{n}$ and the formal potentials for the dithiolene complexes.

15. Investigation of the Electro-oxidative Products of Retinol and B-Carotene

W. A. MacCrehan and E. Schonberger

Retinol and $B$-carotene are two fat-solubie vitamins currently under investigation by the National Cancer Institute for their anti-tumor behavior. To determine in-vivo concentrations of these compounds, we are developing a liquid chromatographic method for their determination in serum using both UV/visible absorbance and oxidative electrochemical detection.

To fully optimize the oxidative detection approach, we must flrst study the electrochemical processes that occur. Both retinol and $\beta$-carotene are all-trans poly-enes which undergo oxidation at glassy carbon electrodes at applied potentials of +0.6 to $+1.0 \mathrm{~V}$ (versus a $\mathrm{Ag} / \mathrm{AgCl}$ reference electrode). Preliminary investigation of the reaction of retinol by cycllc voltammetry indicates that the oxidation is highly irreversible. In the first step, an electron is transferred to the electrode from one of the many carbon-carbon 
double bonds, creating a radical cation. This highly reactive species undergoes a subsequent nucleophilic attack by protic solvents used for the electrolysis. The remaining free radical portion of the molecule may undergo dimerization or further electro-oxidation. Our goal is to sort out the details of the events occurring during the oxidation process by separating and identify the electrode reaction products. Since both vitamins have multiple double bonds which may be susceptible to attack, more than one product may be formed in the reaction. Furthermore, the nature of the solvent used is also crucial to the nature of the products formed, since it reacts to form the adducts with the radical cation.

To investigate the progress of the electrochemical oxidation, we have used small-volume coulometric experiments. The electrolysis cell consists of a glassy carbon rod, porous vycor sample tube, isolated reference and auxiliary electrodes, and $500 \mu \mathrm{L}$ of test solution. Not only can the potential of the working electrode be controlled, but also small volumes (i.e., $20 \mu \mathrm{L}$ ) of the solution may be withdrawn periodically for LC analysis during the electrolysis. The total charge that passes can be related to the number of electrons transferred per vitamin molecule. Preliminary results for retinol in methanol and methanol/water mixtures indicate that between one and four electrons are transferred per retinol molecule depending on the applied potential. At all potentials tested, many different oxidation products are formed. The nearly equivalent electron density around all five of retinol's double-bonds, as well as the delocalization of the charge of the radical, contribute to the formation of the multiple products.

The solvent has a strong influence on the products as well. In pure methanol, methoxy derivatives are formed. The addition of as little as $1 \%$ water changes the nature of the products completely, with the presumed formation of hydroxy and epoxy derivatives. We are currently trying to sort out these products using a liquid chromatographic separation, evaporative concentration, and mass spectrometric identification of the electrochemical oxidation products.

16. Development of Two-Dimensional DEPT CH J-Resolved ${ }^{13} \mathrm{C}$ NMR Spectrum Editing

\section{B. Coxon}

In a previous report (Annual Report, 1983, CAC, NBSIR 83-2786, p. 149152), the development of an experimental method for two-dimensional (2D), DEPT heteronuclear J-resolved ${ }^{13} \mathrm{C}$ NMR spectroscopy was described (DEPT is an acronym for Distortionless Enhancement by Polarization Transfer). This method facilitates separation of ${ }^{1}{ }^{3} \mathrm{C}$ chemical shift and ${ }^{1}{ }^{3} \mathrm{C}-\mathrm{H}$ spin-spin coupling information into different dimensions, with enhancement of ${ }^{13}{ }_{C}$ NMR sensitivity by magnetization transfer from the protons to the ${ }^{13} \mathrm{C}$ nuclei. The DEPT technique has proved to be an outstanding method for one-dimensional (1D) spectrum editing, for example, the decomposition of a complete ${ }^{13} \mathrm{C}$ NMR spectrum into separate $\mathrm{CH}, \mathrm{CH}_{2}$, and $\mathrm{CH}_{3}$ sub-spectra. Our interest, therefore, lay in the experimental realization of a method for $2 \mathrm{D} D E P T C H ~ J-$ resolved ${ }^{13} \mathrm{C}$ NMR spectrum editing, a technique that could be expected to facilitate the disentanglement of complex, overlapped proton coupled ${ }^{1}{ }^{3} \mathrm{C}$ NMR spectra of biomolecules. One goal of this study was to develop automated data acquisition and processing methods that could be employed with current disk-interactive software packages. 
The pulse sequence for 2D DEPT CH J-resolved ${ }^{13} \mathrm{C}$ NMR reported previously has been modified to include an additional delay (D) just prior to the proton pulse $\left(\theta_{y}\right)$ that effects polarization transfer:

$$
\begin{aligned}
& \begin{array}{c}
{ }^{1} \mathrm{H}: \quad \pi / 2-1 / 2 \mathrm{~J}-\pi-1 / 2 \mathrm{~J}-\mathrm{D}-\theta_{\mathrm{y}-}-\pi-0 \\
\vdots
\end{array} \\
& { }^{13} \mathrm{C}: \quad \pi / 2 \ldots-\cdots t_{1 / 2} \ldots-\pi_{1 / 2}--t_{1} \text { acquire }--t_{2} \\
& \left(\mathrm{~J}={ }^{1} \mathrm{~J}_{\mathrm{CH}} \text {, minimum value of } t_{1 / 2}=1 / 2 \mathrm{~J}+\mathrm{D}+\theta_{\mathrm{y}}\right)
\end{aligned}
$$

By using three different flip angles $\left(\theta_{y}=30^{\circ}, 90^{\circ}\right.$, and $\left.150^{\circ}\right)$ for the polarization transfer pulse, an automation program is used to collect a sequence of three, $2 \mathrm{D} \mathrm{CH}$ J-resolved ${ }^{13} \mathrm{C}$ NMR data matrices. The prepolarization transfer delay (D) causes polarization transfer to be complete at the same time for each sequence, thus minimizing phase differences between the three data matrices that lead to inaccurate editing. For the $\theta_{y}=30^{\circ}$, $90^{\circ}$, and $150^{\circ}$ sequences, the values $D=P_{150}-P_{30}, P_{150}-P_{90}$, and 0 , respectively, were used, where $\mathrm{P}_{30}, \mathrm{P}_{90}$, and $\mathrm{P}_{150}$ are the corresponding pulse widths. The different values of $D$ compensate for the different widths of the $\theta_{y}$ pulse, with normalization to the timing of the $150^{\circ}$ sequence.

The use of these three pulse angles with an equal number of acquisitions for each sequence allows the $2 \mathrm{D} \mathrm{J}$-resolved ${ }^{13} \mathrm{CH}$ sub-spectra to be constructed as the simple combinations:

$$
\begin{aligned}
& \mathrm{CH}=\text { Matrix } \\
& \mathrm{CH}_{2}=\text { Matrix } \\
& \mathrm{CH}_{3}=\text { Matrix } \\
& 30+\text { Matrix }
\end{aligned}
$$

Two software methods have been developed for calculation of these combinations. In a first approach, a sequence of microprograms was used to combine the matrices by sequential handling of files. In a more efficient approach, a Pascal program was written, using BLOCKREAD and BLOCKWRITE functions to compute the $\mathrm{CH}_{2}$ and $\mathrm{CH}_{3}$ sub-spectra within a single compound statement.

The methods have been tested by generation of $\mathrm{CH}, \mathrm{CH}_{2}$, and $\mathrm{CH}_{3}$ 2D $J$-resolved sub-spectra from the useful carbohydrate intermediate: - methyl 2,3-anhydro-4 6 - 0 -benzylidene- $\alpha-\underline{D}$-mannopyranoside. This compound was chosen because its ${ }^{13} \mathrm{C}$ assignments are not immediately obvious, i.e., the signals at highest field are not the $\mathrm{CH}_{2}$ and $\mathrm{CH}_{3}$ resonances.

\section{Investigation of Metal-Protein Interactions}

L. Alexander, A. J. Fatiadi, S. A. Margolis, and D. J. Reeder

A series of new metal polymers was prepared and used for the study of the mechanism of separation of serum proteins by metal-chelate affinity chromatography. Immobilized metal-ion affinity columns were prepared by chelating transition metal ions such as $\mathrm{Cu}(\mathrm{II}), \mathrm{Ni}$ (II), $\mathrm{Zn}$ (II), $\mathrm{Co}$ (II), and $\mathrm{Mn}$ (II) to iminodiacetate derivatives of styrene-divinylbenzene beads. The ability of these materials to resolve proteins was tested at various $\mathrm{pH}$ values by adsorbing human serum to column packings to which a single metal had been chelated. The proteins were eluted by increasing the buffer concentration 
and by increasing metal-ion concentrations. The fractions were analyzed by ultra-thin isoelectric focusing techniques, with sensitive silver staining. Generally, three protein fractions were obtained as the buffer strength was increased: (a) albumin and acidic proteins, (b) very basic and some neutral species, and (c) slightly basic proteins. Similar results were obtained with columns of Sepharose $6 \mathrm{~B}$ chelated with metal ions. However, a comparison of the two types of column materials includes the capacity of the Sepharose columns and the recovery of proteins were much better.

This study suggests that hydrophobic, crosslinked polystyrene matrices are not as good as the more commonly used agarose carriers, such as Sepharose. The results suggest also that those polymers that bind metal ions by charge-transfer complexing behave as ion-exchange resins.

In a correlated experiment, the stability of a copper chelate to poly(4-vinylpyridine) was examined by laser ionization mass spectrometry and by Raman spectroscopy.

\section{Viral Proteins from Vaccine Studied by Two-Dimensional Electrophoresis}

J. Edwards, D. K. Hancock, and D. J. Reeder

We are currently engaged in a cooperative study with the Uniformed Services University of the Health Sciences (USUHS) in an effort to discover why a formalin-treated vaccine for respiratory syncitial virus (RSV) not only failed to provide protective immunity, but also suggested that RSV humoral immunity might dispose infected infants to a potentiation of bronchiolitis.

Using our high-resolution, two-dimensional electrophoresis (2DE) techniques, we compared a virus-infected cell line with a control noninfected cell line. High sensitivity silver staining used to visualize the 2DE gels revealed minor differences between the infected and non-infected cell samples. It is unknown whether these observed differences reflect the presence of viral proteins or alternations in the host cell as a response to the virus.

In an attempt to further enhance detection of the viral proteins with regard to both sensitivity and selectivity, immuno-blotting procedures were applied to the 2DE gels. Here the proteins were electrophoretically transferred from the polyacrylamide gels to a nitrocellulose membrane. The nitrocellulose membrane was then serially treated with blocking proteins, cottonrat IgG, rabbit anti-cotton-rat IgG, goat anti-rabbit-glucose oxidase and finally with the substrate for glucose oxidase color development. Unfortunately, background staining was high and sensitivity too low to give definitive results.

We are now preparing to use a more sensitive biotin-avidin alkaline phosphatase immuno-detection system which we believe should give us the required sensitivity and specificity to detect conclusively the viral proteins in the 2DE gels. This will allow more complete characterization of these viral proteins. In addition, we are attempting to recover sufficient viral particles from the cell culture medium to be able to examine the viral proteins themselves, in the absence of cellular proteins from the host cells. Finally, cells which have been cultured with virus for varying time periods 
(4-36 $\mathrm{hr}$. ) are being examined by two-dimensional gel electrophoresis for alterations in the protein components of the host cells resulting from viral infection.

19. Proteins from Honey Differential By Ultra-Thin Isoelectric Focusing and Two-Dimensional Electrophoresis

D. K. Hancock, D.J. Reeder, and K. L. Richie

In a collaborative study with the Food and Drug Administration (FDA), we used high resolution techniques to compare proteins from honey. Although honey is primarily a carbohydrate material, approximately three percent is of a proteinaceous nature. The proteins in honey might originate from the plant nectar, from the enzymes in the gut of the honeybee, or from pollen. However, relatively little has been published regarding the nature of the honey proteins.

The proteins content in honey has been used in Europe as a test of adulteration with such materials as corn syrup or other non-honey products. It was suggested that a detailed analysis of the protein patterns provided by isoelectric focusing and two-dimensional electrophoresis could provide additional information about the source of the honey and the types of adulterants that could be used to extend pure honey.

We examined several types of floral honey provided by the FDA. Sample preparation involved dialysis and centrifugation. The supernatant was then stored frozen until examined by the different techniques.

Using ultra-thin $(-160 \mu \mathrm{m})$ polyacrylamide gels followed by a silver staining method for protein visualization, we found that there were significant differences in the protein patterns in honey that originated in the United States, Argentina, Hungary, and China. Honey protein patterns from the United States and Argentina appeared to be the most similar, while that of China had few bands in common with the other honey samples.

With two-dimensional electrophoresis, preliminary results showed that the patterns from the different honey samples were similar in many respects. However, the China samples showed only major spots to be present and the Hungarian honey did not focus as well as the other samples. Of interest is the observation that although the honey proteins from Argentina gave the best overall gels, with well-focused spots, one major low molecular weight protein present in the other honeys was missing from this honey sample. Further studies with additional samples are being planned.

20. Results from Interlaboratory Analyses of Vitamins and Trace Metals

W. E. May and R. Schaffer

The Organic Analytical Research Division has organized a quality assurance (QA) program for laboratories involved in determinations of retinol (vitamin A), B-carotene (provitamin A), ascorbic acid (vitamin C), $\alpha$-tocopherol (vitamin E), selenium and zinc in serum and plasma. The Chemoprevention Branch of the National Cancer Institute (NCI), sponsors this program. The NCI also supports studies that are being conducted at several medical centers, on the influence of these micronutrients on the occurrence 
of certain forms of cancer, and the objective of the QA program is to help ensure the quality of the analytical measurements made at those institutions. Laboratories in addition to those involved in NCI-supported studies have been recruited into the QA program, so that the number of labs participating would be larger for statistical purposes.

In developing the QA program for selenium and zinc, no significant problems were expected, given the prior NBS experience with analytical methods and standards for those analytes. For the vitamins, however, we started from the beginning. We had to investigate the quality of the commercially available; "reagent-grade" materials, since we needed standards for our analyses and for preparing surrogate samples. We needed to learn how to determine the purity of available materials and we needed methods for determining these analytes in serum and plasma samples. We found commercial samples of ascorbic acid and a-tocopherol that were fairly pure, but all of the $B$-carotene and retinol samples were impure; some were highly impure.

In working with the participating laboratories, we at first sent them surrogate samples to analyze, i.e., aqueous solutions of selenium and zinc, aqueous acetontrile solutions of ascorbic acid (with dithiothreitol added as stabllizing agent), and ethanolic solutions of the trace fat-soluble vitamins. The labs were asked for analyses based on their normally used standards and separately based on the use of standard solutions prepared at NBS. From the enormous variability in the purity of the retinol and B-carotene available to laboratories and also from the instability of solutions of ascorbic acid prepared without a stabilizing agent, we expected the results with the NBS standards to be significantly better than the others; that is what was found. Between-laboratory variability, nevertheless remained the major source of variability in results.

Serum-based samples with the two trace metals and with the vitamins were also analyzed by the labs. The results for the trace metals in serum showed a 2- to 3-fold higher relative standard deviation than the results for the surrogate samples. A corresponding comparison for the vitamin analyses is awaiting reports of analysis from just a few more laboratories before being calculated.

21. Preparation and Certification of Standard Reference Materials for Dioxins, Chlorinated Pesticides and PCBs

S. N. Chesler, L. R. Hilpert, M. M. Miller, R. M. Parris, R. E. Rebbert, and M. J. Welch

The accurate determination of $2,3,7,8$-tetrachlorodibenzo-p-dioxin $(2,3,7,8-T C D D)$, commonly but imprecisely known as dioxin, is an important national measurement problem because of the potential widespread distribution of dioxins in the environment and their reported mutagenicity/ carcinogenlcity. During the past year, we have prepared and certified a dloxin Standard Reference Material. SRM 1614 consists of separate solutions of unlabeled and ${ }^{13} \mathrm{C}$-labeled $2,3,7,8-T C D D$ in $2,2,4-$ trimethylpentane (1sooctane). 
The dioxin solutions were prepared by adding accurately known amounts of the unlabeled and ${ }^{13} \mathrm{C}$-labeled $2,3,7,8-T C D D$ materials to isooctane. Measurements leading to certification were made on randomly selected ampoules using capillary gas chromatography with electron capture detection.

During the course of the certification measurements, both the unlabeled and 13 C-labeled 2,3,7,8-TCDD used in the preparation of SRM 1614 were found to contain a trichlorodibenzo-p-dioxin impurity. Determinations of the concentration of the trichlorobenzo-p-dioxin in the SRM solutions were made using gas chromatography/mass spectrometry with electron impact ionization and the method of standard additions. Because the 2,3,7-trichlorodibenzo-pdioxin was the only trichloro isomer available, it was not possible to positively identify which isomer was present in the SRM solutions. However, the gas chromatographic retention time of the impurity peak was coincident with that of the 2,3,7-trichlorodibenzo-p-dioxin.

The certified concentrations and estimated uncertainties of the unlabeled and ${ }^{13} \mathrm{C}$-labeled $2,3,7,8-T C D D$ solutions as well as the concentrations of the trichlorodibenzo-p-dioxins are given in Table 1.

SRM 1614 is intended primarily for use in the evaluation and calibration of analytical methods used for the determination of $2,3,7,8$-TCDD in environmental samples. The use of SRM 1614 should help to improve the accuracy and precision of measurements for 2,3,7,8-TCDD especially as more sensitive, isomer-specific analytical techniques are developed.

Table 1. Concentrations of Dioxins in SRM 1614

$\begin{array}{lcc}\text { Solution } & \text { Compound } & \begin{array}{c}\text { Concentration } \\ \mathrm{ng} / \mathrm{g}\end{array} \\ \text { Unlabeled } & 2,3,7,8-\mathrm{TCDD} & 98.3 \pm 3.3^{\mathrm{a}} \\ \text { Unlabeled } & \text { trichlorodibenzo-p-dioxin } & 1.5 \pm 0.4^{\mathrm{b}} \\ \text { Labeled } & 2,3,7,8-\mathrm{TCDD}^{13} \mathrm{C} & 95.6 \pm 1.5^{\mathrm{a}, \mathrm{c}} \\ \text { Labeled } & \text { trichlorodibenzon-p-dioxin }^{13} \mathrm{C} & 3.9 \pm 0.4^{\mathrm{b}, \mathrm{d}}\end{array}$

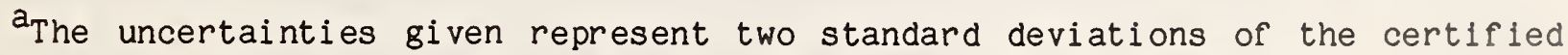
values. These uncertainties include the gravimetric and GC/ECD 2,3,7,8-TCDD measurement variability, and the trichlorodibenzo-p-dioxin measurement variability.

balues not certified; provided for information only.

${ }^{c}$ The concentration given represents the total concentration for all 1sotopic forms of $2,3,7,8-T C D D$ in the solution. The fully 13 -labeled $2,3,7,8-T C D D$ accounts for $80.7 \pm 0.5$ percent of the $2,3,7,8-T C D D$ molecules in the sample.

The concentration given represents the total concentration for all isotopic forms of the trichlorodibenzo-p-dioxin in the solution. 
We are also making measurements on two materials that will be issued as NBS Research Materials (RMs). The designation RM is given to those samples which are available through the NBS Office of Standard Reference Materials (OSRM) but are not certified, usually because values on various constituents have been determined by one technique only.

RM 1588, Cod Liver oil, is a natural material in which the biogenic concentrations of seven chlorinated pesticides and five PCBs have been measured by a single method. This material has also been gravimetrically fortified with six polychlorinated dibenzodioxins and one polychlorinated dibenzof uran.

Components of RM 1588

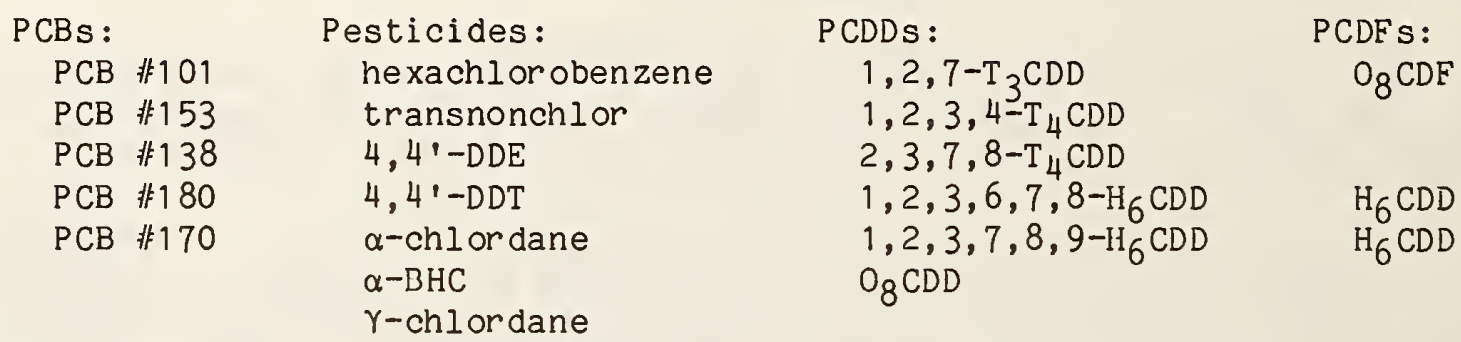

The components of the RM were measured using a combined chromatographic procedure which includes a dimethylformamide/hexane partition to remove the majority of the biogenic interferences, a normal phase HPLC fractionation to isolate and separate the PCB and pesticide fractions and a high resolution $\mathrm{GC} /$ electron capture detection analysis of the separate fractions. Until the constituent concentrations can be certified by a second set of independent measurements, the material will be released by OSRM as a Research Material.

Another Research Material that has not been assigned a number as yet is a mixture of three sediment materials collected by the U.S. Environmental Protection Agency and which is contaminated with $\mu g / g$ (ppb) levels of two industrial PCB mixtures, Aroclor 1242 and 1260. These sediments were homogenized at NBS using a "V" blender and a 30-mesh sieve. This material will be made available to allow researchers to use a universally available, wellhomogenized sample material for such uses as methods development, round robin exercises, and consensus standards. NBS will possibly certify the concentrations of some components of this material and issue it as an SRM in the future.

SRM 1589, PCBs in Human Serum, is a freeze-dried serum which contains a gravimetrically added PCB mixture, Aroclor 1260. The Aroclor 1260 was added as an acetone solution at a level of $100 \mathrm{ng} / \mathrm{g}$ to the serum prior to lyophilization. This SRM was certified by high resolution electron capture GC. Prior to analysis the material was reconstituted by addition of water. An internal standard (PCB \#198) was then introduced into the sample and the PCBs were separated from the serum matrix by extraction with a $1: 1$ ethyl ether:hexane solution. These extracts were then passed through silica microcolumns to further remove analytical interferences. After evaporative concentration, aliquots of these samples were injected onto the GC for final quantitation. 
22. Certification of Standard Reference Material 1587 Nitrated Polycyclic

Aromatic Hydrocarbons in Methanol

W. F. Kline, W. E. May, R. E. Rebbert, and S. A. Wise

Since 1980, interest in the determination of nitrated polycyclic aromatic hydrocarbons ( $\mathrm{N}-\mathrm{PAH}$ ) has grown because $\mathrm{N}-\mathrm{PAF}$ are present in a number of environmental samples and commercial products, and because some $\mathrm{N}-\mathrm{PAH}$ have direct-acting mutagenic properties. To assist in the accurate measurement of these environmentally important compounds, NBS has prepared and certified Standard Reference Material (SRM) 1587 "Nitrated Polycyclic Aromatic Hydrocarbons in Methanol". This SRM is intended primarily for use in calibrating chromatographic instrumentation used for the determination of N-PAH but can also be used to add known amounts of these compounds to methanol-miscible extracts.

SRM 1587 was prepared from N-PAH synthesized by Midwest Research Institute, (MRI) Kansas City, MO, under a contract from the Coordinating Research Council, Inc., Atlanta, GA. Compound purities were determined at MRI to be at least 99 percent; therefore, no correction was made for purity. Instability of $\mathrm{N}-\mathrm{PAH}$ in organic solvents stored at room temperature and exposed to light has been observed. Consequently, amber ampcules were selected to inhibit photochemical degradation and the ampouled material was stored at $-25{ }^{\circ} \mathrm{C}$.

Each unit of SRM 1587 consists of four vials, each containing approximately one $\mathrm{mL}$ of a methanol solution containing seven N-PAH. Because of concerns about the thermal instability of the SRM, each unit will be shipped via an overnight carrier and packaged in dry ice.

The concentrations of N-PAH in SRM 1587 were determined by both gas chromatography and liquid chromatography. Table 1 shows the certified values for six of the seven N-PAH in this SRM. The certified values were derived from the concordant results obtained from the two independent techniques. The uncertainties represent two standard deviations of the certified values. The statistical design allowed for analysis of both the within- and between-vial homogeneity. The value for 6-nitrobenzo[a]pyrene reported in Table 1 , is not certified, and is provided for information only. The analytical data for this compound exhibited the largest uncertainty and between-vial variability. Also, its solubility in the SRM solution appeared to be borderline.

Table 1. Certified Values for N-PAH in SRM 1587

Certified Values $(\mu g / g)$

2-Nitrofluorene

9-Ni troanthracene

3-Ni trofluor anthane

1-Nitropyrene

7-Ni trobenz [a] anthracene

6-Nitrochrysene

6-nitrobenzo[a]pyrene
$9.67 \pm 0.39$

$5.01 \pm 0.11$

$9.24 \pm 0.06$

$8.95 \pm 0.28$

$9.27 \pm 0.27$

$8.13 \pm 0.11$

6.1 


\section{NBS Participation in the Certification of a Canadian Marine Sediment}

Reference Material

W. F. Kline, G. D. Byrd, H. X. Gu, and W. E. May

In 1976, at the recommendation of the Canadian Committee on Oceanography, the National Research Council (NRC) of Canada established the Marine Analytical Chemistry Standards Program to support analytical aspects of marine chemistry. One of the outputs of this program has been a series of reference materials designed to assist analysts in obtaining accurate determinations of selected trace elements and organic constituents in marine samples. Trace elements in sea water, trace elements in sediment, and polychlorinated biphenyls in sediment are among the reference materials currently available through the NRC program. The sediment material is similar to NBS/SRM 1646 (Estuar ine Sediment). The reference materials issued by the NRC are certified through small-scale interlaboratory comparison studies involving selected laboratories based upon previously demonstrated capabilities.

The next reference material to be released by this group is a suite of sediment samples with recommended values for the sixteen polycyclic aromatic hydrocarbons (PAH) on the EPA list of priority pollutants. In the spirit of international cooperation, we agreed to perform analyses for the certification of this material. A marine sediment material with certified values for organic constituents has been requested frequently, but is not currently available from NBS. Values for the requested sixteen PAH and perylene were determined using two independent procedures based on slight modifications of the liquid chromatography/fluorescence wavelength programming and gas chromatography/mass spectrometry procedures that have been developed previously at NBS for the determination of PAH in complex mixtures. These procedures have been utilized in the certification of several SRMs including: 1580 (Organics in Shale 0il), 1581 (Petroleum Crude 0il), 1649 (Urban Air Particulates/Organics), and 1650 (Diesel Particulate Matter). 
C. Outputs and Interactions

(Organic Analytical Research Division)

1. Publications

Blubaugh, E. A., Chiang, C. K., and Yap, W. T., Electrochemical Behavior of Doped Polyacetylene Films, Polymer, 25, 1112-1116 (1984).

Burke, R. T., Blubaugh, E. A., Yap, W. T., and Durst, R. A., Electrochemical Investigation of $\mathrm{N}$-Methyl-4-(5-phenyl-2-oxazolyl)pyridinium p-Toluenesulfonate, J. Electroanal. Chem., 177, 77-88 (1984).

Durst, R. A., Chemically Modified Electrode Sensors for Biocomponents, Proceeding of the Symposium on Biosensors, A. R. Potvin and M. R. Neuman, eds., IEEE/EMBS Publishing Services, Piscataway, NJ, 56-58 (1984).

Fatiadi, A. J., Priority Toxic Pollutants in Human Urine: Their Occurrence and Analysis, Environment International, 10, 175-205 (1984).

Foley, J. P. and Dorsey, J. G., Clarification of the Limit of Detection in Chromatography, Chromatographia, 18, 503-511 (1984).

Hilpert, L. R., Byrd, G. D., and Vogt, C. R., Selectivity of Negative Ion Chemical Ionization Mass Spectrometry for Benzo[a]pyrene, Anal. Chem., 56, $1842(1984)$.

Kamat, P. V., Fox, M. A., and Fatiadi, A. J., Dye Loaded Polymer Electrodes, Photoelectrochemical Sensitization by Croconate Violet in Polymer Solutions and Films, J. Amer. Chem. Soc. 106, 1191-1197 (1984).

Maas, A. H. J., Weisberg, H. F., Zijlstra, W. G., Durst, R. A., and Siggard-Andersen, O., Reference Method for pH Measurement in Blood, IFCC Recommendations and Related Documents, Vol. I, N. E. Saris, ed., W. de Gruyter, NY, 124-132 (1984).

MacCrehan, W. A. and May, W. E., Determination of Nitro-Polynuclear Aromatic Hydrocarbons in Diesel Soot by Liquid Chromatography with Fluorescence and Electrochemical Detection, Polynuclear Aromatic Hydrocarbons: Mechanisms, Methods, and Metabolism, M. Cooke and A. J. Dennis, eds., Battelle Press, Columbus, OH 1413-1427 (1985).

Margolis, S. A. and Coxon, B., Amino Acid Analysis of Angiotensin I by Proton NMR Spectroscopy, Anal. Biochem., 141, 355-360 (1984).

Mattammal, M. B., White V, E., Zenser, T. V., and Davis, B. B., Mass Spectometry of 2-Substituted-4-Arylthiazoles, 3. Identification of Micrososmal Nitroreduction Products by Mass Spectrometry, Biomed. Mass Spectrom., 11 (4), 149-154 (1984).

May, W. E., Chesler, S. N., Hilpert, L. R., Hertz, H. S., Rebbert, R. E., Vogt, C. R., and Wise, S. A., Characterization of Polycyclic Aromatlc Hydrocarbons in Air Particulate Extracts by Liquid and Gas Chromatograph1c Methods, Identification and Analysis of Organic Pollutants in Alr, L. R. Keith, ed., Butterworth Publishers, Woburn, MA, 197-229 (1984). 
Roberts, G. D. and White V, E., Silver Sulfonates as Mass Standards in Field Desorption Mass Spectometry, Biomed. Mass Spectrom., 11 (6) 273-275 (1984).

Sander, L. C. and Wise, S. A., The Influence of Substrate Parameters on Column Selectivity with Alkyl Bonded Phase Sorbents, J. Chromatogr. 316, 163-181 (1984).

Wasik, S. P., Schwarz, F. P., Tewari, Y. B., Miller, M. M., and Purnell, J. H., A Head-Space Method for Measuring Activity Coefficients, Partition Coefficients, and Solubilities of Hydrocarbons in Aqueous Solutions, NBS J. Res., 89, 273 (1984).

Wise, S. A., Fitzpatrick, K. A., Harrison, S. H., and Zeisler, R., Operation of the U.S. Pilot National Environmental Specimen Bank Program, Environmental Specimen Banking and Monitoring as Related to Banking, R. A. Lewis, N. Stein, and C.W. Lewis, eds., Martinus Nijhoff Publishers, Boston, 108-126 $(1984)$.

Wise, S. A. and Zeisler, R., The Pilot Environmental Specimen Bank Program, Environmental Science Technology, 18 302A-307A (1984).

Zelsler, R., Harrison, S. H., and Wise, S. A., Analysis of Human Liver Specimens in the U.S. Pilot National Environmental Specimen Bank Program, Environmental Specimen Banking and Monitoring as Related to Banking, R. A. Lewis, N. Stein, and C. W. Lewis, eds., Martinus Nijhoff Publishers, Boston, 331-351 (1984).

Christensen, R. G. and White V, E., Determination of Dibenzothiophene in Oils by Liquid Chromatography -- Tandem Mass Spectrometry, J. Chromotogr., 323, 33-36 (1985).

Covington, A. K., Bates, R. G., and Durst, R. A., Definition of pH Scales, Standard Reference Values, Measurement of $\mathrm{pH}$ and Related Terminology, Pure Appl. Chem., 57, 531-542 (1985).

Diamondstone, B. I., Wise, S. A., and Sander, L. C., Carbon Analysis for the Study of Bonded Phases in Liquid Chromatography, J. Chromatogr. 321, 318-324 (1985).

Guenther, F. R. and Chesler, S. N., Gas Chromatographic Analysis of Soot, Report to LESC, (1985).

Kline, M. C., Kotola, A. W., and Young, E. P., Effect of Aqueous Chlorine (600 PPM) on the Protein and the Lipid Fractions of Ground Beef, J. Food Quality, I, 229-235 (1985).

Kline, W. F., Wise, S. A., and May, W. E., The Application of Perdeuterated Polycyclic Aromatic Hydrocarbons ( $\mathrm{PAH}$ ) as Internal Standards for the Liquid Chromatographic Determination of $\mathrm{PAH}$ in a Petroleum Crude 011 and Other Complex Mixtures, J. Liquid Chromatogr. $\underline{8}$ (2), 223-237 (1985).

Margolis, S. A., Reference Materials for Organic Nutrient Content in Biological Reference Materials: Availability, Uses, and Need for Validation of Nutrient Measurements, W. R. Wolf, ed., John Wiley \& Sons, NY (1985). 
Mayfield, H. T. and Chesler, S. N., Optimization of Selectivity Using Sequentially Coupled Capillary Columns, Proceedings of the 6th International Symposium on Capillary Chromatography, P. Sandra, ed., Riva del Garda, Italy, 772-785 (1985).

Mayfield, H. T., Mar, T., Bertsch, W., and Staroscik, J., Varietal Classification of Orange Essence Oils by Capillary Column Gas Chromatography and Pattern Recognition, Proceedings of the 6th International Symposium on Capillary Chromatography, P. Sandra, ed., Rivea del Garda, Italy, 555-567 (1985).

Miller, M. M., Wasik, S. P., Huang, G.-L., Shui, W.-Y., and Mackay, D., Relationships Between Octanol-Water Partition Coefficient, Aqueous Solubility, and Bioconcentration Factors, Environmental Science \& Technology, 19, $522(1985)$.

Pandey, R. C., Kalith, C., Gustafson, M. E., Kline, M. C., Leidhecker, M. F., and Ross, J. T., Process Developments in the Isolation of Largomycin F-II, a Chromoprotein Antitumor Antibiotic, Purification of Fermentation Products: Applications to Large Scale Processes, ACS Symposium Series, No. $271(1985)$.

Sander, L. C. and Wise, S. A., Synthesis and Characterization of $\mathrm{C}_{18}$ Stationary Phases for the Liquid Chromatographic Separation of Polycyclic Aromatic Hydrocarbons, Polynuclear Aromatic Hydrocarbons: Mechanisms, Methods, and Metabolism, M. Cooke and A. J. Dennis, eds., Battelle Press, Columbus, OH, 1133-1144 (1985).

Welch, M. J., Pereles, D. J., and White V, E., Photodissociation of the Molecular Ion of n-Butylbenzene: Effect of Photon Energy, Org. Mass Spectrom., 20, 425-426 (1985).

Wise, S. A., Chesler, S. N., Hilpert, L. R., May, W. E., Rebbert, R. E., and Vogt, C. R., Characterization of Polycyclic Aromatic Hydrocarbon Mixtures from Air Particulate Samples Using Liquid Chromatography, Gas Chromatography, and Mass Spectrometry, Polynuclear Aromatic Hydrocarbons: Mechanisms, Methods, and Metabolism, M. Cooke and A. J. Dennis, eds., Battelle Press, Columbus, OH 1413-1427 (1985).

Wise, S. A. and Sander, L. C., Factors Affecting the Reversed-Phase Liquid Chromatographic Separation of Polycyclic Aromatic Hydrocarbon Isomers, J. High Resolution Chromatogr. and Chromatogr. Comm., 8, 248-255 (1985).

Wise, S. A., Recent Progress in the Determination of Polycyclic Aromatic Hydrocarbons by High-Performance Liquid Chromatography, Handbook for Polycyclic Aromatic Hydrocarbons: Volume II, A. Bjørseth and T. Ramdahl, eds., Marcel Dekker, New York, NY, 73-191 (1985).

Zeisler, R. and Wise, S. A., Quality Assurance and Protocols in Sampling and Sample Preparation of Biological Samples, Biological Reference Materials: Availability, Uses, and Need for Validation of Nutrient Measurement, W. R. Wolf, ed., John Wiley and Sons, Inc., New York, 257-279 (1985). 
Byrd, G. D., Fatiadi, A. J., Simons, D. S., and White V, E., Laser Desorption Mass Spectrometry of Some Salts of Squaric Acid, Org. Mass Spectrom., in press.

Durst, R. A., Chemically Modified Electrode Sensors, Proceedings of the International Symposium on Ion-Selective Electrodes, Zhang, Z.-R., ed., Shanghai, P.R.C., in press.

Durst, R. A., Chemically Modified Electrode Sensors, Ion-Selective Electrodes, Vol. 4, E. Pungor and I. Buzas, eds., Akademisi Kiado, Budapest, 115-128 $(1985)$.

Durst, R. A., Clinical Electrode Potentiometry: Sources of Error, Reference Methods and Materials, Direct Potentiometric Measurements in Blood, W. Koch, ed., in press.

Fatiadi, A. J., Development of Metal Chelate Affinity Chromatography (Review), NBS J.Res., in press.

Fatiadi, A. J., The Classical Permanganate Ion: Still A Novel Oxidant in Organic Chemistry, Synthesis, in press.

Eletcher, R. A. and Fatiadi, A. J., Laser Ionization Mass Spectrometry of Affinity Chromatography Column Packing Materials: Poly(4-Vinylpyridine), NBS J. Res., in press.

Fletcher, R. A. and Fatiadi, A. J., Laser Ionization Mass Spectrometry of Poly(4-Vinylpyridine), Polymer Commun., in press.

Glinka, C. J., Sander, L. C., Wise, S. A., Hunnicutt, M. L., and Lochmuller, C. H., Determination of Pore Accessibility in Silica Microparticles by Small Angle Neutron Scattering, Anal. Chem., in press.

Hartmann, A. E., Naito, H. K., Burnett, R. W, and Welch, M. J., Accuracy of Participant Results Utilized as Target Values in the CAP Chemistry Survey Program, Archives of Pathology and Laboratory Medicine, in press.

Lee, M. L., Goates, S. R., Markides, K. E., and Wise, S. A., Frontiers in Analytical Techniques for Polycyclic Aromatic Compounds, Polynuclear Aromatic Hydrocarbons: Chemistry, Characterization, and Carcinogenesis, M. Cooke, and A. J. Dennis, eds., Battelle Press, Columbus, $\mathrm{OH}$, in press.

Miller, M. M., Zielinski, W. L., Jr., Ulma, G., and Wasik, S. P., GLC Separation Behavior of Polychlorinated Biphenyl Isomers Between a Nematic Liquid Crystal Stationary Phase and a Nonpolar Hydrocarbon Phase, Anal. Chem., in press.

Murray, R. W., Ewing, A. E., and Durst, R. A., Chemically Modified Electrodes, Anal. Chem., in press.

Reeder, D. J., Standards for Forensic Electrophoresis, Proceedings of the International Symposium on the Forensic Applications of Electrophoresis, B. Brow, ed., in press. 
Sander, L. C., Glinka, C. J., Wise, S. A., Recent Advances in the Characterization of Bonded Phases, Chemically Modified Surfaces, D. E. Leyden, ed., Gordon and Breach Science Publishers, in press.

Sander, L. C. and Wise, S. A., Investigations of Selectivity in Reversal-phase Liquid Chromatography of Polycyclic Aromatic Hydrocarbons, in Advances in Chromatography Volume 25, J. C. Giddings, E. Gruska, and P. R. Brown, eds., Marcel Rekker, New York, NY, in press.

West, W. R., Wise, S. A., Campbell, R. M., Bartle, K. D., and Lee, M. L., The Analysis of Polycyclic Aromatic Hydrocarbon Minerals Curtisite and Idrialite by High Resolution Gas and Liquid Chromatographic Techniques, Polynuclear Aromatic Hydrocarbons: Chemistry, Characterization and Carcinogenesis, M. Cooke and A. J. Dennis, eds., Battelle Press, Columbus, $\mathrm{OH}$, in press.

Wise, S. A., Campbell, R. M., West, W. R., Lee, M. L., and Bartle, K. D., Characterization of Polycyclic Aromatic Minerals Curtisite, Idrialite, and Pendletonite Using Liquid Chromatography, Gas Chromatography, Mass Spectrometry, and Nuclear Magnetic Resonance Spectroscopy, Chem. Geology, in press.

Wise, S. A., Chesler, S. N., Hilpert, L. R., May, W. E., Rebbert, R. E., Vogt, C. R., Nishioka, M. G., Austin, A., and Lewtas, J., Quantification of Polycyclic Aromatic Hydrocarbons and Nitro-Substituted Polycyclic Aromatic Hydrocarbons and Mutagenicity Testing for the Characterization of Ambient Air, Environment International, in press.

Wise, S. A., Sander, L. C., and May, W. E., Investigations of Selectivity in Reversed-phase Liquid Chromatography on Chemically Bonded $\mathrm{C}_{18}$ Phases, Chemically Modified Surfaces, D. E. Leyden, ed., Gordon and Breach Science Publishers, in press.

Wise, S. A. and Zeisler, R., eds., International Review of Environmental Specimen Banking, NBS SP 706, in press.

\section{Talks}

E. A. Blubaugh, "Electrochemical and Spectroelectrochemical Investigation of a Series of Ruthenium(bpy) 2 Dithiocarbamate Complexes," American Chemical Society 188th National Meeting, Philadelphia, PA, August 27, 1984.

E. A. Blubaugh, "Synthesis, Characterization, and Electrochemistry of Cationic Transdihalo Technetium(III) Arphos Complexes," American Chemical Society 188th National Meeting, Philadelphia, PA, August 29, 1984.

W. E. May, "NBS: Its History, Mission, and Organizational Structure," Chromatography Science Seminar, Shanghai Institute for Testing Technology, Shanghai, China, September 17, 1984. Invited

W. E. May, "Overview of the Organic Analytical Research Division," Chromatography Science Seminar, Shanghai Institute for Testing Technology, Shanghai, China, September 18, 1984. Invited 
W. E. May, "HPLC: Basic Principles and Instrumentation," Chromatography Science Seminar, Shanghai Institute for Testing Technology, Shanghai, China, September 18, 1984. Invited

W. E. May, "GC: Basic Principles and Instrumentation," Chromatography Science Seminar, Shanghai Institute for Testing Technology, Shanghai, China, September 19, 1984. Invited

W. E. May, "Qualitative and Quantitative Analysis," Chromatography Science Seminar, Shanghai Institute for Testing Technology, Shanghai, China, September 19, 1984. Invited

W. E. May, "Quantitative Analysis of Complex Mixture by Selective Detection I," Chromatography Science Division, Shanghai Institute for Testing Technology, Shanghai, China, September 20, 1984. Invited

W. E. May, "Quantitative Analysis of Complex Mixture by Selective Detection II," Chromatography Science Seminar, Shanghai Institute for Testing Technology, Shanghai, China, September 21, 1984. Invited

W. E. May, "Results from Several Interlaboratory Comparison Studies," Chromatography Science Seminar, Shanghai Institute for Testing Technology, Shanghai, China, September 21, 1984. Invited

W. E. May, "Multidimensional Chromatographic Analyses of Complex Mixtures," Chromatography Science Seminar. Shanghai Institute for Testing Technology, Shanghai, China, September 22, 1984. Invited

W. E. May, "Preparation and Certification of Standard Reference Materials," Chromatography Science Seminar, Shanghai Institute for Testing Technology, Shanghai, China, September 24, 1984. Invited

W. E. May, "Determination of Physico-chemical Properties by HPLC," Chromatography Science Seminar, Shanghai Institute for Testing Technology, Shanghai, China, September 24, 1984. Invited

W. E. May, "Determination of Trace Organic Constituents in Complex Mixture by HPLC," Chromatography Science Seminar, Shanghai Institute of Organic Chemistry, Shanghai, China, September 25, 1984. Invited.

W. E. May, "Selectivity Differences Among Liquid Chromatographic Phases," Chromatography Science Seminar, Shanghai Institute for Testing Technology, Shanghai, China, September 26, 1984. Invited

R. A. Durst, "Chemically Modified Electrode Sensors," 4th Scientific Session on Ion-Selective Electrodes, Federation of European Chemical Societies, Hungarian Academy of Sciences, Matrafured, Hungary, October 10, 1985. Invited

W. F. Kline, "The LC Determination of PAH in Petroleum Crude Oil and Other Complex Mixtures," Chemistry Seminar, American University, Washington, DC, October $12,1984$. 
R. A. Durst, "Analytical Aspects of Chemically Modified Electrodes," Department of Chemistry, E. Kardelj University, Ljubljana, Yugoslavia, October 15, 1985. Invited

R. A. Durst, "Organic Electrochemical Research at NBS," Department of Chemistry, E. Kardelj University, Ljubljana, Yugoslavia, October 16, 1985. Invited

R. G. Christensen, "Quantitative LC/MS/MS and MS/MS Selectivity," Analytical Chemistry Department Seminar, University of Ulm, Ulm, West Germany, October 23, 1984. Invited

R. G. Christensen, "MS/MS Selectivity by Adduct Formation," 3rd Workshop on LC/MS and MS/MS of the International Association of Environmental Analytical Chemistry, Maison des Congrès, Montreux, Switzerland, October 24, 1984. Invited

R. G. Christensen, "Quantitative Application of LC/MS/MS," 3rd Workshop on LC/MS and MS/MS of the International Association of Environmental Analytical Chemistry, Maison des Congrès, Montreux, Switzerland, October 24, 1984. Invited

J. J. Edwards, "Demonstration of Protein Markers by 2-Dimensional Electrophoresis After Exposure to Carbon Tetrachloride and Furans," Center for Analytical Chemistry, National Bureau of Standards, Gaithersburg, MD, October 24, 1984.

G. D. Byrd, "Preparation and Analysis of a Quality Assurance Solid Sludge Material," 36th Southeastern Regional Meeting ACS, Raleigh, NC, October 26, 1984.

S. A. Wise, "The Analysis of Polycyclic Aromatic Hydrocarbon Minerals Curtisite and Idrialite by High Resolution Chromatographic Techniques," 9th International Symposium on Polynuclear Aromatic Hydrocarbons, Battelle Columbus Laboratories, Columbus, $\mathrm{OH}$, October $30,1984$.

E. A. Blubaugh, "Investigation of a Series of Ru(bpy) 2 Dithiocarbamate Complexes," Chemistry Department, Villanova University, Villanova, PA, October 30, 1984.

B. Coxon, "Two-Dimensional NMR Spectroscopy of Carbohydratès," Argonne NMR Workshop/Midwest NMR Discusssion Group, Argonne National Laboratory, Argonne, IL, November 3, 1984. Invited

B. Coxon, "Two-Dimensional NMR Spectroscopy," ADABSE Meeting, National Bureau of Standards, Gaithersburg, MD, November 5, 1984. Invited

W. E. May, "Liquid Chromatographic Methods for the Analysis of Nitro-Polycyclic Aromatic Hydrocarbons," NBS/DOE Analytical Characterization Group Meeting, Battelle Conference Facilities, Seattle, WA, November 8, 1984.

E. White V, "Laser Induced Dissociation of Ions from Soft Ionization Techniques," Eastern Analytical Symposium, New York, NY, November 15, 1984. Invited 
S. A. Wise, "The Determination of Organic Species of Atmospheric Interest," Analytical and Environmental Chemistry Division Seminar, University of Maryland, College Park, MD, November 16, 1984. Invited

R. G. Christensen, "Quantitative LC/MS/MS and MS/MS Selectivity," Analytical Chemistry Department Seminar, University of Nebraska, Lincoln, NE, November 19, 1984. Invited

J. P. Foley, "Selected Topics in Modern Liquid Chromatography: Optimization and Secondary Chemical Equilibria," University of Massachusetts, Department of Chemistry, December 10, 1984.

S. A. Margolis, "Separation of Angiotension Isomers by Ion Exchange Chromatography," 4th International Symposium on HPLC of Proteins, Peptides and Polynucleotides, December 11, 1984.

J. P. Foley, "Selected Topics in Modern Liquid Chromatography: Optimization and Secondary Chemical Equilibria," University of Michigan, Department of Chemistry, December 17, 1984.

J. P. Foley, "Optimization of Secondary Chemical Equilibria in Liquid Chromatography," Ohio State University, Department of Chemistry, January 8, 1985.

J. P. Foley, "Optimization of Secondary Chemical Equilibria in Liquid Chromatography," University of Georgia, Department of Chemistry, January $10,1985$.

S. A. Wise, "Factors Affecting Selectivity in Reversed-Phase Liquid Chromatography of Polycyclic Aromatic Hydrocarbons," Chemistry Department Seminar, Duke University, Raleigh, NC, January 10, 1985. Invited

J. P. Foley, "Optimization of Secondary Chemical Equilibria in Liquid Chromatography," Ohio University, Department of Chemistry, January 14, 1985.

J. P. Foley, "Optimization of Secondary Chemical Equilibria in Liquid Chromatography," University of Maryland, Department of Chemistry, January $28,1985$.

J. P. Foley, "Optimization of Secondary Chemical Equilibria in Liquid Chromatography," Georgia Institute of Technology, School of Chemistry, January 29, 1985.

D. J. Reeder, "Chromatography in the Life Sciences," Washington Chromatography Discussion Group, February 21, 1985. Invited

L. R. Hilpert, "Certification of a Diesel Particulate Standard Reference Material," Pittsburgh Conference on Analytical Chemistry and Applied Spectroscopy, New Orleans, LA, February 25, 1985.

M. J. Welch, "The Development of Definitive Methods for Organic Serum Constituents," 1985 Pittsburgh Conference on Analytical Chemistry and Applied Spectroscopy, New Orleans, LA, February 26, 1985. 
J. P. Foley, "Optimization of Secondary Chemical Equilibria in Liquid Chromatography," 36th Annual Pittsburgh Conference on Analytical Chemistry and Applied Spectroscopy, New Orleans, LA, February 28, 1985.

J. P. Foley, "Optimization of Secondary Chemical Equilibria in Liquid Chromatography," Lousiana State University, Department of Chemistry, March 4, 1985.

J. P. Foley, "Optimization of Secondary Chemical Equilibria in Liquid Chromatography," Federal Bureau of Investigation, Forensic Science Division, Quantico, VA, March 8, 1985.

S. A. Wise, "Specimen Banking of Biologicl Indicators," Interagency Toxic Substances Data Committee, Washington, DC, March 12, 1985. Invited

B. Coxon, "Two-Dimensional Spectrum Editing," NBS Staff Research Seminar on Measurement Method, useful to the Biological Sciences, National Bureau of Standards, Gaithersburg, MD, March 21, 1985. Invited

R. A. Durst, "Bioelectrochemical Sensors," NRL Electrochemistry Group Seminar, Naval Research Laboratory, Washington, DC, April 3, 1985. Invited

K. L. Richie, "Isoelectric Focusing: Principles and Applications," National Bureau of Standards, Gaithersburg, MD, April 3, 1985.

L. C. Sander, "Determination of B-Carotene and Tocopherol Purities by HPLC," NBS/NCI Micronutrient Analysis QA Workshop, National Bureau of Standards, Gaithersburg, MD, April 12, 1985. Invited

S. A. Wise, "Specimen Banking for Micronutrient Analysis," NBS/NCI Micronutrient Analysis Quality Assurance Workshop, National Bureau of Standards, Gaithersburg, MD, April 12, 1985. Invited

B. Coxon, "Two-Dimensional DEPT $\mathrm{CH}$ J-Resolved ${ }^{13} \mathrm{C}$ NMR Spectrum Editing," $26 \mathrm{th}$ Experimental NMR Conference, Asilomar, CA, April 24, 1985. Invited

L. R. Hilpert, "Mass Spectrometric Methods for the Determination of Amino Acid Sequence in Polypeptides," American University, Washington, DC, April 26, 1985.

W. A. Maccrehan, "Determination of $1-\mathrm{Nitropyrene}$ and Selected Other $\mathrm{N}-\mathrm{PAH}$ in Diesel Exhaust Particulate Extracts Using Liquid Chromatography with Reductive Electrochemical Detection," 189th ACS National Meeting, Miami, FL, April 29, 1985.

R. A. Durst, "Chemically Modified Electrode Sensors," Northeastern University Chemistry Department Colloquium, Boston, MA, May 7, 1985. Invited

B. Coxon, "One- and Two-Dimensional NMR Spectrum Editing," National Heart \& Lung Institute, National Institutes of Health, Bethesda, MD, May 7, 1985. Invited

S. A. Wise, "Pilot Environmental Specimen Bank Program at NBS," American Petrolium Institute, Washington, DC, May 7, 1985. Invited 
R. A. Durst, "Bioanalytical Sensors," Nova Biomedical, Waltham, MA, May 8, 1985. Invited

S. A. Wise, "Development of a Biomonitoring Specimen Bank in the United States," 9th U.S.-German Seminar of State and Planning in Environmental Specimen Banking, Günzburg, West Germany, May 13, 1985. Invited

S. A. Wise, "Determination of Organochlorine Pesticides and PCB's in Environmental Samples," 9th U.S.-German Seminar of State and Planning in Environmental Specimen Banking, Günzburg, West Germany, May 15, 1985. Invited

S. A. Margolis, "Studies on the Measurement of Ascorbic Acid," Infant Formula Conference, Norfolk, VA, May 15, 1985. Invited

S. A. Margolis, "The Current State of Vitamin Analysis and the Role of Standard Materials," Infant Formula Conference, Norfolk, VA, May 15, 1985. Invited

S. A. Wise, "Selectivity in Reversed-Phase Liquid Chromatography," Analytical Chemistry Division Seminar, University of Stockholm, Stockholm, Sweden, May 22, 1985. Invited

G. D. Byrd, "Determination of Trace Levels of Organics in Gaseous Samples Using ID/MS," 33rd Annual Conference on Mass Spectrometry and Allied Topics, San Diego, CA, May 27, 1985.

M. J. Welch, "Photodissociation of Ions Generated by Fast Ion Bombardment," 33rd Annual Conference on Mass Spectrometry and Allied Topics, San Diego, CA, May 27, 1985.

E. A. Blubaugh, "The Detection of Organohalide Compounds at Rhodium Porphymin Derivatized Polymer Filter Electrodes," Chicago, IL, May 28, 1985.

L. R. Hilpert, "GC/MS Methods for the Analysis of PAH in Diesel Particulates: Certification of a Diesel Particulate Standard Reference Material," 33rd American Society for Mass Spectrometry Meeting, San Diego, CA, May 28, 1985.

R. A. Durst, "Electrochemical Sensors for Monitoring Metabolic Activity in Biochemical Reactors," Process Measurements for Biotechnology, NBS and Lehigh University, National Bureau of Standards, Gaithersburg, MD, May 29, 1985 .

L. R. Hilpert, "Trace Organic SRM's for Environmental Measurements," 33rd American Society for Mass Spectrometry Meeting, San Diego, CA, May 29, 1985. Invited

M. J. Welch, "The Certification of Organic Analytes in SRM 909 Human Serum by Isotope Dilution Mass Spectrometric Definitive Methods," Workshop on Standard Reference Materials for MS, 33rd Annual Conference on Mass Spectrometry and Allied Topics, San Diego, CA, May 29, 1985. Invited 
G. S. Marbury, "A Thin Layer Spectral and Coulometric Approach to the Characterization of a Series of Copper Dithiolene Complexes," 1985 Electroanalytical Symposium, Chicago, IL, May 31, 1985.

D. K. Hancock, "Structural Elucidation of Proteins by NMR," Department of Chemistry, University of Maryland, May 1985.

R. A. Durst, "Sources of Error in Ion-Selective Electrode Potentiometry," Chemistry Department Seminar, Shanghai Normal University, Shanghai, China, June 7,1985 . Invited

R. A. Durst, "Ionic Activity Standards for the Calibration of Ion-Selective Electrodes," Chemistry Department Seminar, Shanghai Normal University, Shanghai, China, June 8, 1985. Invited

R. A. Durst, "Chemically Modified Electrode Sensors," International Symposium on Ion-Selective Electrodes, Shanghai, China, June 12, 1985. Invited

D. J. Reeder, "Electrophoresis: Techniques and Applications in Analytical Chemistry," Food and Drug Administration, Washington, DC, June 14, 1985. Invited

R. A. Durst, "Analytical Applications of Chemically Modified Electrode Sensors," Departments of Physical and Analytical Chemistry, Peking University, Beijing, PRC, June 20, 1985. Invited

L. C. Sander, "Recent Advances in the Characterization of Bonded Phases," Silanes, Surfaces, and Interfaces Symposium, Snowmass, CO, June 21, 1985.

S. A. Wise, "Investigations of Selectivity in Reversed-Phase LC on Chemically Bonded $\mathrm{C}_{18}$ Phases," Silanes, Surfaces, and Interfaces Symposium, Snowmass, C0, June 21, 1985. Invited

L. C. Sander, "Physical Properties of Alkyl Bonded Phase Sorbents," 9th International Symposium on Column Liquid Chromatography, Edinburgh, Scotland, July 1, 1985.

\section{Committee Assignments}

Willie E. May

Chairman, ADABSE, Analytical Workshop Committee

Member, ASTM, Committee D19 on Water,

Committee E19 on Chromatography

Member, ACS, Environmental Chemistry Division

Board of Directors, Washington Chromatography Discussion Group

Member, CRC-Air Polluation Research Advisory Board

Member, Status and Future Reseach Needs for a Database on Polycyclic

Aromatic Hydrocarbons Working Group

Member, NIH Minority Biomedical Instrumentation Review Board 
Bruce Coxon

Secretary, ASTM, Committee E13.07 on Nuclear Magnetic Resonance, Committe E13 on Molecular Spectroscopy

Member, Program Committee, 12th International Carbohydrate Symposium

Member, Program Committee, 27th Experimental NMR Conference

Richard A. Durst

Member, ASTM, Committee D19 on Water

Member, Board of Advisory Editors, Ion-Selective Electrode Reviews

Member, IUPAC, Committee $V$ on Analytical Chemistry,

Subcommittee 5 on Electroanalytical Chemistry

Member, NCCLS, Subcommittee on Electroanalytical Methods

Subcommittee on $\mathrm{pH}$ and $\mathrm{Blood}$ Gases

Member, NBS, Research Advisory Committee

Diane K. Hancock

Referee, U.S. National Committee on Sugar Analysis, Subcommittee 6 on Quartz Control Plates

Associate Referee, International Commission for Uniform Methods of Sugar Analysis, Subcommittee 6 on Quartz Control Plates

Laurence R. Hilpert

Member, ASTM, Committee D34 on Waste Disposal

Member, ASMS, Environmental Committee

Dennis J. Reeder

Member, AACC, Committee on Standards

Study Group on Total Serum Protein

Associate Member, IFCC, Expert Panel on Drug Effects in Clinical Chemistry

Member, NCCLS, Subcommittee on Total Protein

Robert Schaffer

Member, Area Committee on Evaluation Protocols

Subcommittee on Creatinine

Subcommittee on Thiophylline

Member, NCCLS, Area Committee for Clinical Chemistry

Member, Council for National Reference System in Clinical Chemistry

4. Other

a. Seminars

September 5, 1984 - L. S. Lee, General Electric Research Center, "Applications of Molecular Biology to Protein Modification and Vice-Versa." (Division Sponsor: D. J. Reeder)

September 6, 1984 - Jan T. Andersson, University of Ulm, "Analysis of Polycyclic Aromatic Sulfur Heterocycles." (Division Sponsor: S. A. Wise)

December 17, 1984 - Ira S. Krull, Northeastern University, "A New Photoelectrochemical Detector for HPLC and Flow Injection Analysis (HPLC-PED and FIA-PED)." (Division Sponsor: W. A. MacCrehan) 


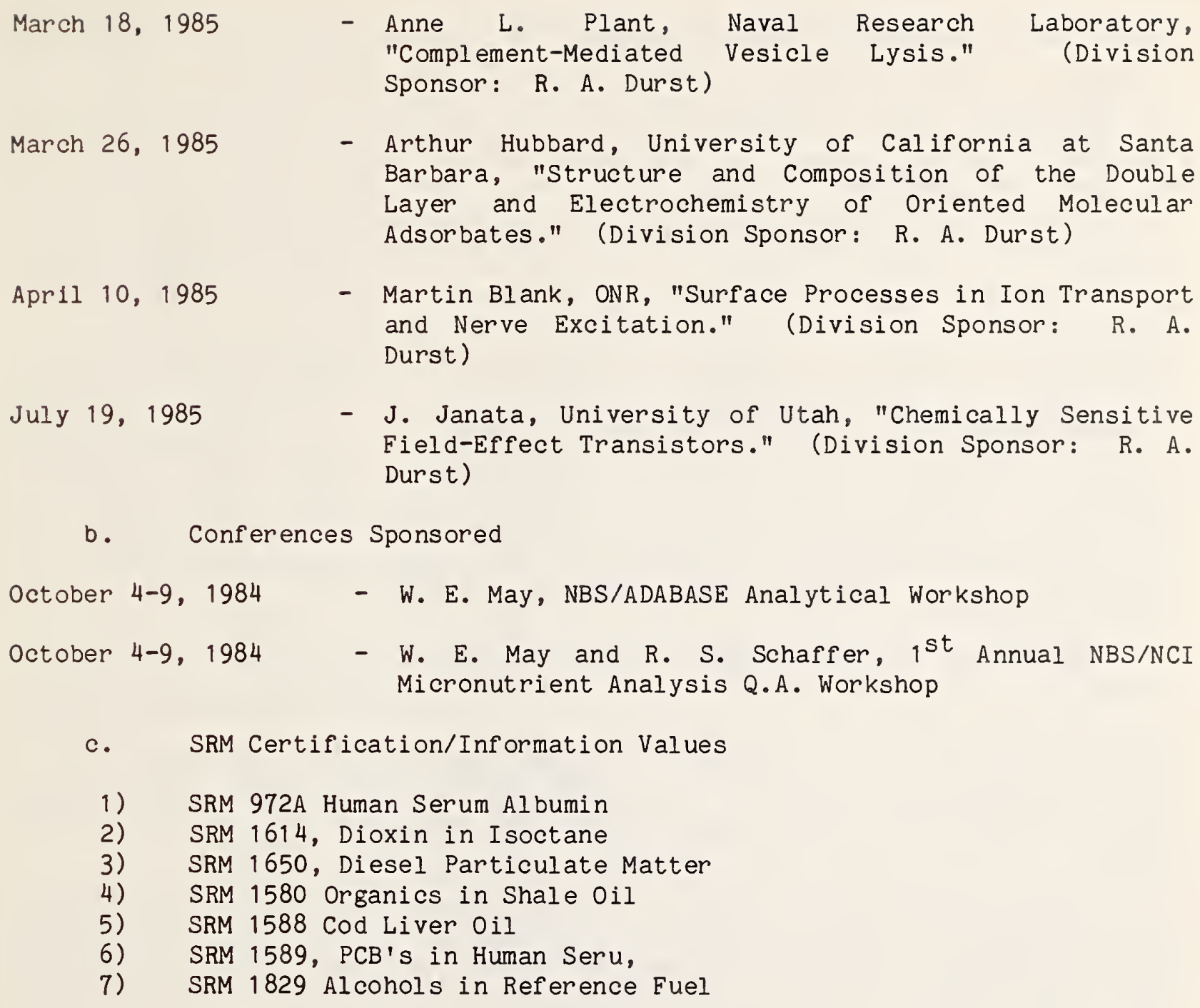

- Arthur Hubbard, University of California at Santa Barbara, "Structure and Composition of the Double Layer and Electrochemistry of Oriented Molecular Adsorbates." (Division Sponsor: R. A. Durst)

April 10, 1985

- Martin Blank, ONR, "Surface Processes in Ion Transport and Nerve Excitation." (Division Sponsor: R. A. Durst)

July 19, 1985

- J. Janata, University of Utah, "Chemically Sensitive Field-Effect Transistors." (Division Sponsor: R. A. Durst)

b. Conferences Sponsored

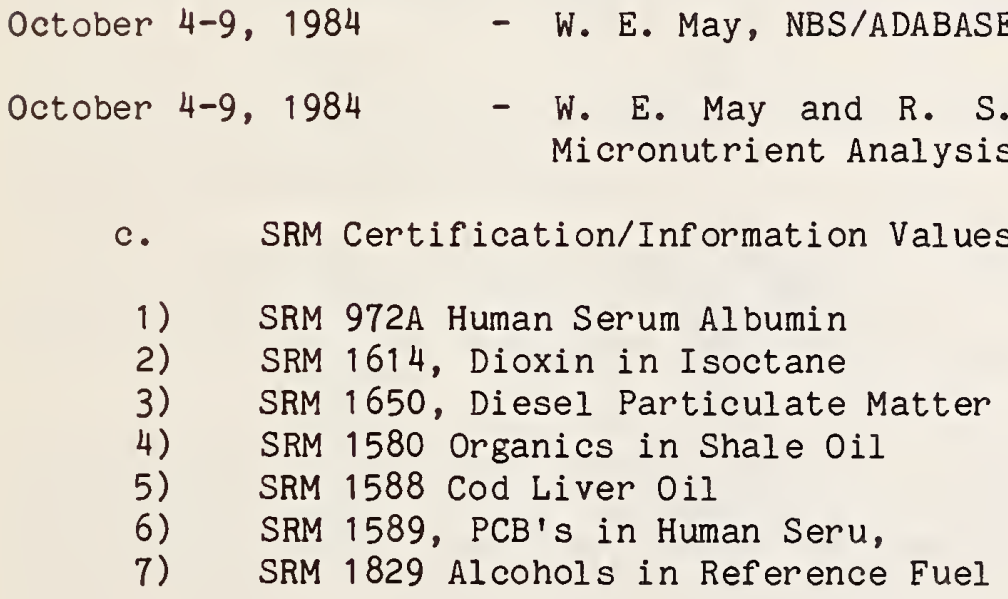


Harry L. Rook, Chief

William D. Dorko, Deputy Chief

\section{A. Division Overview}

The Gas and Particulate Science Division conducts research leading to (a) improved analytical methods for quantitative electron, ion, and photon microanalysis; (b) improved quantitative $x$-ray fluorescence analyses; (c) improved measurements of gaseous species in the atmosphere and in specially prepared gas mixtures; (d) new or improved methods of laser spectrometry for the analysis of specific gaseous molecules; (e) new chemometrics techniques for improved chemical measurements; and ( $f$ ) the preparation and certification of standards for measurement quality assurance in analytical chemistry. The Division responds to the measurement and standards needs of other federal agencies, industrial organizations, universities, and state and local governments. The Division's programs are carried out by five groups with the research efforts divided approximately equally between the two general areas of gas analytical chemistry and microanalytical chemistry.

During the past year, the Division has been reorganized to provide an increased focus on new methods of gas analysis using the wide and increasingly versatile range of laser techniques. Dr. Alan Fried has been appointed as Group Leader of the new Laser Analytical Spectrometry Group. Joining Dr. Fried are Dr. Barry C. Cadoff of the Gas and Particulate Science Division, Mr. Robert Sams formerly of the Inorganic Analytical Research Division, and $\mathrm{Dr}$. Lindsay Lloyd, an NAS/NRC Postdoctoral Research Fellow.

Research in laser spectrometry has been carried out in both fundamental and applied areas. In collaboration with scientists in the Molecular Spectrometry Division, research has been conducted to develop improved lineshape and fitting algorithms for more accurate diode laser absorption measurements. The model-calculated lineshapes, which properly compensate for both the phenomenon of collisional-broadening or collisional-narrowing, have been shown to improve the quantitative accuracy of high resolution infrared measurements by $1.5 \%$. Other sources of systematic errors in diode laser measurements have been studied and substantial improvements have been achieved in analytical accuracy. The obtainable accuracy has been demonstrated on $\mathrm{NO}_{2}$ in air SRMs. Diode laser measurements carried out in collaboration with the Gas Metrology Group have indicated the presence of variable amounts of $\mathrm{HNO}_{3}$ in the $\mathrm{NO}_{2}$ SRMs. The certification measurements have traditionally been made with the chemiluminescence detector (CD) $\mathrm{NO}_{\mathrm{x}}$ analyzer. Intercomparisons carried out on a set of $\mathrm{NO}_{2}$ /air SRMs resulted in systematically high $\mathrm{NO}_{2}$ measurements by chemiluminescence when compared to diode laser absorption. Subsequent research has proven that the $\mathrm{CD}$ was responding to the $\mathrm{HNO}_{3}$ in addition to the $\mathrm{NO}_{2}$. The results of this research have improved the Division's most important output, accurate data on NBS SRMS.

With the separation of laser spectrometry from the Atmospheric Chemistry Group, research has now focused on the use of carbon-14 and other atmospheric molecular and isotopic tracers for source identification and apportionment studies. A second and rapidly growing area of research has been chemometrics. Research accomplishments this year include the first $\mu$ se of methane, carbon monoxide, and other carbonaceous gases coupled with ${ }^{14} \mathrm{C}$ measurements 
to establish potential sources and balances of these gases. The continuing research in small sample input to accelerator mass spectrometry (AMS) was essential in determining the ${ }^{14} \mathrm{C}$ content of the methane and $\mathrm{CO}$. Gas samples

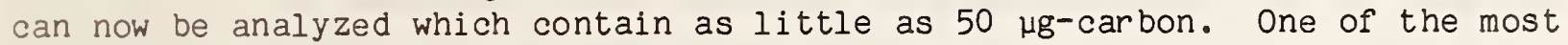
important Chemometrics research developments has been the application of Simulation Test Data (STD) to the assessment and control of quality in the evaluation of analytical data. For the complex data-evaluation phase of chemical analysis, STD thus play a role analogous to SRMs; their importance is therefore likely to increase substantially with increased and automated data evaluation systems.

The Gas Metrology Group has initiated several new projects to provide standard test atmospheres or compressed gas standards not currently available as well as continuing research in long term projects such as trace toxic organic gas standards, dry deposition acid rain standards, and new standard Reference Material gases. Research has been completed on a method to produce predictable test atmospheres containing natural levels of tritium. A prototype standard delivery system has been designed to dilute a known concentration of HT in clean air using either the output of an electrolysis cell or a dilute compressed gas standard. This calibration system will be completed, tested and delivered to the U.S. Air Force for the evaluation of error sources in their Ground Moisture Unit (GMU). This program is a component in the new quality assurance system being implemented by the Division for the Air Force laboratory system.

In the toxic organic gas standards program, two new traceable gas standards have been completed to provide data quality assurance in EPA's national monitoring programs. The standards each contained four components at a nominal concentration of $1 \mathrm{ppb}$. A second and a more ambitious standards research project has been initiated. A 17 component gas mixture of selected toxic organic compounds at approximately $10 \mathrm{ppb}$ concentration has been prepared gravimetrically with predicted concentrations for each component. A gas chromatographic method has been developed using multiple column, multiple detector sample processing to simultaneously analyze all 17 components. Analytical data have been obtained for this standard consistent with the gravimetric preparation data. Stability studies are currently underway.

Other group activities include; the development of two new $\mathrm{CO}_{2}$ gas standards at concentrations of 200 and $1000 \mathrm{ppm}$ to complete the atmospheric $\mathrm{CO}_{2}$ standards set; the development and evaluation of standards and a predictable dilution system to provide calibration mixtures of $\mathrm{SO}_{2}$ in air at concentrations ranging from 100 to $1 \mathrm{ppb}$. This standards system will be used for quality assurance in the EPA national dry deposition acid precipitation program; the completion of several new gas SRMs and special gas analyses in the areas of respiratory gases and natural standards; and the evaluation of pollutant gas levels in indoor air.

During the past year, research in microanalysis has focused on four areas: compositional mapping; improved quantitative analysis technlques; improved particle identification procedures; and the development of new SRMs and other standards for microanalysis.

Research in compositional mapping is a continuing program with partial funding from the Director's Competence Building program and partial funding from the U.S. Air Force. Substantial progress has been made in producing 
direct quantitative digital image maps from the scanning electron microscope (SEM) and the Analytical Electron Microscope (AEM). Procedures have been developed to form digital images, corrected for background, which maintain quantitative integrity in the intensity scale through the entire signal transformation sequence. These maps may then be combined in the computer to create new maps where elemental or isotopic ratios are imaged rather than the original data. Applications of this technology have Deen developed to identify particles or small regions of space which have a unique chemical or isotopic signature.

Research on new types of standards for microprobe analysis has received increased emphasis with the advent of new probes such as the ion microscope, the Laser Microprobe Mass Analyzer (LAMMA) and the use of combined techniques on one sample. A new ultrathin glass film on a support substrate has been fabricated and studied for compositional and structural uniformity. A series of proposed standards has been prepared, analyzed for homogeneity and composition by electron microprobe and is now ready for analysis by a bulk technique. These standards will provide an important addition to those currently available to the microanalysis community. Other standards under development include submicrometer particle standards, a new asbestos standard, and selected bulk glasses with special compositions to study interelement effects in quantitative probe analysis.

Other research activities of the group include: the development of computer-aided imaging for the AEM; investigation of isotopic ratio imaging using the ion microscope; implementation of an advanced multichannel microRaman spectrometer; a study to define the visibility of chrysotile asbestos in scanning electron microscopy; and the development of compositional maps of light element and trace element distributions with the ion microscope.

In $x$-ray fluorescence (XRF), research has continued on the development of a model and computer program for the treatment of interelement $x$-ray absorption/enhancement effects. An important advance in this program is the addition of an algorithm to calculate the spectral output of various types of $x$-ray tubes. After extensive testing of this program at NBS, the program was found suitable for the routine analysis of alloys, powdered minerals and fused specimens. In the area of XRF standards, a cooperative study, with the NBS Polymers and Radiation Physics Divisions, was undertaken to study radiation damage to polycarbonate substrates which have been used in SRMs. A quantitative relationship has been developed to determine the loss in tensile strength as a function of X-radiation. As in past years a major output of the group has been the homogeneity testing and certification analysis of numerous SRMs.

Future research plans for the Division will be influenced by the Center thrusts in compositional mapping, multicomponent analysis, service delivery, and to a lesser extent, biotechnology. Research in compositional mapping has now progressed to where quantitative maps are feasible from most microprobes. However, combining information from different techniques is difficult at best because of the large amount of data and the necessity of point by point verification of combined image composition. This problem will be addressed using direct computer-aided image processing of multiple images, first on previously stored images, and then in an interactive mode as quantitative images are being developed. A major improvement in multicomponent analysis is being 
addressed by the Division's research in chemometrics. Methods using multivariate analysis techniques to optimize data output and to determine the most sensitive parameters in a multicomponent analysis procedure are being studied. This research will be directly coupled with research going on in all three divisions. In the area of the delivery of NBS services, the Division has consistently been at the leading edge of user needs. This year, a program is being planned with the U.S. Air Force to implement a measurement quality assurance program which has been tested on a pilot basis. This program will include blind standard materials for the most sensitive analyses, as well as an automated data verification system. The program will be implemented throughout all of the Air Force analytical laboratories by next year.

\section{Microanalysis Group: Overview}

The Microanalysis Research Group carries out research to advance the development and application of microbeam analysis techniques for the chemical, crystallographic, and morphological characterization of matter on the micrometer and sub-micrometer spatial scale. The analytical techniques utilized are based on primary (excitation) particle beams of electrons, ions, or photons, and secondary (analytical) signals of x-rays, inelastically scattered electrons, inelastically scattered photons, and ions. The techniques include electron microprobe $x-r a y$ analysis, scanning electron microscopy, electron energy loss spectrometry, secondary ion mass spectrometry, laser micro-Raman spectrometry, and laser microprobe mass analysis. Research is conducted on several aspects of each technique, including (1) advancing understanding of the basic physics of sample excitation and attenuation of the secondary radiation; (2) developing methods of quantitation; (3) producing standards and techniques as a means of disseminating developments; and (4) applying results of the research to developing improved compositional mapping techniques and to the study of specific analytical problems in aid of NBS and other government agency activities as well as national scientific priorities.

During FY85, Group research activities included (1) the development of quantitative compositional mapping by means of the electron probe microanalyzer; (2) development and investigation of computer-aided imaging in the analytical electron microscope, including the formulation of advanced image analysis techniques for calibration of the magnification; (3) investigation of isotopic ratio imaging in the ion microscope; (4) implementation of a multichannel micro-Raman spectrometer system; (5) development of a particle collector for sample submission to the analytical electron microscope and laser microprobe mass analyzer; (6) study of the visibility of chrysotile asbestos in the scanning electron microscope; (7) micro-Raman characterization of a complex borate/carbonate new mineral species; (8) implementation of advanced signal acquisition and processing for the laser microprobe mass analyzer; (9) compositional mapping of light elements and trace element distributions with the ion microscope; and (10) measurement of the half-life of rhenium-187 by laser microprobe mass analysis.

A major accomplishment during FY85 has been the first achievement of quantitative compositional maps by means of the electron microprobe. This development has required the extension of the complete procedure used for 
analysis at individual locations to every point in a matrix array image. In addition to the usual deadtime, background, standardization, and matrix correction procedures, the effect of spectrometer defocusing, which is peculiar to scanned images, had to be corrected. The resulting quantitative compositional images had similar accuracy and precision to individual point analyses. The additional problem of presenting compositional information in a quantitative fashion in an image viewed by an observer was investigated. A color encoding scheme based upon the "black body curve" ("thermal scale") was found to provide an intuitive representation.

\section{Future Plans:}

Further development of computer-aided imaging and compositional mapping is planned, with special emphasis on combining images from different techniques to take advantage of the special attributes of each, such as scanning electron microscopy for structural imaging combined with ion microscopy for trace element imaging. In the area of analytical electron microscopy, we plan to implement computer-aided imaging of the conventional static transmission electron image and static electron diffraction modes to complement the digital imaging capabilities which have now been established for the scanning imaging functions. Further development of advanced image processing software is planned to carry out high level automated analyses of particle arrays with minimal operator intervention. Automatic interpretation and analysis of electron diffraction patterns will be investigated as an important analysis mode to complement morphological and compositional information. Acquisition of quantitative secondary ion images in the ion microscope will be investigated. Studies of signal generation and detection in the laser microprobe mass analyzer will seek to place that analysis method on a quantitative basis. In the area of molecular microanalysis, we will continue to improve the multichannel micro-Raman spectrometer. Studies of the molecular microanalysis by laser microprobe will attempt to define sensitivity and spatial resolution.

Dale E. Newbury, Group Leader; Adville A. Bell, David S. Bright, Peter H. Chi, Edgar S. Etz, Robert A. Fletcher, Ryna B. Marinenko, Raymond L. McKenzie, Robert L. Myklebust, Thomas R. Pereles, Patrick J. Sheridan, David S. Simons, John A. Small, Eric B. Steel, and Barbara B. Thorne.

\section{X-Ray Fluorescence Group: Overview}

Major continuing efforts of the X-Ray Fluorescence Group have been directed to the improvement of the accuracy and sensitivity of $x$-ray fluorescence spectrometry for the determination of elemental composition. To achieve these goals, research on first principle data reduction methods has continued with the intent of increasing the accuracy of elemental quantitative analysis. Development of improved sample preparation techniques to increase the analytical sensitivity also remains an important activity of the group. A considerable portion of our work is oriented towards the quantitative analysis and homogeneity testing of new, and renewal SRMs. In addition, we maintain current expertise in the fabrication and characterization of new thin glass films for XRF calibration.

During the past year, we have published a first principle computer program which uses theoretical corrections for treatment of interelement $x$-ray absorption/enhancement effects in bulk specimens. An important feature 
of this program is an NBS-developed algorithm for the calculation of the spectral output distribution of $x$-ray tubes. The computer program called NBSGSC is a result of a cooperative effort between NBS and the Geological Survey of Canada and was developed primarily in response to a need in the $x$-ray fluorescence community for a generally available first principles computer program specifically for minicomputers. The fact that NBSGSC is not a proprietary document, unlike most software available from vendors, allows maximum flexibility in its implementation. After extensive testing of this program at NBS including intercomparison with other data reduction procedures, we propose that NBSGSC is suitable for routine analysis of alloys and minerals, both as powders and as fused specimens.

A closed-system apparatus has been constructed for automated preconcentration of trace elements from solutions onto films impregnated with either ion-exchange resins or various specific chelating ligands. This procedure will allow rapid equilibration of the collected ions with the active sites of the filter, substantially reducing the time for obtaining quantitative recovery of the ions, and therefore preconcentration will no longer be the limiting step in a separation. An evaluation of this apparatus is currently in progress, and the experience gained from this prototype will enable us to advance preconcentration methodology for $x$-ray analysis.

A cooperative study with the NBS Polymers and Radiation Physics Divisions has been undertaken to characterize the radiation damage to polycarbonate substrates which occurs when the films are exposed to X-radiation from high-powered $x$-ray tubes. The substrates are used in NBS/SRM thin film standards for XRF calibration. This work was performed to establish guidelines regarding expected film lifetime for users of these SRMs. A quantitative relationship was found between the amount of $x$-radiation a film received and loss of tensile strength. Further work is in progress with radiation dosimeters to intercompare radiation levels from various types of spectrometers with the intent of establishing guidelines for users.

Finally, during the past year several kinds of samples such as cements, coal, refractories, glasses, tungsten carbide, and over two hundred austenite samples were measured for either elemental homogeneity and/or quantitative analysis.

\section{Future Plans:}

Future plans in $\mathrm{x}$-ray fluorescence research focus on shedding more light on the uncertainties in the fundamental parameters used in first principle calculations of elemental composition, in an effort to determine their influence on accuracy. We plan to study the influence of different sources of mass absorption coefficients in XRF analysis. The fabrication of a limited number of new thin glass films for calibration and quality assurance studies will continue. These films will be used as research materials by the Environmental Protection Agency.

Our efforts in preconcentration methodology are expected to increase significantly next year with the arrival of a guest worker who will devote full time to this project. We intend to automate the quantitative collection of trace elements from solution and to initiate work on fllters containing specific chelating ligands for preconcentration. 
In the area of SRM characterization, we plan to evaluate the homogeneity and analyze several types of alloy materials.

Peter A. Pella, Group Leader; Anthony A. Marlow, John R. Seiber, and Gerald A. Sleater.

\section{Atmospheric Chemistry Research Group: Overview}

The mission of the Atmospheric Chemistry Research Group comprises: a) the development of advanced measurement techniques, plus standard materials, instruments and data for the scientific investigation of trace gases and particles in the atmosphere; and b) basic studies of the design and evaluation of the Chemical Measurement Process, using modern mathematical and statistical methodology, in order to enhance the precision, accuracy and sensitivity of analytical measurements. Research emphasis during the past year has been on high-accuracy atmospheric ozone photometry, source apportionment of atmospheric carbon plus advances in ${ }^{14} \mathrm{C}$ accelerator mass spectrometry, and the application of simulation test data to the assessment of accuracy in the evaluation of analytical data.

Basic measurements of the ozone absorption cross section as a function of wavelength and temperature are being continued, under Air Force sponsorship, to cover the region $350-700 \mathrm{~nm}$. This work extending into the visible part of the spectrum will complement the NBS UV absorption cross section data which has been recommended by the World Meteorological Organization's meeting of experts for the determination of atmospheric ozone concentrations from satellite UV radiance measurements. Modification of the apparatus used for the earlier UV work is underway in order to attain sufficient sensitivity to measure the small absorption cross section in the visible region.

Two additional Standard Reference Ozone Photometers have been fabricated and calibrated, and delivered to the EPA, for inclusion in the national monitoring network. The network will be further augmented by standard Photometers No. 7 and 8; these are under construction, and scheduled for delivery in December 1985.

Atmospheric carbon research has emphasized advances in the measurement capabilities for ${ }^{14} \mathrm{C}$ samples containing less than $100 \mu g-\mathrm{C}$ and also for natural materials having extremely small ${ }^{14} \mathrm{C} /{ }^{12} \mathrm{C}$ ratios -- ca. $1 \times 10^{-16}$ and below. These measurement advances are being pursued in collaboration with accelerator mass spectrometry (AMS) groups at the Universities of Arizona and Rochester, and ETH in Zürich. Approaches include extremely clean, singlecompartment chemical processing, and isotopic enrichment via electromagnetic (E-M) ion separation and micro-thermal diffusion, A manuscript in press gives the first application of the $\mathrm{E}-\mathrm{M}$ method to ${ }^{14} \mathrm{C} \mathrm{AMS}$; in this experiment we detected a signal equivalent to just $140 \mathrm{ng}$ of modern carbon.

The objectives of the extended natural ${ }^{14} \mathrm{C}$ measurement capabilities include the study of very rare nuclear processes in nature and the investigation of individual organic fractions of atmospheric gases and particles to identify sources of toxic and climatically - active species. During FY85 we published the first data on ${ }^{14} \mathrm{C}$ in ambient methane; such data are quite important in terms of natural vs. anthropogenic sources of the increasing atmospheric concentrations of this important "greenhouse" gas. The importance of ${ }^{14} \mathrm{C}$ measurements in establishing the woodburning contribution to 
local air pollution has led to our participation in the EPA Integrated Air Cancer Project. Samples obtained from Raleigh and Albuquerque during last winter's woodburning season will be separated into selected chemical fractions for individual ${ }^{4} \mathrm{C}$ measurements. In this way we may obtain reliable, quantitative information on the woodburning contribution to such noxious spenies as the polycyclic aromatic hydrocarbons.

Work in the area of chemometrics has included participation in Center and international committee activities related to: a) quality assurance and statistics in analytical chemistry; and b) interlaboratory data-evaluation quality assessment and improvement through the use of multivariate (MV) simulation test data (STD). Committee activities have included work on the CAC Quality Assurance Task Force, the thrust of which has been with the quality of laboratory records, reports of analysis, and (statistical) characterization of methods and reporting of data. Work with Commission V. 3 of IUPAC has been directed toward internationally-accepted nomenclature for the evaluation of analytical methods. Two drafts on this topic have been prepared for IUPAC during the current year.

The original NBS Receptor Modeling multivariate STD chemometric intercomparison exposed a number of subtle, assumption and modeling pitfalls in the evaluation of multivariate data. The STD have, as a result, become a research data set (in analogy with research SRM applications), important for developing improved and robust methods of MV chemical data evaluation. We reported on the role of STD in chemometric QA and method development at the first NBS Chemometrics Symposium in May, 1985.

Research activities for FY86 will include: a) completion of the final ozone Standard Reference Photometers (No. 9 and 10) for the EPA National ozone monitoring network, plus establishment of a definite protocol for maintenance and recertification of network instruments relative to the NBS primary standard; b) measurements of the ozone absorption cross section extending to $700 \mathrm{~nm}$, plus initiation of absolute cross section measurements at the wavelengths of the $\mathrm{Hg}$ UV lines; c) completion of the first phase of the Integrated Air Cancer Project, including further development of microradiocarbon chemistry for the assignment of sources of individual classes of toxic organic species; d) continued investigations of carbon isotopes in atmospheric gases and volatile organic matter; e) application of isotopic enrichment - AMS methods to the study of rare nuclear reactions and rare geological or archeological samples; and f) basic studies of experimental design and multicomponent data analysis with emphasis on modeling accuracy, detection limits, and the incorporation of 'scientific intuition'.

L. A. Currie, Group Leader; A. M. Bass, G. A. Klouda, J. E. Norris, W. Ollison, A. E. Sheffield, T. Stafford, J. M. Sullivan, and R. M. Verkouteren.

\section{Gas Metrology Research Group: Overview}

The Gas Metrology Research Group conducts fundamental and applied research leading to a) the improvement of measurements for ambient, trace, and ultra-trace gas analysis, and b) the development of accurate and stable gas standards for a wide variety of inorganic and organic species ranging in concentration from the percent level to $1 \mathrm{ppb}$. 
Reliable inorganic and organic gas standards are developed to provide data quality assurance in measurements made in federal and state programs and by the U.S. industrial community. Analytical measurements and research are carried out to ensure that the resultant standards are both accurate and stable. Research also is carried out in an attempt to improve the scientific understanding of the causes of chemical instability of gas mixtures, to more fully characterize spectroscopic and chromatographic detection parameters, and to gain a better understanding of the basic properties of gas molecules that affect accurate gas analysis and the certification of gas standards.

The Group directly responds to and interacts with gas measurement and standards needs of other agencies, industrial organizations, and standardssetting bodies at the local, state, and national levels, and also performs a limited degree of gas analyses for external organizations.

Activities and accomplishments of the Group during the past year are highlighted in the following sections:

During the past year, new $\mathrm{CO}_{2}$ in air SRMs at 340 and 375 ppm were certified in a program jointly sponsored by the U.S. Department of Energy's Carbon Dioxide Research Division and the NBS Office of Standard Reference Materials. These SRMs are intended for research and monitoring programs to assess global changes in atmospheric $\mathrm{CO}_{2}$. The addition of these two SRMs makes a total of five such SRMs now available in the 300-400 ppm range of interest. These new SRMs also have been certified for $\mathrm{N}_{2} \mathrm{O}$ at 300 and 335 $\mathrm{ppb}$, with information values provided for methane and for halocarbons $\mathrm{F}-11$ and $\mathrm{F}-12$. Confirmatory analyses of $\mathrm{CO}_{2}$ by absolute manometry at the Scripps Institution of Oceanography further validated the Group's absolute gravimetric procedure used for preparing primary gas standards. Work on an isotope-dilution technique using a specially designed mass spectrometer system developed in the Inorganic Analytical Research Division is nearing refinement as an independent NBS reference method for accurate measurements of $\mathrm{CO}_{2}$ in air.

In a continuing NBS/EPA program to provide data quality assurance in national ambient and hazardous waste incineration measurements, two stable multi-component toxic organic gas standards were prepared at the $1 \mathrm{ppb}$ level. One of these contained benzene, toluene, bromobenzene, and chlorobenzene; the other contained vinyl chloride monomer, chloroform, carbon tetrachloride, and tetrachloroethylene. In addition, the Group evaluated the feasibility of developing a 17-component accurate and stable mixture of toxic organics at the $10 \mathrm{ppb}$ level. Such mixtures are needed for the accurate analysis of ambient air samples using capillary GC-MS. Research also was carried out for the development of eight-component standards at 150 and $10 \mathrm{ppb}$ (representing EPA's "Group Three Organics") and a five-component mixture at 2 ppm (representing EPA's "Group One Organics"), for EPA's hazardous waste incineration program. SRMs completed during the past year included two multi-component SRMs at $10 \mathrm{ppm}$ and $250 \mathrm{ppb}$ containing benzene, toluene, chlorobenzene, and bromobenzene, and a tetrachloroethylene permeation device. The Group's present inventory of primary standards for this program comprises over 80 gas cylinder mixtures, covering about 25 organics over a range of 50 ppm to 1 $\mathrm{ppb}$. 
Work under the Group's Air Force (AFTAC) project included the development of a stable source of tritium as a calibrant for the detection of changes in the atmospheric tritium level (nominally, about $10^{-15} \mathrm{ppm}$ ). Work also was completed on the development of a set of homogeneous gas standards of tritiated methane for use by AFTAC laboratories in measurements of atmospheric tritiated methane. A new electrolysis cell was developed and evaluated as a stable, predictable source of tritium. A prototype tritium calibration system is presently being designed and fabricated for delivery to AFTAC in early 1986.

A new NBS/EPA project focusing on the development of calibration mixtures of $\mathrm{SO}_{2}$ in air for dry acid deposition studies, validated the feasibility of such standards at $100 \mathrm{ppb}$. A dynamic dilution system intended for field use has been designed and is being evaluated for the predictable dilution of such standards down to $1 \mathrm{ppb}$. Calibrations have been based on the use of an $\mathrm{SO}_{2}$ dilution system using pulsed fluorescence and flame photometric detectors. Temperature and input pressure effects on the performance of the mass flow controllers used for the dilution system have been quantified. Work in two related areas also was initiated: viz., an evaluation of the feasibility of developing stable standards of $\mathrm{NO}$ in $\mathrm{N}_{2}$ at $100 \mathrm{ppb}$ and of $\mathrm{H}_{2} \mathrm{~S}$ in $\mathrm{N}_{2}$ at 5-20 ppm. The latter standards also are needed for calibrating reduced sulfur emissions produced by the U.S. pulp and paper industry.

In a program supported by the Chemical Manufacturers Association, research was carried out to quantify the temperature dependence of band strengths for halocarbons $\mathrm{F}-11$ and $\mathrm{F}-12$ at stratospherically-relevant temperatures. This research was conducted using Fourier-transform infrared spectroscopy and a specially-designed cryogenic gas cell. The results of this research will provide base-line data for quantifying and predicting fluorocarbon levels in the earth's upper atmosphere.

Other research accomplishments of the past year have included:

- The certification of four new SRMs containing carbon dioxide and oxygen specifically designed for blood gas measurements. Such measurements are made at a level of hundreds of thousands annually in hospitals throughout the U.S. These are the first such standards produced by NBS, and were developed at the request of a national committee for clinical laboratory standards.

- A detailed analytical characterization of natural gas standards to provide NBS traceability to both GC and calorimetric measurements of natural gas made throughout the U.S. These measurements were made to minimize the potentially significant fiscal error associated with the uncertainty of such measurements as the U.S. converts from billing by volume to billing by BTU and changes from calorimetry to GC analysis for such measurements.

- A study involving real-time measurements of pollutant gases $\left(\mathrm{SO}_{2}\right.$, $\mathrm{NO}_{x}$, and $\mathrm{O}_{3}$ ) in storage and reading room areas was carried out at the request of the National Library of Medicine to allow it to assess its potential needs for upgrading the facility's air handling systems. A detailed report of the findings has been prepared and submitted. 
- Research studies using chemiluminescence and diode laser spectroscopy resulted in the detection and quantification of nitric acid as a heretofore undetected species in $\mathrm{NO}_{2}$ SRMs.

- Research was carried out for the development of an electrochemicallybased analysis system for $\mathrm{SO}_{2}$ mixtures, representing the first serious venture of the Group into the development of absolute electrochemical methods (i.e., traceable to the coulomb) for gas analysis. The first prototype system designed for this purpose (based on the use of electrodes and photocells) has provided a precision error of less than $1 \%$ for the analysis of a number of $50 \mathrm{ppm} \mathrm{SO}_{2} \mathrm{SRMs}$

Future activities of the Group will involve: a) the certification of $\mathrm{CO}_{2}$ in air SRMs at 100 and $1000 \mathrm{ppm}$ to assist agricultural research on the potential effects of changing levels of atmospheric $\mathrm{CO}_{2}$ on vegetation growth; b) the continued development of NBS-traceable toxic organic standards for ambient monitoring and hazardous waste incineration audits (including two new multi-component toxic aliphatic organic mixtures as SRMs); c) the continuation of research on the development of electrochemically-based systems for the analysis of polar gases; d) automation of the Group's inorganic mass spectrometer; e) the development of low ppb mixtures of $\mathrm{SO}_{2}$, NO, and $\mathrm{H}_{2} \mathrm{~S}$ dry acid deposition research; and f) continued research on fundamental spectroscopic properties of important gas species.

Group staff changes during the year have included the transfer of Dr. Barry Cadoff to a new Analytical Laser Spectrometry Group. Francois Abbo, from the Center for Research and Development of L'Air Liquide, Paris, France spent eight months in the Group as a Research Associate in the areas of reactive gas instability and statistical methods for gas analysis. The appointment of a second scientist (Zhong-tao Cai, from the Shanghai Institute of Ceramics) was renewed for a second year as a Guest Worker involved in the analysis of ultra-trace levels of reactive gases. Another Guest Worker from the People's Republic of China will be joining the Group in November of this year.

More detailed write-ups of selected activities and accomplishments of the Gas Metrology Research Group are provided in the following section.

Walter L. Zielinski, Jr., Group Leader; Z.-T. Cai, William F. Cuthrell, William D. Dorko, James W. Elkins, Ernest E. Hughes, Patricia, A. Johnson, Rudolph Von Kelly, Gerald D. Mitchell, W. Robert Miller, Richard D. Myers, George C. Rhoderick, James E. Suddeuth

\section{Analytical Laser Spectrometry Group: Overview}

Research in analytical laser spectrometry has been carried out in previous years in the Atmospheric Chemistry Group. However, because of the extensive and rather specialized nature of this field a new group, the Analytical Laser Spectrometry Group, has been formed this year. The Analytical Laser Spectrometry Group conducts research on the development, characterization and application of state-of-the-art laser-based spectroscopic techniques for the detection of trace and ultra-trace level gaseous atmospheric constituents. The analytical techniques utilized include a) photoacoustic spectroscopy, b) phase fluctuation optical heterodyne detection, c) photothermal deflection, and d) tunable diode laser and Fourier Transform IR (FTIR) 
absorption spectrometry. A primary objective of the research carried out in the group is the improvement of measurement sensitivity, selectivity and accuracy of these various techniques for the analysis of trace reactive atmospheric gases. Other objectives include: (1) development of new calibration approaches for the above laser-based techniques; (2) measurement of funtamental molecular parameters necessary for quantitative spectrometry such as infrared absorption, pressure-broadening and collisional-narrowing coefficients; (3) intercomparison of concentration determinations by various techniques; and (4) application of tunable diode laser spectrometry in the verification of gas standards and in kinetic measurements of transient species.

Research this past year, both fundamental and applied, has focused on tunable diode laser absorption spectrometry (TDLAS). In collaboration with the Molecular Spectroscopy Division, research has been conducted to develop sophisticated lineshape and fitting algorithms for accurate quantitative diode laser measurements. These sophisticated lineshapes, which not only incorporate the phenomenon of collisional-broadening but also collisionalnarrowing, have been shown to improve the quantitative accuracy of high resolution infrared measurements by 1-5\%. In addition, studies have also been completed that identify and characterize much larger systematic error sources (in the 5-30\% range) in diode laser measurements carried out in the direct absorption mode. Such sources, which are caused by multi-mode lasing, can be manifested in a variety of different ways. This will be further discussed in one of the selected technical reports that follow.

Significant progress has also been achieved this past year on a number of other fronts to improve the accuracy of direct absorption tunable diode laser measurements for the determination of trace atmospheric constituent concentrations and fundamental molecular parameters. First, all direct absorption measurements are now carried out simultaneously with relative frequency measurements from a high resolution confocal interferometer using a double beam set-up. This instrument, as discussed in last year's report, allows the laser linewidth to be determined for each absorption feature under study. The double beam configuration implemented this year, further eliminates relative frequency drifts due to drifts in temperature that arise when the absorption and interferometer spectra are recorded at different times. Secondly, we have adopted the technique of sweep integration in our direct absorption measurements. In this data acquisition mode, the diode laser is repetitively swept at high repetition rates through each spectral region of interest and the data from many such repetitive scans is averaged in a dualchannel signal averager. This technique was found to significantly reduce the problems associated with frequency instabilities which can occur using the more traditional slow scan (fixed frequency integration) procedure. As a final improvement in our set-up achieved this past year, we have irterfaced the signal averager to a laboratory microcomputer. Data analysis can now be carried out using the newly developed line fitting algorithms directly on the digitized absorption spectra output from the signal averager.

In the area of applied research, TDLAS has been employed this past year in the analysis of high concentration $\mathrm{NO}_{2} / \mathrm{air}$ (250-2500 ppm range) compressed gas standards. Such studies are part of our long term effort to verify gas standards employing independent measurement techniques. This research, carried out in collaboration with the Gas Metrology Research Group, was in1tiated because the traditional technique of Chemiluminescence Detection (CD) 
is not specific to $\mathrm{NO}_{2}$. Other nitrogen oxide species, if present, would also be simultaneously detected thus causing systematically high $\mathrm{CD} \mathrm{NO}_{2}$ determinations. TDLAS, on the other hand, is very selective and is therefore not susceptible to this systematic error. Intercomparisons carried out on a selected group of $\mathrm{NO}_{2}$ /air cylinders resulted in systematically high CD determinations of $\mathrm{NO}_{2}$ in the 5-15\% range. Additional TDL measurements in a different spectral region unequivocally identified the presence of $\mathrm{HNO}_{3}$ in each of the cylinders examined. Subsequent measurements revealed that the $C D$ was in fact responding to $\mathrm{HNO}_{3}$ in addition to $\mathrm{NO}_{2}$. This gas has since been found in each and every high concentration $\mathrm{NO}_{2}$ cylinder (over 25) examined to date.

The Group has also been active this past year in recommending, and subsequently in providing guidance and oversight, to NASA in the design and construction of an ultra-trace level $\mathrm{NO}_{2}$ calibration system. This system will play an integral part in field experiments carried out later this year as part of NASA's Global Tropospheric Experiment. Because of this importance, significant group effort is being expended in planning and implementing a series of laboratory intercomparisons utilizing Gas-Phase-Titration (GPT), $\mathrm{NO}_{2}$ permeation, and TDLAS to calibrate the NASA system.

Research planned for the upcoming year will continue many of the efforts initiated this past year. In particular, research will focus on employing TDLAS in: (1) the re-investigation of GPT, (2) the determination of absorption and pressure-broadening coefficients for selected lines of $\mathrm{NO}_{2}$, (3) studies to characterize $\mathrm{HNO}_{3}$ in high concentration $\mathrm{NO}_{2}$ /air compressed gas cylinders, (4) in research efforts to develop a dynamic $\mathrm{HNO}_{3}$ generation and calibration system for ppm and sub-ppm concentration levels, (5) the implementation of procedures and protocols by which EPA can calibrate a mobile TDLAS for field measurements of $\mathrm{NO}_{2}$, (6) the continued investigation of systematic error sources, and (7) in the determination of absorption coefficients for $\mathrm{HO}_{2}$.

Alan Fried, Croup Leader; Barry Cadoff, and Linda Nunnermacker. 
1. Development of Ultra-Trace (1 ppb) and SRM Multi-Component Toxic Organic Gas Standards

W. F. Cuthrell, G. C. Rhoderick, and W. L. Zielinski, Jr.

Two of the major accomplishments during the past year in a continuing NBS/EPA program for the development of standards of toxic organic gases for national ambient air monitoring programs have been: a) the development of multi-component aromatic and aliphatic toxic gas mixtures at nominal concentrations of 1 part-per-billion ( $p p b)$; and b) the certification of two fourcomponent aromatic gas SRMs at nominal concentrations of 10 part-per-million $(\mathrm{ppm})$ and $250 \mathrm{ppb}$.

\section{a. Multi-component Toxic Organic Gas Standards at 1 ppb:}

Two NBS-traceable toxic organic gas standards were gravimetrically prepared in the $1 \mathrm{ppb}$ range and were analytically verified. The first was a four-component aromatic mixture of benzene, toluene, chlorobenzene, and bromobenzene in nitrogen, characterized at concentrations of $0.93,0.88,1.42$, and $1.22 \mathrm{ppb}$ by mole, respectively. The uncertainties of these concentrations at the 95\% confidence level were 0.07, 0.07, 0.06, and 0.08 ppb, respectively. The second was a four-component aliphatic mixture of vinyl chloride monomer, chloroform, carbon tetrachloride, and tetracholorethylene in nitrogen, characterized at concentrations of $0.90,1.08,1.15$, and 1.85 $\mathrm{ppb}$ by mole, respectively. The uncertainties of these concentrations were $0.08,0.04,0.03$, and $0.04 \mathrm{ppb}$, respectively. These standards have been used in EPA field studies to quantify and evaluate sampling procedures for toxic organics in ambient air. A six-month reanalysis of these standards has shown the concentrations of all of the analytes to be unchanged since the preparation of the standards. These standards represent the lowest concentrations of gaseous toxic organics prepared to date which are both accurate and stable.

\section{b. Certification of Multi-component Toxic Aromatic Gas SRMs:}

Two fifty-cylinder batches of compressed gas containing benzene, toluene, chlorobenzene, and bromobenzene in nitrogen were certified as SRMs during the past year at nominal concentrations of $10 \mathrm{ppm}$ and $250 \mathrm{ppb}$, respectively. The certification process involved: (a) the preparation of primary gravimetric gas standards containing each of these analytes at concentrations bracketing the two SRM concentrations; (b) characterization of randomlyselected samples ("internal standards") from each batch, using the primary gravimetric gas standards; (c) intercomparative analyses of all samples in each of the two batches with the characterized batch internal standards, to assess batch homogeneity and long-term stability of the samples; and (e) final analytical rechecks. The uncertainty of the analyte concentrations at the $95 \%$ confidence level in each batch varied from less than $1 \%$ relative for benzene to less than $2 \%$ relative for bromobenzene. These SRMs represent the first multi-component toxic organio gas SRMs certified by NBS, and are intended for the calibration of instruments and methods for the analysis of these analytes in ambient air. 
2. Sampling and Analysis of Nitrous Oxide, Carbon Dioxide, and Methane to Characterize Nitrogen and Carbon Cycles During NITROP-85 Cruise in the Peru Coastal Upwelling Region

\section{J. Elkins}

The coastal waters off Peru are an area of high biological productivity which are fed by nutrient rich Antarctic seawater. Biological rates for the transformation of both nitrogen and carbon into useful nutrients for plant and animal life are the highest in this region of the ocean. High rates for photosynthesis by plankton in the surface water yield an oxygen deficient zone at 150-300 meters depth produced by the decay of falling organic material. The "Nitrogen Transformations in the Oxygen Minimum Zone off Peru" or NITROP-85 cruise between February 1 and March 4, 1985, was sponsored by the National Science Foundation. This cruise offered an excellent opportunity to study these transformations and compare these results with previous work completed in March 1978. Scientists from four countries participated in this expedition representing Bigelow Laboratory, Duke University, Harvard University, University of Copenhagen, Scripps Institution of Oceanography, and the National Bureau of Standards.

Three biologically mediated gases, nitrous oxide $\left(\mathrm{N}_{2} \mathrm{O}\right)$, methane $\left(\mathrm{CH}_{4}\right)$, and carbon dioxide $\left(\mathrm{CO}_{2}\right)$, were measured by gas chromatography on board oregon State University's ship, the R/V WECOMA. In total, more than 300 air samples and 800 water samples were analyzed during the cruise. The gas standards used to calibrate the gas chromatographs were prepared at NBS. These same standards were used to certify a series of gas Standard Reference Materials (SRMs) for $\mathrm{CO}_{2}$ and $\mathrm{N}_{2} \mathrm{O}$ with information values for $\mathrm{CH}_{4}$ and halocarbons $\mathrm{F}-11$ and F-12. All three gases measured may contribute to the predicted "greenhouse effect" warming in the atmosphere by absorbing re-radiated infrared energy from the earth's surface. Characterizing oceanic sources and sinks of these gases may help in our understanding of the complex interaction between the ocean and atmosphere.

The preliminary findings indicate that the highest $\mathrm{N}_{2} \mathrm{O}$ saturations occurred in the surface waters at stations exhibiting strong coastal upwelling. Indeed, the highest value of $\mathrm{N}_{2} \mathrm{O}$ ( 8.5 micrograms per liter) ever observed in the open ocean was at 8 meters depth near $10^{\circ} \mathrm{S}$. Generally, $\mathrm{N}_{2} \mathrm{O}$ varied inversely with the dissolved oxygen concentration, indicating a nitrification or ammonium $\left(\mathrm{NH}_{4}^{+}\right)$or nitrite $\left(\mathrm{NO}_{2}^{-}\right)$oxidation source. This trend continued until mixing occurred with very low dissolved oxygen water $(<0.1$ $\mathrm{mL} / \mathrm{L}$ ) in the secondary nitrite maximum or region of denitrification (reduction of nitrate, $\mathrm{NO}_{3}$, to dinitrogen gas, $\mathrm{N}_{2}$ ). In this region, the concentration of $\mathrm{N}_{2} \mathrm{O}$ was lowest where the $\mathrm{NO}_{2}$ was the highest. This was indirect evidence that $\mathrm{N}_{2} \mathrm{O}$ is consumed during denitrification. Profiles of $\mathrm{N}_{2} \mathrm{O}$ during this cruise showed that regions for sinks of $\mathrm{N}_{2} \mathrm{O}$ were closer to the coast and existed in some locations as two distinct minima in the water column, whereas data from 1978 had only one minimum at 200 meters. High supersaturations of methane with respect to air were observed below 50 meters in coastal stations near $15^{\circ}$ when hydrogen sulfide $\left(\mathrm{H}_{2} \mathrm{~S}\right)$ was present. All surface water samples were supersaturated with respect to atomspheric $\mathrm{CO}_{2}$. 
3. Application of Electrochemical Methods for the Absolute Measurement of $\mathrm{SO}_{2}$ Gas SRMS

G. D. Mitchell and A. A. Bell

Gas Standard Reference Materials (SRMs) with few exceptions are certified from primary gas standards prepared gravimetrically. Sulfur dioxide gas mixtures have been difficult to prepare as a stable primary standards. Because of the difficulty of preparing $\mathrm{SO}_{2}$ standards gravimetrically, the peroxide titration method is used to certify the concentration. The peroxide method has problems of imprecision which require extensive analyses in order to develop a satisfactory level of statistics to specify the concentration of $\mathrm{SO}_{2}$ in SRMs.

Recently, research on an electrochemical method was initiated in an attempt to establish an absolute method of analysis with traceability to the coulomb. The chemistry involved in the electrochemical method is identical to that of the peroxide titration method. The coulometric method explored here is specific to the determination of $\mathrm{SO}_{2}$ in a gas stream. This is realized by feeding back the amplified photometric end-point detection output as a coulometric titration current. With sulfur dioxide, sodium hydroxide is generated at the cathode at a rate equivalent to the rate of formation of sulfuric acid (from the reaction of $\mathrm{SO}_{2}$ with $\mathrm{H}_{2} \mathrm{O}_{2}$ ) and at equilibrium the current is proportional to the concentration of sulfur dioxide in the gas stream.

The primary criteria for a successful procedure is recognized as (1) complete current efficiency, and (2) complete reaction of $\mathrm{SO}_{2}$ with $\mathrm{H}_{2} \mathrm{O}_{2}$.

\section{Reaction:}

Sulfur dioxide reacts with hydrogen peroxide to form sulfuric acid:

$$
\mathrm{SO}_{2}+\mathrm{H}_{2} \mathrm{O}_{2}=\mathrm{H}_{2} \mathrm{SO}_{4}=2 \mathrm{H}^{+}+\mathrm{SO}_{4}=
$$

When current flows through the electrochemical cell the cathode reaction is

$$
2 \mathrm{Na}^{+}+2 \mathrm{H}_{2} \mathrm{O}+2 \mathrm{e}^{-}=2 \mathrm{NaOH}+\mathrm{H}_{2}
$$

and the sodium hydroxide generated neturalizes the sulfuric acid

$$
2 \mathrm{NaOH}+\mathrm{H}_{2} \mathrm{SO}_{4}=\mathrm{Na}_{2} \mathrm{SO}_{4}+2 \mathrm{H}_{2} \mathrm{O}
$$

The electrode system used in this study is a platinum cathode and a silver anode with an alternative cathodic and anodic reaction of

$$
2 \mathrm{H}^{+}+2 \mathrm{e}^{-}=\mathrm{H}_{2}
$$

and

$$
\mathrm{Cl}^{-}+\mathrm{Ag}=\mathrm{AgCl}+\mathrm{e}^{-}
$$


The results to date using $\mathrm{SO}_{2}$ in nitrogen SRMs at the $50 \mathrm{ppm}$ level reveal that the relative precision of the method is comparable to that of the peroxide titration method.

Work is continuing on the assessment of precision and accuracy, improving the current efficiency, and the sensitivity to the part-per-billion level.

4. Measurement of Nitric Acid in High Concentration $\mathrm{NO}_{2}$ SRMs Using Diode Laser Spectroscopy Coupled with Chemiluminescence Analysis

W. Dorko, A. Fried, R. Sams, and Z.-T. Cai

There are currently four gaseous SRMs of nitrogen dioxide $\left(\mathrm{NO}_{2}\right)$ in air available from NBS, ranging in concentration from 250 to $2500 \mathrm{ppm}$. The great majority of users of these SRMs will employ them to calibrate chemiluminescent detectors (CD) to analyze for $\mathrm{NO}_{2}$ in the atmosphere, or in emissions from industrial stacks. Because of the predominant use of CD for this purpose, the SRMs were certified using this technique. The CD is basically a nitric oxide (NO) analyzer in which the detector responds to the light given off by the gas phase reaction of ozone $\left(\mathrm{O}_{3}\right)$ with $\mathrm{NO}$. To measure $\mathrm{NO}_{2}$, the sample is passed through a hot stainless-steel reaction chamber to convert the $\mathrm{NO}_{2}$ to $\mathrm{NO}$, following which the sample passes into the detector where the NO reacts with $\mathrm{O}_{3}$ and is detected. Other nitrogen compounds, such as $\mathrm{HNO}_{3}$, $\mathrm{N}_{2} \mathrm{O}_{4}$, and $\mathrm{N}_{2} \mathrm{O}_{3}$ can also be converted to $\mathrm{NO}$ in the reaction chamber. In such cases, the $C D$ serves as an $\mathrm{NO}_{\mathrm{x}}$ detector. Research was carried out in which the $C D$ was coupled with a tunable diode laser absorption spectrometer (TDLAS) to more specifically characterize the composition of the $\mathrm{NO}_{2} \mathrm{SRMS}$. The $\mathrm{NO}_{2}$ level determined by the TDLAS was found to be consistently lower than the $\mathrm{NO}_{2}$ level as determined by the $\mathrm{CD}$. The TDLAS was subsequently scanned through other spectral regions, revealing the presence of nitric acid $\left(\mathrm{HNO}_{3}\right)$ in the $\mathrm{NO}_{2}$ SRMs. When the $\mathrm{HNO}_{3}$ and $\mathrm{NO}_{2}$ contents determined by TDLAS were added together, the results came much closer to those obtained using the $\mathrm{CD}$. This finding indicated that both $\mathrm{NO}_{2}$ and $\mathrm{HNO}_{3}$ are converted to $\mathrm{NO}$ in the $\mathrm{CD}$ reaction chamber. Literature reports indicated that nylon selectively scrubs $\mathrm{HNO}_{3}$ from $\mathrm{NO}_{2}$ mixtures; therefore, a nylon scrubber was fabricated, tested, and found to be very selective for $\mathrm{HNO}_{3}$. This scrubber, in conjunction with the $\mathrm{CD}$, was then used to determine the $\mathrm{HNO}_{3}$ content in a number of cylinders of each of the four SRMs. This was done by observing the difference in the $\mathrm{NO}_{\mathrm{X}}$ signal with and without the scrubber.

At the $250 \mathrm{ppm} \mathrm{NO} 2$ level (SRM 非653), ten cylinders were analyzed for $\mathrm{HNO}_{3}$, providing $\mathrm{HNO}_{3}$ values ranging from 9 to $24 \mathrm{ppm}$. Nine cylinders of SRM \#2654 (500 ppm $\mathrm{NO}_{2}$ ) were analyzed, for which $\mathrm{HNO}_{3}$ ranged from 48 to $67 \mathrm{ppm}$. For SRM 非655 ( $1000 \mathrm{ppm} \mathrm{NO} 2$ ), five cylinders had a range of 29 to $39 \mathrm{ppm}$. A range of 49 to $116 \mathrm{ppm} \mathrm{HNO}_{3}$ was detected in nine cylinders of the $2500 \mathrm{ppm}$ $\mathrm{NO}_{2}$ (SRM \#2656).

The finding of $\mathrm{HNO}_{3}$ in these cylinder mixtures at such relatively high levels was unexpected. However, this finding does not adversely effect their utility as $\mathrm{NO}_{2}$ standards, since essentially all of the measurements for which they are used are for total $\mathrm{NO}_{\mathrm{X}}$. 
5. Development of New SRMs for $\mathrm{CO}_{2}$ in Air at Atmospheric Concentrations for World-Wide Monitoring of Atmospheric $\mathrm{CO}_{2}$ Changes

E. E. Hughes, J. Elkins, and W. L. Zielinski, Jr.

During the past year, four important SRMs were certified for both $\mathrm{CO}_{2}$ and $\mathrm{N}_{2} \mathrm{O}$ in the ambient concentration range of 300-400 ppm by mole and 250-350 ppb by mole, respectively, in both 150 and 30 cubic-foot cylinders. These SRMs are intended to serve the world-wide $\mathrm{CO}_{2}$ research community's needs for standards to provide long-term quality data for accurate monitoring of the upward trend of global $\mathrm{CO}_{2}$ in the atmosphere. One of two fifty-cylinder batches, representing two of the SRMS (separate SRM numbers are used for the large and small cylinders in each of two batches), contains $\mathrm{CO}_{2}$ and $\mathrm{N}_{2} \mathrm{O}$ at nominal concentrations of $340 \mathrm{ppm}$ and $300 \mathrm{ppb}$, respectively; the second of the two batches (representing two different SRMs), contains $\mathrm{CO}_{2}$ and $\mathrm{N}_{2} \mathrm{O}$ at nominal concentrations $375 \mathrm{ppm}$ and $334 \mathrm{ppb}$, respectively. The actual concentration of $\mathrm{CO}_{2}$ is individually certified in each cylinder of these SRMs. Information values also are provided for these SRMs for methane (1.7-1.8 ppm) and for halocarbons $F-11$ and $F-12$ in the 300-500 parts-per-trillion range. Completion of these SRMs, encompassing a period in excess of two years, involved the preparation of numerous gravimetric primary standards, extensive analytical characterization, and intercomparative analyses of $\mathrm{CO}_{2}$ in selected samples by constant volume manometry (performed by C. D. Keeling and P. Guenther of the Scripps Institution of Oceanography of the University of California-LaJolla).

The concentration of $\mathrm{CO}_{2}$ in each of these SRMs is certified to a total uncertainty not exceeding $+/-0.1 \%$ relative $(0.3 \mathrm{ppm}$ at $300 \mathrm{ppm})$ at $95 \%$ conf idence level. Primary standards of such mixtures have been found to be stable over periods in excess of 3.5 years. The concentrations of $\mathrm{CO}_{2}$ in the SRMs are certified to be stable within their uncertainty for a period of two years from date of purchase from NBS. A quality assurance program operated by the Gas Metrology Group involves the routine reanalysis of samples of all gas SRMS that have been certified to verify that their certified concentrations have remained unchanged.

This work, supported by the U.S. Department of Energy's Carbon Dioxide Research office, completes the transfer of responsibility for $\mathrm{CO}_{2}$ in air standards from the Scripps Institution of Oceanography to NBS. With the addition of the four new SRMs, NBS now offers seven SRMs of $\mathrm{CO}_{2}$ in air, in the 300-400 ppm concentration range. Research is currently underway to complete two additional SRMs of $\mathrm{CO}_{2}$ in air at a nominal concentration of 300 ppm, as well as two new SRMs at 200 and $1000 \mathrm{ppm}$.

6. Indoor Air Measurements for Sulfur Dioxide, Nitrogen Oxides, and Ozone in the National Library of Medic ine

Richard C. Myers

Several locations of the indoor air environment at the National Library of Medicine were evaluated for pollutant gases, specifically sulfur dioxide, nitrogen oxides, and ozone. The measurements of these gases were made between April 8 and April 15, 1985. Continuous monitoring analyzers were 
used to collect data to determine the concentrations of these substances entering the building from the outside atmosphere via the ventilation system.

The locations at which these species were monitored, were a stack area used for the storage of reading material and a corner of the main reading area. The air exiting the ventilation system was sampled for a period of approximately 48 hours at each site. The air inside an unventilated room containing 5 photocopy machines also was sampled for ozone. Measurements of ozone made in the photocopy room were intended only to quantify any ozone produced by the photocopiers.

Ambient sulfur dioxide levels were measured with a pulsed fluorescent sulfur dioxide analyzer. Nitrogen oxides, as $\mathrm{NO}_{x}\left(\mathrm{NO}+\mathrm{NO}_{2}\right)$, were measured with a chemiluminescence analyzer. A microcoulomb ozone sensing instrument was used for measuring ozone levels.

Calibrations of the sulfur dioxide and nitrogen oxides analyzers were performed on a daily basis using sulfur dioxide and nitrogen dioxide permeation devices, previously calibrated at NBS. A flow of diluent air passed over each tube was measured with a calibrated mass flow meter. The sensitivity of the ozone instrument was determined at NBS using an ultraviolet adsorption analyzer and a standard reference photometer.

A conclusion which could be drawn from the measurements made, is that, the interior atmosphere of the library will reflect almost without change the external atmosphere. Increases in nitrogen oxide levels usually occurred twice daily which could be correlated with nearby traffic patterns. Increases in sulfur dioxide levels were observed when the wind direction was such that it passed in line of a nearby powerplant before reaching the library. Ozone also was detected in the air sampled from the ventilation vents. It was found that a significant amount of ozone was being generated and accumulated within the photocopy room at times when the photocopy machines were in frequent use. 7. Development of NBS Traceable Standards for Measurements of U.S. Natural

G. C. Rhoderick

The natural gas industry has for years been assigning heating values using calorimetric measurements. There have been discrepancies over what the heating value of a specific natural gas sample is when measured by different companies and laboratories. Since natural gas is sold on the basis of BTU/cubic foot, small but significant errors could equate to large amounts of money for both the supplier and the user. A project, funded by the Institute of Gas Technology (IGT), was undertaken by the NBS to certify, as reference standards, several binary mixtures and a simulated natural gas mixture. The samples were to be analyzed using gas chromatography and cross checked against primary gravimetric standards prepared by NBS. The concentrations of each component in these mixtures were determined and certified. The heating value for the mixtures were calculated from the heating value and concentration of each constituent hydrocarbon, and then summing all the heating values of each hydrocarbon in the mixture: 
Heating value $\mathrm{C}=$ [heating value $\mathrm{C} \times \frac{\% \text { concentration }}{100 \%}$ ] (where $\mathrm{C}$ is hydrocarbon) Heating value mixture $=\left[\right.$ BTU $\left.C_{1}+C_{2}+\cdots+C_{n}\right]$

Gas chromatography has been used as a means of determining the concentration of each component found in natural gas and thus for determining the heating value based on composition. This has been found to be a much more accurate method for determining heating value.

Four mixtures were sent to NBS by IGT for certification. The first sample was pure methane and it was analyzed for any impurities. The methane was then determined by difference with low uncertainty since the impurities found were at low levels. This pure sample was found to have concentration of $99.987 \pm 0.007 \%$ (.007\% relative uncertainty at the $95 \%$ confidence interval). The second sample contained nitrogen in methane. Insignificant amounts of impurities were found, hence the concentrations determined by a ratio of the responses of nitrogen and methane resulted in very low uncertainty levels: $18.49 \pm 0.04 \%(.2 \%$ relative uncertainty) nitrogen and $81.51 \pm 0.06 \%(.07 \%$ relative uncertainty) methane.

The third sample consisted of ethane in methane and it also had insignificant impurities present, hence the ratio method, used for the sample above, was applied. The concentration and uncertainty for these samples were determined to be: $25.03 \pm 0.04 \%$ (.2\% relative uncertainty) ethane and $74.97 \pm$ $0.06 \%$ (.08\% relative uncertainty) methane.

The fourth sample was a simulated natural gas sample. The minor components were analyzed, concentrations determined, and uncertainties were calculated which ranged from .26 to $3.8 \%$ relative. The methane was determined by gas chromatography and by difference, with no significant difference found between the two values. The uncertainty of the methane was determined by summing the minor component uncertainties, as a \pm percent. Hence, the methane had a value of $90.64 \pm .06 \%$ (.06\% relative uncertainty at the $95 \%$ confidence level). Thus, the main component of the natural gas had a low uncertainty in its heating value which was the objective of the gas industry.

\section{Development of Tritiated Methane Standards for Atmospheric Monitoring}

E. Hughes and R. Miller

The object of this project was to produce a set of tritiated methane standards $\left(\mathrm{CTH}_{3}\right)$ for use in quality control between several laboratories engaged in the measurement of $\mathrm{CTH}_{3}$ in the atmosphere. All standards were to be made from a single batch of gas to insure that they would be as nearly identical in concentration of $\mathrm{CTH}_{3}$ as possible. The quantity of gas in each standard was to be no less then 5 liters and the number of standards was to be at least 6 . The activity of $\mathrm{CTH}_{3}$ in the methane $\left(\mathrm{CH}_{4}\right)$, which formed the bulk of the mixture, was to be about 0.5 disintegrations/minute/cubic centimeter $\left(\mathrm{dpm} / \mathrm{cm}^{3}\right)$ with a total uncertainty of less than $5 \%$ relative.

Accordingly, it was decided to prepare the standards gravimetrically by stepwise dilution of a high concentration of $\mathrm{CTH}_{3}$ to the desired level us $1 \mathrm{ng}$ analysis of the $\mathrm{CTH}_{3}$ at each dilution level as a confirmation of the accuracy 
of the dilution. The concentration of the final mixture therefore would be based on two independent numbers, the predicted value based on the measured weights of each component and the measured value obtained at each step in the process. In addition, agreement between the predicted value based on dilution and the measured value would confirm the validity of the dilution process and the absence of selective adsorption of $\mathrm{CTH}_{3}$ within the container.

The samples were prepared, gravimetrically, by stepwise dilution of a sample containing a high concentration of $\mathrm{CTH}_{3}$ in $\mathrm{CH}_{4}$, to an intermediate concentration, then finally to a concentration around $0.5 \mathrm{dpm} / \mathrm{cm}^{3}$. The diluent gas was methane containing no detectable concentrations of $\mathrm{CTH}_{3}$. The gravimetric procedure involved adding the known mass of the minor component $\left(\mathrm{CTH}_{3}\right)$ to a pre-weighed, evacuated cylinder, and then adding a known mass of the diluent $\left(\mathrm{CH}_{4}\right)$.

All samples, after being oxidized to water, were analyzed by the Radioactivity Group (532) at NBS using liquid scintillation counting. The $\mathrm{CH}_{4}$ used as the diluent gas was analyzed for tritium content by scintillation counting and for impurities using mass spectrometry and gas chromatography.

Samples for counting were prepared by oxidizing the $\mathrm{CTH}_{3} / \mathrm{CH}_{4}$ mixture over hot $\left(700^{\circ} \mathrm{C}\right)$ copper oxide. The resultant water was collected by condensation in a glass ampoule which was then sealed and delivered to the Radioactivity Group for analysis. At least two samples from each cylinder were prepared and analyzed for tritium content. Periodically, between oxidation of active samples, the diluent $\mathrm{CH}_{4}$ was passed through the combustion system in order to detect residual contamination.

Ten samples were prepared. The mean $\mathrm{CTH}_{3}$ concentration of all samples was $0.550 \mathrm{dpm} / \mathrm{cm}^{3} \mathrm{CH}_{4} \pm 0.022 \mathrm{dpm} / \mathrm{cm}^{3}$. Agreement between the gravimetrically calculated value of the final dilution and the analyzed value was $0.54 \%$. Six of the samples have been shipped to various laboratories involved in the atmospheric monitoring for $\mathrm{CTH}_{3}$.

9. Characterization of Stable NBS Traceable Standards of $\mathrm{SO}_{2}$ in Air at 100 ppb for Dry Acid Deposition Studies

W. Dorko, Z. -T. Cai, and F. Abbo

Currently, the NBS has a number of sulfur dioxide-in-nitrogen gaseous SRMs in cylinders ranging in concentration from $50 \mathrm{ppm}$ to $3500 \mathrm{ppm}$. Also available from NBS are $\mathrm{SO}_{2}$ permeation tube SRMs which can be incorporated into a gas dilution system to produce calibration gases. Permeation tubes are generally used to produce mixtures with concentrations ranging from 0.1 $\mathrm{ppm}$ to $5 \mathrm{ppm} \mathrm{SO}$. By using the cylinder mixtures directly or by diluting them with reasonable flow ratios, concentrations from $0.5 \mathrm{ppm}$ to $3500 \mathrm{ppm}$ can be generated. Neither the cylinder mixtures nor the permeation tubes can be used conveniently to achieve accurate calibration mixtures at $1 \mathrm{ppb}$. For meaningful dry acid deposition studies, the USEPA requires accurate measurements approaching this level. To satisfy this need, cylinder mixtures of $\mathrm{SO}_{2}$ in air at $100 \mathrm{ppb}$ are being studied; if these could be well characterized and remain stable, they could be used in a dilution system with reasonable flow ratios to produce $\mathrm{SO}_{2}$ calibration mixtures as low as $1 \mathrm{ppb}$. 
Mixtures of $100 \mathrm{ppb} \mathrm{SO}_{2}$ were obtained from two different commercial suppliers; each claimed to be able to provide stable mixtures. A pulsed fluorescence $\mathrm{SO}_{2}$ analyzer is being used to intercompare the cylinders with the output of a permeation tube dilution system. To provide the most accurate calibration mixtures using the permeation tube dilution system, the three main features of the system (temperature of the chamber, permeation ate, and flow over tube) have to be monitored or evaluated. For this purpose, the temperature of the constant temperature chamber is monitored and the $\mathrm{SO}_{2}$ permeation tube is periodically weighed. The flow rates are controlled by mass flow controllers, and these have been evaluated for both input pressure and ambient temperature dependence. Both effects have to be monitored to characterize system performance. To check the dilution system, an experiment was performed in which the permeation tube system was adjusted to produce $1 \mathrm{ppm} \mathrm{SO} \mathrm{SO}_{2}$. A $50 \mathrm{ppm} \mathrm{SRM}$ mixture of $\mathrm{SO}_{2}$, analyzed by the standard peroxide method, was incorporated into the dilution system and the flows were adjusted to achieve $1 \mathrm{ppm}$ (i.e., a 50 to 1 dilution). The pulsed fluorescence detector was used to compare the diluted sample obtained from the cylinder with the permeation tube system. The signal observed was within $0.2 \%$ of the predicted signal. This finding indicated that the controllers were well characterized.

The controllers were subsequently used in conjunction with the permeation tube dilution system to generate $\mathrm{SO}_{2}$ calibration mixtures from 90

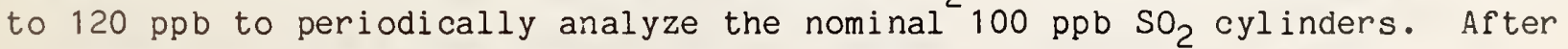
three months, there has been no sign of decay. The work will continue to assure stability over a longer period.

10. Intercomparison of Tunable Diode Laser, Chemiluminescent Detector, and Fourier Transform IR Measurements of High Concentration NO 2 /A ir SRMs

A. Fried, W. Dorko, R. Sams, and J. Elkins

The important reactive gas $\mathrm{NO}_{2}$ is a key molecule in atmospheric studies. It is well known that this gas plays an important role in the occurrence of "acid rain" and the generation of photochemical smog. Concentrations of several hundred parts-per-million by mole (ppm) of $\mathrm{NO}_{2}$ and $\mathrm{NO}$ are continuously produced by the combustion of fossil fuels from various stationary and mobile sources. To meet the ensuing need for accurate standards by which field instruments are calibrated, NBS has recently issued a new series of compressed gas $\mathrm{NO}_{2}$ /air standards at nominal concentrations ranging from 250 $\mathrm{ppm}$ to $2500 \mathrm{ppm}$. These mixtures, in addition, may also serve as convenient source of high concentration $\mathrm{NO}_{2}$ for atmospheric-related studies carried out in the laboratory and the field.

Commercial chemiluminescent detectors (CD) have traditionally been employed for measuring both $\mathrm{NO}$ and $\mathrm{NO}_{2}$ gas mixtures. Detection is accom$\mathrm{pl}$ ished via the chemiluminescent reaction between $\mathrm{NO}$ and $\mathrm{O}_{3}$. In the case of $\mathrm{NO}_{2}$, the gas sample must first pass through a converter to effect the conversion of $\mathrm{NO}_{2}$ to $\mathrm{NO}$. Such measurements of $\mathrm{NO}_{2}$ are accurate as long no other nitrogen oxide species are present. However, the chemistry of high pressure cylinders is not well understood, and the possibility exists of converting other nitrogen oxide species to $\mathrm{NO}_{2}$ and subsequently to $\mathrm{NO}$. While the measurement of total nitrogen oxide $\left(\mathrm{N}_{\mathrm{X}} \mathrm{O} y\right)$ may be correct under such conditions, the $\mathrm{NO}_{2}$ concentration would certainly be in error. 
Because of this potential source of systematic error and the rather widespread use of $\mathrm{CDs}$ for measuring $\mathrm{NO}_{2}$, we have undertaken in the present study a detailed intercomparison between the extremely sensitive and selective technique of tunable diode laser absorption spectrometry (TDLAS) and CD for a selected group of high concentration $\mathrm{NO}_{2} /$ air cylinders. An intercomparison was also carried out on one particular cylinder using the above two techniques along with FTIR.

Quantitative diode laser measurements were performed on both NO, eluting from the converter, and $\mathrm{NO}_{2}$ using direct absorption and second harmonic detection. In all $\mathrm{NO}_{2}$ cylinders examined, the $\mathrm{CD}$ consistently resulted in "NO $\mathrm{N}_{2}$ " values 5 to 15\% higher than TDALS. Subsequent TDL and FTIR absorption studies revealed the presence of $\mathrm{HNO}_{3}$ in each and every cylinder examined. After accounting for $\mathrm{HNO}_{3}$, as quantitatively measured by all three techniques, the $\mathrm{NO}_{2}$ determinations by each technique were generally found to be in good agreement within the measurement uncertainties. Future efforts will focus on determining the source of such high $\mathrm{HNO}_{3}$ concentrations as well as assessing its stability as a function of various cylinder parameters.

\section{Identification and Characterization of Systematic Error Sources in Tunable Diode Laser Absorption Measurements}

A. Fried and R. Sams

In last year's panel report, we described on-going efforts to improve the accuracy of tunable diode laser (TDL) direct absorption measurements. The studies presented here are a continuation of this important long-term program.

Diode laser measurements can be made in both an absolute and a relative mode. In the former, as in any direct absorption technique, the concentration of a species of interest is related to the incident and transmitted intensities using the Beers-Lambert Law. Accurate concentration determinations employing direct absorption require not only highly accurate measurements of these parameters, but also accurate pathlength data and absorption and pressure-broadening coefficients as well. Unfortunately, TDL direct absorption measurements are susceptible to many different types of systematic errors. Such error sources reported in the literature include: a nonuniform laser scanning rate, an appreciable laser linewidth relative to the absorption features under study, and the presence of multi-mode lasing. Systematic errors associated with this last scurce can be further manifested in a variety of different ways. In the present study, we have identified and characterized two such error sources which have not been discussed in the literature previously.

When multi-mode lasing occurs, as is of ten the case in TDL studies, the true photometric 100\% absorption level (the opaque limit) cannot simply be obtained by placing a shutter in the beam path. Instead, one must establish this level for each absorption line under study by increasing the pressure of the target gas of interest until the line center absorption becomes saturated, as evidenced by a flattened peak. Other lasing modes are generally not absorbed. However, in the case of polyatomic molecules like $\mathrm{NO}_{2}$ where there is a high density of lines, additional lasing modes on occasion may be absorbed by these lines simultaneously with the line under study. As we have found in the present work, this causes a structured-opaque limit which can 
affect the proper determination of the true 100\% absorption level. Concentration determinations affected by this type of error were found to be systematically 1 ow by as much as $10 \%$. However, even larger systematic errors can readily result from this cause. In addition, each lasing mode can be emitted in a preferred direction. Since most diode laser spectrometers utilize more than one beam, there is a strong possibility that systematic errors in frequency and/or concentration may result due to a different fraction of each spatial mode in each arm.

This past year, we have made significant progress in identifying, characterizing, and devising procedures to eliminate these as well as other systematic error sources. Employing a high resolution interferometer is very important in this regard.

\section{The Investigation of Simulated Test Data (STD) for Basic Research and Accuracy Evaluation in Chemometrics}

\section{A. Currie}

The development of methods for the analysis of complex materials and systems, and the realistic evaluation of analytical uncertainties -- especially for multicomponent systems -- is one of the more important challenges for current chemical and chemometric research. For the overall Chemical Measurement Process (CMP), Standard Reference Materials (SRMs) are recognized as vital for meeting these dual needs of method development and validation. In recent years, however, there has been a growing awareness that the data evaluation step of the CMP also is in need of validation and research direction. Common test data sets (STD) which are realistic and well-characterized have provided important insight, through interlaboratory comparisons, concerning the quality and research needs of the Analytical Data Evaluation process. Real data analyzed by different groups, can indicate discrepancies (W. $H$. Kirchhoff, Ed., NBSIR 82-2511, 1982), but data of known chemical-model and error structure are mandatory if one is to assess accuracy. The first major STD exercise was organized by the International Atomic Energy Agency (IAEA) for laboratories engaged in instrumental neutron activation analysis ( $R$. $M$. Parr, et al., Computers in Activation Analysis and Gamma-Ray Spectroscopy, DOE CONF-780421, 1979), the second, organized by NBS and EPA, was for those engaged in aerosol source apportionment via multivariate chemical pattern recognition (L. A. Currie, et al., Atm. Environ. 18, 1984, 1517).

Research undertaken during FY85 grew out of the multicomponent analytical 'chemometric' (experimental design, data evaluation) needs as demonstrated by the foregoing STD laboratory intercomparisons. Specific research needs and directions were indicated by the following facts (STD intercomparison outcomes): (a) a significant portion of the results from both exercises exhibited large deviations from the "truth" as well as large interlaboratory differences, even though such labs evaluated exactly the same data, often reportedly using the same data evaluation techniques, b) uncertainty estimates were often missing, and when given were mostly too small or too large in comparison with the observed dispersion and/or deviations from the truth, and (c) component detection limits and systematic error bounds were totally absent. The importance of these matters is such that, following the initial exercises, the IAEA has continued to supply the gamma-ray STD together with their Certified Reference Materials as a regular part of the $1 \mathrm{r}$ 
Analytical Quality Control Service program; and our Group at NBS has continued to meet requests of laboratories in the U.S. and Europe for magnetic tapes containing the source apportionment STD.

New research in chemometrics has been stimulated and aided by the STD in several institutions. The two-fold thrust of our work at NBS has been to: (a) develop methods to investigate the quality of alternative multivariate data evaluation techniques, plus causes of the discrepancies among STD results, and (b) develop chemometric techniques which take into account external ('expert') scientific knowledge or constraints, and robust techniques which can give reliable estimates for analyte concentrations, given the intrinsic need for assumptions to solve most multicomponent analytical problems. Among our results:

- An STD adaptation of the "Youden" concordance diagram has been developed to expose laboratories applying different types of "scientific judgment" (implicit algorithm or assumption differences) while using the same basic data evaluation technique (e.g., multiple linear regression) [L. A. Currie, First NBS Chemometrics Research Conf., May $1985]$.

- A compilation of guidelines and cautions for STD synthesis and intercomparison organization; plus a summary of outstanding chemometric multicomponent research questions evolving from the STD exercises [L. A. Currie, idem].

- A more realistic approach to the estimation of analyte (or component) uncertainty in connection with the use of non-negativity constraints and systematic error arising from multiple applications of pure component patterns of spectra containing measurement error [D. Lowenthal, K. Rahn, and L. A. Currie, internal report, August 1985].

Many important activities related to STD intercomparison and the resultant chemometric research needs will continue in the coming years. We expect to gain further information on the value of STD, as a complement to SRMs in other areas of multicomponent chemical analysis. In addition, we plan to perform research on such outstanding questions as: a) the influence (and optimization) of the experimental design -- i.e., sampling and measurement strategies -- on multicomponent resolution; b) the computation of realistic bounds for systematic (model) error, detection limits, and imprecision for multivariate, multicomponent experiments; c) the systematic incorporation of physicochemical constraints and "scientific intuition" into the design and evaluation process.

13. Improved Measurements of Environmental Radiocarbon via Chemical and Isotopic Separation Coupled to Accelerator Mass Spectrometry

R. M. Verkouteren and L. A. Currie

The utility of carbon isotope ratio measurements for the purposes of carbon cycle geochemistry, environmental pollutant tracing, and radiocarbon dating is dependent upon radiocarbon measurement processes able to differentiate indigenous sample levels of cosmogenic ${ }^{14} \mathrm{C}$ from background levels and 
contamination. For uncontaminated samples containing at least one milligram of total carbon of moderate to modern age ( $30 \mathrm{ka})$, accelerator mass spectrometry (AMS) has proven to give accurate measurements of carbon isotope ratlos with good precision. Beyond these bounds, however, analytical difficulties from ubiquitous carbon contamination and operator dependences have limited the utility of AMS as a dating tool for measuring very old or very small ( $\overline{<} 10 \mathrm{\mu g} / \mathrm{C}$ ) samples. A major objective of our work, therefore, is to develop ultra-clean microchemical techniques which will allow AMS measurements to reach their intrinsic potential.

Our research focuses on the characterization and optimization of a carbon isotope measurement process which is relatively simple and controllable, involving sample combustion, carbon dioxide separation, purification, and reduction to a target suitable for AMS isotope measurement. An ultra-clean gas manifold equipped with a turbo molecular pump, furnace control systems, and high resolution capacitance manometers has been designed and constructed in order to control and evaluate sources of analytical inaccuracy and imprecision. Ongoing studies include assessing the importance of reagent quality and pretreatment, characterization of chemical/isotopic fractionation during the chemical and physical steps, and qualitative measurements of contamination carbon dioxide perfusion across quartz at annealing temperatures.

Application of a radiocarbon enhancement technique (e.g., thermal diffusion, electromagnetic enrichment-deposition, laser fractionation) to the measurement process can enable measurement of carbon isotope ratios very much lower than those attainable by conventional AMS, hence leading to an improvement in the radiocarbon dating range (L. A. Currie, G. A. Klouda, D. Elmore, and H. E. Gove, Nucl. Instrum. Meth., 1985, in press). To this end, a microthermal diffusion column has been designed and is under construction which, when integrated with the ultra-clean sample preparation system, should allow measurement of "ultimate" carbon isotope ratios; i.e., those hitherto unmeasured ${ }^{14} \mathrm{C}$ abundances arising solely from the environmental neutron flux in the terrestrial subsurface. Initial estimates of such underground nuclear reactions imply a natural limit to radiocarbon dating of - $100 \mathrm{ka}$. Our chemical-isotopic enhancement studies thus are directed toward extending the dating range toward this limit, as well as determining its magnitude experimentally. An important and interesting by-product of this research will be the ability to study the rare terrestrial nuclear reactions, per se, possibly also gaining thereby knowledge of "paleo" neutron fluxes in geological and glaciological contexts.

\section{Carbon Isotope Measurements for Source Apportionment of Pollutant} Aerosols and Gases

G. A. Klouda, W. Ollison, A. E. Sheffield, and L. A. Currie

Carbon isotope measurements of carbonaceous aerosols and gases serve as important inputs to Receptor Models for source apportionment. In particular. ${ }^{4} \mathrm{C}$ measurements unequivocally discriminate fossil fuel carbon from biogenic (living) carbon emission sources. Radiocarbon results of speciflc subfractions of aerosols, e.g., the polycyclic aromatic hydrocarbon fractions (PAH) extracted from Urban Dust SRMs 1648 and 1649 , have shown that ${ }^{14} \mathrm{C}$ measurements when coupled with chemical selectivity can significantly improve the model resolution. Accelerator Mass Spectrometry (AMS) ${ }^{14} \mathrm{C}$ measurements, 
with a sensitivity at less than $100 \mu \mathrm{g}$ size samples (1984 Annual CAC Report), now makes possible investigations into sources of specific fractions and individual trace compounds.

This years' progress in "carbon isotope chemistry" has focused on specific carbon species that have effects on visibility, human health or climate. Because the concentration of $\mathrm{CO}$ exceeds the National Ambient Air Quality Standard (NAAQS) $9 \mathrm{ppm}(8 \mathrm{hr}$ ) in some urban environments and because of the importance of $\mathrm{CO}$ and $\mathrm{CH}_{4}$ in relation to the "Greenhouse Effect", a method was developed for extraction of $\mathrm{CO}$ and $\mathrm{CH}_{4}$ fractions from $0.1 \mathrm{~m}^{3}$ air samples (cf. C. M. Stevens and L. Krout, Int. J. Mass Spectr. Ion Phys. 8 , 265, 1972) for AMS ${ }^{14} \mathrm{C}$ measurements. Radiocarbon measurements of these species provide direct apportionments for fossil and biogenic combustion sources. In addition, work is underway to develop and validate field sampling and laboratory extraction methods for collection of Reactive Volatile Organic Carbon (RVOC). RVOC is the controlled precursor used to assure attainment of the photochemical oxidant $\left(\mathrm{O}_{3}\right)$ NAAQS.

In order to gain information concerning the impact of residential wood combustion on the significant winter-time excesses of $C O$ ( $>9 \mathrm{ppm})$ in Las Vegas, Nevada, we extracted $\mathrm{CO}$ (and $\mathrm{CH}_{4}$ ) fractions for ${ }^{14} \mathrm{C}$ assay from $0.1 \mathrm{~m}^{3}$ air samples collected in January 1984, by the Clark County Health District, Air Pollution Control Division. Preliminary ${ }^{14} \mathrm{C}$ results for $\mathrm{CO}$ and $\mathrm{CH}_{4} \mathrm{frac}-$ tions from two of the six samples suggest that vehicle emissions are primary sources of $\mathrm{CO}$ and contribute to excess $\mathrm{CH}_{4}$ (above the natural background). Also, the ambient $\mathrm{CO}$ and $\mathrm{CH}_{4}$ levels in these samples show a good correlation, additional evidence for a common source. Radiocarbon results for the remaining samples will indicate whether wood burning emissions contribute significantly to ambient concentrations on other days.

The preliminary sampling method for RVOC employs a pumped, four-bed, heated sampling train that separates the predominant ambient carbon species $\left(\mathrm{CO}_{2}, \mathrm{CH}_{4}\right.$, and particulate carbon) from RVOC, oxjdizes the RVOC and subsequently traps the resulting $\mathrm{CO}_{2}$ on a $\mathrm{LiOH}$ bed for ${ }^{14} \mathrm{C}$ assay. Tests of trapping efficiency and background contamination are underway. A continuous 7 day sampling period $\left(10-20 \mathrm{~m}^{3}\right.$ of ambient air) is anticipated to yield $5-10 \mathrm{mg}$ C/ppm RVOC. Preliminary testing of field samplers, is planned during the 1985 smog season in Washington, DC. Knowledge of the ${ }^{14} \mathrm{C}$ content of RVOC at urban sites will determine whether uncontrolled vegetative emissions constitute a significant emission source.

Research, which will continue into FY86, has been initiated in cooperation with the EPA (Integrated Air Cancer Program) and with Sandia National Laboratories on the application of ${ }^{14} \mathrm{C}$ measurements for source apportionment of organic particulate carbon and $\mathrm{CO}$, respectively - in connection with elevated levels during the "wood burning season" in Albuquerque. In connection with these and other studies, our future work on aerosol source apportionment will include the evaluation of thermal and/or chemical means for separation and isolation of elemental carbon (EC), volatile organic carbon (VOC), and organic sub-fractions, e.g., the PAH fraction, for carbon isotope measurements. 
15. Quantitative Compositional Mapping with the Electron Microprobe Using Wavelength and Energy Dispersive Techniques

R. Marinenko, R. Myklebust, D. Bright, and D. Newbury

Digital compositional mapping with the electron microprobe is replacing conventional x-ray area scans. The added flexibility during data acquisition and the reliability of the final result make digital procedures preferable to photographic records. True counts recorded from each point are preserved on disk or tape and made available for subsequent manipulation by quantitative image processing algorithms.

Mapping can be carried out with either energy-dispersive (EDS) or wavelength-dispersive (WDS) spectrometers. Mapping by EDS poses few technical problems and data for many elements, eight or more, can usually be acquired simultaneously. There are many applications for which mapping with WDS is desirable in spite of the fact that only a few elements can be observed simultaneously. The higher count rates permitted in WDS analysis make this technique preferable when observing low-concentration element distributions. There has been little application of wDS quantitative mapping probably because of defocusing problems, which cause a large decrease in spectrometer efficiency when the beam is scanned off-axis.

We have developed a program to control our automated commercial electron probe to acquire either WDS or EDS maps with dimensions of $32 \times 32,64 \times 64$, or 128 x 128 pixels. This program moves the electron beam, point by point in a raster, over the specified sample area, accumulating $r$ aw $x$-ray counts for each element. Data is collected on a floppy disk and transferred to a large computer where data reduction and display manipulations are done.

In order to quantitatively correct spectrometer defocusing which becomes serious at magnifications below $8000 x$, a "standard map" procedure was developed. A map of each standard taken under the same conditions as the unknown material is needed to determine appropriate unknown-to-standard intensity. After background and dead-time corrections, each point in the unknown map is ratioed to the corresponding point in the standard map. A data reduction procedure (FRAME) developed in our laboratory, is used to calculate the concentration of each point from the k-ratios. In order to test the procedure, maps were prepared on homogeneous NBS SRM specimens. The resulting maps had accuracy and precision equivalent to individual spot analyses.

The problem of quantitative presentation to an observer of the compositional data in an image has been studied. Various color scales for representation of data have been examined. The "black body curve" or "thermal scale", which is based upon the sequence of colors emitted by a body upon heating, has been found to give a representation which can be interpreted intuitively. 
16. Development of New Techniques for Light Element and Trace Element Compositional Mapping

\section{E. Newbury}

Compositional mapping by microbeam analysis techniques can provide direct evidence of elemental distributions on a micrometer scale in solids. Such information is frequently useful in determining the relationship between the microstructure and the macroscopic properties and behavior of the solid. Most compositional mapping is currently carried out with the electron probe microanalyzer (EPMA), which is limited by the nature of the characteristic $x$-rays to detecting elements with atomic number greater than 5 . Moreover, the detection limits in a mapping mode are typically greater than 1-5\% depending on the element of interest.

Imaging by the form of secondary ion mass spectrometry (SIMS) known as ion microscopy offers several special capabilities which do not suffer from the limitations of the conventional elemental mapping techniques. These special capabilities include isotopic, light element, and trace element imaging. In this work, compositional mapping by ion microscopy has been employed to attack two materials science problems: (1) the distribution of lithium in Al-Li alloys and (2) the origin of differences in the secondary electron coefficient observed in reaction-bonded silicon carbide ( $\mathrm{SiC}$ ). In studying these systems, digital imaging techniques have been used to combine information from several imaging methods, including ion microscopy, scanning electron microscopy, and optical microscopy. The combination of compositional mapping from SIMS imaging with structural information from the other forms of microscopy has proven invaluable in interpreting the structures of these materials.

In the Al-Li alloys, structures observed by optical microscopy on the surface of specimens after polishing have been found to be completely unrepresentative of the true lithium distribution in the bulk material, which can be revealed by ion etching. These surface structures appear to result from surface segregation due to preferential leaching of lithium during the polishing process. The ability to separately image the surface and interior of a sample can be used to study the leaching process, the understanding of which is critical to employing the alloy in service. The general distribution of lithium-rich precipitates has been observed in bulk material after heat treatment. Lithium segregates to grain boundaries and denuded zones develop adjacent to the boundaries. Such segregation may affect the mechanical properties of the alloy. Direct imaging is a useful adjunct to bulk analysis to characterizing the behavior of the alloy as a function of composition.

When viewed in the SEM, the reaction-bonded silicon carbide displays anomalous secondary electron contrast within the partially melted and regrown SiC grains. This unusual effect arises despite the lack of apparent compositional differences between the regions which show the strong contrast, as measured with the EPMA. Examination of the trace constituents by SIMS reveals the presence of aluminum at an approximate level of $100 \mathrm{ppm}$. SIMS images of the trace aluminum distribution show a significant degree of correlation with the secondary electron emission pattern seen in the SEM images. The presence of the aluminum in the semiconductor SiC may alter its band structure, leading to the differences in secondary electron emission. 
17. Determination of the Half-Life of ${ }^{187}$ Re by Laser Microprobe Mass

D. Simons, M. Lindner (LLNL), and D. Leich (LLNL)

The long-lived naturally-occurring nuclide ${ }^{187} \mathrm{Re}$ is important to geochemists and to cosmochemists as a nucleochronometer that could be used to determine independent terrestrial, solar-system and cosmic chronologies. For such measurements, the half-life of ${ }^{187} \mathrm{Re}$ is a necessary parameter. Recent literature points to a probable value around 45 billion years on measurements normalized to accepted ages of meteorites and rocks.

We have conducted an experiment to make a direct determination of the half-life of ${ }^{187} \mathrm{Re}$ by observing, the ingrowth with time of the decay product 187 Os relative to ${ }^{190} \mathrm{Os}$ and 192 os spikes added to a purified solution containing $1 \mathrm{~kg}$ of rhenium. For this experiment we have developed a technique to obtain isotopic analyses of nanogram quantities of osmium with relative precision and accuracy of $2-3 \%(1 \sigma)$ on isotope ratios between 0.3 and 3.0 using the Leybold-Heraeus LAMMA 500 laser microprobe mass analyzer. We typ 1cally accumulate about 100 separate mass spectra from an individual sample that contains less than $1 \mathrm{ng}$ of osmium, perform channel-by-channel summations of all spectra, and measure ratios of the resultant summed peak areas. This allows us to achieve good ion statistics while minimizing detector nonlinearity effects and averaging out any electronic noise in the recorded spectrum. Problems with isobaric interferences in the osmium mass range due to $\mathrm{K}_{3} \mathrm{Cl}_{2}{ }^{+}$, $\mathrm{Cu}_{3}{ }^{+}$, and $\mathrm{W}^{+}$have been solved by using gold (instead of copper) electron microscope grids with Sio films vacuum-evaporated from tantalum (instead of tungsten) boats, and by using ultrapure (low-potassium) $\mathrm{HCl}$ as the solvent from which the samples are deposited by evaporation onto the filmed grids.

Four aliquots of the original rhenium solution have been extracted over a time period of three years since the addition of the osmium isotopic spikes. The half-life of ${ }^{187} \mathrm{Re}$ can be calculated from the slope of the bestfit line that correlates the 187 os to os spike ratio with the growth time. The half-life determined in this way is 43.6 billion years, with an associated uncertainty of $3 \%(1 \sigma)$. The osmium isotopic ratios of the individual samples have been independently measured by inductively coupled plasma mass spectrometry (ICPMS), and the agreement with LAMMA-determined ratios is within 1\% in almost every case. Four additional kilograms of rhenium, for which results are not yet available, will provide independent determinations of the half-life.

\section{Unique Molecular Characterization of Complex Minerals by Micro-Raman Spectroscopy}

E. S. Etz

Modern analytical methods employing microprobe instrumentation are increasingly being applied to the task of comprehensive mineral characterization. Among these are the electron beam methods, ion beam techniques and, more recently, optical microprobe methods such as microspectrofluorlmetry, micro-Raman, and infrared microspectrophotometry. Microprobe methodlogles become especially important in studies of new mineral or complex mineral phases where the specimen may indeed be of microscopic size only, and whenever it is necessary to obtain spatially resolved analytical information. In 
combination, these various methods provide information on homogeneity, stoichiometric relationships, the chemical formula of the mineral, its crystal system and various other classifying parameters. Despite this array of analytical techniques, a full description of an unknown or complex mineral is of ten hampered by difficulties in the quantitative analysis of light elements by electron and ion beam techniques.

Recognizing the limitations of electron and ion beam techniques in the chemical analysis of minerals which contain light elements, we are applying Raman microprobe spectroscopy to the kinds of problems where the vibrational Raman spectrum can furnish the desired molecular and bonding information. This approach of comprehensive, synergistic microanalysis is presently being pursued in two research areas of complex mineral characterization. In collaboration with workers at the Smithsonian Institution, Washington, DC, and at the National Musuem of Natural Sciences, Ottawa, Canada, we are elucidating the compositions and structures of a series of new minerals containing borate and carbonate species. The micro-Raman spectra furnish information on the types of molecular units $\left(\mathrm{e} . \mathrm{g} \cdot, \mathrm{CO}_{3}{ }^{2-}, \mathrm{BO}_{3}{ }^{3-}, \mathrm{HBO}_{3}{ }^{2-}, \mathrm{B}(\mathrm{OH})_{4}^{-}, \mathrm{SO}_{4}{ }^{2-}, \mathrm{PO}_{3}{ }^{4-}\right.$, $\mathrm{H}_{2} \mathrm{O}$ ) present in these structures and resolves questions pertaining to coordination and stoichiometry among the constituents of the sample. An example is borate minerals containing either 3- or 4- coordinated boron resulting in trigonal or tetrahedral configuration. One case study furnished conclusive spectral evidence that contributed to the identification of a new mineral -named moydite -- found in granitic pegmatite deposits at Evans-Lou mine in Québec province, Canada. The spectra support the presence of tetrahydroxo borate groups and carbonate ions in what is deduced to be a compound yttrium borate of chemical formula $\mathrm{Y}\left[\mathrm{B}(\mathrm{OH})_{4}\right] \mathrm{CO}_{3}$ in the orthorhombic crystal system.

A second area of mineral characterization with the Raman microprobe addresses the detailed aspects of biological mineralization, involving the study of mineralizing tissues (bones and teeth) and calcified tissues (aortic plaques) with the aim to monitor mineral changes as a function of age and maturation. This work is conducted in collaboration with researchers at the American Dental Association and at several medical institutes involved in mineralized tissue research. Of particular interest is the incorporation of carbonate ions in the biological apatite ( $\mathrm{i} . e .$, phosphate, $\mathrm{PO}_{4}{ }^{3-}$ ) mineral matrix, a process concurrently studied in the calcification of the connective tissue of the human aortic wall leading to atheroscelerotic disease. This work is extended to studies of the calcification of bioprosthetic circulatory assist devices, such as heart pumps and aortic valves made of various natural or synthetic materials, implanted in animals and man. The formation of calcified deposits upon implantation of such devices often serves as an indication of the biocompatibility of the materials used.

\section{Development of Digital Imaging on the Analytical Electron Microscope}

E. Steel, R. Myklebust, A. Bell, and B. Thorne

The analytical electron microscope (AEM) can provide a comprehensive characterization of a sample, including morphology, crystal structure, and major and minor elemental constituents, at a spatial resolution as small as $10 \mathrm{~nm}$. Because of the potential for a high rate of information flow from multiple signals available in the AEM and the frequent desire to reduce the exposure of the sample to minimize radiation damage, we have undertaken a comprehensive program of automation to achieve efficient computer-aided 
microscopy. Such a system will allow unattended operation to increase our capabilities for processing more samples. A first stage of such a development must necessarily involve computer control of the electron beam and detectors for image formation.

A VAX $11 / 730$ computer has been interfaced to a JEOL 200CX AEM for the purpose of producing and manipulating digital images from the microscope, and communicating in real time with a VAX 11/780. This combination of computers allows fast acquisition and sophisticated manipulation of large image arrays. The scanning coils (bright field and dark field) of the electron microscope are controlled by the $11 / 730$ and the output of the secondary electron, transmitted electron, and electron energy loss spectrometer (EELS) detectors on the microscope are input to the computer. The x-ray emissions from the specimen may be detected using two energy dispersive x-ray spectrometers (EDS) (a zero degree take-off-angle ultra-thin window EDS, and a high-takeoff-angle, reryllium-window EDS) whose outputs are processed through a multiplexed multichannel analyzer (MCA) controlled by the 11/730. A network and a direct memory access (DMA) channel link the VAX 11/730 to a VAX 11/780 equipped with an image processor. The network communicates between the two computers at 19,200 baud, while the DMA communicates at a rate of greater than 100,000 words per second. The 11/730 controls the image acquisition process while the $11 / 780$ handles all of the image processing and display. The image analyzer has two independent stations, one at the AEM for viewing images during live time experiments and another which is used for software development or viewing of archived images. An array processor on the 11/780 will be used for accelerating computing times for complex algorithms.

The image acquisition software controls the microscope so that a scanning electron microscope (SEM) image, a scanning transmission electron microscope (STEM) image, EDS $x$-ray or EELS image can be obtained concurrently or sequentially. Image arrays up to 1024 by 1024 pixels at magnifications of $20 \mathrm{x}$ to $800,000 \mathrm{X}$ with each pixel having a signal resolution of 12 bits ( 4096 gray levels) can be acquired and manipulated. Typically, 512 by 512 pixels by 8 bit images are collected for the electron images and, due to $x$-ray signal limitations, selected area or 64 by 64 pixel by 8 bit images are collected for EDS x-ray images. The software for the system is written in a combination of Macro, Fortran, and LISP giving speed, flexibility, and computing power on a level currently unachievable by micro-computer based systems. Some early applications of the system included analyses of air particulates, thin film standards, asbestos, and several other mineral particulates. Techniques which have been developed include the use of image analysis for particle finding, image comparing, electron diffraction analysis, magnilication calibration and film thickness measurement.

20. The Development of a Particle Collector for Microanalysis of Fine Particulate Matter

J. A. Small

Previous research in microbeam analysis has demonstrated the powerful combination of analytical electron microscopy (AEM) and laser microprobe mass analysis (LAMMA) for comprehensive characterization of individual particles. Morphology, crystal structure, major, minor, and trace elemental composition, and isotopic composition can be determined by sequential application of AEM and LAMMA techniques. In order to fully exploit these capabilities, the 
particles must be placed on an ultra-thin carbon film (ca $20 \mathrm{~nm}$ ). Research into particle collection methods has sought to develop methods to collect particles directly onto thin films. In this way, the particles need not be exposed to possibly damaging chemicals during dissolutions which must normally be used to transfer particles from filter media to films. A particle collector has been developed for direct collection on AEM/LAMMA film substrates.

The sampler consists of two separate collection devices, an electrostatic precipitator and a thermal precipitator. These two devices are designed to be connected in series but may be used independently if desired. In addition, it is also possible to connect a back-up filter onto the collector. The sampler is made from lucite in the shape of a cylinder $6 \mathrm{~cm}$ in diameter by $20 \mathrm{~cm}$ long, weighs less than $1 \mathrm{~kg}$ and is usable for field collections.

In the electrostatic precipitator, the particles are charged with a negative $3-5 \mathrm{kV}$ potential. The voltage is applied to a sharpened tungsten needle which is used to create the charge field. Four collection surfaces each holding one transmission electron microscope grid are arranged radially $1.2 \mathrm{~cm}$ downstream from the needle. The manifold is $1.9 \mathrm{~mm}$ in diameter at the electrostatic preciptator and the four collection plates extend about $2 \mathrm{~mm}$ into the manifold. An additional five samples are collected from the middle of the air stream $2.4 \mathrm{~cm}$ downstream from the needle. All of the downstream collection plates are held at ground potential. One plate which is located directly opposite the needle is connected to a $600 \mathrm{~V}$ ac source. This plate, which can also serve as a collection surface, is used to maintain the charge zone. The flow rate through the electrostatic unit is 5-10 liters per minute. The thermal precipitator can accommodate as many as ten grids and is differentially pumped with respect to the electrostatic precipitator. The collection plates are designed so that they can be cooled with water or other recirculating liquids if necessary. The thermal precipitator is located downstream about $5 \mathrm{~cm}$ behind the electrostatic unit. Flow rates through the thermal unit are 0.1-1.0 liters per minute.

Preliminary tests of the device with particle streams generated in the laboratory indicate that it is effective in collecting particle size down to 0.02 micrometers in diameter, as verified by transmission electron microscopy. The device has been used to collect particles generated by spark source emission spectrometer to study material transport during the "burn" process and to study the particulate emissions as possible standards. In addition, the device is currently being used by the Center for Fire Research to collect smoke particles for microscopic analysis.

21. The Determination of the Visibility of Chrysotile Asbestos Fibers Imaged in the Scanning Electron Microscope

J. A. Small

The development of analytical methods for accurate characterization of environmental samples which contain asbestos is an importance national problem which impacts on a variety of public health issues. Considerable debate has occurred over the best microscopy methods to employ. In this work, the scanning electron microscope has been compared to imaging with transmission electron microscopy for characterization of asbestos. 
Most manufacturers of conventional scanning electron microscopes (SEM's) claim resolution on the order of 3-10 nm for their instruments, a value which is substantially less than the diameters of $20-30 \mathrm{~nm}$ reported for singlefibril chrysotile. With this level of resolution, it appears that these instruments should be able to image single fibrils of chrysotile asbestos under normal operating conditions in a real-time imaging mode appropriate to rapid sample searching. The limiting resolution performance of an SEM, however, can only be realized with an ideal high contrast sample such as a thin edge or a strongly scattering particle viewed against a weakly scattering background. In analyzing a material such as chrysotile asbestos with a low electron scattering coefficient, the visibility of chyrsotile asbestos fibers is limited by the contrast of the sample rather than the ultimate resolution of the SEM used for the analysis.

The only practical method to unambiguously image all of the chrysotile fibers in a sample is to use the transmission (TEM) or scanning transmission electron microscope (STEM) which have sufficient contrast and resolution to image even the smallest fibrils. We have studied the visibility of chrysotile asbestos in the SEM by making use of the superior imaging of the TEM/STEM to record the size and locations of thin asbestos fibers in a test sample. Once the thin fibers have been located and photographed, these same fibers and fibrils were photographed with either the TEM/STEM, operating as an SEM, or the conventional SEM. By increasing the thickness of the substrate and/or decreasing the accelerating voltage of the beam, it was possible to illustrate the difference in visibility for chrysotile fibers between a TEM/STEM analysis procedure at $100-200 \mathrm{keV}$ with a thin substrate, and a conventional SEM analysis procedure at $25-40 \mathrm{keV}$, with at thick substrate.

The results of this comparison show that the visibility in the SEM of very thin chrysotile fibers, less than 0.2 micrometers in diameter, is severely limited because of weak contrast when the fibers are prepared on a conventional bulk substrate. In addition, the results demonstrate that the visibility of thin fibers in the SEM is improved when the fibers are prepared on a thin-film substrate of low atomic number such as carbon and analyzed at a beam energy of $30 \mathrm{keV}$ or greater. These results suggest that if an SEM is to be used for asbestos characterization, careful attention must be paid to the specimen preparation method which is employed. Moreover, since the fiber size range of interest extends to the limit of visibility in the SEM, the results are likely to show substantial variability.

22. Magnification Calibration of the Scanning Transmission Electron Microscope by Hough-Transformed Images of Grating Replicas

D. S. Bright and E. B. Steel

Accurate knowledge of the magnification of a mircoscope is a vital parameter in any characterization procedure in which the physical dimensions of the object are important. A traditional method of calibrating the magnification of a scanning transmission electron microscope (STEM) is to measure the spacings of an optical diffraction grating replica. Typically the spacings are measured along an intensity profile taken perpendicular to the lines of the grating. A small number of linear intensity profiles do not take into account the local nonlinearities or bumps of the grating replica: many measurements are required. Our method uses an algorithm that averages the grating spacings over the whole image rather than over a limited number of 
linear traces across the image. The reproducibility of this algorithm is on the order of a tenth of a pixel for a given image, which is better than that needed for our applications.

A JOEL 200CX analytical electron microscope was used in STEM mode, with digital image acquisition controlled by a PDP $11 / 23$ computer. The PDP $11 / 23$ was linked to a VAX $11 / 780$ equipped with a DeAnza IP8400 image processor with 512 by 512 pixel resolution. The VAX was used for image analysis and the image processor was used for viewing. The first step in analysis of the grating images was to take the gradient of the images. The gradient operation emphasizes short range changes in intensity and enhances the lines of our shadowed gratings. The lines were adequately represented by the brightest five percent of the pixels in the gradient image. These pixels formed lines that were slightly spotty and wavy, hence the need for averaging all available data. The second step was to apply the Hough transform to our images. This had the effect of mapping each of the grating lines into a bright spot. The spots were then located automatically. Since the grating lines were parallel and evenly spaced, the algorithm searched for three or more spots that were evenly spaced. Each spot position was determined by an intensity weighted average of all of the pixels in the spot. The line spacing was then calculated by averaging the spacing of all of the spots.

The standard error of the magnification measurement was less than three percent in all cases over a six month period. We believe that the system and algorithm are stable enough for routine use. The algorithm also should be useful for the characterization of many other linear features in all types of microscopies.

\section{A Comparison of Two Transient Recorders for Use with The Laser Microprobe Mass Analyzer}

R. Fletcher and D. Simons

In the Laser Microprobe Mass Analyzer (LAMMA), a transient waveform recorder is used to capture the mass spectrum produced in a time-of-flight mass spectrometer from a single pulsed ionization event. The recorder has the characteristics of a digital oscilloscope. It incorporates a fast analog-to-digital converter combined with a larger memory for storage of the digitized waveform and is the key component that permits high sensitivity to be achieved simultaneously for multiple elements in the LAMMA. The recorder originally supplied with the LAMMA instrument had an A/D converter with a maximum digitization rate of $100 \mathrm{MHz}$, bandwidth of $25 \mathrm{MHz}$, a nominal resolution of 8 bits, and a memory capacity of 2048 locations ( 2 Kbytes). Recently, a new generation of transient waveform digitizers has become available that offers modular design based on the CAMAC standard, maximum digitization rate of $100 \mathrm{MHz}$, bandwidth of $>100 \mathrm{MHz}$, a nominal amplitude resolution of 8 bits, and a memory capacity of 32,768 storage locations (32 Kbytes). The purpose of this comparison is to evaluate one of these new recorders and to compare its performance to that of the original recorder for quantitative applications on the LAMMA instrument.

One experiment involved analyzing missing output codes in the A/D converter using the histogram test. In this test, a full scale sine wave of known frequency $(100 \mathrm{KHz}, 1 \mathrm{MHz}$, and $10 \mathrm{MHz})$ is sampled by each transient recorder and the digitized waveform level is collected over many cycles. A 
histogram is then produced giving the relative probability of occurrence of the 256 amplitudes. While both $2 \mathrm{~Kb}$ and $32 \mathrm{~Kb}$ recorders have an increase in lost codes for increasing slew rate, the $2 \mathrm{~Kb}$ recorder had approximately 90 percent of its codes missing for the $10 \mathrm{MHz}$ input. On the other hand, the $32 \mathrm{~Kb}$ recorder missed less than 10 percent of the codes at this frequency. This implies a dynamic amplitude resolution of greater than 7 bits, while the $2 \mathrm{~Kb}$ recorder has only 4 bit resolution under the same conditions. For a direct comparison of the two recorders, each collected in a simultaneous manner the waveform produced by the ion detector in the LAMMA 500. The sample used in this comparative study was a sputtered glass film containing oxides of 10 elements (similar to a zircon) at various weight percentages which produce positive ion mass spectra with $\mathrm{m} / \mathrm{z}$ values ranging from 1 to 270.

The main advantage of the $32 \mathrm{~Kb}$ transient recorder is that a very large portion of the mass range can be recorded at the maximum digitization rate of $100 \mathrm{MHz}$. Using only the $8 \mathrm{~Kb}$ memory fraction and the highest digitization rate, spectra containing all the elements from hydrogen to uranium (actual mass range of $\mathrm{m} / \mathrm{z} 0$ to 367 ) can be recorded from a single laser ionization event. The $2 \mathrm{~Kb}$ recorder must have a digitization rate of $20 \mathrm{MHz}$ (50 ns between samples) to gather the full elemental mass range ( $\mathrm{m} / \mathrm{z} 1$ to 300$)$. A spectrum from the zircon glass film was recorded simultaneously at the same input sensitivity by the $2 \mathrm{~Kb}$ recorder operated at a digitization rate of 20 $\mathrm{MHz}$ and by the $32 \mathrm{~Kb}$ recorder at $100 \mathrm{MHz}$. The $5 \mathrm{X}$ longer time between samples of the $2 \mathrm{~Kb}$ recorder results in very poor peak shape (due to the lack of point density), often with only one data point per peak. This can lead to large errors in peak amplitude measurements. On the other hand, the $10 \mathrm{~ns}$ sampling interval of the $32 \mathrm{~Kb}$ recorder does not have this problem since there are a sufficient number of data points to define a peak. We conclude that the larger memory, modular design, and better high frequency performance of the $32 \mathrm{~Kb}$ recorder offer substantial advantages for quantitative work with the LAMMA.

\section{Automated Method for Analyzing Images Containing Electron Diffraction Spots}

D. S. Bright and E. B. Steel

The analytical electron microscope provides the possibility for comprehensive charcterization of a sample at a spatial resolution as fine as $10 \mathrm{~nm}$. Morphology can be determined from various imaging techniques, and major and minor elemental constituents can be analyzed by means of $x$-ray and electron energy loss spectrometries. A third major source of information is available from the phenomenon of electron diffraction, which can provide the crystal structure. In environmental samples, the solution of diffraction patterns is often difficult because of the superposition of several different patterns from the individual phases in complex aggregates. We have developed an automated computer method for the analysis of electron diffraction images of agglomerate particles. The method isolates the zone axis diffraction pattern in a polycrystalline diffraction image by isolating the spots from other features of the image and by selecting the spots that belong to a regular array. The method then determines the basis vectors for the array which can be used to identify the particle by comparison with standard diffraction data. 
Several particles of differing crystal type often contribute to the diffraction image yielding several superimposed diffraction patterns. The particle of interest is oriented to a zone axis while the other particles are at random orientations. Thus the diffraction maxima from the particle of interest form a regular array amidst the less regularly positioned maxima from the other particles. Automated analysis of such images is difficult because of the overlapping diffraction images that yield complex combinations of rings, arrays of spots, and randomly placed spots. Our automated method includes image processing to locate all of the spots in the image and an algorithm to select groups of spots that belong to regular arrays. Each array is described by a pair of basis vectors, which are then used for compound identification by comparison with standard diffraction data.

The first step in processing such a diffraction image is to isolate the spots from the rings, the background, and the image of the beam stop. The next step is to select from all of the spots, a group or subset of spots that represents a single crystal and thus gives a pair of basis vectors. The last step is a more accurate determination of the basis vectors by averaging all of their occurrences between the selected spots. The pattern thus identifled can be subjected to further analysis. The spacings between the diffraction spots can be accurately measured and converted into equivalent lattice spacings, which can be used in conjunction with elemental analysis data to determine the crystal structure of the sample. In many cases, knowledge of the crystal structure provides the information necessary to deduce the chemical speciation and valence state of the elemental constituents of the sample.

\section{Determination of the Radiation Damage to Polycarbonate Film SRMs Used in X-Ray Spectrometry}

G. L. Sleater, J. Crissman, and P. A. Pella

During the development of thin film XRF standards for calibration of $\mathrm{x}$-ray spectrometers issued as SRM 1832 and SRM 1833, both energy (EDX) and wavelength-dispersive (WDX) spectrometers were used. Although no physical change was observed in standards irradiated in the EDX spectrometer, specimens irradiated in the WDX spectrometer exhibited small cracks parallel to the striation pattern of the polycarbonate substrates. Repeated exposure in the WDX system caused further cracks to form which eventually led to fallure of the film. This failure was due to the effect of $x$-ray radiation from high-powered $x$-ray tubes (up to $3 \mathrm{~kW}$ ) used in conventional WDX spectrometers. A study of radiation damage was undertaken to establish guidelines and to make recommendations regarding use of these SRMs to potential users. Specimens of polycarbonate were irradiated at different $x$-ray tube power settings for known periods of time in the NBS WDX spectrometer. The tensile strengths of both irradiated and control (virgin $\mathrm{film}$ ) specimens were measured using a servo-controlled hydraulic test machine in directions both parallel and perpendicular to the striation pattern of the polycarbonate films. These measurements showed that a quantitative relationship existed between irradiation expressed as a function of $x$-ray tube power and exposure time and the loss of tensile strength by the polycarbonate film. For control specimens which were not irradiated, the mean value of the strain necessary to cause the specimen to tear apart (i.e., strain at break) was 0.16 with a standard deviation of 0.02. Such a variation in the strain at break can arise from factors such as inhomogeneities in the films. With increased $x$-ray doses it was found that the strain at break tends to decrease reaching a value of about one-half 100 
kilowatt-minutes. Because of the significant variation in the strain at break among the control specimens it can be argued that for doses below 30-40 kilowatt-minutes, there is little, if any deterioration in the mechanical properties of the films. These results showed that the effect of radiation exposure is cumulative and not solely dependent on the $x$-ray tube power used.

a result of this investigation, some guidelines have been established warn potential users of these films that there exists a safety limit (determined easily by measuring the x-ray power and exposure time) beyond which significant deterioration of the standard will occur.

In the future, we expect to compare radiation levels from EDX with WDX spectrometers using radiation dossimeters in order to obtain an estimate of exposure limits for standards measured in EDX systems as well. A research paper describing this study is currently in preparation and should be submitted for publication before the end of 1985.

\section{Improvements in NBSGSC - A Fortran Program for Quantitative X-Ray Fluorescence Analysis}

G. Y. Tao, P. A. Pella, and R. M. Rousseau

In a continuing effort to assess and improve interelement correction procedures, we developed and published a computer program for performing quantitative analysis of bulk specimens. The program (NBSGSC) written in Fortran IV corrects for $x$-ray interelement effects from first principles (fundamental parameter) calculations using hypothetical elemental compositions, and is available as "NBS Technical Note 1213". Fundamental parameter methods are particularly attractive especially in analytical situations where standards of the same type as the analyte specimens are not available.

Interelement effects are corrected by NBSGSC using the comprehensive alpha coefficient algorithm proposed by Lachance (COLA). The program is a revision of ALPHA and CARECAL originally written by $R$. M. Rousseau of the Geological Survey of Canada. Part one of the program (CALCO) performs the calculation of theoretical corrections called alpha coefficients, and part two (CALCOMP) computes the composition of the analyte specimens. The analysis of alloys, pressed minerals, and fused specimens can currently be treated by the program. An important feature of NBSGSC is that in addition to using measured $\mathrm{x}$-ray tube spectral distributions, spectra from seven commonly used $x$-ray tube targets could also be calculated with an NBS algoritrm included in the program. Other features include: 1) fundamental parameters required for calculating alpha coefficients such as mass absorption coefficients, fluorescence yields, jump ratios, analyte line wavelengths, and absorption edge wavelengths are either computed or stored in the program to minimize data input by the user, 2) the user has the option of selecting the algorithm of Heinrich, or Thinh and Leroux for calculating mass absorption coefficients, 3) one of three sample preparation conditions can be chosen when fusing specimens to allow greater flexibility in sample-to-flux ratios used in varlous laboratories, and 4) when analyzing specimens, known concentrations of elements previously determined by other techniques and are not to be analyzed can be entered as fixed concentrations. A menu procedure of operating NBSGSC is followed where the user answers a question, selecting the appropriate answers among the ones provided, and enters the required data. 
An evaluation of the COLA algorithm has been performed and is the subject of a technical paper submitted for publication in which results of analysis are intercompared with another well-known program - NRLXRF. Theoretical alpha coefficients provide the general relationship of matrix influences on the analyte, and actual standard reference materials are used to adjust calculations of specimen composition from theory. Therefore, appropriate standards are very important for obtaining best results as is the case with other fundamental parameter methods. An important element of the COLA algorithm is that it is applicable over the entire analyte composition range from 0 to $100 \%$. We expect that NBSGSC will be of significant utility to the $x$-ray fluorescence community and invite comments from users. Future research in fundamental parameters will be directed to a critical examination of some of the constants that are used in these theoretical calculations in an effort to improve the accuracy of analysis. 
C. Outputs and Interactions

(Gas and Particulate Science Division)

1. Publications

Cavioff, B. C., and Hodgeson, J., Passive Sampler for Ambient Levels of Nitrogen Dioxide, Analytical Chemistry, 55, 2083-2085 (1983).

Dunn, P. J., Peacor, D. R., Simmons, W. B., and Newbury, D. E., Fredrikssonite, A New Member of the Pinakiolite Group, From Langban, Sweden, Geologiska Foreningesn i Stockholm Forhandlingar, 105, 335-340 (1983).

Zielinski, W. L., Jr., Kirchhoff, W. H., and Eberhardt, K. R., Interlaboratory Testing of Newly Developed Physical/Chemical Property and Transformation Tests: Interlaboratory Evaluation of Vapor Pressure Test Standard Based on Gas Saturation Procedure, Final Report to EPA (1983).

Bright, D. S., Myklebust, R. L., and Newbury, D. E., Stereo Presentation of Monte Carlo Electron Trajectory Simulations, J. Microscopy, 136 113-120 (1984).

Butrymowicz, D. B., Newbury, D. E., Turnbull, D., and Cahn, J. W., Diffusion-Induced Grain Boundary Migration in the Au-Ag System, Scripta Metallurgica, 18, 1005-1010 (1984).

Currie, L. A., ${ }^{14} \mathrm{C}$ As A Tracer for Carbonaceous Aerosols: Measurement Techniques, Standards and Applications, Aerosols, B. Y. H. Liu, D. Y. H. Pui and H. J. Fisson, Eds., Elsevier Science Publishing Co., New York, 375 (1984).

Currie, L. A., Klouda, G. A., and Voorhees, K. J., Atmospheric Carbon: The Importance of Accelerator Mass Spectrometry, Nuclear Instrum. Methods, 233, 371 (1984).

Klouda, G. A., Currie, L. A., Donahue, D. J., Jull, T. and Zabel, T. M., Accelerator Mass Spectrometry Sample Preparation: Methods for ${ }^{14} \mathrm{C}$ In 50-1000 Microgram Samples, Nuclear Instrum. Methods 233, 265 (1984).

Newbury, D. E., Williams, D. B., Goldstein, J. I., and Fiori, C. E., Observations on the Calculation of $k_{A B}$ Factors for Analytical Electron Microscopy, Analytical Electron Microscopy, San Francisco Press, 276-278 (1984).

Taylor, H. F. W. and Newbury, D. E., An Electron Microprobe Study of A Mature Cement Paste, Cement and Concrete Research, 14, 565-573 (1984).

Williams, D. B., Newbury, D. E., Goldstein, G. M., and Fiori, C. E., On the Use of Ionization Cross Sections in Analytical Electron Microscopy, J. Microscopy, 136, 209-218 (1984).

Bass, A. M. and Paur, R. J., The Ultraviolet Cross-Sections of Ozone, Atmospheric Ozone, Symposium 1984, C. S. Zerefos and A. Ghazi, Eds, Rediel Publ. Co., 606-616, (1985). 
Bright, D. S. and Steel, E. B., STEM Calibration of Analysis of Hough Transformed Images of Optical Grating Replicas, Microbeam Analysis, San Francisco Press, 155 (1985).

Bright, D. S. and Steel, E. B., Automated Method for Analyzing Images Containing Electron Diffraction Spots, Microbeam Analysis, San Francisco Press, 163 (1985).

Byrd, G. D., Fatiadi, A. J., Simons, D. S., and White, E., Laser Desorption Mass Spectrometry of Some Salts of Squaric Acid, Organic Mass Spectrometry (submitted 1985).

Currie, L. A., Recommendations for Nomenclature in Evaluation of Analytical Methods, International Union of Pure and Applied Chemistry, (submitted 1985).

Currie, L. A., On the Use of Simulation Data Sets for Assessing Interlaboratory Pattern Recognition Accuracy, Optical Engineering (accepted for publication 1985).

Currie, L. A., Klouda, G. A., Schjoldager, J., and Ramdahl, T., The Power of ${ }^{14} \mathrm{C}$ Measurements Combined with Chemical Characterization for Tracing Urban Aerosol in Norway, (submitted to Radiocarbon 1985).

Currie, L. A., Klouda, G. A., Elmore, D., and Gove, H. E., Radiocarbon Dating of Microgram Samples: Accelerator Mass Spectrometry and Electromagnetic Isotope Separation, Nuclear Instrum. Methods, (in press 1985).

Currie, L. A., The Many Dimensions of Detection In Chemical Analysis, Chapter 5, Chemometrics in Pesticide/Environmental Residue Analytical Determination, D. Kurtz, Ed., ACS Symposium Series, No. 284, American Chemical Society (1985).

Currie, L. A., The Limitations of Models and Measurements as Revealed Through Chemometric Intercomparison, (to be published in NBS J. Res. 1985).

Etz, E. S., Newbury, D. E., Dunn, P. J., and Grice, J. D., Application of Synergistic Microanalysis Techniques to the Study of A New Mineral Containing Light Elements, Microbeam Analysis, San Franciso Press, 60 (1985).

Fletcher, R. A. and Fatiadi, A. J., Laser Ionization Mass Spectrometry of Poly(4-vinylpyridine), Poly. Comm. (in press 1985).

Fletcher, R. A. and Simons, D. S., A Comparison of Two Transient Recorders for Use With the Laser Microprobe Mass Analyzer, Microbeam Analysis, San Francisco Press, 319 (1985).

Fried, A. and Sams, R., Tunable Diode Laser Absorption Spectrometry for Ultra-Trace Measurement and Calibration of Atmospheric Constituents American Society for Testing Materials, Volume Sampling and Calibration for Atmospheric Measurements (submitted 1985). 
Fried, A., Sams, R., Dorko, W. and Elkins, J., Intercomparison of Tunable Diode Laser, Chemiluminescence and Fourier Transform IR Detection for the Determination of High Concentration Nitrogen Dioxide in Air Gas Mixtures, Analytical Chemistry (submitted 1985).

Grice, J. D., Van Velthuizen, J., Dunn, P. J., Newbury, D. E., and Etz, E. S., Moydite, (Y.REE) $[\mathrm{B}(\mathrm{OH}) 4] \quad\left(\mathrm{CO}_{3}\right)$, A New Mineral from Evans-Lou Pegmatitie, Quebec, Canadian Mineralogist (submitted 1985).

Hughes, E. E., Standards for the Measurement of Atmospheric Carbon Dioxide Based on Absolute Gravimetry, Tellus (submitted 1985).

Klouda, G. A., Currie, L. A., Tompkins, G. B., Wise, S. A., Allen, C. F., and Diamondstone, B. I., Reference Materials and Blank Evaluation Techniques for ${ }^{14} \mathrm{C}$ Measurements on Small Aerosol Samples, Radiocarbon, (submitted 1985).

Klouda, G. A.9 Currie, L. A., Donahue, and Jull, A. J. T., Atmospheric ${ }^{14} \mathrm{CO}$ and and ${ }^{14} \mathrm{CH}_{4}$ Measurements by Accelerator Mass Spectrometry, Radiocarbon (submitted 1985).

Lindner, M., Leich, D. A., Borg, R. J., Russg G. P., Bazan, J. M., Simons, D. S., and Date, A. R., The Half-Life of 187 Re, Nature (submitted 1985).

Lowenthal, D. H., Hanamura, C. R., Rahn, K. A., and Currie, L. A., Estimation and Error in Chemical Mass Balance Apportionments; Atm. Environ. (submitted 1985).

Marinenko, R B., Myklebust, R. L., Bright, D. S., and Newbury, D. E., Wavelength-Dispersive Techniques for Compositional Mapping in Electron Probe Microanalysis, Microbeam Analysis, San Francisco Press, 159 (1985).

Musselman, H., Linton, R. W., and Simons, D. S., The Use of Laser Microprobe Mass Analysis for Nickel Speciation in Individual Particles of Micrometer Size, Microbeam Analysis, San Francisco Press, 337 (1985).

Mulholland, G. W., McKenzie, R. L., Marx, E., and Fletcher, R. A., Refractive Index and Evaporation Rate of Individual Smoke Droplets, Langmuir 1, No. 3. 367 (1985).

Myers, R. C., Indoor Pollutant Measurements of Sulfur Dioxide, Nitrogen Oxides, and Ozone in the National Library of Medicine, Final Report to the National Library of Medicine (1985).

Myklebust, R. L, Marinenko, R. B., Newbury, D. E., and Bright, D. S., Quantitative Calculations for Compositional Mapping Techniques in Electron Probe Microanalysis, Microbeam Analysis, San Francisco Press, 101 (1985).

Myklebust, R. L., Marinenko, R. B., Newbury, D. E., and Bright, D. S., Quantitative Compositional Mapping On An Electron Microprobe, The Institute of Physics (to be published 1985). 
Newbury, D. E., Compositional Mapping of Thick Specimens, Microbeam Analysis, San Francisco Press, 204 (1985).

Pella, P. A., Feng, L., and Small, J. A., An Analytical Algorithm for Calculation of Spectral Distributions of $X$-Ray Tubes for Quantitative X-Ray Fluorescence Analysis, X-Ray Spectrum, 14, 125 (1985).

Pella, P. A., Tao, G., Dragoo, A. L., and Epp, J. M., X-Ray Spectrometric Determination of Ceria-Yttria Mixtures After Borate Fusion, Analytical Chemistry, 571752 (1985).

Pella, P. A., Newbury, D. E., Steel, E. B., and Blackburn, D. H., Development of NBS Thin Glass Standard Films for X-Ray Fluorescence Spectrometry, Analytical Chemistry, (submitted 1985).

Pella, P. A. and Tao, G., Intercomparison of Fundamental Parameter Interelement Correction Methods -- Part 2, J. of X-Ray Spectrometry, (submitted 1985).

Pine, A. S., Fried, A., and Elkins, J. W., "Spectral Intensities in the Fundamental Bands of $\mathrm{HF}$ and $\mathrm{HCl}, \mathrm{J}$. Molec. Spectros., 109, 30-45 (1985).

Pine, A. S. and Fried, A., Self-Broadening in the Fundamental Bands of HF and $\mathrm{HCl}$, J. Molec. Spectros., (submitted 1985).

Rhoderick, G. C., Cuthrell, W. F., and Zielinski, W. L., A Gravimetric Technique for the Preparation of Accurate Trace Organic Gas Standards, Transactions, APCA International Specialty Conference, Quality Assurance in Air Pollution Measurements, 239-246 (1985).

Rook, H. L., The Role of Neutron Activation Analysis in Trace Analysis, J. of Trace and Microprobe Techniques, $\underline{2}$, No. 3 \& $4,189-216$ (1984-85)

Steel, E. B. and Small, J. A., Accuracy of Transmission Electron Microscopy for the Analysis of Asbestos in Ambient Environments, Analytical Chemistry, $\underline{57}$, No. 1, 209-213 (1985).

Steel, E. B., Myklebust, R. L., and Bell, A. A., Development of an Automated Digital Image Acquisition System for Analytical Electron Microscopy, Microbeam Analysis, San Francisco Press, 151 (1985).

Steel, E. B. and Small, J. A., Analytical Methods: Light and Electron Microscopy, Proceedings of Workshop on the Monitoring and Evaluation of Airborne Levels Following An Abatement Program.

Tao, G., Pella, P. A., and Rousseau, R. M., NBSGSC -- A Fortran Program for Quantitative X-Ray Fluorescence Analysis, NBS Tech. Note 1213 (1985).

Zielinski, W. L., Jr., Miller, M. M., Ulma, G., and Wasik, S. P., GLC Separation Behavior of Polychlorinated Biphenyl Isomers Between A Neumatic Liquid Crystal Phase and a Non-Polar Phase, Analytical Chemistry (submitted 1985). 
2. Talks

Etz, E. S., "Optical Microprobe Spectroscopy," Atlantic Richfield Company, Exploration and Production Research Center, Plano, TX, October 9, 1984. Invited

Rhoderick, G. C., "A Gravimetric Technique for the Preparation of Accurate Trace Organic Gas Standards," APCA International Specialty Conference on Quality Assurance in the Air Pollution Measurements, Boulder, CO, October 16, 1984.

Elkins, J. W., "Current Laboratory Spectroscopy Techniques by FTIR, Spectroscopy Workshop, NASA Langley Research Center, Norfolk, VA, October 17, 1984. Invited

Sheridan, P. J., "Quantitative Elemental Analysis of Individual Particles from Environmental Aerosols," Division of Analytical, Nuclear, and Environmental Chemistry, Department of Chemistry, University of Maryland, College Park, MD, November, 1984.

Newbury, D. E., "Microbeam Chemical Analysis," NBS ADABSE Workshop, November, $5,1984$.

Simons, D. S., "Laser Microprobe Mass Spectrometry," Symposium on Surface Modification by Directed Deposition of Energy, Greater New York Chapter, American Vacuum Society, IBM Thomas J. Watson Research Center, Yorktown Heights, NY, November 8, 1984. Invited

Fletcher, R. A., "The Use of the Laser Microprobe Mass Analyzer in Analytical Chemistry," Eighth Annual Users Conference, Major Analytical Instruments Facility of Case Western Reserve University, Cleveland, OH, November 26, 1984. Invited

Sheridan, P. J., "The Sources of Particles Collect,ed on the GTE/CITE Experiment," American Geophysical Union (AGU) Meeting, San Francisco, California, December 4, 1984.

Currie, L. A., "On the User of Simulation Data Sets for Assessing Interlaboratory Pattern Recognition Accuracy," US Army Conference on Spectral Pattern Recognition, Aberdeen, MD, December 11, 1984. Invited

Currie, L. A., "Lower Limits of Detection," Health Physics Society 18th Midyear Topical Symposium, Colorado Springs, CO, January 8, 1985.

Newbury, D. E., "Elemental Analysis at the Nanometer Scale", National Engineering Laboratory, February 11, 1985. Invited

Newbury, D. E., "Future Trends, Microanalysis Techniques," Microbeam Analys1s Society of Southern California, Scripps Institution of Oceanography, February 15, 1985. Invited

Dorko, W. D., "Simultaneous Quantitative Tunable Dlode Laser and Chemilumenscent Detector Measurements of High Concentration $\mathrm{NO}_{2}$ in $\mathrm{A}$ ir Gas Mixtures," 1985 Pittsburgh Conference on Analytical Chemlstry and Applied Spectroscopy, New Orleans, LA, February 25, 1985. 
Cadoff, B. C., "Cryogenic Preconcentration Technique for the Analysis of Trace Organic Vapors in Gas Mixtures," Pittsburgh Conference, New Orleans, LA, February 26, 1985.

Sleater, G. L., The Application of X-Ray Fluorescence Analysis to the Certification of Standard Reference Materials," The 1985 Pittsburgh Conference, paper No. 392, New Orleans, LA, February 26, 1985.

Zielinski, W. L., Jr., "Microgravimetric Development and GLC Verification of Accurate, Stable Mixtures of Volatile Toxic Organics in the $10 \mathrm{ppm}$ to 1 ppb Range," 1985 Pittsburgh Conference on Analytical Chemistry and Applied Spectroscopy, New Orleans, LA, February 27, 1985.

Fried, A., "NO $\mathrm{N}_{2}$ Standards Normalization in NASA's Cite 2 Global Tropospheric Experiment," NASA's Third Science Team Meeting for the Global Tropospheric Experiment, Arlington, VA, March 18, 1985. Invited

Small, J. A., "Visibility of Chrysotile Asbestos in the SRM," Asbestos Fiber Measurements in Building Atmospheres Workshop, Organized by Ontario Research Foundation on Behalf of Health and Welfare Canada, March 26, 1985.

Newbury, D. E., "Compositional Mapping for Microstructural Characterization of Materials," Department of Metallurgy and Materials Engineering Seminar Series, Lehigh University, Bethlehem, PA, March 28, 1985. Invited

Small, J. A., "AEM-LAMMA Analysis of Particles," Joint Meeting of the American Vacuum Society and Rocky Mountain Microscopy Society, Denver, CO, May 8, 1985. Invited

Newbury, D. E., "Compositional Mapping by Multiple Techniques," Center for Materials Science Seminar, NBS, May 10, 1985. Invited

Currie, L. A., "The Limitations of Models and Measurements as Revealed Through Chemometric Intercomparison," Chemometrics Research Conference, Gaithersburg, MD, May 20, 1985.

Etz, E. S., "Molecular Microanalysis with the Laser Raman Microprobe," 2nd International Symposium on the Biology and Toxicology of Metals Using Nuclear Analytical Methods," Brookhaven National Laboratory, Upton, Long Island, NY, May 21, 1985. Invited

Newbury, D. E., "Compositional Mapping," Physics Discussion Group, May 28, 1985. Invited

Myklebust, R. L., "Quantitative X-Ray Microanalysis Using the ETEC SEM. The Use and Abuse of NBS FRAME C," Center for Material Science Electron Microscope Users Group Seminar, May 30, 1985. Invited

Newbury, D. E., "Quantitative X-ray Microanalysis Using the ETEC SEM; the Use and Abuse of NBS FRAME C," Center for Materials Science, Electron Microscope Users Group Seminar, May 30, 1985. Invited 
Klouda, G. A., "Reference Materials and Blank Evaluation Techniques for ${ }^{14} \mathrm{C}$ Measurements on Small Aerosol Samples," 12th International Radiocarbon Conference, Norwegian Inst. of Technology, Trondheim, Norway, June 24, 1985.

Currie, L. A., "The Power of ${ }^{14} \mathrm{C}$ Measurements Combined with Chemical Characterization for Tracing Urban Aerosol in Norway," 12th International Radiocarbon Conference, Norwegian Institute of Technology, Trondheim, Norway, June 26, 1985.

Etz, E. S., "Advances in Micro-Raman Instrumentation Applied to Calcium Phosphate Research," Gordon Research Conference on Calcium Phosphates, Plymouth State College, Plymouth, NH, June 26, 1985. Invited

Klouda, G. A., "Atmopspheric ${ }^{14} \mathrm{CO}$ and ${ }^{14} \mathrm{CH}_{4}$ Measurements by Accelerator Mass Spectrometry," 12th International Radiocarbon Conference, Norwegian Institute of Technology, Trondheim, Norway, June 26, 1985.

Currie, L. A., "Chemometric, Isotopic and Organic Techniques to Study Man's Impact on the Atmosphere," Norwegian Institute for Air Research, Lillestrom, Norway, July 1, 1985.

Currie, L. A., "Trace Carbon in the Atmosphere: Knowledge Gained Through Receptor Modeline and ${ }^{14} \mathrm{C}$ Accelerator Mass Spectrometry," RISO National Laboratory, Roskilde, Denmark, July 3, 1985.

Currie, L. A., "Pitfalls in the Application of Linear Models to Atmospheric Source Apportionment; Assumption-Testing and Validation via Isotope Measurement," Instituut voor Nucleaire Wetenschappen, University of Gent, Gent, Belgium, July 5, 1985.

Etz, E. S., "Application of Synergistic Microanalysis Techniques to the Study of a Possible New Mineral Containing Light Element," 20th Annual Conference of the Microbeam Analysis Society, Louisville, KY, August 5, 1985.

Mykelbust, R. L., "Quantitative Calculations for Compositional Mapping Techniques in Electron Probe Microanalysis", Microbeam Analysis 1985 , Louisville, KY, August 5, 1985.

Steel, E. B., "Development of an Automated Digital Image Acquisition System for Analytical Electron Microscopy," 20th Annual Conference of the Microbeam Analysis Society, Louisville, KY, August 5, 1985.

Newbury, D. E., "Compositional Mapping of Thick Specimens," Annual Conference of the Microbeam Analysis Society, Louisville, KY, August 6, 1985. Invited

Newbury, D. E., "Trace Element and Light Element Imaging by Secondary Ion Mass Spectrometry," Annual Conference of the Microbeam Analysis Society, Louisville, KY, August 6, 1985.

Fletcher, R. A., "A Comparison of Two Transient Recorders for Use With Laser Microbeam Mass Analyzer," 1985 Microbeam Analysis Society, Louisvllle, KY, August 8, 1985. 
Etz, E. S., "Raman Microprobe Spectroscopy in Chemical Microanalysis," Gordon Research Conference on Analytical Chemistry, New Hampton School, New Hampton, $\mathrm{NH}$, August 12, 1985. Invited

Newbury, D. E., "Compositional Mapping of Thick Specimens on A Micrometer Spatial Scale," Gordon Conference on Analytical Chemistry, August 12, 1985. Invited

Currie, L. A., "Performance Characteristics of the Chemical Measurement Process: Proposed International Nomenclature," NBS, August 13, 1985. Invited

Dorko, W. D., "Special Calibration Systems for Reactive Gases and Other Difficult Measurements," ASTM Conference on Sampling and Calibration for Atmospheric Measurements, Boulder, CO, August 13, 1985. Invited

Mitchell, G. D., "Trace Gas Calibration Systems Using Permeation Devices," ASTM Conference on Sampling and Calibration for Atmospheric Measurements, Boulder, C0, August 13, 1985. Invited

Fried, A. and Sams, R., "Tunable Diode Laser Absorption Spectrometry for Ultra-Trace Measurements and Calibration of Atmospheric Constituents," ASTM Conference on Sampling and Analysis of Atmospheres, Boulder, CO, August 14, 1985. Invited

Rhoderick, G. C., "Preparation of Standards for Gas Analysis," Symposium on Natural Gas Energy Measurement, Chicago, IL, August 26, 1985. Invited

Myklebust, R. L, "Compositional Mapping," A.E.R.E., Harwell, England, August 27, 1985. Invited

Myklebust, R. L., "Compositional Mapping," University of Bath, Bath, England, August 28, 1985. Invited

Pella, P. A., "NBSGSC -- A Fortran Program for Quantitative X-Ray Fluorescence Analysis," The 24th Colloquium Spectroscopicum Internationale, Garmisch-Partenkirchen, Federal Republic of Germany, September, 1985. Invited

Myklebust, R. L., "Quantitative Compositional Mapping on An Electron Microprobe," EMAG 85, Newcastle Upon Tyne, England, September 5, 1985.

Myklebust, R. L., "Compositional Mapping," University of Cambridge, England, September 6, 1985. Invited

Verkouteren, R. M., "Characterization and Optimization of Carbon Chemistry Preceeding Accelerator Mass Spectrometry," ACS Symposium on Accelerator Mass Spectrometry, Chicago, IL, September 11, 1985. 
Simons, D. S., "Laser Microprobe Mass Spectrometry," Microbeam Analysis Society National Tour Speaker, Houston Area Microbeam Analysis Society, Houston, TX, December 3, 1984; New Mexico Microbeam Users Group, Albuquerque, NM, December 4, 1984; Arizona Society for Electron Microscopy and Microanalysis, Phoenix, AZ, December 5, 1984; Southern California Society for Electron Microscopy and Microbeam Analysis Society of Southern California, Los Angeles, CA, December 6, 1984 ; Washington Area Microbeam Analysis Society of Southern California, Los Angeles, CA, December 6, 1984; Washington Area Microbeam Analysis Society, NBS, April 18, 1985. Invited

Newbury, D. E., "Compositional Mapping: Future Trends in Microanalysis," New England Society for Electron Microscopy, Newton, MA, December 5, 1985. Invited

\section{Committee Assignments}

Harry Rook

Chairman, EPA Scientific Review Panel on Quality Assurance Chairman, Office of Water Data Coordination, Committee $5 \mathrm{~F}$ Chairman, ASTM D-22.03 Sampling and Analysis of Ambient Atmospheres Member, ASTM D-22 Sampling and Analysis of Atmospheres Member, ASTM D-22.01 Quality Assurance Member, IUPAC Commission V.3 (Analytical Nomenclature)

Arnold Bass

Member, ASTM D-22 Sampling and Analysis of Atmospheres

Member, ASTM D-22.01 Quality Assurance

Member, ASTM D-22.03 Sampling and Analysis of Ambient Atomspheres

Member, Ozone Science Guidance Comm., NESD/S

David Bright

Member, ASTM E-29 Particle Size Measurement

Member, ASTM SC.10 Liquid Particle Measurement

Lloyd Currie

Member, CAC, Quality Assurance Task Force

Associate Member, IUPAC Commission on Analytical Nomenclature

Consultant, International Atomic Energy Agency, on Limit of Detection

Member, Interagency Workshop on the Future of Accelerator Mass Spectrometry in the U.S.A.

William Dorko

Member, American Chemical Society, Washington Section, Board of Managers

Member, ASTM D-22 Sampling and Analysis of Atmospheres

Edgar Etz

Member, ASTM D-22 Sampling and Analysis of Atmospheres

Alan Fried

Member, NASA's Third Science Team Committee for the Global Tropospheric Experiment 


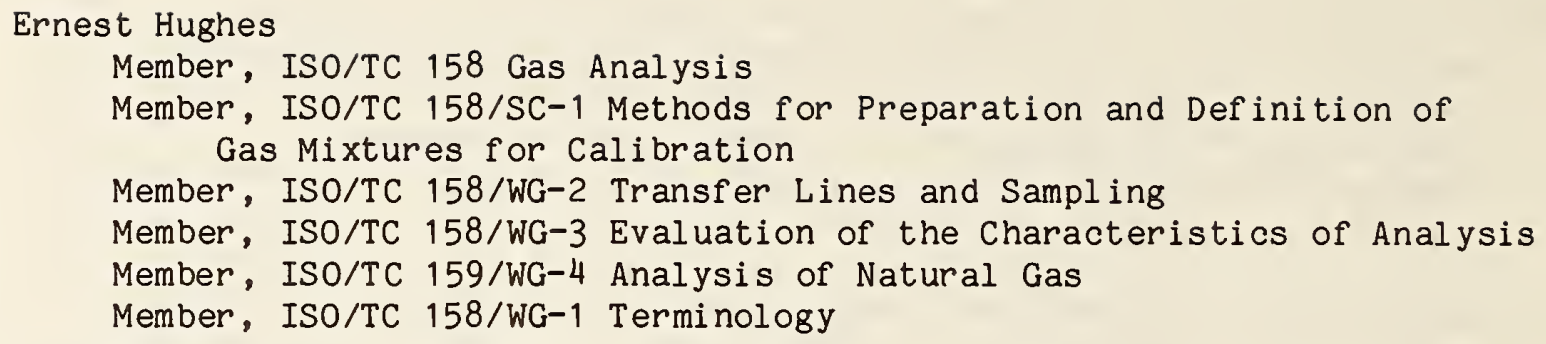

Dr. David Joy, Bell Laboratories, "Modeling Energy Dispersive X-Ray Spectrometers." (Division Sponsor: D. Newbury)

May 14,1985

Dr. Dae Won Moon, Chemistry Department, Princeton University, "Study of Organic Monolayers on Silver Surfaces by Angle-Resolved SIMS." (Division Sponsor: D. Simons) 
May 16,1985

May 22, 1985

May 29, 1985
M. Keenlyside, Thor Surface Science, Oxford, England, "Microarea Photoelectron Imaging and Spectroscopy." (Division Sponsor: D. Newbury)

Dr. Ulrich Seydel, Research Inst. Borstel, W. Germany, "Desorption/Ionization Mechanisms at High Irradiances in Laser Desorption Mass Spectrometry." (Division Sponsor: D. Simons)

Dr. Louis Codispoti, Bigelow Laboratory for Ocean Science, "Effects of Man's Impingement and E1 Nino Events on the Biology and Chemistry of the Ocean Off Peru." (Division Sponsor: J. Elkins).

b. Standard Reference Materials

\section{$\underline{X-R a y ~ F l u o r e s c e n c e ~}$}

$\begin{array}{lrl}\text { SRM } & 88 \mathrm{~b} & \text { Dolomitic limestone } \\ \text { SRM } & 1632 \mathrm{~b} & \text { Trace elements in Coal } \\ \text { SRM } & 76 a, 77 a, 78 a, & \text { Burnt refractories } \\ \text { SRM } & 888 & \text { Tungsten Carbide } \\ \text { SRM } & 1832 & \text { Orange Cap Cement } \\ \text { SRM } & 1833 & \text { Grey Cap Cement } \\ \text { SRM } & 1411 & \text { Multi-Component Glass Squares } \\ \text { SRM } & 1412 & \text { Multi-Component Glass Squares } \\ \text { SRM } & 1413 & \text { Glass Sand }\end{array}$

Gas Metrology

$\begin{array}{ll}\text { SRM } & 1626 \\ \text { SRM } & 1629 a \\ \text { SRM } & 1668 \mathrm{~b} \\ \text { SRM } & 1683 \mathrm{~b} \\ \text { SRM } & 1684 \mathrm{~b} \\ \text { SRM } & 1685 \mathrm{~b} \\ \text { SRM } & 1686 \mathrm{~b} \\ \text { SRM } & 1687 \mathrm{~b} \\ \text { SRM } & 1693 \mathrm{a} \\ \text { SRM } & 1700 \\ \text { SRM } & 1701 \\ \text { SRM } & 1702 \\ \text { SRM } & 1703 \\ \text { SRM } & 1912 \\ \text { SRM } & 2607 \\ \text { SRM } & 2608 \\ \text { SRM } & 2609 \\ \text { SRM } & 2610 \\ \text { SRM } & 2626 \mathrm{a}\end{array}$

$\mathrm{SO}_{2}$ Permeation Tube $\mathrm{NO}_{2}$ Permeation Device Propane in Air

$\mathrm{NO}$ in $\mathrm{N}_{2}$

NO in $\mathrm{N}_{2}^{2}$

$\mathrm{NO}$ in $\mathrm{N}_{2}^{2}$

$\mathrm{NO}$ in $\mathrm{N}_{2}$

$\mathrm{NO}$ in $\mathrm{N}_{2}^{2}$

$\mathrm{SO}_{2}$ in $\mathrm{N}_{2}$

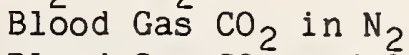

Blood Gas $\mathrm{CO}_{2}$ and $\mathrm{O}_{2}$ in $\mathrm{N}_{2}$

Blood Gas $\mathrm{CO}_{2}$ and $\mathrm{O}_{2}$ in $\mathrm{N}_{2}^{2}$

Blood $\mathrm{Gas} \mathrm{CO}_{2}$ and $\mathrm{O}_{2}$ in $\mathrm{N}_{2}$

Tetrachloroethylene Permeation Device

$\mathrm{CO}_{2}$ and $\mathrm{N}_{2} \mathrm{O}$ in $\mathrm{Air}$

$\mathrm{CO}_{2}$ and $\mathrm{N}_{2} \mathrm{O}$ in $\mathrm{Air}$

$\mathrm{CO}_{2}$ and $\mathrm{N}_{2} \mathrm{O}$ in $\mathrm{Air}$

$\mathrm{CO}_{2}$ and $\mathrm{N}_{2}^{2} \mathrm{O}$ in $\mathrm{Air}$

$\mathrm{CO}_{2}$ in $\mathrm{N}_{2}$ 
Analytical Laser Spectrometry

$\begin{array}{lll}\text { SRM } & 1686 \mathrm{~b} & \text { Nitric Oxide in Nitrogen } \\ \text { SRM } & 1687 \mathrm{~b} & \text { Nitric Oxide in Nitrogen } \\ \text { SRM } & 2630 & \text { Nitric Oxide in Nitrogen } \\ \text { SRM } & 2631 & \text { Nitric Oxide in Nitrogen } \\ \text { SRM } & 2653 & \text { Nitrogen Dioxide in Air } \\ \text { SRM } & 2654 & \text { Nitrogen Dioxide in Air } \\ \text { SRM } & 2655 & \text { Nitrogen Dioxide in Air } \\ \text { SRM } & 2656 & \text { Nitrogen Dioxide in Air }\end{array}$


NBS.114A IREV. 2 ACI

U.S. DEPT. OF COMM.

1. PUBLICATION OR REPORT NO.

BIBLIOGRAPHIC DATA NBSIR $85 / 3272$

2. Performing Organ. Report Nof 3. Publication Date

SHEET (See instruction s)

4. TITLE AND SUBTITLE

Technical Activities, 1985, Center for Analytical Chemistry

5. AUTHOR(S)

R. A. Durst, H. S. Hertz, J. K. Taylor

6. PERFORMING ORGANIZATION (If joint or other than NBS, see instructions)

7. Contrac/Grant No.

MATIONAL BUREAU OF STAMDARDS

DEPARTMENT OF COMMERCE

8. Type of Report \& Period Covered

WASHINGTON, D.C. 20234

9. SPONSORING ORGANIZATION NAME ANO COMPLETE ADORESS (Street, City, State, ZIP)

Same as above.

10. SUPPLEMENTARY NOTES

Document describes a computer program; SF-185, FIPS Software Summary, is attached.

11. ABSTRACT (A 200-word or less foctual summory of most significant information. If document includes a significant

bibliogrophy or literoture survey, mention it here)

This report summarizes the technical activities of the Center for Analytical Chemistry at the National Bureau of Standards. It emphasizes activities over the Fiscal Year 1985 in the Inorganic Analytical Research Division, the Organic Analytical Research Division, and the Gas and Particulate Science Division. In addition, it describes certain special activities in the Center including quality assurance and voluntary standardization coordination.

12. KEY WORDS (Six to twelve entries; alphabetical order: copitalize only proper names; and separate key words by semicolons) analytical chemistry; analytical services; gas and particulate science; inorganic analytical chemistry; organic analytical chemistry; quality assurance; voluntary standards

13. AVAILABILITY

[X] Unlimited

For Official Distribution. Do Not Release to NTIS

Order From Superintendent of Documents, U.S. Government Printing Office, Washington. O.C. 20402.

14. NO. OF

PRINTEO PAGES

Х Order From National Technical Information Service (NTIS), Springfield, VA. 22161

189

15. Price

$\$ 16.95$ 






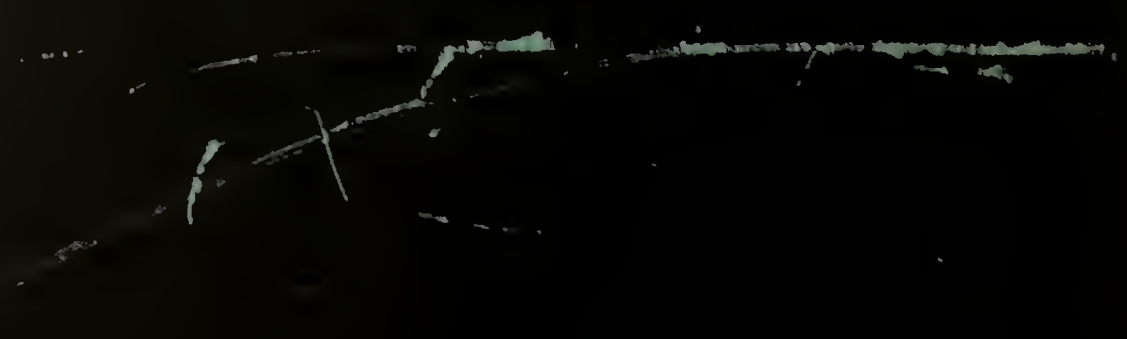

